\title{
Dealing with grief and requesting donation : an international challenge : effects of the European Donor Hospital Education Programme
}

Citation for published version (APA):

Blok, G. A. (2003). Dealing with grief and requesting donation : an international challenge : effects of the European Donor Hospital Education Programme. [Doctoral Thesis, Maastricht University]. Universiteit Maastricht. https://doi.org/10.26481/dis.20031009gb

Document status and date:

Published: 01/01/2003

DOI:

10.26481/dis.20031009gb

Document Version:

Publisher's PDF, also known as Version of record

Please check the document version of this publication:

- A submitted manuscript is the version of the article upon submission and before peer-review. There can be important differences between the submitted version and the official published version of record.

People interested in the research are advised to contact the author for the final version of the publication, or visit the DOI to the publisher's website.

- The final author version and the galley proof are versions of the publication after peer review.

- The final published version features the final layout of the paper including the volume, issue and page numbers.

Link to publication

\footnotetext{
General rights rights.

- You may freely distribute the URL identifying the publication in the public portal. please follow below link for the End User Agreement:

www.umlib.nl/taverne-license

Take down policy

If you believe that this document breaches copyright please contact us at:

repository@maastrichtuniversity.nl

providing details and we will investigate your claim.
}

Copyright and moral rights for the publications made accessible in the public portal are retained by the authors and/or other copyright owners and it is a condition of accessing publications that users recognise and abide by the legal requirements associated with these

- Users may download and print one copy of any publication from the public portal for the purpose of private study or research.

- You may not further distribute the material or use it for any profit-making activity or commercial gain

If the publication is distributed under the terms of Article $25 \mathrm{fa}$ of the Dutch Copyright Act, indicated by the "Taverne" license above, 


\title{
DEALING WITH GRIEF AND REQUESTING DONATION
}

\author{
AN INTERNATIONAL CHALLENGE
}



Cover Detail of mixed-media painting 'GG 1' by Limmy Scheres

Cover design Limmy Scheres

Lay-out Agnes Scholing

Printing Unigraphic

ISBN 90-5681-179-7

(C) Springer-Verlag, Chapters 2 and 3

(C) Kluwer Academic Publishers, Chapter 4

(C) Geke Blok, others chapters 



\section{DEALING WITH GRIEF AND REQUESTING DONATION}

\section{AN INTERNATIONAL CHALLENGE}

Effects of the European Donor Hospital Education Programme

\section{ProefsChrifT}

ter verkrijging van de graad van doctor aan de Universiteit Maastricht, op gezag van de Rector Magnificus,

Prof. dr. A.C. Nieuwenhuijzen Kruseman, volgens het besluit van het College van Decanen, in het openbaar te verdedigen

op donderdag 9 oktober 2003 om 14.00 uur

door

Geesje Aaltje Blok 
Promotores

Prof. dr. C.P.M. van der Vleuten

Prof. dr. G. Kootstra

Beoordelingscommissie

Prof. dr. W. Buurman (voorzitter)

Prof. dr. H.W. van den Borne

Prof. dr. W.H. Gijselaers

Prof. dr. H.F. Kraan (Universiteit Twente)

Prof. dr. M.J.H. Slooff (Rijksuniversiteit Groningen)

The development of EDHEP was made possible by funding from Novartis International AG (formerly Sandoz Pharmaceutical Basel) and was facilitated by the Eurotransplant International Foundation, Leiden, and the Rowland Dyson Company, Zürich. EDHEP workshops in the Netherlands and in the United Kingdom were made possible financially by the Dutch Kidney Foundation, the Dutch Heart Foundation, the Dutch Department of Health, the British Department of Health, the North West Regional Health Authority, Central Manchester Healthcare NHS Trust, Royal Liverpool \& Broadgreen University Hospital NHS Trust, Novartis Pharmaceutical United Kingdom, and Roche Products, Ltd.

The studies described in this thesis were financially supported by the Dutch Kidney Foundation (Chapter 4 and 6), the British Ministry of Health, the Renal Transplant Unit of the Royal Liverpool Hospital and the Renal Transplant Unit of Manchester Royal Infirmary (Chapter 2 and 4), the Dutch Transplantation Society (chapter 7 and 8) and Novartis International AG (Chapter 9).

Publication of this thesis was financially supported by the Dutch Kidney Foundation, the Dutch Institute for Healt Promotion and Disease Prevention-Foundation for Donor Information, the Eurotransplant International Foundation and Novartis International AG. 
Paranimfen

Stella Beeldsnijder

Erna Ponds 



\section{Contents}

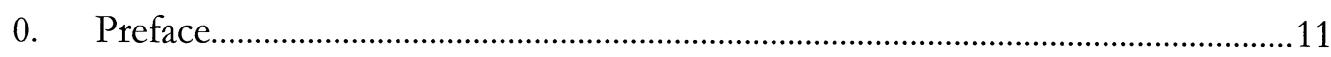

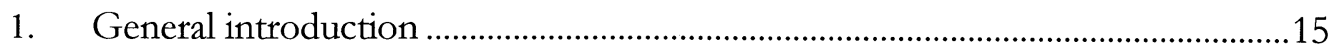

2. The European Donor Hospital Education Programme: addressing the training needs of doctors and nurses who break bad news, care for the bereaved, and request donation

3. Participants' judgements of the European Donor Hospital Education Programme: an international comparison.

4. Requesting Organ and Tissue Donation: the case of self-efficacy. Effects of the European Donor Hospital Education Programme.

5. Two ways of measuring communication skills concerning breaking bad news and requesting organ donation compared: a validation study ......

6. Effects of the European Donor Hospital Education Programme on cognitive skills in communication.

7. Effects of an educational programme on teamwork in the intensive care........103

8. The impact of changes in practice in organ procurement on the satisfaction of donor relatives.

9. Continuing professional development regarding dealing with grief and requesting donation. Worldwide evaluations of Train-the-Trainer courses......141

10. Discussion

Summary

Acknowledgements 187

Samenvatting .191

Dankwoord. 203

Curriculum Vitae 207 



\section{Preface}

Death is the great pan-cultural and inescapable human leveller and human awareness of death is a near life-long awareness. However metaphysically or religiously conceived, however long postponed by medical science, however softened by belief of faith, the basic human fact and fear of death cannot be denied. Neither, in opposition, can the basic buman craving for more life,

Maxine Sheets-Johnstone Journal of Consciousness Studies 2002;9(2):p.49.

The educational programme which is the focus of this thesis, the European Donor Hospital Education Programme (EDHEP), was introduced in 1992 at the $8^{\text {th }}$ International Conference of the European Society for Organ Transplantation in Maastricht, the Netherlands. Since its introduction it has been translated into seventeen languages and is part of continuing professional education in over thirty countries.

EDHEP is the result of a very successful collaboration between The Eurotransplant Foundation, the initiator and driving force, the Academic Hospital Maastricht, the University Maastricht and the Rowland Dyson Company Ltd.. EDHEP consists of two parts, EDHEP Part One: 'Meeting the donor shortage', a hospital based presentation and EDHEP Part Two: 'The grief response and donation request', an interactive workshop for mixed groups of intensive care doctors and nurses.

The programme was developed by a team, consisting of Kitty Jager, medical doctor and project coordinator from the Eurotransplant Foundation; Rene Wijnen, medical doctor and transplant coordinator from the Academic Hospital Maastricht; Miriam Ryan, communication specialist from the Rowland Dyson Company Zürich; Jan van Dalen, psychologist at the Skillslab of the University of Maastricht and Geke Blok, psychologist at the Department of Educational Development and Research of the University of Maastricht. 
In developmental stage it was obvious that there would be huge international interest in the programme, as worldwide the gap between demand and supply of donor organs was widening and EDHEP was seen as part of the solution to this problem. The Eurotransplant Foundation offered the programme free to all countries, provided it had an organ procurement network, a National EDHEP Working Group, well qualified moderators and participated in a Train-the-Trainer Course.

The Eurotransplant Foundation appointed Celia Wight, former chair and founder of the European Transplant Coordinators Organization, as the international EDHEP coordinator. Celia Wight was very successful in promoting EDHEP worldwide. Her efforts resulted in seven Train-the-Trainers courses in Leiden in the Netherlands in the period 1992-1994, and additional Train-theTrainers courses in Hong Kong, Sao Paulo, Mexico City, Tel Aviv, Riyadh, Kuwait City, Bern, Manchester, Luxembourg and Paris in the period 1995-1998, with more than 300 participants.

In my opinion, EDHEP's success has the following reasons:

- The expertise of all developers was used optimally, resulting in a very well structured, compact educational programme containing all the essential ingredients.

- The promotional material appealed to the target audience.

- Celia Wight was the right person to promote EDHEP, having ample experience in the domain and being well known by key people in the field.

- The Train-the-Trainers courses appealed to all participants and were, without exception, very well received.

- The EDHEP material was developed in such a way that local adaptations were easy to make.

But most importantly, the issues EDHEP addresses are universal:

- The loss of a loved one is a very sad experience for everyone. Although the expression of grief may differ from country to country, all over the world relatives experience a feeling of profound loss. The loss may be even more traumatic, when death is unexpected and sudden.

- Dealing with death and grief and requesting organ donation is very hard for intensive care doctors and nurses all over the world. The death of a patient is also a loss to the staff. Relatives in distress often confront these professionals at a point in medical and nursing care, where professional expertise and personal experience converge.

My parents both died in the period when I was working on my dissertation. My father died suddenly at home, at the age of 77 years. We were not able to say goodbye, it happened very sudden. It was a shock to the whole family. 
Five years later, in 2001, my mother died in a nursing home, at the age of 75 , after 5 years of grieving over my father and a body and mind that finally abandonded her. I think were all relieved that she did not have to suffer anymore.

It was odd to write about bereaved relatives' reactions, whilst being a bereaved relative myself. I recognized the reactions I read about in myself and in the reactions of the members of my family. I also noticed, that I was very keenly aware of the reactions of the professionals involved. Positive and negative remarks I will never forget. I was very alert, that staff were caring and empathetic and showed that they really trying to understand what these experiences meant to me.

Both my parents could have been tissue donors. In a way I am relieved that we were never asked if we would consider tissue donation. I would have faced an internal conflict. Knowing that many people could benefit from these donations and at the same time not wanting to have my parents undergo any operation.

I have tremendous respect for all those, who do consent in organ and/or tissue donation, because I understand how hard the decision can be and I also learned that a donation procedure is a profound experience.

I did not know all these things when we started this project. My personal experience has only strengthened my belief that it is a good cause to help doctors and nurses in intensive care to feel more competent in dealing with these issues. Relatives will leave the hospital with the feeling that they were treated well, whatever their decision. Intensive care doctors and nurses will be able to look back on satisfying experiences. 


\section{1}

\section{General introduction}

\section{Background}

Since the mid 1970's transplantation has become an accepted medical intervention. Successful transplantation is generally regarded as offering a better quality of life to patients and their families. Organ transplantation is the only option for patients in the end stage of liver and heart disease, and it is more cost effective than dialysis in the treatment of end-stage renal disease and it offers a better quality of life to the recipient. Advances in transplantation surgery, new principles of organ allocation and improved tissue preservation have ensured that donated organs are used effectively.

However, the development of transplant programmes throughout the world is hampered by a chronic shortage of donor organs. The number of patients on waiting lists for transplantation has increased significantly, whereas the number of donor organs has lagged behind. ${ }^{1,2}$ All over the world solutions are being sought to bridge the increasing gap ${ }^{3}$ between demand for and availability of donor organs , by changes in legislation, ${ }^{4}$ by using marginal donors and non-heart-beating donors ${ }^{2}$, by using living-related and living-unrelated donations, ${ }^{5}$ by improving the organization of organ procurement and donor recognition. ${ }^{6,7}$ The use of animal organs (xenotransplantation) is not as yet a realistic alternative. ${ }^{8}$ Ethical considerations play an important role in the discussions surrounding organ donation. ${ }^{9-12}$

A major reason for the shortage of donor organs and tissues is relatives' refusal to consent. ${ }^{1}$ Recovery of donor organs and tissues from patients who are brain dead (heart-beating donors) and from patients with cardiac arrest (non-heartbeating donors) requires prior discussion of the option of donation with relatives. In many countries up to thirty percent of relatives refuse consent for post-mortem donation, and a significant minority of relatives of potential donors may not be asked at all. ${ }^{13,14}$ In 2002 in the Netherlands the refusal percentage for organ en tissue donation was even $70 \% .{ }^{15}$ 
Although opinion polls show a positive attitude among the public towards organ and tissue donation, ${ }^{16}$ this is not reflected in the number persons who give consent to donation. ${ }^{17,18}$ Several information campaigns have been suggested or are being implemented which target (specific) audiences to increase their knowledge about organ and tissue donation and address any specific worries they may have. ${ }^{19-22}$

The main reasons why relatives refuse consent to donation are the wishes of the deceased, cultural or religious considerations, fears and worries about the donation procedure due to lack of knowledge, and dissatisfaction with their treatment by intensive care staff. ${ }^{23-26}$ Being asked for donation does not appear to affect their grief. ${ }^{27}$ Inadequate communication and inappropriate support, on the part of doctors or nurses contributes to relatives' reluctance to consider organ donation. The timing of the request ${ }^{27-29}$ and the knowledge and confidence of those making the request, influence the satisfaction of donor relatives with how they are treated and have a significant influence on the decision they make. ${ }^{26}$

Research has shown that doctors and nurses find it difficult to deal with death and dying. They may be afraid to add to relatives' distress or to express their own emotions or they may be uncertain whether they are capable of dealing with unexpected reactions from relatives. As a result, doctors and nurses may experience feelings of interpersonal inadequacy due to lack of training, knowledge and the necessary communication skills. Additionally, they often feel they have nothing more to offer; that this is the point where professional expertise fails to provide guidance. ${ }^{30-33}$ The same reasons are found to underlie the hesitation and reluctance expressed by many doctors and nurses with respect to requesting donation. ${ }^{25,34-39}$

The need for training to improve professionals' competence in caring for the bereaved and requesting donation is evident. ${ }^{35,40-42}$ Nevertheless, there is little empirical validation of the effects of training programmes intended to improve docotors' and nurses' (inter)personal competence of doctors and nurses regarding death and donation. A few publications have reported on training programmes addressing these issues, ${ }^{43-46}$ but none have directly measured the effects of these programmes staff competence in communicating with relatives. There is increasing recognition that staff awareness of interpersonal variables will improve communication with bereaved relatives. ${ }^{47,48}$ There is also substantial evidence from other areas in medicine that communication skills can be improved by training based on identified needs. ${ }^{49,50}$

\section{Training healthcare staff to break bad news and request donation sensitively}

Conveying bad news, explaining brain death, and approaching the next of kin with a request for donation, places a considerable burden upon doctors and nurses in critical care and the donation procedure places medical and nursing staff under even greater strain. ${ }^{51}$ Doctors' and nurses' knowledge and attitudes to brain death, donation and transplantation may augment their difficulties in communicating woth relatives. ${ }^{38,45,52}$ Educating doctors and nurses about the criteria for organ and 
tissue donation and underlining their role in requesting for donation have resulted in measurable increases in donation. ${ }^{45,53}$ The willingness of doctors and nurses to cooperate with organ procurement is strongly related to their attitudes regarding the value of transplantation and the lack of donors, the perceived value and acceptability of making a donation request; and being prepared to make a donation request. ${ }^{38,39,51,54}$ Experience and training will make doctors and nursed feel more confident in approaching families and relatives. Those who feel insecure and uncomfortable about making the request have more refusals than those who feel confident. ${ }^{26,55}$

Critical elements in addressing the competence of intensive care doctors and nurses to communicate with relatives in the breaking of bad news and requesting donation thus are:

- Knowledge. Acquisition and integrated use of knowledge about good practice in breaking news of death and requesting donation; about brain death; about organ procurement and about the communication process involved.

- Communication skills. Mastery of communication skills as well as the ability to adequately interpret the situation at hand and to recognize and use those communication skills that are relevant and effective in that situation; key skills in the communication with relatives are: 1) providing information in a clear and understandable way; 2) dealing with relatives' (emotional) reactions in a sensitive way showing compassion and understanding; 3) dealing with relatives' questions by helping them express their thoughts and feelings and 4) structuring the process in a well timed way. ${ }^{26,27}$

- Self-efficacy. Self-efficacy, i.e. the belief that one can successfully accomplish a given task, is considered a key factor of human competence. Bandura ${ }^{56}$ argues that knowledge, skills and prior behaviour are often poor predictors of subsequent behaviour, because the beliefs that individuals hold about their abilities and about the outcome of their efforts influence their behaviour. Increased self-efficacy will diminish hesitation to approach relatives and increase confidence in one's ability to handle the communication with relatives.

- Attitudes. Attitudes about brain death, about the value and acceptability of organ donation, about approaching relatives concerning death and donation and about teamwork in this area have proven to have a significant impact on the behaviour of intensive care staff. Exploration of these attitudes and facing the reality of the professional requirements concerning death and donation will facilitate communication with the relatives and team members.

- Teamwork. Donation procedures add to the workload in intensive care units, they involve additional tasks and place considerable psychological demands on the staff. More teamwork concerning death and donation (e.g. division of tasks, sharing experiences and mutual feedback) will improve the quality of consultations with relatives, the continuity of care and staff support. 
Intensive care staff's competence in communication and teamwork regarding death and donation will be reflected in the quality of the communication with relatives, the number of donation requests made, the donation rate and in the degree of relatives' satisfaction.

An educational programme designed to improve health professionals' effectiveness in breaking bad news and requesting donation should thus meet several prerequisites in terms of format and contents. It needs to draw upon a combination of validated educational methods, tailored to participants' working conditions, to promote maximal transfer of what is learned to the working routine.

${ }^{57,58}$ Effective didactic methods should be supplemented with experiential methods to raise awareness and understanding of grief, thereby underscoring the necessity of clear and sensitive communication with the bereaved. ${ }^{59}$ Teaching methods should reinforce principles of good practice in breaking bad news and the donation request by giving participants the opportunity to apply these principles in authentic exercises. ${ }^{60,61}$ The use of simulated patients or relatives, provides a realistic and effective method to help participants to identify their own strengths and weaknesses in communication. ${ }^{62-64}$

\section{The European Donor Hospital Education Programme (EDHEP)}

The findings from the studies described above were at the basis of the development of The European Donor Hospital Education Programme (EDHEP). The issues addressed in the EDHEP workshop are considered to cover the domain of communication relating to death and donation. The requirements regarding content and educational format have resulted in an educational programme with the following features:

- Domain specific and contextual information about transplantation results, organ procurement and results of relatives' studies is provided. Participants who are well informed when approaching relatives about organ and tissue donation will be able to explain brain death, the donation procedure, how organs can be used, and what happens with donated organs and tissues in a language that is easy to understand for the relatives.

- Exercises to increase participants' awareness of their own feelings, emotions and attitudes concerning death and donation and communicating with relatives in order to explore those feelings, emotions and attitudes and relate them to professional behaviour.

- Behavioural information through video examples and modelling by the moderators.

- Information about the communication process and specific communication skills (dealing with emotions, providing (clear and honest) information, eliciting information and structuring) and good practice in breaking bad news and requesting donation is provided in structured presentations and throughout the workshop whenever applicable. 
- Cognitive use of communication skills in combination with exploration of personal emotions and attitudes are practiced using short authentic trigger vignettes, in which simulated relatives express different reactions to either the news of the death of a relative or the donation request.

- Authentic simulations with simulated relatives to practise communication skills, teamwork skills and feedback skills, in which the information acquired in the workshop so far has to be used. Observation assignments are used to direct attention.

EDHEP is a domain specific, highly focused educational programme, which addresses many issues in a short time. It was designed as an awareness-raising workshop and should not be regarded as a formal training course. The issues addressed in the EDHEP workshop are considered to cover the broad domain of communication relating to death and donation and are expected to affect the professional behaviour of critical care staff. EDHEP has been conducted in Western Europe, the Middle and the Far East and in Latin and South America.

\section{Aim of this thesis}

The four goals of this thesis are: 1) to describe the background and format of EDHEP; 2) to describe how participants evaluated the format, contents and learning effects of the programme, and the international appreciation of this programme for continuing professional education of intensive care staff; 3) to describe the results of studies investigating the effects of EDHEP on the competence of intensive care staff regarding breaking news of death and requesting donation, both on an individual level as well as on the level of teamwork in intensive care units; 4) to establish the relationship between donor relatives' satisfaction and the issues addressed in EDHEP.

The main question addressed in this thesis is: How is EDHEP perceived nationally and internationally, and what are its effects the competence of professional intensive care staff concerning the breaking of news of death and requesting organ donation? How does this relate to the satisfaction of donor relatives?

There is much debate about the definition of professional competence and its assessment. There are some suggestions to be taken seriously in order to be able to infer effects of assessment results on actual practice. Assessment objectives should match educational objectives. This means that assessment tasks should reflect professional practice as close as possible and test material should offer appropriate contexts to enable the use and measurement of higher cognitive abilities and to establish differences in professional expertise. ${ }^{65}$ It is essential that assessment uses authentic (patient) problems from real practice, given the available evidence that learning is context dependent. ${ }^{61}$

According to Crossley et al. ${ }^{66}$ systematically defining the critical elements in the practice of health professionals is fundamental to good assessment, and optimal 
reliability is achieved by using multiple methods of assessment. The definition of an explicit focus will prevent that a competence is being mistaken for a performance test, or a knowledge test is being mistaken for a skill test. Van der Vleuten ${ }^{65}$ and Crossley et al. ${ }^{66}$ indicate that test design is a compromise between measurement rigour and practicality.

The key constituent variables of professional competence addressed in this thesis are: knowledge; communication and teamwork skills; attitudes regarding donation and communication with relatives; and self-efficacy. The focus is on communication and teamwork skills and self-efficacy. In developing the instruments to measure the effects of EDHEP we attempted to design tasks that reflected professional reality as much as possible. For reasons of feasibility, compromises had to be made between measurement rigour and practicality.

The potential donor pool and rate of donation are influenced by many organizational and professional factors. Adequate and sensitive communication with bereaved families is not automatically followed by consent for donation, as relatives tend to respect the wishes of the deceased. Any effect of EDHEP on donor rates can only be indirect and is beyond the scope of this thesis.

\section{Research questions}

1. What is the opinion of participants about the issues addressed and the learning effects of EDHEP? Does the programme meet doctors' and nurses' comnpetence needs regarding the breaking of bad news and requesting organ donation? Are the issues addressed recognized as relevant for actual practice? How is EDHEP perceived worldwide as part of continuing professional education?

2. What is the effect of EDHEP on intensive care doctors and nurses' selfefficacy regarding breaking bad news and requesting donation?

3. What is the effect of EDHEP on (the cognitive use of) communication skills in breaking news of death and requesting donation?

4. What is the effect of EDHEP on the collaboration of intensive care teams concerning breaking bad news of death and requesting organ donation?

5. How are the issues addressed in EDHEP related to the satisfaction of donor relatives?

\section{Outline of the thesis}

In Chapter 2 a description is given of the background of the development of EDHEP; reasons for the widening gap between demand and supply of human donor organs and tissues. The contents and format of EDHEP is described from an educational point of view, based on the outcomes of relevant research. Chapter 3 is devoted to programme evaluations and learning effects of EDHEP in the Netherlands and United Kingdom. Similarities and differences between the results of the two countries are described. In Chapter 4 the effects of EDHEP on selfefficacy beliefs concerning breaking news of death, requesting donation and 
dealing with (emotional) reactions of relatives are described. Dutch and British data were used for this study. The relationship between self-efficacy, perceived difficulty of requesting donation and professional experience is considered in relation to the effects of EDHEP. Chapter 5 is devoted to a comparison of two ways of measuring communication skills: a performance test and a paper-cases test. In the study in the United Kingdom communication skills were measured with a performance test with simulated relatives (not in this thesis). ${ }^{67}$ In the Netherlands communication skills were measured with a paper-cases test, that measured the cognitive skills in communication. The predictive value of this proxy test about breaking bad news and requesting donation for a performance test concerning the same domain is examined. In Chapter 6 the effect of EDHEP on cognitive skills in communication is described. In this study the instrument used was a paper-cases test, which measures diagnostic accuracy concerning authentic situations depicted in written cases, written proficiency in communication skills and the degree to which these two cognitive skills are related. The relationship between the results with specific parts in the programme of EDHEP is discussed. The effects of EDHEP on the teamwork in intensive care units is described in Chapter 7. For this study a nationwide inventory in the Netherlands was made of EDHEP participation rates in intensive care units. Two contrasting groups were made, one with high and one with low EDHEP participation rates. How to break bad news and request donation is described from a team viewpoint. Differences and similarities in teamwork relating to death and donation and team support between the two contrasting groups are examined

Chapter 8 deals with the satisfaction of donor relatives. Data from 1995, 1998 and 2001 were compared. In these three years the same instrument was used to measure the satisfaction of donor relatives with the donation process. The analyses were focused on any changes that may have occurred in the satisfaction ratings and to what degree these were related to specific interactions between key professionals and relatives. The results were interpreted in the light of choices to be made for future interventions to increase donor rates. In Chapter 9 EDHEP is described from the viewpoint of continuing professional education. Programme evaluations and learning effects of both international EDHEP Train-The-Trainer Courses and EDHEP workshops are presented. The relevance and applicability of EDHEP as part of continuing professional education worldwide is discussed. Chapter 10 presents a general discussion of the various findings and conclusions of this thesis.

Since this thesis consists of articles that have been published or submitted for publication, some overlap between the different chapters is inevitable. 


\section{References}

1. Miranda B, Fernandez LM, Matesanz R. The potential organ donor pool: international figures. Transplant Proc 1997;29:1604-6.

2. Kootstra G, Kievit J, Nederstigt A. Organ Donors: Heartbeating and Non-heartbeating. World J Surg 2002;26(2):181-4.

3. Persijn G, Smith M, Vries de E, Boer dJ, Smits J, Cohen B. Trilogy 2001 Symposium: Tackling the Organ Shortage Problem. Transplant Proc 2002;34:2553-5.

4. Michielsen P. Informed or presumbed consent legislative models. London: Arnold; 1997.

5. Terasaki PI, Cecka JM, Gjertson DW, Takemoto S. High survival rates of kidney transplants from spousal and living unrelated donors. N Engl J Med 1995;333(6):333-6.

6. Wight C, Cohen B, Roels L, Miranda B. Donor Action: A quality assurance programme for intensive care units that increases organ donation. J Intensive Care Med 2000;15:104-14.

7. Matesanz R. A decade of continuous improvement in cadaveric organ donation: the Spanish model. Nefrologia 2001;5:59-67.

8. Arrundell M, McKenzie I. The Acceptability of Pig Xenografts for Patients Awaiting a Transplant. Xenotransplantation 1997;4:62-6.

9. Kootstra G. Ethical questions in non-heart-beating donorship. Transplant Proc 1996;28(6):3417-8.

10. Arnold R-M, Siminoff L-A, Frader J-E. Ethical issues in organ procurement: a review for intensivists. Crit Care Clin 1996;12(1):29-48.

11. Elliott C. Doing harm: living organ donors, clinical research and The Tenth Man. J Med Ethics 1995;21(2):91-6.

12. Calne SR. Ethics in rogan donation and transplantation: the position of the Transplant Society (1996). London: Arnold; 1997.

13. Gore SM, Ross Taylor RM, Wallwork J. Availability of transplantable organs from brain stem dead donors in intensive care units. BMJ 1991;302:149-53.

14. New B, Solomon M, Dingwall R, Mchale J. A question of give and take. Improving the supply of donor organs for transplantation. Kings Fund Institute London 1994.

15. Rosendal H, Beekum vWT, Legemaate J, Buisen MJAM, Hulst EH, Berg vd, M., et al. Evaluatie. Wet op de orgaandonatie [Evaluation of the Law on Organdonation]. Den Haag: ZonMw; 2001.

16. Smith K, Braslow J. Public attitudes toward organ and tissue donation. London: Arnold; 1997.

17. Schutt GR, Smit H, Duncker G. Huge discrepancy between declared support of organ donation and actual rate of consent for organ retrieval. Transplant Proc 1995;27(1):1450-1.

18. Cosse $\mathrm{T}$, Weisenberger $\mathrm{T}$. Words versus actions about Organ Donation: A Four Year Tracking Study of Attitudes and Self-Reported Behavior. J Busn Res 2000;50:297-303.

19. Guadagnoli E, McNamara P, Evanisko M-J, Beasley C, Callender C-O, Poretsky A. The influence of race on approaching families for organ donation and their decision to donate. Am J Public Health 1999;89(2):244-7. 
20. Randhawa G, Baluch B. Attitude Measures, Prsonality Traits and the Role of Persuasion in Organ Donation. Transplantationsmedizin 1998;10:106-10.

21. Siminoff L-A, Saunders-Sturm C-M. African-American reluctance to donate: beliefs and attitudes about organ donation and implications for policy. Kennedy Inst Ethics J 2000;10(1):59-74.

22. Reubsaet A, van-den-Borne B, Brug J, Pruyn J, van-Hooff H. Determinants of the intention of Dutch adolescents to register as organ donors. Soc Sci Med 2001;53(3):383-92.

23. United Kingdom Transplant Coordinators Association (UKTCA) and British Association of Critical Care Nurses (BACCN). Relatives' refusal of organ donation. Report of a two year study. London: Department of Health; 1995.

24. Shaheen FA, Souqiyyeh MZ, Huraib S, al Khader A, Attar MB, Ibrahim SM, et al. The causes of family refusal to consent for organ donation from a brain-death relative in Saudi Arabia. Transplant Proc 1996;28(1):387.

25. Franz H, Jong dW, Wolfe M, Nathan HM, Payne D, Reitsma W, et al. Explaining brain death; a critical feature of the donation process. J Transplant Coordination 1997;7:14-21.

26. Siminoff L, Gordon N, Hewlet J, Arnold R. Factors influencing Families' Consent for Donation of Solid Organs for transplantation. JAMA 2001;286(1):71-7.

27. Cleiren M-P-H-D, van-Zoelen A-A-J. Post-mortem organ donation and grief: A study of consent, refusal and well-being in bereavement. Death Studies 2002;26(10):837-49.

28. Painter LM, Langlands JM, Innes Walker J. Donor families experience of organ donation: a New Zealand study. N Z Med J 1995;28 july 1995:295-6.

29. Pearson IY, Bazeley P, Spencer Plane T, Chapman JR, Robertson P. A survey of families of brain dead patients: their experiences, attitudes to organ donation and transplantation. Anaesth Intensive Care 1995;23(1):88-95.

30. Buckman R. Breaking bad news: why is it still so difficult? Br Med J Clin Res Ed 1984;288(6430):1597-9.

31. Christaki K. A personal reflection on the issues surrounding the use of euphemisms following sudden death. Nurs Crit Care 1998:3(5) 249-52.

32. Townsend A. Sudden death in critical care units. Care of the Critically Ill 1995;11(3):126-8.

33. Maguire P. Breaking bad news. Eur J Surg Oncol 1998:24(3) 188-91.

34. Wakeford RE, Stepney R. Obstacles to organ donation. Br J Surg 1989;76 may:435-9.

35. Stein A, Hope T, Baum JD. Organ transplantation: approaching the donor's family. BMJ 995;310:1149-50.

36. Pearson IY, Zurynski Y. A survey of personal and professional attitudes of intensivists to organ donation and transplantation. Anaesth Intensive Care 1995;23(1):68-74.

37. Sque M, Payne S, Vlachonikolis I. Cadaveric donortransplantation: nurses' attitudes, knowledge and behaviour. Soc Sci Med 2000;50(4):541-52.

38. Kent B. Psychosocial factors influencing nurses' involvement with organ and tissue donation. Int J Nurs Stud 2002;39:429-40.

39. Siminoff LA, Arnold RM, Caplan AL. professional attitudes toward donation: effect on practice and procurement. J Trauma Inj Infec Crit Care 1995;39:553-9. 
40. Sanner M. Attitudes towards organ donation and transplantation. A model for understanding reactions to medical procedures after death. Soc Sci Med 1994;38:1141-52.

41. Siminoff LA, Arnold RM, Caplan AL, Virnig BA, Seltzer DL. Public policy governing organ and tissue procurement in the United States. Results from the National Organ and Tissue Procurement Study. Ann Intern Med 1995;123(1):10-7.

42. Randhawa G. Coping with grieving relatives and making a request for organs: principles for staff training. Med Teach 1998;20(3):247-9.

43. Politoski G, Boller J. Making the critical difference: an innovative approach to educating nurses about organ and tissue donation. Crit Care Nurs Clin North Am 1994;6(3):581-5.

44. Coolican MB, Politoski G. Donor family programmes. Crit Care Nurs Clin North Am 1994;6(3):613-23.

45. Riker RR, White BW. The effect of physician education on the rates of donation request and tissue donation. Transplantation 1995;59(6):880-4.

46. Serwint J, Rutherford L, Hutton N, Rowe P, Barker S, Adamo G. "I learned that no death is routine": Description of a death and bereavement seminar for pediatrics residents. Acad Med 2002;77(4):278-84.

47. Novack DH, Volk G, Drossman DA, Lipkin M, Jr. Medical interviewing and interpersonal skills teaching in US medical schools. Progress, problems, and promise. JAMA 1993;269(16):2101-5.

48. Ong LML, Haes de CJM, Hoos AM, Lammes FB. Doctor-patient communication: a review of the literature. Soc Sci Med 1995;40:903-18.

49. Kurtz S, Silverman J, Draper J. Teaching and Learning Communication Skills in Medicine. Abington: Radcliffe Medical Press Ltd.; 1998.

50. Aspergen K. BEME Guide No. 2: Teaching and learning communication skills in medicine a review with quality grading of articles. Med Teach 1999;21(6):563-70.

51. Prottas J, Batten HL. Health professionals and hospital administrators in organ procurement: attitudes, reservations, and their resolutions. Am J Public Health 1988;78(6):642-5.

52. Younger SJ, Landefeld CS, Coulton CJ, Juknialis BW, Leary M. 'Brain death' and organ retrieval. A cross-sectional survey of knowledge and concepts among health professionals. JAMA 1989;261(15):2205-10.

53. Cumberland B, Wit dR, Kootstra G. Organ and tissue procurement rates improve after professional healthcare education by hospital development coordinators and time sensitive requesting. Transplant Proc 1995;27:2957-8.

54. McGough EA, Chopek MW. The physician's role as asker in obtaining organ donations. Transplant Proc 1990;22:267-72.

55. Malecki MS, Hoffman MC. Getting to Yes: How Nurses' Attitudes Affect Their Succes in Obtaining Consent for Organ and Tissue Donations. Dialysis and Transplantation 1987:2768.

56. Bandura A. Self-efficacy: Toward a unifying Theory of Behavioral Change. Psychol Rev 1977;84 (2):191-215.

57. Patrick J. Training. Research \& Practice. London: Academic Press; 1992. 
58. Sanson-Fisher R, Cockburn J. Effective teaching of communication skills for medical practice: selecting an appropriate clinical context. Med Educ 1997:31(1) 52-7.

59. Wright B. Sudden death. London: Churchill Livingstone; 1991.

60. Brown J, Collins A, Duguid P. Situated cognition and the culture of learning. Educational Researcher 1989;18:32-42.

61. Regehr G, Norman G. Issues in cogntive Psychology: Implications for Professional Education. Acad Med 1996;71:988-1001.

62. Vleuten van der CPM, Swanson DB. Assessment of Clinical Skills With Standardized Patients: State of the Art. Teach Learn Med 1990;2 (2):58-76.

63. Vu NV, Barrows HS. Use of Standardized Patients in Clinical Assessments: Recent Developments and Measurement Findings. Educational Researcher 1994;23(3):23-30.

64. Rethans J-J, Sturmans F, Drop R, Vleuten van der C. Assessment of the performance of general practioners by the use of standardized (simulated) patients. J Gen Pract 1991;March 1991:97-9.

65. Vleuten van der CPM. The Assessment of Professional Competence. Developments, Research and Practical Implications. Adv Health Sci Educ 1996;1:41-67.

66. Crossley J, Humphris G, Jolly B. Assessing health professionals. Med Educ 2002;36(9):800-4.

67. Morton J, Blok GA, Reid C, van-Dalen J, Morley M. The European Donor Hospital Education Programme (EDHEP): enhancing communication skills with bereaved relatives. Anaesth Intensive Care 2000;8(2):184-90. 


\section{2}

\section{The European Donor Hospital Education}

Programme:

addressing the training needs of doctors and nurses

who break bad news, care for the bereaved, and

request donation ${ }^{1}$

The competence of critical care staff when it comes to death and organ donation can make the difference between a family's agreement to or refusing donation. Doctors and nurses often feel uncomfortable approacbing relatives about donation and attribute this to lack of training. Bereaved relatives express dissatisfaction with inappropriate communication and support when brain death is announced and thereafter when a request for donation is made. The European Donor Hospital Education Programme (EDHEP) was designed to meet the training needs of critical care staff in breaking bad news, caring for the bereaved, and requesting donation. EDHEP is a two part educational package consisting of a presentation on the donor shortage followed by a one day workshop. The implementation of EDHEP throughout the world has been facilitated through effective national working groups and standardised "Train-the-Trainer Courses". Several countries anecdotally report increases in donation following implementation.

\footnotetext{
${ }^{1}$ Published as: Blok G, van Dalen J, Jager K, Ryan M, Wijnen R, Wight C, et al. The European Donor Hospital Education Programme (EDHEP): addressing the training needs of doctors and nurses who break bad news, care for the bereaved, and request donation. Transpl Int 1999:12(3) $161-7$.
} 


\section{Introduction}

The development of transplant programmes throughout the world is limited due to a chronic shortage of donor organs. ${ }^{1}$ Successful transplantation is generally regarded as offering a better quality of life to patients and their families. Organ transplantation is the only option for patients in the end stage of liver and heart disease, and in the case of end-stage renal disease it is a more cost-effective treatment than dialysis. ${ }^{2}$ The number of patients on waiting lists for transplantation has grown significantly over the past five years while the rate of donation appears to have reached a plateau. ${ }^{3}$ The procurement of organs relies on cooperation between different disciplines and both the potential donor pool and rate of donation, are influenced by a complex mix of organisational and professional variables. Loss of donor organs from the potential pool can occur by failing to identify a potential donor, and by not approaching the family to request donation. Family refusal and poor management of the potential donor also reduces the availability of organs for transplantation. ${ }^{4}$ In many countries up to $35 \%$ percent of relatives refuse consent for cadaveric donation, and a significant minority of relatives of potential donors may not be asked at all. ${ }^{4-6}$

It is widely acknowledged that doctors and nurses find dealing with death and dying difficult ${ }^{7-9}$ and that they hesitate in asking for donation. At least two barriers to communication with bereaved relatives have been identified: fear of adding to their distress, and the lack of training in communication skills. ${ }^{10}$ Relatives may refuse donation for several reasons ${ }^{11}$ but being asked for donation does not appear to affect their grief. ${ }^{12-14}$ Inadequate communication or inappropriate support, on the part of doctors or nurses, will contribute to a family's reluctance to consider donation. It may also affect their satisfaction with the donation process. The timing of the request and the confidence of those who make the request will also influence how the relatives of brain-dead patients will feel and react to any such request. ${ }^{11-16}$ However, little research has been devoted to the interpersonal competence of doctors and nurses in the areas of death and donation, or to the contribution of inappropriate or insensitive communication to family refusal. ${ }^{17}$ There are few training opportunities that address all of the above issues, but there is increasing recognition that enhanced awareness of these interpersonal variables is necessary for improvement of communication with the bereaved. ${ }^{7818}$ The need for training to improve competence in caring for the bereaved and requesting donation is evident, ${ }^{19}$ yet there is little empirical validation of the effects of such training programmes. ${ }^{17,20}$ There is substantial evidence from general practice and oncology that particular communication skills can be improved with training based on identified needs. ${ }^{21,22}$ 
The need to train healthcare staff to request donation sensitively

Conveying bad news, explaining brain death, and approaching the next of kin for permission to donate, places considerable demands upon doctors and nurses in critical care. The donation procedure implies an additional burden for the medical and nursing staff ${ }^{23}$ in which caring for bereaved relatives and asking for donation are not the only difficulties. Doctors' and nurses' knowledge and attitudes towards brain death, donation and transplantation may contribute to their difficulties with communication. ${ }^{24-26}$ The concept of brain death, even when rationally understood, can cause confusion and mixed feelings, and can make it even harder to approach the family. $\Lambda$ study from the United States revealed that only $35 \%$ of a sample of 195 physicians and nurses from intensive care and neurosurgery units correctly identified the legal and medical criteria for determining death. ${ }^{26}$ However, those staff who had participated in formal teaching about brain death and organ donation prior to being questioned were significantly more likely to know the criteria. Educating doctors and nurses about the criteria for organ and tissue donation, and underlining their role in making the request, has lead to measurable increases in donation. ${ }^{27,28}$

Although opinion polls suggest that a majority of the general public favour donation, their response to the request for organ donation from a beloved family member is not nearly as positive. The factors that determine the attitudes of the general public and the healthcare professionals in the areas of organ donation and transplantation are complex and poorly understood. ${ }^{19}$ The attitudes of doctors and nurses to donation appear to influence the donation rate in a number of ways. Willingness of doctors and nurses to participate in organ procurement programmes is strongly related to the attitudes about the value of transplantation and about the lack of donors, the perceived value and acceptability of making a donation request of bereaved relatives, and the degree to which they are prepared to make a donation request. ${ }^{23,24,29,30}$ Experience and training enhance their confidence in approaching families and improve the manner in which the request is made by the doctor or nurse; those who feel insecure and uncomfortable in making the request have more refusals than those who do not. ${ }^{31}$ There is increasing evidence that families who have donated appreciate being offered the choice, although sensitive handling of the relatives by medical staff before, and particularly after, donation is not always apparent. ${ }^{12,13,20}$ While there is always a degree of urgency to proceed with the donation procedure, there is empirical evidence that relatives are much more likely to consent to organ donation if the request is made some time after they have been informed that brain death has occurred. 16,32,33 Families who consent to donation also express more satisfaction with the donation procedure when they are given sufficient time between the announcement of brain death and the request so that they can accept the fact that their family member has died. ${ }^{15}$ Relatives of potential donors may not comprehend the diagnosis of brain death ${ }^{13,32}$, and those who refuse donation appear to have far less understanding of brain death than those who consent. ${ }^{32}$ 


\section{Background to the Development and Format of The European Donor Hospital Education Programme (EDHEP)}

Educational initiatives designed to increase donation must aim to address several aspects of professional competence in making the donation request. For such training to be effective it needs to draw upon a combination of validated educational methods, tailored to the working circumstances of the participant, which allow maximal transfer to the working routine. ${ }^{34}$ Nurses' self-confidence appears to improve following attendance at an educational programme that addresses issues similar to those of the EDHEP workshop. ${ }^{35}$ Traditional didactic teaching methods should be supplemented with experiential methods that raise awareness and understanding of grief, and thereby underscore the need for clear and sensitive communication with the bereaved. ${ }^{36}$ These teaching methods should interlink and reinforce principles of good practice in breaking bad news and the donation request, allowing participants the opportunity to apply these principles within encounters with simulative relatives of brain-dead patients. The use of simulated patients or relatives provides a realistic and effective method to help participants identify their own strengths and weaknesses in communication. ${ }^{37-39}$

\section{Good Practice regarding Breaking News of Brain Death and Requesting Donation}

Clear and appropriate communication from doctors and nurses is particularly needed to ensure that brain death is understood as death before a request can be made. Breaking bad news and requesting donation should always be made in planned interviews. Ideally, a doctor and a nurse should discuss these issues with the next of kin, accompanied by supportive relatives or friends, in a comfortable and adequately furnished room. It is important to break news of brain death fairly early in the conversation; ${ }^{22}$ and to show understanding and empathy, especially by reflecting the bereaved relatives' feelings and by attending to their concerns; discussing the near future should ideally be initiated by the relative. It is essential that all information be presented to the family in a clear and truthful manner, avoiding technical jargon. When explaining brain death, it should be very clear that this means the person is dead. Relatives should be told, sometimes more than once, what is going to happen next. The donation request should be made in a separate consultation from the one in which the death was announced. ${ }^{16}$ During the donation procedure close cooperation among all staff members is needed with regard to communication with the family. The latter must have a clear idea of the donation procedure without feeling under pressure to consent. They must know which organs are suitable for donation. The time schedule must also be addressed. Discussing the operation procedure can remove any fears the family may have about the body being mutilated. Prior to seeing the body, relatives must be warned that organ donors look much paler than brain dead patients who do not donate organs. It is important to offer relatives the opportunity to see the body after the 
donor operation and to encourage them to view the body at as many stages as possible to give a realistic perception of the loss.

\section{Format of the European Donor Hospital Education Programme (EDHEP)}

The European Donor Hospital Education Programme (EDHEP) was developed in 1991 to address the above issues by helping medical professionals feel more comfortable in dealing with bereavement and donation. EDHEP consists of a hospital-based lecture and an interactive workshop, both of which are in a well structured, fixed format. The moderators are provided with detailed manuals in which the two parts are described. The separate parts contain slides, presentations, exercises and instructions. EDHEP was produced and developed by a team of professionals including clinical psychologists from University of Maastricht, a Dutch transplant-coordinator from the Academic Hospital Maastricht and a consultant from the Eurotransplant Foundation, in close collaboration with communication specialists from The Rowland Dyson Company. ${ }^{40,41}$ Three pilots of the workshop were conducted in the Netherlands in 1991 with an expert 'target group' of senior consultant intensivists and senior intensive care nurses. Their comments led to the final version of the programme that has been used since. EDHEP was developed as an adaptable prototype allowing for adjustments to meet national demands.

Part One: 'Meeting the donor shortage'

EDHEP Part One, a background briefing called 'Meeting the donor shortage', is a hospital based lecture by the transplant coordinator. It is an slide presentation that covers the history and state of the art in organ and tissue transplantation. The aim of this lecture is to raise awareness and understanding of organ and tissue donation and transplantation among all levels of medical, nursing and paramedical staff. The briefing is described in the manual and is suitable for adaptation, depending on local and national circumstances. This briefing is followed, at a later date, by EDHEP Part Two, 'The grief response and donation request'-workshop (Figure 1). The remainder of this article focuses on this workshop.

Part Two: 'The grief response and donation request'- workshop

'The grief response and donation request'-workshop is a one-day, highly interactive, workshop preferably held outside the hospital, where the group cannot be disturbed by hospital matters. EDHEP is hosted by the transplant coordinator and conducted with small mixed groups - preferably eight doctors and eight nurses - working in critical care. The group should consist of doctors and nurses from different hospitals and different units of hospitals in order to neutralise any particular local difficulties and to encourage exchange of experiences. The workshop is moderated by two experienced communication skills trainers, ideally 
'The grief response and donation request'-workshop

1. Welcome and introduction $*$ Transplant coordinator

2. Reasons for lack of donors $\quad *$ Logistics of donation procedure

Presentation

* Overview of health professionals' reasons for hesitance to request donation

3. Loss and separation

* Acknowledgement of own reactions to loss Exercise

Coffee Break

4. Vignettes Brief videotaped dramatization

5. Health professionals can be effective Presentation

6. Talking about loss Videotaped interviews with relatives who consented to organ donation

7. Sudden death Video drama

8. Breaking news of death Role play with simulated relatives
Lunch Break

* Communication guidelines when breaking news

* Practise relevant communication skills

* Structured feedback to help identify strengths and weaknesses

Coffee Break

9. The donation request Role play with simulated relatives

* Practise relevant communication skills

* Structured feedback to help identify strengths and weaknesses

* Overview of learning objectives

* Guidelines for protocols

10. Overview and summary Presentation

Figure 1. Overview of the programme

clinical psychologists, experienced in working with medical and nursing staff. The day allows the participants to move from their personal response to bereavement and donation to appropriate professional responses. Short presentations about loss, grief, and crisis intervention alternate with exercises in which participants can discuss and apply the theory previously expounded.

During the morning session, participants have the opportunity to reflect on their knowledge of, and personal and professional attitudes towards loss, bereavement and donation. One communication skill that is emphasised throughout the morning is 'reflection of feeling'. This communication skill enables the health professional to acknowledge the relatives' emotional reaction, to facilitate their expression of emotion, and to help direct communication during a crisis. 
Guidelines for good practice when breaking bad news and making the donation request, based upon consensus from research, are then presented. 16,18,22,33,42 Videotapes of relatives' experiences identify and reinforce some of these guidelines. Awareness of the guidelines for approaching families about brain death and donation are emphasised during two role plays -breaking news of brain death and requesting donation - that account for a large part of the afternoon session. The participants are divided into two groups and those who do not play a role use observation assignments to direct their attention. The role plays are discussed afterwards and the simulated relative, the observers, and the trainer give feedback. Finally, the satisfaction of the participants with the workshop is evaluated using a programme evaluation questionnaire offering the opportunity for both quantitative and qualitative feedback. ${ }^{43,44}$

\section{Implementation and evaluation of EDHEP}

Nineteen standardised "Train-the-Trainer Courses" have so far accompanied the implementation of EDHEP in new countries, conducted by the programme's authors and principal trainers. The international "Train-the-Trainer Course" is designed to guarantee the quality of the EDHEP workshop, and also supply national working groups with guidelines regarding particular activities and tasks needed to implement EDHEP. Thus far EDHEP has been implemented in over thirty countries all over the world and the programme has been translated into 17 languages. The first 430 participants in the Netherlands showed a very high degree of satisfaction with EDHEP, as well as a high learning effect and a decrease in the 'barrier' to ask for donation. There were no differences in the judgements of participants with regard to their region, their profession and gender or experience in critical care. Different moderators and transplant coordinator combinations also did not lead to differences in satisfaction. The learning effect was primarily attributed to feedback of the moderators, practising with simulated relatives, watching videotaped interviews with bereaved relatives and using observation assignments during the exercises. ${ }^{43}$ Comparable results were found in an international comparison of participants' judgements about EDHEP. ${ }^{44}$

\section{Conclusion}

In the face of the continuing shortfall of donor organs across the world, there have been successful efforts to remedy the situation by changing the law ${ }^{25}$ and by professionalizing and strengthening the transplant coordinator networks. ${ }^{45}$ The need for education for healthcare professionals regarding organ procurement has been well documented. Even brief training can positively influence donation rates, if only temporarily. ${ }^{27,28}$ However, an effective medical training programme in the area of donation aims not only at knowledge of transplantation and donation (EDHEP Part One), but also at the difficulties doctors and nurses experience in communicating with the bereaved and in requesting donation (EDHEP Part Two). 
EDHEP Part two, 'The Grief Response and Donation Request' workshop has been designed as an awareness raising programme to sensitise doctors and nurses to the issues involved in breaking bad news and requesting donation. By 1998, it had become a recognised part of postgraduate training in over 30 countries in Europe, the Far and Middle East and Latin America. In all of these countries, participants' judgements are very positive. There are anecdotal reports of increases in donation rates. ${ }^{46}$

The potential donor pool and the rate of donation are influenced by many organisational and professional factors. Adequate and sensitive communication with bereaved families is not automatically followed by a consent for donation as relatives tend to respect the wish of the deceased. Any effect of EDHEP on donor rates can only be indirect. Research into the effectiveness of EDHEP is therefore focused on intermediate variables, such as the quality of communication, teamwork and satisfaction of bereaved relatives.

The potential for the EDHEP programme to increase the competence of intensive care staff, the satisfaction of the bereaved, and subsequent rates of organ donation ${ }^{46}$ underlines the need to evaluate organisational and interpersonal competencies in the procurement of donor organs. The issues addressed in the EDHEP workshop are considered to cover the domain of communication relating to death and donation in a broad sense. It is therefore important to assess how and to what degree the issues addressed affect the competence (knowledge, attitudes, self-efficacy and communication skills) of critical care staff and the teamwork in intensive care, the satisfaction of bereaved relatives and donation rates. In the period 1995-2001 an international collaborative research project between the Netherlands and the United Kingdom was conducted to investigate the effects of EDHEP on the competence of staff, the collaboration in intensive care units, the satisfaction of bereaved. 


\section{References}

1. New B, Solomon M, Dingwall R, Mchale J. A question of give and take. Improving the supply of donor organs for transplantation. Kings Fund Institute London 1994.

2. Beech R, Gulliford M, Mays N, Melia J, Roderick PJ. Renal Disease. In: Stevens A, Raftery J, editors. Healthcare needs assessment: the epidemiologically based needs review. Oxford: Radcliffe Medical Press, 1994:1-56.

3. Miranda B, Fernandez LM, Matesanz R. The potential organ donor pool: international figures. Transplant Proc 1997;29:1604-1606.

4. Thompson J, McCorker C, Hibberd A, Chapman J, Compton J, Mahony J, et al. The identifiaction of potential cadaveric organ donors. Anaesth Intensive Care 1995;23:75-80.

5. Gore SM, Hinds CJ, Rutherfort AJ. Organ donation from intensive care units in England. BMJ 1989;299:1193-1197.

6. Gore SM, Ross Taylor RM, Wallwork J. Availability of transplantable organs from brain stem dead donors in intensive care units. BMJ 1991;302:149-153.

7. Novack DH, Suchman AL, Clark W, Epstein RM, Najberg E, Kaplan C. Calibrating the physician. Personal awareness and effective patient care. Working Group on Promoting Physician Personal Awareness, American Academy on Physician and Patient. JAMA 1997;278(6):502-9.

8. Randhawa G. Coping with grieving relatives and making a request for organs: principles for staff training. Med Teach 1998;20(3):247-249.

9. London RCoPo. Improving Communication Between Doctors and Patients. A report of a working party. London: Royal College of Physicians of London, 1997.

10. Wakeford RE, Stepney R. Obstacles to organ donation. Br J Surg 1989;76 May:435-439.

11. United Kingdom Transplant Coordinators Association (UKTCA) and British Association of Critical Care Nurses (BACCN). Relatives' refusal of organ donation. Report of a two year study. London: Department of Health, 1995.

12. Painter LM, Langlands JM, Innes Walker J. Donor families experience of organ donation: a New Zealand study. N Z Med J 1995;28 July 1995:295-296.

13. Pearson IY, Bazeley P, Spencer Plane T, Chapman JR, Robertson P. A survey of families of brain dead patients: their experiences, attitudes to organ donation and transplantation. Anaesth Intensive Care 1995;23(1):88-95.

14. Tijmstra T, Heyink JW, Pruim J, Slooff MJ. Experience of bereaved relatives who granted or refused permission for organ donation. Fam Pract 1992;9(2):141-4.

15. Blok G, Dalen Jv, Gurp Mv, Vecht Evd. Leven na Geven 2. Ervaringen van nabestaanden van orgaan- en/of weefseldonoren. [Translation: Living after giving 2. Experiences of donor relatives] Leiden: Bureau Transplantatiecoordinatoren, 1996.

16. Garrison RN, Bentley FR, Raque GH, Polk HC, Jr., Sladek LC, Evanisko MJ, et al. There is an answer to the shortage of organ donors. Surg Gynecol Obstet 1991;173(5):391-6.

17. Stein A, Hope T, Baum JD. Organ transplantation: approaching the donor's family. BMJ 1995;310:1149-50.

18. Ong LML, Haes de CJM, Hoos AM, Lammes FB. Doctor-patient communication: a review of the literature. Soc Sci Med 1995;40:903-918. 
19. Sanner M. Attitudes towards organ donation and transplantation. A model for understanding reactions to medical procedures after death. Soc Sci Med 1994;38:1141-1152.

20. British Association for Accident and Emergency Medicine and The Royal College of Nursing. Bereavement care in A and E departments. Londen: Royal College of Nursing, 1995.

21. Gask L, Goldberg D, Boardman A. Training general practitioners to teach psychiatric interviewing skills: an evaluation of group training. Med Educ 1991;25:444-451.

22. Maguire $\mathrm{P}$, Booth K, Elliott C, Jones B. Helping health professionals involved in cancer care acquire key interviewing skills--the impact of workshops [see comments]. Eur J Cancer 1996;32a(9):1486-9.

23. Prottas J, Batten HL. Health professionals and hospital administrators in organ procurement: attitudes, reservations, and their resolutions. Am J Public Health 1988;78(6):642-5.

24. Kent B, Owens RG. Conflicting attitudes to corneal and organ donation: a study of nurses' attitudes to organ donation. Int J Nurs Stud 1995;32(5):484-92.

25. Michielsen P. Effect of transplantation laws on organ transplant procurement. In: Touraine JL, editor. Organ shortage: the solutions. Proceedings of the 26Th Conference of transplantation and clincal immunology. Dordrecht: Kluwer Academic Publishers, 1995:3339.

26. Younger SJ, Landefeld CS, Coulton CJ, Juknialis BW, Leary M. 'Brain death' and organ retrieval. A cross-sectional survey of knowledge and concepts among health professionals. JAMA 1989;261(15):2205-10.

27. Cumberland B, Wit de R, Kootstra G. Organ and tissue procurement rates improve after professional healthcare education by hospital development coordinators and time sensitive requesting. Transplant Proc 1995;27:2957-2958.

28. Riker RR, White BW. The effect of physician education on the rates of donation request and tissue donation. Transplantation 1995;59(6):880-4.

29. McGough EA, Chopek MW. The physician's role as asker in obtaining organ donations. Transplant Proc 1990;22:267-272.

30. Siminoff LA, Arnold RM, Caplan AL. Healthcare professional attitudes toward donation: effect on practice and procurement. J Trauma Inj Infec Crit Care 1995;39:553-559.

31. Malecki MS, Hoffman MC. Getting to Yes: How Nurses' Attitudes Affect Their Succes in Obtaining Consent for Organ and Tissue Donations. Dialysis and Transplantation 1987:276278.

32. Franz H, Jong de W, Wolfe M, Nathan HM, Payne D, Reitsma W, et al. Explaining brain death; a critical feature of the donation process. J Transplant Coordination 1997;7:14-21.

33. Pohle von WR. Obtaining organ donation. Who should ask? Heart Lung 1996;25:304-309.

34. Sanson-Fisher R, Cockburn J. Effective teaching of communication skills for medical practice: selecting an appropriate clinical context. Med Educ 1997:31(1) 52-7.

35. Politoski G, Boller J. Making the critical difference: an innovative approach to educating nurses about organ and tissue donation. Crit Care Nurs Clin North Am 1994;6(3):581-5.

36. Wright B. Sudden death. London: Churchill Livingstone, 1991. 
37. Blok GA, Bogels SM. Teaching professional skills in mental healthcare with simulated patients. In: Klein HE, editor. Problem Solving with Cases and Simulation. Waltham MA, USA: Bentley college press, 1990:79-84.

38. Rethans J-J, Sturmans F, Drop R, Vleuten van der C. Assessment of the performance of general practioners by the use of standardized (simulated) patients. J Gen Pract 1991;March 1991:97-99.

39. Vu NV, Barrows HS. Use of Standardized Patients in Clinical Assessments: Recent Developments and Measurement Findings. Educational Researcher 1994;23(3):23-30.

40. Jager K, Ryan M, Dalen van J, Blok GA, Wijnen RMH. European Donor Hospital Education Programme. The grief response and donation request. Moderators manual. Leiden: Eurotransplant International Foundation/Sandoz Pharma Ltd., 1991.

41. Blok GA, Jager K, Dalen van J. European Donor Hospital Education Programme. The grief response and donation request. Participants Manual. Leiden: Eurotransplant International Foundation/Sandoz Pharma Ltd., 1991.

42. Ptacek JT, Eberhardt TL. Breaking bad news. A review of the literature. JAMA 1996;276(6):496-502.

43. Dalen van J, Blok GA, Kranenburg J, Haase B. European Donor Hospital Education Programme. Transpl Proc 1996;28(1):398-9.

44. Dalen van J, Blok GA, Morley M, Morton JB, Haase-Kromwijk B, Sells RA, et al. Participants' judgements of the European Donor Hospital Education Programme (EDHEP): an international comparison. Transpl Int 1999;12:182-7.

45. Matesanz R, Miranda B, Felipe C, Naya MT. Continous improvement in organ donation - the Spanish experience. Transplantation 1996;61:1119-21.

46. Wight C, Cohen B. Shortage of organs for transplantation [editorial]. BMJ 1996;312(7037):98990. 


\section{Participants' judgements of the European Donor Hospital Education Programme: an international comparison $^{1}$}

The European Donor Hospital Education Programme (EDHEP) is a one-day workshop, aimed at providing guidelines for breaking the news of the death of a relative and for raising the issue of organ donation with bereaved relatives. Participants' judgments of the workshop in the Netherlands and in the United Kingdom were compared to determine whether EDHEP meets doctors' and nurses' training needs in breaking bad news and requesting organ donation. In both countries EDHEP appears to be greatly appreciated by intensive care medical and nursing staff; the judgements are more positive in the United Kingdom than in the Netherlands. It seems that, irrespective of their professional experience, intensive care staff consider EDHEP as a valuable teaching programme, that increases confidence in communicating with bereaved relatives about death and organ donation.

\footnotetext{
${ }^{1}$ Published as: Dalen van J, Blok GA, Morley M, Morton JB, Haase-Kromwijk B, Sells RA, et al. Participants' judgements of the European Donor Hospital Education Programme (EDHEP): an international comparison. Transpl Int 1999;12:182-187.
} 


\section{Introduction}

Due to the success of organ transplantations since the development of modern immuno-suppressants in the 1980's, waiting lists for donor organs have been increasing. The availability of donor organs does not keep up with the increasing demand. Currently, the refusal rate of organ donation by relatives is approximately $30 \%$, with an additional $6 \%$ of the families of potential donors never being approached about donation. ${ }^{1}$ Communication with relatives about donation is often quite difficult. ${ }^{2-4}$ Attending to grieving families and making requests for organ donation requires personal insight and awareness of the needs of bereaved relatives as well as good communication skills, both of which may be influenced by experience. ${ }^{5}$ Self-confidence in approaching relatives to make a donation request donation influences the consent rate. Malecki et al. ${ }^{6}$ showed that nurses who were insecure and uncomfortable making the donation request mainly had refusals, in contrast to nurses who felt more secure and less uncomfortable. Lack of training and fear of adding to relatives' distress, have been identified as important barriers to raising the topic of organ donation with families. ${ }^{7}$ To help health professionals overcome these barriers, the Eurotransplant International Foundation initiated the development of the European Donor Hospital Education Programme (EDHEP) in 1991. EDHEP is a highly interactive, one-day workshop organised and hosted by transplant coordinators and moderated by communication skills training experts, preferably clinical psychologists. The workshop consists of different working formats, such as oral presentations, case studies, videotapes and exercises, including role plays with simulated relatives. Evaluation of the programme by the first 430 participants in the Netherlands showed a high degree of satisfaction with EDHEP, as well as a high learning effect and a decrease in the 'barrier' to approach families for donation. ${ }^{8}$ EDHEP was developed as an adaptable prototype, available to interested parties around the world. By 1998 EDHEP had been translated in 17 languages, and it is a recognised part of postgraduate training in 30 countries in and outside of Europe. The condition under which the programme was made available by the Eurotransplant International Foundation was that the original format be kept. ${ }^{9}$ National topics have been added to the programme (e.g. legal issues in France, religious issues in Israel). Sixteen standardized 2.5-day "Train-the-Trainer Courses" have accompanied the deployment of EDHEP in new countries and were conducted by the programme's authors and principal trainers in order to guarantee acceptable uniformity and quality control. Anecdotal reports of the positive reception of EDHEP have been equally apparent in such diverse countries as Saudi Arabia, Japan, Mexico, and all of Europe. In the North-West region of England, EDHEP was implemented in 1994. A review of the degree to which EDHEP participants in the Netherlands and the United Kingdom are satisfied with the programme has been conducted. The main question to be answered is: to what extent has the deployment of EDHEP been successful? EDHEP was designed to heighten the sensitivity of intensive care medical and nursing staff to relatives' 
needs in times of crisis and to provide guidelines for communication with bereaved relatives. The format of the day and the teaching aids used are specifically tailored to breaking the news of (brain)death and to raising the issue of donation (see Figure 1). The workshop is conducted in small groups with a maximum of sixteen participants, preferably eight doctors and eight nurses, working in critical care. EDHEP takes place outside the hospital setting and its inevitable distractions. ${ }^{9-13}$

'The grief response and donation request'-workshop

1. Welcome and introduction

2. Reasons for lack of donors Presentation

3. Loss and separation Exercise

4. Vignettes Brief videotaped dramatization

Coffee Break

* Identification of the personal and the professional response to grieving relatives

5. Health professionals can be effective Presentation

6. Talking about loss Videotaped interviews with relatives who consented to organ donation

\section{Lunch Break}

7. Sudden death Video drama

8. Breaking news of death Role play with simulated relatives

* Practise relevant communication skills

* Structured feedback to help identify strengths and weaknesses

Coffee Break

9. The donation request

* Practise relevant communication skills

Role play with simulated relatives

* Structured feedback to help identify strengths and weaknesses

10. Overview and summary Presentation

* Overview of learning objectives

* Guidelines for protocols

Figure 1. Overview of the programme

The principal questions in this study are: is there a difference in satisfaction with, and in recognition of the issues addressed by EDHEP between participants from the Netherlands and those from the United Kingdom? Is there a difference between the reported learning effect and the requests for follow-up by EDHEP 
participants in the Netherlands and in the United Kingdom? Three specific issues are additionally addressed:

6. Sanson-Fisher et al. ${ }^{14}$ recommend that for training to be effective it should be given within a context that is familiar and encountered in clinical practice. In the original EDHEP teaching material provided by the Eurotransplant International Foundation, one teaching video programme ('Vignettes') is in Dutch, with English subtitles. It was suggested that the 'Vignettes' programme be reproduced to suit national circumstances. After 1.5 years of experience in the United Kingdom with the original EDHEP 'Vignettes' programme, this was remade into an English version. Are participants more positive about teaching material that reflects their own national situation than about foreign teaching material?

7. Interactive training in communication skills appears to occur less frequently in medical and nursing schools in the United Kingdom than in the Netherlands. ${ }^{15}$ 16-22 It has been reported that participants who have actually had practice in skills trainings report results on formal behaviour tests that are similar to those participants who only observed skills performance, albeit in clinical skills training. ${ }^{23}$ Half of the participants in EDHEP have the opportunity to practise in role plays with simulated relatives, whereas the other half observe these interactions with predefined observation forms. Is there a difference in learning effect for those who practise in a role play compared to those who only observe? Are these differences national or international?

8. As has been noted in the implementation of EDHEP in Germany, the condition that EDHEP is conducted in mixed groups of doctors and nurses may create problems of acceptance amongst doctors. ${ }^{24}$ What is the participants' judgement about the group composition? Is there a difference between these judgements in the two countries?

\section{Method}

Programme evaluation has been shown to be a reliable technique to measure participants' satisfaction with a course. ${ }^{25-27}$ The programme evaluation questionnaire is provided as part of the EDHEP training package by the Eurotransplant International Foundation. The English form of the questionnaire is a direct translation of the Dutch original. The translation was done by the authors of the programme, native Dutch and native English speakers, familiar with the concepts relating to training in the areas of bereavement and donation. The first section of the questionnaire consists of items detailing date, biographical information, position and experience of the participant and questions about the difficulty of the donation request. These questions are answered on a 10-point scale ranging from 'no problem at all' to 'extremely difficult'. The second section of the questionnaire consists of statements about the organization, information, 
teaching aids and learning effect of the workshop; it is to be answered on a 5-point scale ranging from 'disagree completely' to 'agree completely'.

In the final section, the participants indicate their desire for further information and training. ${ }^{28}$ The forms were distributed, completed and subsequently collected at the end of each workshop to guarantee the highest possible response rate. The forms did not require identification of the respondent in order to reduce the likelihood of socially desirable responses.

Frequencies, descriptive statistics, one-way ANOVA's and chi-square tests were calculated with SPSS 6.1.2 for Windows. Effects were considered significant when the p-value was less then 0.001 .

\section{Results}

Because of the procedure of distributing and collecting the forms, in total no more than 20 forms were lost. The response rate was $98 \%$. The descriptive statistics of the EDHEP participants in both groups are shown in Table 1.

The proportions of doctors/nurses that attend EDHEP in both countries differ. The participants in the Netherlands are relatively more experienced in asking for tissue donation, whereas their British colleagues have relatively more experience in asking for organ donation. Not every participant has (had) the opportunity to make the donation request. Formally, this is the responsibility of the doctor, although often a doctor and nurse pair conduct this interview. For this reason, the questions about the difficulty of the donation requests were phrased in such a way that they were applicable to both professions. EDHEP participants from the Netherlands experience/expect less difficulty when asking for organ or tissue donation than their colleagues in the United Kingdom.

Table 1. Descriptive statistics of respondents in the Netherlands (NL) and the United Kingdom (UK).

\begin{tabular}{|c|c|c|c|c|c|}
\hline Participants & $\begin{array}{c}\mathrm{NL} \\
(\mathrm{n}=1170)\end{array}$ & $\begin{array}{c}\text { UK } \\
(\mathrm{n}=382)\end{array}$ & $\mathrm{df}$ & Value & p-value \\
\hline Doctors/nurses (\%) $^{1}$ & $33 / 61^{\mathrm{a}}$ & $16 / 81^{\mathrm{a}}$ & 1 & 48.3 & $<0.001$ \\
\hline \multicolumn{6}{|l|}{ Experience } \\
\hline \multicolumn{6}{|l|}{$\begin{array}{l}\text { Previous contacts with bereaved } \\
\text { relatives: }\end{array}$} \\
\hline Mode: Several times/month & $53 \%^{a}$ & $56 \%{ }^{\mathrm{a}}$ & 3 & 17.8 & $<0.001$ \\
\hline Requests for organ donation: & & & & & \\
\hline Never & $44 \%{ }^{a}$ & & & & \\
\hline 1-2 per year & & $43 \%{ }^{a}$ & 3 & 39.6 & $<0.001$ \\
\hline Requests for tissue donation: & & & & & \\
\hline Never: & $49 \%^{a}$ & $63 \%{ }^{a}$ & 4 & 37.4 & $<0.001$ \\
\hline
\end{tabular}

${ }^{1}$ A number of participants were 'others': in the Netherlands $6 \%$ and the United Kingdom 3\%.

In the Netherlands, asking for organ donation is seen as more difficult than asking for tissue donation. The judgements of the British participants are reversed (Table 2). 
Table 2. Difficulty of donation requests (10-point scale)

\begin{tabular}{lcccccccc}
\hline & \multicolumn{2}{c}{ NL } & & \multicolumn{2}{c}{ UK } & & & \\
\cline { 2 - 3 } & Mean & sd & & Mean & Sd & df & F & p \\
\hline $\begin{array}{l}\text { Organ } \\
\text { donation }\end{array}$ & $5.42^{\mathrm{a}}$ & 2.21 & & $6.02^{\mathrm{a}}$ & 2.44 & 1522 & 18.99 & $<0.001$ \\
$\begin{array}{l}\text { Tissue } \\
\text { donation }\end{array}$ & $4.86^{\mathrm{a}}$ & 2.19 & & $6.29^{\mathrm{a}}$ & 2.47 & 1472 & 106.75 & $<0.001$ \\
\hline
\end{tabular}

Programme and learning effect

Satisfaction with the programme as well as the learning effect, as expressed by participants in both countries, are given in Table 3. Participants from both countries rate all aspects of the workshop (very) high. The organization of the workshop, the instructiveness of simulated relatives and the learning effect are valued higher in the United Kingdom than in the Netherlands. The judgements about the recognition of the issues addressed and about the teaching aids in general are largely the same in both countries. The barrier to request donation is apparently lowered more, following EDHEP, in the United Kingdom than in the Netherlands. Further analysis showed that there was no apparent relationship between duration of professional experience and the learning effect. The correlation between prior experience with the donation request and learning effect for Dutch doctors is -0.16 (Pearson, $\mathrm{n}=386, \mathrm{p}<0.005$ ), a significant, but not very strong, inverse relation.

Doctors from the United Kingdom and nurses in both countries show no relationship between prior experience with the donation request and learning effect.

Table 3. Satisfaction with EDHEP and learning effect (5-point scale).

Organisation

Information recognizable

Teaching aids

Simulated relatives

Learning effect

Barrier to donation request reduced

\begin{tabular}{|c|c|c|c|c|c|}
\hline \multicolumn{2}{|c|}{ NL } & \multicolumn{2}{|c|}{ UK } & \multirow[b]{2}{*}{$\mathrm{df}$} & \multirow[b]{2}{*}{$\mathrm{F}$} \\
\hline Mean & $\mathrm{sd}$ & Mean & $\mathrm{Sd}$ & & \\
\hline $4.50^{\mathrm{a}}$ & 0.41 & $4.63^{\mathrm{a}}$ & 0.41 & 1550 & 28.35 \\
\hline 4.36 & 0.53 & 4.44 & 0.55 & & \\
\hline 4.29 & 0.43 & 4.37 & 0.45 & & \\
\hline $4.43^{\mathrm{a}}$ & 0.56 & $4.74^{\mathrm{a}}$ & 0.43 & 1544 & 98.76 \\
\hline $3.86^{\mathrm{a}}$ & 0.52 & $4.04^{\mathrm{a}}$ & 0.65 & 1547 & 28.70 \\
\hline $3.61^{\mathrm{a}}$ & 0.87 & $3.87^{\mathrm{a}}$ & 0.87 & 1529 & 25.36 \\
\hline
\end{tabular}

${ }^{\mathrm{a}} \mathrm{p}<0.001$

Further information and training

The requests for further information and training reveal a marked difference between the participants from the two countries. In the Netherlands, 35\% of the participants require more information compared to $44 \%$ in the United Kingdom $\left(\varkappa^{2}(1)=7.86, \mathrm{p}<0.005\right)$. In the Netherlands, $29 \%$ of the participants show a desire for more training compared to $50 \%$ in the United Kingdom $\left(x^{2}(1)=46.56\right.$, 
$\mathrm{p}<0.001)$. The proportions of participants requesting further information and training in the United Kingdom are higher and the priorities are reversed.

Origin of video vignettes

The 'Vignettes' video programme is a series of very short fragments of grief reactions of relatives, played by Dutch actors. For non-Dutch-speaking audiences the programme is subtitled. The vignettes are used to evoke personal as well as professional responses by the participants. After 1.5 years of experience with EDHEP in the United Kingdom, an British version of the 'Vignettes' programme was made. This version was highly comparable to the original; its intention was kept in the depiction of the scenes, using similar scenarios but British actors. Participants' judgments about the instructiveness of the different versions are given in Table 4. The Dutch subtitled version was judged as less instructive by the participants from the United Kingdom than by Dutch participants. The participants from the United Kingdom judged the British version as high as the Dutch participants judged the Dutch version.

Table 4. Instructiveness of different versions of 'vignettes' teaching video programmes (5-point scale).

\begin{tabular}{|c|c|c|c|c|c|c|}
\hline & \multicolumn{3}{|c|}{$\mathrm{NL}$} & \multicolumn{3}{|c|}{ UK } \\
\hline & Mean & sd & $\mathrm{n}$ & Mean & $\mathrm{sd}$ & $\mathrm{n}$ \\
\hline Dutch 'vignettes' programme & $4.16^{\mathrm{a}}$ & 0.72 & 1170 & $3.84^{\mathrm{a}, \mathrm{b}}$ & 0.88 & 241 \\
\hline UK 'vignettes' programme & not & wn & & $4.13^{b}$ & 0.76 & 141 \\
\hline
\end{tabular}

${ }^{a} \mathrm{p}<0.001 ; \mathrm{df}=1408, \mathrm{~F}=37.81$

${ }^{\mathrm{a}} \mathrm{p}<0.001 ; \mathrm{df}=381, \mathrm{~F}=11.21$

Participation in role play

The influence of participation in the role play session on the learning effect was different for the two countries. In the United Kingdom, a difference in reported learning effect was apparent between participants who played the role of a doctor or a nurse (mean 4.13, sd: 0.55 ) and those who did not (mean 3.89, sd: 0.75 ). The difference is significant at the $\mathrm{p}<0.001$ level $(\mathrm{F}(346)=11.01)$. In the Netherlands, participants who played a role and those who only observed report a mean learning effect of 3.88 and 3.86, respectively (sd: in both groups 0.52 ).

\section{Group composition}

The British participants rated the group composition higher than the Dutch did (NL: mean 4.58, sd: 0.63; UK: mean 4.75, sd: 0.57; F(1529)=19.80, $<<0.001)$. This difference is accounted for only by the groups of nurses: UK nurses appreciate training in mixed groups of doctors and nurses more than Dutch nurses do (NL: mean 4.63, sd: 0.58; UK: mean 4.77, sd: 0.54; $F(1110)=13.56, \mathrm{p}<0.001)$. Doctors' judgments are equally high in both countries (NL: mean 4.51, sd: 0.69; UK: mean 4.59, sd: $0.75 ; \mathrm{F}(440)=0.71, \mathrm{p}=\mathrm{ns})$. 


\section{Discussion}

The results from the evaluation in the United Kingdom are highly similar to the results of the first group $(n=430)$ of EDHEP participants in the Netherlands. ${ }^{8}$ In Germany and Denmark, similar results have been published. ${ }^{24,29,30,31}$ The workshop is based on the needs expressed by intensive care medical and nursing staff, which is reflected in the appreciation of the issues addressed. Participants report high satisfaction with the programme and its learning effect, irrespective of their prior professional experience and country of origin. The difference in educational culture may be reflected in a higher satisfaction with this highly interactive teaching programme in the United Kingdom, where this is a relatively new teaching format. This conclusion is supported by the finding that the participants who actively took part in the role play session in the United Kingdom reported a higher learning effect than those who merely observed the role play, whereas in the Netherlands these two groups showed no difference in reported learning effect. It has been demonstrated that the programme is adaptable and that satisfaction with the programme is increased when parts are nationalised. Participants in both countries are satisfied with the group composition. This is a nuance of the issue raised by Muthny in Germany, ${ }^{24}$ who discusses the possibility of mono-disciplined groups. It has not been shown that this would increase the proportion of doctors attending the workshop. Furthermore, it would not model what is advocated in the workshop: breaking the news of the death of a relative and asking for donation is a team effort, in which collaboration is much needed. These findings support the view that EDHEP is adaptable to diverse national circumstances. The issues addressed appeal to healthcare professionals in different countries, as has been suggested in other publications. The 1-day workshop promotes increased confidence in communicating with bereaved relatives about death and organ donation. This will increase the probability of a higher quality of communication, more satisfied relatives and the possibility of more donor organs. 


\section{References}

1. Gore SM, Ross Taylor RM, Wallwork J. Availability of transplantable organs from brain stem dead donors in intensive care units. BMJ 1991;302:149-153.

2. Kirste G, Muthny FA, Wilms H. Psychological aspects of the approach to donor relatives. Clinical Transplantation 1988;2:67-79.

3. McGough EA, Chopek MW. The physician's role as asker in obtaining organ donations. Transplant Proc 1990;22:267-272.

4. Prottas J, Batten HL. Health professionals and hospital administrators in organ procurement: attitudes, reservations, and their resolutions. Am J Public Health 1988;78(6):642-5.

5. Verble MS, Worth JK. Family counseling. In: Brightbill FS, editor. Corneal Surgery: Theory , Technique and Tissue: St. Louis: The CV Mosby Company, 1986.

6. Malecki MS, Hoffman MC. Getting to Yes: How Nurses' Attitudes Affect Their Succes in Obtaining Consent for Organ and Tissue Donations. Dialysis and Transplantation 1987:2768.

7. Wakeford RE, Stepney R. Obstacles to organ donation. Br J Surg 1989;76 May:435-9.

8. Dalen van J, Blok GA, Kranenburg J, Haase B. European Donor Hospital Education Programme. Transplant Proc 1996;28(1):398-9.

9. Wight C, Jager K, Cohen B, Dalen van J, Blok GA, Wijnen R. The European Donor Hospital Education Programme. In: Englert Y, editor. Organ and tissue transplantation in the European Union. Dordrecht: Martinus Nijhoff, 1995:175-9.

10. Blok GA, Van Dalen J., Jager K, Wight C, Wijnen R. Omgaan met rouw en donatie: een vaardigheidsprogramma. [Dealing with grief and donation: a skills programme] In: Metz JCM, Scherpbier AJJA \& Houtkoop E. (Eds). Gezond onderwijs 2. Nijmegen: Universitair publicatiebureau KUN, 1993:41-8.

11. Blok G, van Dalen J, Jager K, Ryan M, Wijnen R, Wight C, et al. The European Donor Hospital Education Programme (EDHEP): addressing the training needs of doctors and nurses who break bad news, care for the bereaved, and request donation. Transpl Int 1999:12(3):161-7.

12. Stevens P, Jager K, Ryan M, Blok G, Dalen Jv. The European Donor Hospital Education Programme (EDHEP). In: Charro Fd, Hessing D, Akveld J, editors. Systems of donor recruitment. Rotterdam: Erasmus University Press, 1992:105-9.

13. Wight C, Jager K, Blok GA, van Dalen J, Cohen B. Overview of the European Donor Hospital Education Programme. Transplant Proc 1996;28(1):422-3.

14. Sanson-Fisher R, Cockburn J. Effective teaching of communication skills for medical practice: selecting an appropriate clinical context. Med Educ 1997:31(1) 52-7.

15. Bursari J, Scherpbier A, Boshuizen H. Compartive study of medical Education as perceived by students at three Dutch universities. Adv Health Sci Educ 1997;1:141-51.

16. Cantwell BM, Ramirez AJ. Doctor-patient communication: a study of junior house officers. Med Educ 1997;31:17-21.

17. Frederikson L, Bull P. An appraisal of the current status of communication skills training in British Medical Schools. Soc Sci Med 1992;34 (5):515-22.

18. Authority NHS. What seems to be the matter: communication between hospitals and patients. London: HMSO, 1993. 
19. Rousseau C, Heusch N. The trip: A creative expression project for refugee and immigrant children. Art Therapy 2000;ol 17(1):31-9.

20. Whitehouse CR. The teaching of communication skills in United Kingdom medical schools. Med Educ 1991;25(4):311-8.

21. World Health Organisation. Doctor-patient interaction and communication. Geneva: WHO, 1993.

22. Wouda J, Wiel $\mathrm{H}$ vd. Communicatieve vaardigheden: een diagnose en advies [Communication skills: diagnosis and advice]. Bulletin Medisch Onderwijs 1992;11:116-8.

23. Mir M, Marshall R, Evans R, Hall A, Duthie H. Comparisons between videotape and personal teaching as methods of communicating clinical skills to students. BMJ 1984;289:31-4.

24. Muthny FA. Fortbildungsprogramm zur Gesprächsführung mit den Angehörigen plötzlich Verstorbener als Beispiel von KommuniKationstraining und affektiv-emotionalen Lernzielen in der Ärztlichen Ausbildung. [Developmental programme for consultations with suddenly bereaved relatives as an example of communication skills training and affective-emotional learning goals in the training of doctors]. Medizinische Ausbildung 1996;13 (1) Mai:57-64.

25. Cook D, Brown L, Skakun E. Factors which influence the outcome of student evaluation of teaching. In: Scherpbier A, Vleuten van der C, Rethans J, Steeg A vd (eds). Advances in medical education. Dordrecht: Kluwer, 1997:545-7.

26. Dolmans D, Wolfhagen $H$, Schmidt $H$, Vleuten van der C. A ratingscale for tutor evaluation in a problem based curriculum: validity and reliability. Med Educ 1994;28:550-8.

27. Gijselaers W. Kwaliteit van het onderwijs gemeten: studies naar de betrouwbaarheid, validiteit en bruikbaarheid van studentoordelen. [Measuring quality of education: reliability, validity and feasibility of student judgments]. Dissertation. Maastricht, 1988.

28 Jager K, Ryan M, Dalen J van, Blok G, Wijnen R. European Donor Hospital Education Programme, Moderators' Manual. Leiden: Eurotransplant International Foundation; 1991.

29. Muthny FA. Das Gespräch mit den Angehörigen plötzlich Verstorbenen als zentraler Schlüssel zur Organspende -Notwendigkeiten und Möglichkeiten psychosozialer Fortbildung am Beispiel des EDHEP-programms. [Communication with the next of kin of the suddenly deceased as the key to organdonation -needs and potential of psychosocial postgraduate training: EDHEP as an example] Transplantationsmedizin 1995;7:66-70.

30. Scheidtmann W, Muthny FA. Einstellung von Ärtzen zur Organtransplantation -Ergebnisse einer empirischen Studie. [Doctors' attitudes towards organ transplantation -results of an empirical study] Transplantationsmedizin 1995;9:2-7.

31. Birkeland SA, Christensen AK, Kosteljanetz M, Svarre HM. Rise in organ donations. Lancet;349:1558. 


\section{4}

\section{Requesting Organ and Tissue Donation: the case of self-efficacy. Effects of the European Donor Hospital Education Programme ${ }^{1}$}

One of the major reasons for the shortage of donor organs is the high number of refusals by relatives. Studies have shown that the quality of communication with the bereaved relatives influences whether to object or agree to organ and/or tissue donation. Breaking news of brain stem death, approaching relatives for permission to donate organs while also appropriately managing emotional reactions of relatives are complex tasks, which require knowledge of the domains as well as adequate skills to communicate information and understanding. In this study the effect of the European Donor Hospital Education Programme (EDHEP) on the self-efficacy of ICU-staff is evaluated. Self-efficacy scores significantly improved after attending EDHEP; an effect that was maintained at six month follow-up. EDHEP participants with bigh baseline scores on self-efficacy, maintained the increase at follow-up. EDHEP participants with low baseline scores on self-efficacy showed the greatest increase at the post-test. Increases in self-efficacy were significantly related to decreases in the perceived difficulty of requesting. Experience had a significant effect on both selfefficacy beliefs and perceived difficulty of requesting donation. As self-efficacy beliefs are perceived as better predictors for future behaviour than prior attainments, the results call for further research in this domain. The data indicate that training programmes should be tailored not only to working circumstances of participants, but should also take levels of experience and self-efficacy into account. Further study is necessary and the best way to proceed is to relate the outcomes of this study to behavioural outcomes.

\section{Introduction}

One of the reasons for the shortage of donor organs is the number of refusals by bereaved relatives. Studies have shown that the quality of the communication with

\footnotetext{
${ }^{1}$ Accepted for publication: Blok GA, Morton J, Morley M, Mansum W van, Vleuten CPM van der. Requesting Organ and Tissue Donation: the case of self-efficacy. Effects of the European Donor Hospital Education Programme (EDHEP). Adv Health Sci Ed.
} 
the bereaved relatives influences the decision made by the next of kin. Doctors and nurses find it difficult to deal with death and dying. ${ }^{1-5}$ Breaking news of death, explaining brain stem death, approaching the next of kin for permission to donate organs while also appropriately managing emotional reactions of relatives are complex tasks, which require knowledge about these domains as well as skills to communicate information and understanding. Staffs' attitudes toward brain death and organ donation as well as their confidence about their ability to communicate effectively with the next of kin play an important role in this. ${ }^{6-9}$

In the communication with bereaved relatives about organ and tissue donation, at least two barriers have been identified: fear of adding to their distress, and the lack of training in communication skills. ${ }^{10}$ The timing of the request and the confidence of those who make the request influence how the relatives of brain death patients will feel and react to the donation request. ${ }^{9,11-16}$ One of the areas in which attempts have been made to increase the number of donor organs is training staff in communicating with bereaved relatives. Some research has been devoted to the interpersonal competence of doctors and nurses in the areas of death and donation and to the contribution of inappropriate or insensitive communication to family refusal. ${ }^{9,17,18}$

Enhanced awareness of interpersonal variables and training in order to improve competence is necessary for improvement of communication with the bereaved. ${ }^{4,9}$ There is, however, little empirical validation of the effects of such training programmes. ${ }^{20,21}$

Communication skills can be improved, resulting in more effective consultations for both patients and doctors and nurses. There is substantial evidence from other areas in medicine as well as in other areas, in undergraduate education as well in continuing (medical) education, that particular skills can be improved with training based on identified needs ${ }^{5,22-26}$ (see Kurtz et al. ${ }^{27}$ for an overview).

\section{Self-efficacy and the request for organ donation.}

Self-efficacy, the belief that one can successfully accomplish a given task, is considered a key factor of human competence. Bandura ${ }^{28,29}$ argues that knowledge, skill and prior behaviour are often poor predictors of subsequent behaviour, because the beliefs that individuals hold about their abilities and about the outcome of their efforts influence the ways in which they will behave. An efficacy expectation is the conviction that one can successfully perform the behaviour required to produce the outcome: "the strength of people's convictions on their own efficacy is likely to affect whether they will even try to cope with given situations (...) People behave assuredly when they judge themselves capable of handling situations that would otherwise be intimidating" ${ }^{28}$ (p. 193-194). The stronger the perceived self-efficacy is, the more active the efforts. People often do not perform optimally even though they know full well what to do and possess the requisite skills to do it. 
There is a large body of evidence that specific self-efficacy estimates predict behaviour across a wide range of behaviours. The domains that have been examined include driving ability, ${ }^{30}$ complex interpersonal skills, ${ }^{31,32}$ computer performance, ${ }^{33}$ problem solving in adults, ${ }^{34,35}$ assertiveness, ${ }^{36}$ self-management regarding arthritis, ${ }^{37,38}$ and ability to cope in a new work setting. ${ }^{39}$

The significant influence of the degree of comfort the healthcare professionals themselves experience when requesting donation on the answer they receive, was demonstrated by Malecki and Hofman. ${ }^{40}$ Experience and training enhanced their confidence in approaching families and improved the manner in which a request was made by the doctor or nurse: those who felt secure and comfortable with making the request had more consents than those who did not. Siminoff et al. ${ }^{9}$ found that the degree of comfort with answering families' questions about donation had a significant positive impact on consent to donate.

According to Bandura, individuals' beliefs in their self-efficacy can be influenced by four main sources: ${ }^{29,41}$ mastery experiences, vicarious experiences, social persuasion and the attribution of physiological arousal. The most effective way is by mastery experiences. A second way is strengthening self-efficacy beliefs, is through vicarious experiences provided by social models. ${ }^{34,41}$ The third influence on self-efficacy beliefs is social persuasion. Constructive feedback on behaviour is thus very important; only positive appraisal is not sufficient. People need to be encouraged to measure their success in terms of self-improvement rather than compare themselves with others. ${ }^{29,42}$ The fourth and last influence on self-efficacy beliefs is to correctly interpret bodily arousal and use it in a constructive way. People with a high sense of self-efficacy will interpret affective arousal as an energising factor, those who have low levels of self-efficacy regard their arousal as negative. ${ }^{29}$

In a review on research in academic settings Pajares ${ }^{43}$ concludes that “....performances are generally better predicted by self-efficacy than by prior attainments" (p. 554). "In general, there is ample reason to believe that self-efficacy is a powerful motivation construct that works well to predict academic self beliefs and performances at varying levels but works best when theoretical guidelines and procedures regarding specificity and correspondence are adhered to" (p. 557). According to Bandura ${ }^{29,41}$ a high correspondence between efficacy and performance is found when precise and detailed measurements of self-efficacy are made. Pajares ${ }^{43}$ added to this, that "Findings on self-efficacy coincide on two points: when efficacy beliefs are globally assessed and/or do not correspond with the criterial tasks with which they are compared, their predictive value is diminished or can even be nullified; and that when efficacy assessments are tailored to the criterial task, prediction is enhanced."

An educational programme aiming at increasing peoples' self-efficacy beliefs should therefore contain elements of all sources of information that influence these self-efficacy beliefs, and efficacy assessments should be tailored to criterial tasks. 


\section{The European Donor Hospital Education Programme (EDHEP)}

The European Donor Hospital Education Programme (EDHEP) workshop was developed in order to improve the competence of intensive care staff in breaking news of death and requesting donation. ${ }^{44,45}$ EDHEP aims specifically at improvement of the communication with the relatives regarding death and donation, by establishing insight in the grieving process and about relatives' emotional reactions as well as providing insight in the donation procedure. Furthermore it provides hands-on practice in relevant communication skills needed in sensitively breaking news of death and making a request for organ donation. ${ }^{46}$ During the workshop participants have the opportunity to reflect on their knowledge of, and personal and professional attitudes towards loss, bereavement and donation. Guidelines for good practice when breaking bad news and making the donation request, based upon consensus from research, are presented. ${ }^{22,47-49}$ Video vignettes with relatives' reactions are used to identify and reinforce some of these guidelines and to reflect upon personal reactions and attitudes. Use of the guidelines for approaching families about brain death and donation is emphasized during two role plays with simulated relatives; breaking news of brain death and requesting donation. Those who do not play a role use observation assignments to direct their attention. The role plays are discussed afterwards and the simulated relative, the observers and the trainer give feedback. For more detailed information on the design and content of the programme see Blok et al.. ${ }^{46}$

The programme is tailored to the working circumstances of the participants, which allows maximal transfer to the working routine. ${ }^{50,51}$ Programme evaluations of the EDHEP workshop are very positive. Participants report high satisfaction with the programme and its learning effects, irrespective of their prior experience and country of origin. Participants indicate that they find the donation request less difficult after participation. ${ }^{52,53}$ The EDHEP workshop, "The grief response and donation request', is translated in 15 languages and is part of post-graduate education in 35 countries all over the world. ${ }^{54}$

\section{EDHEP and self-efficacy}

EDHEP aims at increasing several aspects of professional competence in breaking bad news and making the donation request. In the design all factors that influence individuals' beliefs in their self-efficacy are present. In the EDHEP workshop mastery experiences, described earlier as the most effective and most authentic way of influencing self-efficacy beliefs, are built in the programme in two ways: responding to vignettes and role play with simulated relatives. Vicarious learning can take place through the observation of the trainers. Throughout the workshop the trainers model the skills that the participants are to learn, thus providing participants with social modelling of desired behaviours. Successful application of the desired behaviour by other participants provides an additional source. Strengthening self-efficacy beliefs through vicarious experiences provided by social models is powerful, because seeing people similar to one self succeed, raises 
observers' beliefs that they, too, possess the capabilities to master comparable activities. ${ }^{34,41}$

Social persuasion, the third influence on self-efficacy beliefs is strongest via constructive feedback. "People who are persuaded verbally that they possess the capabilities to master given activities are likely to mobilise greater effort and sustain it than if they harbour self-doubts and dwell on personal deficiencies when problems arise". ${ }^{42}$ In the exercises the participants get immediate constructive feedback on the use of the skills and knowledge on which the workshop is focused.

Constructive attribution of physical and/or psychological arousal is dealt with specifically in the exercise using vignettes: participants are encouraged to acknowledge their arousal and use this in an effective way.

\section{Aim of the study}

Given the potential impact of the workshop, we wanted to investigate the effectiveness of the programme on the self-efficacy of the participants. Firstly, we wanted to establish the effect of EDHEP on self-efficacy beliefs relating to breaking news of (brain stem) death, requesting organ donation and responding to bereaved relatives' emotional reactions. Secondly, programme evaluations show that participants find the donation request less difficult after participation. The second research question, therefore, dealt with establishing the effect of EDHEP on perceived difficulty in requesting donation. Thirdly, we wanted to know if increases in self-efficacy beliefs would be reflected in reductions in perceived difficulty of requesting donation. Finally, we wanted to investigate the assumption in selfefficacy theory, that performances are better predicted by self-efficacy beliefs than by prior attainments. The fourth research question was, whether experience played a role in changes in self-efficacy beliefs.

The four hypotheses that were tested, were:

1. Attending EDHEP leads to increased self-efficacy beliefs in breaking news of (brain) death requesting organ donation, introducing the donation procedure, and in responding to bereaved relatives' emotional reactions.

2. Attending EDHEP leads to a reduction in the perceived difficulty in making a request for donation.

3. An increase in self-efficacy beliefs is reflected in a reduction of experienced difficulty in making a donation request.

4. Experience has no influence on changes in self-efficacy over measurements.

A randomised controlled study with three repeated measures was carried out in two settings in Europe, in the Netherlands and in the United Kingdom, with measures of self-efficacy and perceived difficulty of the donation request as dependent variables. 


\section{Method}

Subjects

Subjects were doctors and nurses working in intensive care from two countries.

The Netherlands. In the Netherlands the recruitment of subjects was nationwide; subjects were doctors and nurses from over 40 hospitals, who volunteered for participation in an EDHEP workshop. During the period in which the research took place, the allocation of participants to EDHEP workshops was coordinated nationally. Potential participants were registered centrally and randomly assigned to either an experimental condition (attendance at an EDHEP workshop during the study) or a control condition (attendance at an EDHEP workshop after the study). During the research period of one and a half year, 7 EDHEP workshops took place. In order to control for effects due to dispersion in time, per EDHEP workshop an equal number of future participants were allocated to the control condition. The number of subjects in the experimental condition was 71 ; in the control condition 61. Both conditions were comparable on all the descriptive characteristics. The proportion of doctors is rather low compared to the proportion of nurses; about one fifth in both conditions. The sample had a mean age of 33 years and a mean experience of six years in their profession.

United Kingdom. In the North West of England twenty hospital intensive care units were matched for numbers of beds and the area they served in terms of population served. They were randomly assigned to an experimental or control condition. In order to make sure all intensive care units of the selected hospitals were represented in the study, all consultants were included in the study. Nurses were randomly paired up with a consultant from their ICU. All subjects in the experimental group participated in one of the twenty-two EDHEP workshops conducted over a period of one year. The subjects in the control group were offered EDHEP workshops after the research period, which took one and a half year. The number of subjects in the experimental condition was 29; in the control condition 27. In both conditions both profession and sex were evenly divided. The mean age in both groups was 39 years. Both conditions were thus well matched on all characteristics, except for the mean years of experience in intensive care; the doctors and nurses in the control group had significantly more experience $(\mathrm{p}<0.05)$.

In Table 1 general experience, experience with bereaved relatives and with making a donation request is listed. It can be seen that conditions in both countries are well matched. The sample as a whole has substantial experience in contacts with bereaved relatives. In both conditions the subjects have more experience with requesting organ donation than with requesting tissue donation. Comparison of the subjects in both countries shows that subjects in the British sample have more general experience, also in making a request for organ donation than in the Dutch sample. 
Table 1. Experience of the subjects in the Netherlands and in the United Kingdom with bereaved relatives and requesting donation of organs and tissues in percentages.

\begin{tabular}{|c|c|c|c|c|}
\hline & \multicolumn{2}{|c|}{ The Netherlands } & \multicolumn{2}{|c|}{ United Kingdom } \\
\hline & $\begin{array}{c}\text { Experimental } \\
\mathrm{n}=71\end{array}$ & $\begin{array}{l}\text { Control } \\
\mathrm{n}=61\end{array}$ & $\begin{array}{c}\text { Experimental } \\
\mathrm{n}=29\end{array}$ & $\begin{array}{l}\text { Control } \\
\mathrm{n}=27\end{array}$ \\
\hline \multicolumn{5}{|l|}{$\begin{array}{l}\text { Experience with bereaved } \\
\text { relatives }\end{array}$} \\
\hline None & $6 \%$ & $6 \%$ & $3 \%$ & $4 \%$ \\
\hline few times/year & $44 \%$ & $38 \%$ & $14 \%$ & $22 \%$ \\
\hline few times/month & $45 \%$ & $56 \%$ & $69 \%$ & $52 \%$ \\
\hline few times/week & $4 \%$ & - & $14 \%$ & $22 \%$ \\
\hline Missing & $1 \%$ & - & & \\
\hline \multicolumn{5}{|l|}{$\begin{array}{l}\text { Experience with requesting } \\
\text { organs }\end{array}$} \\
\hline None & $44 \%$ & $43 \%$ & $17 \%$ & $22 \%$ \\
\hline 1-2 times/year & $46 \%$ & $51 \%$ & $52 \%$ & $37 \%$ \\
\hline 3-4 times/year & $7 \%$ & $3 \%$ & $24 \%$ & $26 \%$ \\
\hline more than 4 times/year & $3 \%$ & $3 \%$ & $7 \%$ & $15 \%$ \\
\hline \multicolumn{5}{|l|}{$\begin{array}{l}\text { Expierence with requesting } \\
\text { tissues }\end{array}$} \\
\hline None & $51 \%$ & $54 \%$ & $55 \%$ & $55 \%$ \\
\hline 1-2 times/year & $30 \%$ & $39 \%$ & $24 \%$ & $30 \%$ \\
\hline 3-10 times/year & $14 \%$ & $5 \%$ & $14 \%$ & $15 \%$ \\
\hline$>10$ time & $4 \%$ & $2 \%$ & - & - \\
\hline Missing & $1 \%$ & - & $7 \%$ & - \\
\hline General experience in yrs (sd) & $6.3(5.3)$ & $6.1(4.6)$ & $14.8(7.6)$ & $10.9(6.9)^{*}$ \\
\hline
\end{tabular}

Procedure

The experimental design used was an 'untreated control group design with pre-test and post-test' with a follow-up. ${ }^{55}$ There were three measurements: one before attending the EDHEP workshop (pre-test), one after attending the EDHEP workshop (post-test) and one six months after the post-test (follow-up). The independent between-subjects variable was condition (participation in EDHEP or control); the independent within-subjects variable was measurement. The dependent variables were the scores on a self-efficacy instrument and on a question about the perceived difficulty of making a donation request. Different kinds of experience were treated as covariates.

Measurements in the control condition took place at similar points in time. Questionnaires were sent to the subjects at all three measurements. The subjects in the experimental group handed the filled-out questionnaires to the EDHEP workshop moderators before the start of the workshop. The future EDHEP participants used pre-stamped envelopes for returning the questionnaires to the researchers. At post-test and follow-up this procedure was applied for all subjects. All data were anonimised by allocating a number to each subject. 
Instruments

Self-efficacy. Following the recommendations from self-efficacy theory, a list of criterial tasks was developed. The criterial tasks involved breaking the news of brain death, requesting organ- or tissue donation, dealing with the bereaved relatives reaction in the two aforementioned situations; and explaining the donation procedure. Self-efficacy was measured using two sorts of statements referring to these criterial tasks. ${ }^{42}$ Twelve statements were formulated, referring to six different activities. These were derived directly from specific areas addressed in the EDHEP workshop: explaining brain death, dealing with relatives' reactions to the news of brain death, requesting organ donation, requesting tissue donation, dealing with relatives' reactions to the donation request and explaining the donation procedure (see Figure 1 for some examples).

Below you will find 12 statements, about topics that are often discussed with bereaved relatives. Half of the statements deal with how much knowledge you have about the behaviour required. Half of the statements deal with how certain you are that you can do what is required. Your answers are not meant to indicate of how difficult the topic itself is.

Instruction for completion.

Below every statement is a $10 \mathrm{~cm}$ bar. The ends of the bar represent the extreme values of opinion. Please indicate what your opinion is about each statement by marking the bar in a position that indicates the degree of your disagreement or agreement. If you decide to change your answer, would you please put $a$ single line through the wrong answer.

1a I know how to explain the diagnosis of brain death in a clear and understandable way to bereaved relatives.

Disagree $\quad<10 \mathrm{~cm} \mathrm{bar}>\quad$ agree

1b I can explain the diagnosis of brain death in a clear and understandable way to bereaved relatives.

Disagree $\quad<10 \mathrm{~cm} \mathrm{bar}>\quad$ agree

5a I know how to deal with relatives' emotional reactions to a donation request.

Disagree $\quad<10 \mathrm{~cm} \mathrm{bar}>\quad$ agree

5b I can deal with relatives' emotional reactions to a donation request.
Disagree
$<10 \mathrm{~cm}$ bar $>$
agree

Figure 1. Excerpt from the EDHEP self-efficacy questionnaire.

For each of these statements participants had to indicate their position on a tencentimetre Visual Analogue Scale (VAS-scale), ranging from 'disagree' to 'agree'. The finer the distinctions that can be made between subjects' responses, the greater the precision of the measure. ${ }^{56}$ Six statements reflected knowledge about described behaviour (the 'Know'-subscale); six statements reflected performance of this behaviour (the 'Can'-subscale.). All scores together comprised the 'Total'-scale. A 
high score reflects a high appraisal of one's knowledge as well as of one's ability to perform.

In each country a panel of 30 experts, experienced intensive care doctors and nurses, rated the validity of the instrument. Dutch and British experts agreed on the content validity of the instrument. In both countries the reliability of the total scale was very high (Cronbach's $\alpha=0.93$ in the Netherlands and 0.92 in the United Kingdom). The reliabilities of the subscales were also high. The 'Know'-subscale had reliabilities of $\alpha=0.88$ in the Netherlands and $\alpha=0.86$ in the United Kingdom. For the 'Can'-subscale the alphas were 0.86 and 0.83 respectively.

Difficulty of the donation request. All subjects were asked to rate the (perceived) difficulty of requesting organ or tissue donation on two separate 10-point-scales, ranging from 'no problem' (1) to 'extremely difficult' (10). The two questions were phrased differently for doctors and nurses as they may have different roles in the request process: "How difficult do you find making a request for organ donation "How difficult do you find making a request for tissue donation (or how difficult do you find being involved in a request for tissue donation)"

Experience. All subjects were asked to indicate the number of years of experience in medical and nursing care. Besides this the subjects were asked to indicate their experience with bereaved relatives and with making a request for organ and tissue donation (see Table 1).

Statistical analyses

Means, frequencies and percentages were calculated for the descriptive data; Chisquare was used to check for any differences in the descriptive data within and between countries. In order to calculate any differences in self-efficacy scores and in the scores on the difficulty of the donation request (hypotheses one and two) over measurements, analyses of variance (ANOVA's) were carried out using a general linear model (GLM). Tukey's Honest Significant Difference was calculated to establish any differences between separate measures; T-Tests for independent samples were done to establish differences between experimental and control conditions. For the establishment of the relationship between self-efficacy and the difficulty of the donation request (hypothesis three) correlation analysis was applied. Testing the fourth hypothesis took two steps. First, ANCOVA's were carried out to calculate any effect of the different kinds of experience on the dependent variables. Second, secondary dummy regression models were used to test for differential effects within groups. For a good understanding of the results of the regression analyses, the description of the development of the dummy variables is given in the results section when applicable. All calculations were made with SPSS 10.0 for Windows. Effects were considered significant when the p-value was less then 0.05 . 


\section{Results}

The effect of EDHEP on self-efficacy (hypothesis 1)

In Table 2 self-efficacy scores are given. EDHEP-participants in both countries show a marked increase in the total scores on self-efficacy. Self-efficacy scores in the experimental (EDHEP) groups in both countries show a significant increase in the total score immediately following participation in EDHEP, an effect that was maintained at follow-up. There is a main effect for measure on the total score (NL: $\mathrm{F}(2)=25.74 ; \mathrm{p}<0.0001 ; \mathrm{UK}: \mathrm{F}(2)=7.12 ; \mathrm{p}<0.001)$. These effects are also reflected in the results on the subscales ('Know'-scale: $(\mathrm{NL}: \mathrm{F}(2)=26.33$; $\mathrm{p}<0.0001$; UK: $\mathrm{F}(2)=7.37 ; \mathrm{p}<0.001)$ and the 'Can'-scale (NL: $\mathrm{F}(2)=18.15 ; \mathrm{p}<0.0001 ; \mathrm{UK}$ : $\mathrm{F}(2)=6.21 ; \mathrm{p}<0.01)$.

The control group in the Netherlands showed a slight increase at follow-up compared with the pre-test on the total score $(\mathrm{F}(2)=3.33 ; \mathrm{p}<0.05)$ and on the 'Know'-scale $(\mathrm{F}(2)=3.30 ; \mathrm{p}<0.05)$ (both Tukey's HSD). However, the follow-up scores of the Dutch experimental group were significantly higher on all scales (Ttest, 'Total': $\mathrm{p}<0.01$, 'Know': $\mathrm{p}=0.001$, 'Can': $\mathrm{p}<0.01)$ ). There were no significant changes in the control group scores in the United Kingdom over measurements.

The scores of the control group in the United Kingdom are higher than those of the experimental group at the pre-test (T-Test: $\mathrm{p}<0.05$ ). At the post-test this difference had disappeared. At follow-up, the scores of the experimental group were significantly higher for the 'Know'-scale $(\mathrm{p}<0.05)$.

Table 2. Mean total scores on self-efficacy and mean scores on the 'Know'-subscale and the 'Can'-subscale (standard deviation between brackets).

\begin{tabular}{|c|c|c|c|c|c|c|}
\hline & \multicolumn{6}{|c|}{ The Netherlands } \\
\hline & \multicolumn{3}{|c|}{ Experimental $(\mathrm{n}=71)$} & \multicolumn{3}{|c|}{ Control $(n=61)$} \\
\hline & pre & post & $\mathrm{fu}$ & pre & post & fu \\
\hline Know & $4.9(1.9)$ & $6.9(1.4)^{\mathrm{a}}$ & $6.8(1.5)^{b}$ & $4.8(1.9)$ & $5.3(1.9)$ & $5.7(1.8)^{\mathrm{c}}$ \\
\hline Can & $4.6(1.8)$ & $6.4(1.4)^{\mathrm{a}}$ & $6.2(1.5)^{b}$ & $4.7(1.9)$ & $5.0(1.6)$ & $5.3(1.6)^{c}$ \\
\hline \multirow[t]{4}{*}{ Total } & $4.7(1.8)$ & $6.7(1.4)^{\mathrm{a}}$ & $6.5(1.4)^{b}$ & $4.7(1.7)$ & $5.2(1.6)$ & $5.5(1.5)^{\mathrm{c}}$ \\
\hline & \multicolumn{6}{|c|}{ United Kingdom } \\
\hline & \multicolumn{3}{|c|}{ Experimental $(n=29)$} & \multicolumn{3}{|c|}{ Control $(\mathrm{n}=27)$} \\
\hline & pre & post & $\mathrm{Fu}$ & pre & post & $\mathrm{Fu}$ \\
\hline Know & $5.4(2.2)$ & $7.1(1.9)^{\mathrm{a}}$ & $7.5(1.5)^{b}$ & $6.5(1.6)$ & $7.1(1.8)$ & $6.5(1.6)$ \\
\hline Can & $5.6(2.2)$ & $7.2(1.7)^{\mathrm{a}}$ & $7.5(1.4)^{b}$ & $6.8(1.6)$ & $7.0(1.8)$ & $7.1(1.5)$ \\
\hline Total & $5.5(2.2)$ & $7.2(1.7)^{\mathrm{a}}$ & $7.5(1.4)^{b}$ & $6.6(1.5)$ & $7.0(1.7)$ & $6.8(1.5)$ \\
\hline
\end{tabular}

${ }^{\mathrm{a}} \mathrm{p}<0.001$ : difference between pre and post; ${ }^{\mathrm{b}} \mathrm{p}<0.001$ : difference between pre and follow-up; ${ }^{\mathrm{c}}$ $\mathrm{p}<0.05$ : difference between pre and follow-up.

In order to find out if existing prior levels of self-efficacy led to different gains in self-efficacy over measurements 'dummy regression models' were used. Two independent variables were used: condition (experimental or control) and levels of 
self-efficacy; additionally a variable was included for the interaction between these two variables.

Dummy variables, with values 1 and 0 , were created to reflect low and high values respectively, on self-efficacy total scores on the pre-test and post-test : low = $0-5$ and high $=>5$ in the Netherlands and low $=0-6.5$ and high $=>6.5$ in the United Kingdom (these are different because the median in both groups was different). Three variables were created that reflected the differences in scores between measurements on self-efficacy (post minus pre; follow-up minus post and follow-up minus pre, for all three self-efficacy scales ('Total', 'Know' and 'Can')). These were the dependent variables in the analyses.

The regression analyses revealed that Dutch subjects, who attended EDHEP, increased their total self-efficacy score at the post-test $(B=0.09 ; \mathrm{p}<=0.006)$, this was maintained at follow-up. Control and experimental subjects, who had low baseline levels of self-efficacy increased their score at post-test $(B=1.0 ; p=0.002)$ (the latter can be regarded as a manifestation of the 'regression toward the mean'effect). The interaction coefficient indicated that there was an greater increase for those attending EDHEP with low baseline levels $(\mathrm{B}=1.2 ; \mathrm{p}=0.008)$. These subjects thus showed an increase of 3.1 units on the $10-\mathrm{cm}$ bar. However, between the pretest and the follow-up the interaction term is insignificant, the effect identified is only a temporary effect as the extra increases had disappeared at follow-up. For the 'Know'-scale a similar pattern showed, with a total increase of about three-quarters of a point ( $\mathrm{B}=0.74 ; \mathrm{p}=0.043)$. For the performance part of self-efficacy ('Can') for control and experimental subjects with low baseline levels, there was an increase which was maintained at follow-up $(B=1.4 ; \mathrm{p}=0.000)$.

In the United Kingdom only some of the above applied. On the 'Total'- scale, as well as on the 'Know'-scale, all subjects who attended EDHEP increased their scores at follow-up with about 2 units $(B=2.0 ; p=0.001$ and $B=2.1 ; p=0.001$ respectively). All subjects who attended EDHEP increased their 'Can'-scores at follow-up with almost 2 units $(B=1.8 ; p=0.003)$.

Control and experimental subjects with low baseline levels on the performance aspect of self-efficacy at the pre-test increased their score at post-test $(B=0.8$; $\mathrm{p}=0.026$ ). This can also be regarded as a manifestation of the 'regression toward the mean'- effect. This effect had disappeared the follow-up.

The effect of EDHEP on perceived difficulty in making a request for donation (hypothesis 2)

In Table 3 the scores for the perceived difficulty in making a donation request are given. EDHEP-participants in both countries show a marked decrease the perceived difficulty in making a request for organs $(N L: F(2)=5.51 ; p<0.01$; UK: $\mathrm{F}(2)=4.30 ; \mathrm{p}<0.05)$, in the Netherlands the pattern for requesting tissues was similar; in the United Kingdom there were no effects on this variable. The decreases in the Netherlands occurred immediately after attending EDHEP and were maintained at follow-up; in the United Kingdom the decrease in perceived 
difficulty in requesting organs in the experimental group in the United Kingdom shows an effect over time. There are no changes in the control conditions in both countries.

Table 3. Mean total scores on Difficulty of the donation request for organs and tissues (standard deviation between brackets)

\begin{tabular}{|c|c|c|c|c|c|c|}
\hline & \multicolumn{6}{|c|}{ The Netherlands } \\
\hline & \multicolumn{3}{|c|}{ Experimental $(\mathrm{n}=71)$} & \multicolumn{3}{|c|}{ Control $(n=61)$} \\
\hline & pre & post & $\mathrm{fu}$ & pre & post & fu \\
\hline \multicolumn{7}{|l|}{ Difficulty request: } \\
\hline Organs & $5.9(2.4)$ & $4.7(2.1)^{\mathrm{a}}$ & $4.6(2.2)^{\mathrm{c}}$ & $5.5(2.2)$ & $5.2(2.3)$ & $5.3(2.3)$ \\
\hline Tissues & $5.4(1.8)$ & $4.3(2.3)^{b}$ & $4.2(2.2)^{\mathrm{c}}$ & $5.3(2.3)$ & $4.9(2.1)$ & $5.1(2.2)$ \\
\hline & \multicolumn{6}{|c|}{ United Kingdom } \\
\hline & \multicolumn{3}{|c|}{ Experimental $(\mathrm{n}=29)$} & \multicolumn{3}{|c|}{ Control $(n=27)$} \\
\hline & pre & post & $\mathrm{fu}$ & pre & post & $\mathrm{fu}$ \\
\hline \multicolumn{7}{|l|}{ Difficulty request: } \\
\hline Organs & $5.5(2.4)$ & $4.6(2.4)$ & $3.9(2.0)^{d}$ & $5.4(2.7)$ & $4.7(2.6)$ & $4.3(2.4)$ \\
\hline Tissues & $5.1(2.4)$ & $5.0(2.6)$ & $4.6(2.1)$ & $4.6(2.6)$ & $4.8(2.9)$ & $5.1(2.8)$ \\
\hline
\end{tabular}

T-tests comparing the experimental and control conditions on the three measurements concerning requesting organs revealed no significant differences. In the Netherlands there was a difference between the scores in the two conditions at follow-up, but this was not significant $(\mathrm{t}=-1.87 ; \mathrm{p}=0.64)$. In contrast to the request for organs T-tests revealed a significant difference in the Netherlands between the experimental and control condition at follow-up $(t=-2.34 ; \mathrm{p}<0.05)$. In the United Kingdom there were no changes in the perceived difficulty in making a request for tissues in either group.

The standard deviations in both conditions at all measurements are quite high for both the requests for organs and for tissues; there is differentiation within the groups.

The effect of EDHEP on the relationship between self-efficacy and perceived difficulty of the donation request (hypothesis 3 )

First the overall correlations between self-efficacy and perceived difficulty of the donation request for organs and tissues were calculated (Table 4). High levels of self-efficacy correspond with low levels of perceived difficulty in requesting organs as well as in requesting tissues. The correlations in both countries show the same pattern, those between the performance component of self-efficacy ('Can') and the perceived difficulty of requesting being the highest. Although significant, the correlations are all moderate. 
Table 4. Correlations between mean scores on self-efficacy and perceived difficulty of the donation request for organs and tissues for all subjects over all measurements .

\begin{tabular}{|c|c|c|c|c|}
\hline & \multicolumn{2}{|c|}{$\begin{array}{l}\text { The Netherlands } \\
\text { Difficulty requesting: }\end{array}$} & \multicolumn{2}{|c|}{$\begin{array}{c}\text { United Kingdom } \\
\text { Difficulty requesting: }\end{array}$} \\
\hline & Organs & Tissues & Organs & Tissues \\
\hline Know & -.33 & -.31 & -.35 & -.25 \\
\hline Can & -.40 & -.37 & -.40 & -.40 \\
\hline Total & -.39 & -.36 & -.39 & -.33 \\
\hline
\end{tabular}

All correlations significant at $\mathrm{p}<0.01$

In determining the effect of EDHEP on the relationship between self-efficacy and the perceived difficulty of the donation request, changes over measurements for all subjects were compared. Therefore six new variables were created in a similar way as for the self-efficacy scores; three for the request for organs and three for the request for tissues. These six variables reflect the differences in scores between measurements on the perceived difficulty in requesting (post minus pre; follow-up minus post and follow-up minus pre).

In Table 5 the correlations between changes over measurements in self-efficacy scores and changes over measurements in the perceived difficulty of the donation requests over measurements are given. The table shows that only in the experimental groups the expected negative correlations turn up: increases in selfefficacy are related to decreases in the perceived difficulty of requesting. The effect is stronger in the United Kingdom than in the Netherlands. In the United Kingdom the increase in self-efficacy and decrease in perceived difficulty happened immediately after participating in EDHEP and was maintained at follow-up. In the Netherlands there was an effect over time; the expected correlations were those between pre-test and follow-up. There are strong correlations between changes in self-efficacy over measurements and changes in perceived difficulty in requesting tissues in the United Kingdom; the effect on the 'Can'-scale however is temporary. In the Netherlands there was an effect over time in the experimental group, similarly as for requesting organs. The only significant correlation between pre-test and follow-up for EDHEP-participants was the one between the 'Know'-scale and requesting tissues.

The influence of experience on changes in self-efficacy scores over measurements (hypothesis 4)

Univariate analyses of variance were carried out to establish the impact of different kinds of experience on self-efficacy scores, using the different kinds experiences listed in table 1 as covariates.

In the United Kingdom general experience in hospital had a main effect on selfefficacy scores over measurements $(F(1)=4.00 ; p<0.05)$, whereas this was not the case in the Netherlands. In both countries experience with bereaved families had a 
Table 5. Correlations between changes over measurements in self-efficacy and in perceived difficulty requesting organs and tissues over all measurements in the Netherlands and the United Kingdom. (A = pretest minus post-test; $\mathrm{B}=$ follow-up minus post-test; $\mathrm{C}=$ follow-up minus pre-test)

\begin{tabular}{|c|c|c|c|c|c|c|}
\hline & \multicolumn{3}{|c|}{$\begin{array}{c}\text { The Netherlands } \\
\text { Difficulty requesting }\end{array}$} & \multicolumn{3}{|c|}{$\begin{array}{c}\text { United Kingdom } \\
\text { Difficulty requesting }\end{array}$} \\
\hline & A & B & C & A & B & $\mathrm{C}$ \\
\hline \multicolumn{7}{|c|}{ Organs } \\
\hline \multicolumn{7}{|c|}{ Know } \\
\hline Exp & -.11 & $.21^{\mathrm{c}}$ & $-.22^{b}$ & $-.41 *$ & -.07 & $-.43 *$ \\
\hline Con & .01 & .19 & .15 & .02 & .17 & .31 \\
\hline \multicolumn{7}{|l|}{ Can } \\
\hline Exp & -.04 & .02 & $-.20^{\mathrm{d}}$ & $-.42 *$ & -.08 & $-.33 b$ \\
\hline Con & .07 & $.27^{\mathrm{a}}$ & .04 & .16 & -.29 & .12 \\
\hline \multicolumn{7}{|l|}{ Total } \\
\hline Exp & -.08 & .12 & $-.22^{b}$ & $-.43 *$ & -.08 & $-.39 *$ \\
\hline Con & .05 & .24 & .10 & .10 & -.05 & .23 \\
\hline \multicolumn{7}{|c|}{ Tissues } \\
\hline \multicolumn{7}{|l|}{ Know } \\
\hline Exp & -.14 & .03 & $-.20^{b}$ & $-.52^{*}$ & -.29 & $-.57^{*}$ \\
\hline Con & -.06 & .11 & .13 & .30 & .35 & .08 \\
\hline \multicolumn{7}{|l|}{ Can } \\
\hline Exp & -.07 & .06 & -.18 & $-.69^{*}$ & -.33 & -.41 \\
\hline Con & .01 & .22 & .05 & .31 & -.29 & -.30 \\
\hline \multicolumn{7}{|l|}{ Total } \\
\hline Exp & -.14 & .13 & -.20 & $-.71 *$ & -.29 & $-.45^{\mathrm{c}}$ \\
\hline Con & .03 & .17 & .10 & .25 & -.15 & -.23 \\
\hline
\end{tabular}

main effect over measurements $(\mathrm{NL}: \mathrm{F}(1)=5.24 ; \mathrm{p}<0.05 ; \mathrm{UK}: \mathrm{F}(1)=4.42 ; \mathrm{p}<0.05)$, as well as experience with requesting organs $(\mathrm{NL}: \mathrm{F}(1)=27.29 ; \mathrm{p}<0.001$; UK: $\mathrm{F}(1)=5.48 ; \mathrm{p}<0.05)$ and experience with requesting tissues (NL: $\mathrm{F}(1)=18.08$; $\mathrm{p}<0.001$; UK: $\mathrm{F}(1)=13.76 ; \mathrm{p}<0.001)$.

In order to explore how the different kinds of experience executed their influence dummy variables were created in the same way as described earlier, in order to carry out secondary regression analyses. For each country two dummy variables were created for general experience, where a distinction had to be made between the two countries. For the Netherlands little experience was defined as 0-5 years and much experience as more than 5 years; for the United Kingdom this was respectively $0-10$ years and more than 10 years. For the other kinds of experience it was not necessary to create dummies, as these variables were already ordinal variables. The earlier created variables reflecting differences between measurements on self-efficacy were used as the dependent variables.

Secondary regression analyses revealed that in the Netherlands those with little general experience in the experimental group showed the greatest increase in selfefficacy at the post-test $(B=2.3 ; \mathrm{p}=0.001)$; these subjects also showed the greatest 
drop in scores compared to the post-test at follow-up $(B=-1.1 ; p=0.01)$. Differences in experience with bereaved families had no differential effect on selfefficacy. With respect to experience with requesting organs the subjects with little experience in the experimental group showed the greatest increase at the post-test $(\beta=0.4 ; p<0.05)$. There were no differential effects for experience with requesting tissues. In the United Kingdom for none of the above types of experience any differential effects on self-efficacy scores could be established.

Similar analyses of variance as described above were carried out to establish the impact of different kinds of experience on the perceived difficulty of requesting. In the Netherlands as well as in the United Kingdom general experience had no influence on the perceived difficulty in requesting organs or tissues. Experience with bereaved families had no influence in the Netherlands, but had a significant impact on perceived difficulty in requesting organs in the United Kingdom $(\mathrm{F}(1)=9.35 ; \mathrm{p}<0.01)$. Experience with requesting organs had a significant impact in both countries (NL:F(1)=22.35; $<<0.001 ; \mathrm{UK}: \mathrm{F}(1)=12.14 ; \mathrm{p}<0.001)$ as well as experience with requesting tissues $(\mathrm{NL}: \mathrm{F}(1)=40.60 ; \mathrm{p}<0.001 ; \mathrm{UK}: \mathrm{F}(1)=8.74$; $\mathrm{p}<0.01)$.

\section{Discussion}

The current study was undertaken to measure the effect of participation in EDHEP workshops, in the Netherlands and the United Kingdom, on self-efficacy with regard to certain criterial tasks: breaking news of brain stem death, requesting organ and tissue donation, dealing with the (emotional) reactions of relatives and explaining the donation procedure. These criterial tasks were the focus of the EDHEP workshop. As all factors which influence self-efficacy beliefs are incorporated in the workshop, it was expected that participants' self-efficacy beliefs regarding these criterial tasks would increase.

\section{Main findings}

Hypothesis 1. The data show that indeed EDHEP-participants' self-efficacy scores in both countries increased after participation. All participants believe they know how to break news of brain death in a better way, how to request donation and to explain the donation procedure in a better way and how to attend to bereaved relatives' emotional reactions in a better way. They also indicate that they can better perform the required behaviour. This improvement is maintained at follow-up; it is a lasting effect. The first hypothesis is therefore accepted. Although follow-up scores of the subjects in the control group in the Netherlands are higher then the pre-test scores, the data indicate, that they appraise their knowledge has improved. Their appraisal of their ability to perform has not changed. In the United Kingdom the experimental group had significantly lower scores than the control group at the start. Following the workshop their self-efficacy scores were similar of the control group at post-test and significantly higher to those of the control group at followup. 
Those who had low baseline levels of self-efficacy on the pre-test in the Dutch experimental group, showed a significant extra growth at the post-test compared to those with high baseline levels, this extra growth had disappeared at follow-up. It seems therefore that for the Dutch subjects starting with low self-efficacy beliefs, attending EDHEP has a greater effect than for those with high self-efficacy beliefs initially. Apparently the effect identified was only a temporary boost for these subjects' self-efficacy, as the extra increases had disappeared at follow-up. These findings did not apply for the British EDHEP-participants.

Hypothesis 2. Hypothesis two stated that participation in EDHEP would lead to decreases in the perceived difficult of requesting. This hypothesis is also accepted. EDHEP-participants find making a request for organ or tissue donation less difficult. In the United Kingdom this pattern was found for the organ donation request only. Dutch EDHEP-participants found making a request for tissue donation equally less difficult at post-test and follow-up. In the EDHEP workshop the focus is on requesting organ donation; in the Dutch sample transfer to requesting tissue donation seems to have taken place, whereas in the British sample there is no indication for this transfer. The high standard deviations, reflecting differentiation within the British groups, might explain that no more significant effects could be established.

Hypothesis 3. Hypothesis three was accepted as well: an increase in self-efficacy is reflected in a decrease in the perceived difficulty in requesting donation after participation in EDHEP. Overall there is a significant negative correlation between these two variables. The highest correlation between self-efficacy and the perceived difficulty of requesting donation was with the performance component of selfefficacy ('I can...' rather than 'I know...') and the perceived difficulty of requesting donation. Presumably the perceived difficulty in requesting is more related to the appraisal of behaviour than to the appraisal of knowledge. The high standard deviations in the data for the perceived difficulty of requesting organs or tissues indicated that there was substantial variance within the groups. In both countries only for the EDHEP-participants the expected relationship between increases selfefficacy and decreases in perceived difficulty of requesting donation applied, for both the knowledge and the performance component of self-efficacy. The effect in the United Kingdom was stronger and more immediate than in the Netherlands. It is interesting that the British experimental group as a whole did not find the request for tissues less difficult after participation, but showed a very strong relationship between increases in self-efficacy and decreases in the perceived difficulty of requesting over measurements. High variance in the scores, reflecting differences between individuals on the two variables is probably responsible for this effect.

Although the expected correlations between the two variables are significant, they are moderate. This might indicate that there are other factors, which play a role in the relationship between self-efficacy and perceived difficulty of requesting.

Hypothesis 4 . The fourth hypothesis stated that experience would not have a significant added effect on changes in self-efficacy over measurements. This 
hypothesis was rejected. Subjects in both countries had varying levels of experience. The analyses revealed that experience actually had a significant influence. General experience in the profession did not have an impact in the Netherlands, but it did execute influence in the United Kingdom. The self-efficacy scores of British EDHEP participants were significantly higher at the pre-test than those of their Dutch colleagues. These higher scores might be related to more general experience, as the British sample as a whole had more general experience. It can be argued based on self-efficacy theory, that these experiences have been positive and have therefore added to their self-efficacy beliefs. Experience with bereaved relatives and with requesting organs and tissues had a significant impact in both countries. A closer look at the data revealed that only in the Dutch experimental sample those with little experience in general and with requesting organs showed the greatest changes over measurements. Presumably there is a complex relationship between self-efficacy and experience. The data in this study seem to indicate that above a certain level of general experience differential effects on self-efficacy are less apparent. Already high baseline self-efficacy scores can still increase; this might be due to the fact that those with high self-efficacy beliefs initially, were strengthened in their beliefs through mastery experiences and constructive feedback offered in the EDHEP workshop.

\section{Self-efficacy and self-assessment}

Self-efficacy ratings can be seen as a specific type of self-assessment. In reviews of the literature on self-assessment the conclusion is that self-assessment of professional behaviour may be suspect and that both overestimation as underestimation is found. ${ }^{57,58}$ According to Gordon self-assessments by adult learners are intimately tied to stable self-concepts or to global attributions of ability and therefore less vulnerable for influences from external sources. It is therefore interesting that the experienced British sample still increased their self-efficacy scores after participation. Ward et al. ${ }^{59}$ examined the methodological issues that "plague the measurements of self-assessment". Comparison of group means generated by the participants and some external standard clearly hides individual differences. High achievers tend to underestimate their performance relative to the golden standard, and underachievers tend to overestimate their performance relative to the golden standard. Peer assessment is often more accurate than selfassessment: presumably individuals can distinguish between good and bad performance, but are unable or unwilling to apply the same standards to their own performance. Gordon ${ }^{57,60}$ suggests that self-assessments can only improve if it is conceived as a skill requiring clear goals and explicit training with feedback.

In the EDHEP workshop participants were made aware of, but not specifically trained in the skill of reflecting on their own knowledge and behaviour with regard to the criterial tasks measured in the self-efficacy instrument. Experts, successful in communicating with bereaved relatives and in getting consent for organ donation were interviewed about their experiences. They underlined the importance of the 
complex tasks they are confronted with when a patient dies and when organ donation is a possibility. They indicated, they felt very self-efficacious in their approach of the next of kin and they showed to have very good skills in reflecting upon their own knowledge and behaviour. Some of them mentioned that participation in the EDHEP workshop had made them more aware, and had helped them to execute more adequate skills in dealing with bereaved relatives. Reflective skills in combination with well established communication skills seem more important than experience in the domain alone, as the experience from these experts ranged from a few years to more than 30 years. ${ }^{61}$

Implications of the findings

It is not clear whether subjects in the sample had adequate skills to assess their own knowledge and behaviour, whether subjects used the scales and questions consistently, and whether they either overestimated or underestimated themselves. We also do not know what the effect of experience on actual behaviour is in this domain. If self-efficacy theory is right, those with high self-efficacy scores should perform better than those with low scores, irrespective of experience. Future research in this domain will probably give a more satisfying explanation for the relationship between self-efficacy and experience.

One important suggestion that arises from this study is that educational programmes for professionals should not only be tailored to the working circumstances of the participants and expressed needs, but also to personal characteristics of the participants, such as the amount and quality of experience. The data also indicate that training of relatively inexperienced subjects and subjects with low self-efficacy beliefs either need longer training and/or regular follow-up sessions to maintain the gains from initial training. Further study is necessary and the best way to proceed is to relate the outcomes of this study to behavioural outcomes. 


\section{References}

1. Siminoff LA, Arnold RM, Caplan AL. Professional attitudes toward donation: effect on practice and procurement. J Trauma Inj Infec Crit Care 1995;39:553-9.

2. Girgis A, Sanson Fisher RW. Breaking bad news: consensus guidelines for medical practitioners. J Clin Oncol 1995;13(9):2449-56.

3. Randhawa G. Enhancing the health professional's role in requesting transplant organs. Br J Nurs 1997;6(8):429-34.

4. Randhawa G. Coping with grieving relatives and making a request for organs: principles for staff training. Med Teach 1998;20(3):247-9.

5. Fallowfield L, Jenkins $\mathrm{V}$, Beveridge $\mathrm{H}$. Truth may hurt but deceit hurts more: communication in palliative care. Palliat Med 2002:16(4) 297-303.

6. Prottas J, Batten HL. Health professionals and hospital administrators in organ procurement: attitudes, reservations, and their resolutions. Am J Public Health 1988;78(6):642-5.

7. Kent B, Owens RG. Conflicting attitudes to corneal and organ donation: a study of nurses' attitudes to organ donation. Int J Nurs Stud 1995;32(5):484-92.

8. Younger SJ, Landefeld CS, Coulton CJ, Juknialis BW, Leary M. 'Brain death' and organ retrieval. A cross-sectional survey of knowledge and concepts among health professionals. JAMA 1989;261(15):2205-10.

9. Siminoff L, Gordon N, Hewlet J, Arnold R. Factors influencing Families' Consent for Donation of Solid Organs for transplantation. JAMA 2001;286(1):71-7.

10. Wakeford RE, Stepney R. Obstacles to organ donation. British Journal of Surgery 1989;76 may:435-9.

11. Garrison RN, Bentley FR, Raque GH, Polk HC, Jr., Sladek LC, Evanisko MJ, et al. There is an answer to the shortage of organ donors. Surg Gynecol Obstet 1991;173(5):391-6.

12. Tijmstra T, Heyink JW, Pruim J, Slooff MJ. Experience of bereaved relatives who granted or refused permission for organ donation. Fam Pract 1992;9(2):141-4.

13. Painter LM, Langlands JM, Innes Walker J. Donor families experience of organ donation: a New Zealand study. N Z Med J 1995;28 july 1995:295-6.

14. Pearson IY, Bazeley P, Spencer Plane T, Chapman JR, Robertson P. A survey of families of brain dead patients: their experiences, attitudes to organ donation and transplantation. Anaesth Intensive Care 1995;23(1):88-95.

15. United Kingdom Transplant Coordinators Association (UKTCA) and British Association of Critical Care Nurses (BACCN). Relatives' refusal of organ donation. Report of a two year study. London: Department of Health; 1995.

16. Blok G, Kraan G, Dalen van J, Gurp Mv, Vecht Evd, Wezel Hv. Ervaringen van nabestaanden van donoren met de donatieprocedure; vergelijking tussen 1995 en 1998. [Experiences of donor relatives with the donation procedure; comparison between 1995 and 1998] Ned Tijdsch Geneesk 2000;144(14):663-7.

17. Cushing AM, Jones A. Evaluation of a breaking bad news course for medical students. Med Educ 1995;29(6):430-5.

18. Marrow J. Telling relatives that a family member has died suddenly. Postgrad Med J 1996;72(849):413-8 . 
19. Novack DH, Suchman AL, Clark W, Epstein RM, Najberg E, Kaplan C. Calibrating the physician. Personal awareness and effective patient care. Working Group on Promoting Physician Personal Awareness, American Academy on Physician and Patient. JAMA 1997;278(6):502-9.

20. Sanner M. Attitudes towards organ donation and transplantation. A model for understanding reactions to medical procedures after death. Soc Sci Med 1994;38:1141-52.

21. Fallowfield L, Jenkins V, Farewell V, Saul J, Duffy A, Eves R. Efficacy of a Cancer Research UK communication skills training model for oncologists: a randomised controlled trial. Lancet 2002;359(February 23):650-6.

22. Maguire P, Booth K, Elliott C, Jones B. Helping health professionals involved in cancer care acquire key interviewing skills--the impact of workshops [see comments]. Eur J Cancer 1996;32a(9):1486-9.

23. Vleuten van der CPM. The Assessment of Professional Competence. Developments, Research and Practical Implications. Adv Health Sci Educ 1996;1:41-67.

24. Sanson-Fisher R, Cockburn J. Effective teaching of communication skills for medical practice: selecting an appropriate clinical context. Med Educ 1997:31(1) 52-7.

25. Fallowfield L, Jenkins V. Effective communication skills are the key to good cancer care. Eur J Cancer 1999;35(11):1592-7.

26. Dalen van J. Teaching and assessing communication skills in Maastricht: the first 20 years. Med Teach 2001;23(3):245-51.

27. Kurtz S, Silverman J, Draper J. Teaching and Learning Communication Skills in Medicine. Abington: Radcliffe Medical Press Ltd.; 1998.

28. Bandura A. Self-efficacy: Toward a unifying Theory of Behavioral Change. Psych Rev 1977;84 (2):191-215.

29. Bandura A. Exercise of personal and collective efficacy in changing societies. In: Bandura A, editor. Self-efficacy in changing societies. New York: Press Syndicate of the University of Cambridge; 1995. p. 1-46.

30. Groeger JA, Grande GE. Self-preserving assessments of skill? Br J Soc Psych 1996;87:61-79.

31. Gist M, Stevens C, Bavetta A. Effects of self-efficacy and post-training interventions on the acquisition and maintenance of complex interpersonal skills. Personnel Psychology $1991 ; 44: 837$.

32. Stevens CK, Bavetta AG, Gist ME. Gender differences in the acquisition of salary negotiation skills: the role of goals, self-efficacy, and perceived control. J Appl Psychol 1993;78(5):723-35.

33. Harrison A, Rainer RJ, Hochwater W, Thompson K. Testing the self-efficacy-Performance Linkage of Social -Cognitive Theory. The Journal of Social Psychology 1997;137(1):79-87.

34. Gist M. The inflluence of training method on self-efficacy and idea generation among managers. Personnel Psychology 1989;42:787-805.

35. Bandura A, Wood R. Effect of Perceived Controllability and Performance Standards on SelfRegulation of Complex Decision Making. J Pers Soc Psych 1989;56(5):805-14.

36. Lee C. Accuracy of Efficacy and Outcome Expectations in Predicting Performance in a Simulated Assertiveness Task. Cognitive Therapy and Research 1984;8 (1):37-48. 
37. Lorig K, Chastain RL, Ung E, Shoor S, Holman HR. Development and evaluation of a scale to measure perceived self-efficacy in people with arthitis. Arthritis and Rheumatism 1989;32 (1):37- 44 .

38. Barlow J, Williams $B$, Wright $C$. The reliability and validity of the arthritis self-efficacy scale in a UK Context. Psychology, Health \& Medicine 1997;2(1):3-17.

39. Saks AM. Longitudinal field investigation of the moderating and mediating effects of selfeffcicacy on the relationship between training and bewcomer adjustment. Journal of Personality and Social Psychology 1995;80(2):211-25.

40. Malecki MS, Hoffman MC. Getting to yes: how nurses' attitudes affect their succes in obtaining consent for organ and tissue donations. Dialysis and Transplantation 1987:276-8.

41. Bandura A. The explanatory and predictive scope of self-efficacy theory. Journal of Social and Clinical Psychology 1986;4 (3):359-73.

42. Litt MD. Self-efficacy and percieved control: cognitive mediators of pain tolerance. Journal of Personality and Social Psychology 1988;54 (1):149-60.

43. Pajares F. Self-efficacy Beliefs in Academic Settings. Review of Educational Research 1996;66(4):543-78.

44. Jager K, Ryan M, Dalen van J, Blok GA, Wijnen RMH. European Donor Hospital Education Programme. The grief response and donation request. Moderators manual. Leiden: Eurotransplant International Foundation/Sandoz Pharma Ltd.; 1991.

45. Blok GA, Jager KJ, Dalen van J. European Donor Hospital Education Programme. The grief response and donation request. Participants' Manual. Leiden: Eurotransplant International Foundation/Sandoz Pharma Ltd.; 1991.

46. Blok G, Dalen van J, Jager K, Ryan M, Wijnen RMH, Wight C, et al. The European Donor Hospital Education Programme (EDHEP): addressing the training needs of doctors and nurses who break bad news, care for the bereaved, and request donation. Transpl Int 1999;12:161-7.

47. Ong LML, Haes de CJM, Hoos AM, Lammes FB. Doctor-patient communication: a review of the literature. Soc Sci Med 1995;40:903-18.

48. Pohle von WR. Obtaining organ donation. Who should ask? Heart Lung 1996;25:304-9.

49. Ptacek JT, Eberhardt TL. Breaking bad news. A review of the literature. Jama 1996;276(6):496-502

50. Knowles MS. Adults are not grown-up children as learners. Community Services Catalyst 1983;13(4):4-8.

51. Norman G-R. The adult learner: A mythical species. Acad Med 1999;ol 74(8):886-9.

52. Muthny FA. Fortbildungsprogramm zur Gesprächsführung mit den Angehörigen plötzlich Verstorbener als Beispiel von Kommunikationstraining und affektiv-emotionalen Lernzielen in der Arztlichen Ausbildung. Medizinische Ausbildung 1996;13 (1) Mai:57-64.

53. Dalen van J, Blok GA, Morley M, Morton JB, Haase-Kromwijk B, Sells RA, et al. Participants' judgements of the European Donor Hospital Education Programme (EDHEP): an international comparison. Transpl Int 1999;12:182-7. 
54. Wight C, Cohen R. The European Donor Hospital Education Programme (EDHEP). In: Chapmen JR, Deierhoi M, Wight C, editors. Organ and Tissue Donation for Transplantation. London: Arnold; 1997. p. 373-81.

55. Cook TD, Campbell DT. Quasi-experimentation: Design and analysis issues for field settings. Chicago: Rand-McNally; 1979.

56. Bowling A. Measuring Health. A review of quality of life measurement scales. Milton Keynes: Open University Press; 1991.

57. Gordon MJ. A Review of the Validity and Accuracy of Self-assessments in Health Professions Training. Acad Med 1991;12:762-9.

58. Arnold L. Assessing professional behavior: yesterday, today, and tomorrow. Acad Med 2002;77(6):502-15.

59. Ward M, Gruppen L, Regehr G. Measuring self-assessment: current state of the art. Adv Health Sci Educ Theory Pract 2002;7(1):63-80.

60. Gordon M-J. Self-Assessment Programmes and Their Implications for Health Professions Training. Acad Med 1992;67(10):672-79.

61. Blok G. Het bespreken van orgaan- en weefseldonatie met nabestaanden. Ervaringen en meningen van experts. Discussing organ and tissue donation with relatives. Experiences and opinions of experts] Leiden: Dutch Transplantation Society; 2002. 


\section{Two ways of measuring communication skills concerning breaking bad news and requesting organ donation compared: a validation study ${ }^{1}$}

The quality of the communication with relatives of potential donors is of critical importance for the increase in the numbers of donor organs. One of the major reasons for the shortage of organs for transplants is the refusal by relatives. There is a significant relationship between the communication skills of the intensive care staff and the decision relatives make about organ donation. Breaking news of death and requesting donation, while also appropriately managing emotional reactions of relatives are complex tasks, which require knowledge about these domains as well as skills to communicate information and understanding. A training programme, The European Donor Hospital Education programme (EDHEP), focussing on these knowledge and skills was developed and implemented. In order to measure the effect of this programme on participants' knowledge and skills, two different methods have been used, a paper-and-pencil test of communication skills, feasible to implement on a large scale and a performance test. The aim of the current study was to determine the predictive value of the paper-and-pencil test for the performance test in breaking bad news and requesting donation. Diagnostic accuracy about authentic situations in intensive care units depicted in paper cases has reasonable predictive value for performance of communication skills in this domain. The predictive value of written proficiency in identified key communication skills is less straightforward. Ratings of simulative relatives underscored the construct validity of the performance test. The significant correlations between ratings of simulative relatives and written proficiency in communication skills indicate that the written test measured cognitive skills that are relevant for the actual use of communication skills.

\footnotetext{
${ }^{1}$ Submitted as: Blok GA, Ramsay G, Vleuten CPM van der. Two ways of measuring communication skills concerning breaking bad news and requesting organ donation compared: a validation study.
} 


\section{Introduction}

One of the reasons for the shortage of donor organs is the number of refusals by relatives. Studies have shown that the quality of the communication with relatives is of critical importance and influences both their satisfaction with the donation procedure and the decision they make about organ donation. ${ }^{1-3}$ Relatives prefer professionals who show compassion, are knowledgeable on the topic and provide adequate support throughout the process. It is important that medical and nursing staff take time to answer questions and use understandable language without jargon. ${ }^{4-6}$

Breaking news of death, explaining brain stem death and approaching the next of kin for permission to donate organs require appropriate management of emotional reactions of relatives. This complex task situation necessitates profound clinical and social knowledge as well as advanced skills to communicate information and understanding. However, research has shown that doctors and nurses find it difficult to deal with death and dying ${ }^{7-20}$ and with requesting organs. ${ }^{21-24}$ There are only few publications about other training programmes is which all these issues are addressed. ${ }^{25-28}$

The European Donor Hospital Education Programme (EDHEP), focussing on the communication with relatives when breaking news of death and requesting organ donation, was developed in 1991 and implemented since 1992 all over the world. ${ }^{29}$ To our knowledge, EDHEP is the only training programme in this area of which the effects on the competence of the participants in breaking bad news and requesting donation has been evaluated in randomised controlled trials. ${ }^{30-33}$

There is substantial evidence from other areas in medicine that communication skills can be improved with training based on identified needs ${ }^{34-41}$ (for overviews see Kurtz et al. ${ }^{42}$ and Aspergen ${ }^{43}$ ).

Effects of training in (communication) skills are usually measured with Objective Structured Clinical Examinations (OSCE). ${ }^{44}$ These are multi-station-examinations using standardized (simulative) patients in which actual performance is assessed by expert raters. Patient and simulated patient ratings have been identified as valid indicators of the construct validity of OSCE's, provided that these (simulative) patients are carefully trained. ${ }^{4546}$ There is usually a good correlation (often higher than 0.80) between patient and expert ratings, if similar attributes are being measured. ${ }^{47}$ This method of assessment is time-consuming and expensive, especially when evaluations have to be carried out for large numbers of subjects. Therefore, especially in large scale programmes paper-and-pencil tests measuring students' or trainees' skills, are used. These are usually called knowledge-aboutskills-tests, because cognitions about skills instead of actual behaviour is assessed. The construct validity of these tests, i.e. the predictive value for performance tests of skills, has been subject of many studies in undergraduate, postgraduate and continuing medical education. Moderate to excellent true correlations (ranging from 0.65 to 1.0 ) have been found. ${ }^{48-53}$ In these studies, the knowledge-about- 
skills-tests measurements were conducted for (clinical) technical procedural skills. The tests used in these studies, all with a 'true-false-?' format, seem to have predictive value for performance on an OSCE and are therefore particularly useful for less expensive outcome evaluations, where evaluation is at group level.

Other studies focussed on the assessment of communication skills. In this domain the correlations between knowledge-about-skills-tests and OSCE's are less pronounced. Van Dalen et al. ${ }^{54}$ found observed correlations of 0.20 and 0.28 between a knowledge-about-skills test with a true-false-?-format and an OSCE (disattenuated: 0.48 and 0.88 respectively). Humphris ${ }^{55}$ used structural equation modelling to establish the relationship between a video-based, paper-and-pencil test devised to assess knowledge and understanding of communication skills and an OSCE. In the paper-and-pencil test the student was instructed to recognize, describe consequences and suggest alternatives to the communication skills they observed in a standardized video interaction between a patient and a medical practitioner. Knowledge levels predicted weakly, and positively, performance at baseline (coefficient was 0.14 ), and weakly and negatively performance at a second measurement about one and a half year later $(-0.17) .{ }^{55}$ In a study measuring psychiatric interviewing performance, Bögels et al. ${ }^{56}$ found that process skills (needed to build a good working relationship) correlated hardly with accuracy of diagnostic formulation and treatment plan (knowledge of the domain); the observed correlation was 0.07 (disattenuated 0.09).

An explanation for the lack of substantial predictive value of knowledge tests of communication skills is that skilled communication performance may also be influenced by prior acquisition of these skills or by the level of social skills in general, which may have also have a certain resistance to change. ${ }^{545}$ An additional explanation may be that technical, procedural skills usually have to be performed according to a certain order, irrespective of the person on whom the procedure is carried out (e.g. to give an intravenous injection). Communication skills are interactive and it is good practice to adapt the communicative style to the patient with whom one is interacting to establish a good working relationship. The (non-) verbal behaviour of a (simulative) patient may evoke different communicative behaviour on the part of the professional than similar (non-) verbal behaviour described in a paper-and-pencil test. Behaviour described in a paper-and-pencil test may be more liable for individual interpretations than behaviour shown by a (simulative) patient in a performance test. The professionals' experience in dealing with these emotions may play a critical role. In the above describe studies comparison of knowledge-about-skills-tests with OSCE's were made on a general level and in the knowledge-about-skills-tests, subjects were asked to give evidence of their insight in and judgment of adequate use of communication skills. There may be a stronger relationship between knowledge-about-skills-tests and OSCE's, when performance on communication skills is required in both tests and when focusing on specific communication skills. Competence in communication involves 
not only mastery of communication skills but also the ability to adequately interpret the situation at hand and to recognize and use those communication skills that are relevant and effective in that situation.

Guidelines for good practice when breaking bad news and requesting donation, based upon consensus from literature, ${ }^{1,35,57-59}$ advocate that the consultation is well structured. It is important to break news of brain death fairly early in the conversation (Phase I) ; and to show understanding and empathy, especially by reflecting the bereaved relatives' feelings and by attending to their concerns (Phase II); discussing the near future (Phase III) should ideally be initiated by the relative. It is essential that all information be presented to the family in a clear and truthful manner, avoiding technical jargon. When explaining brain death it should be made very clear that this means the person is dead. Relatives should be told, sometimes more than once, what is going to happen next. The donation request should be made in a separate consultation, subsequent to the one in which the death is announced. 1,58 Adequate use of specific key communication skills by key staff is thus of critical importance: providing information in a clear and understandable way, dealing with relatives' (emotional) reactions in a sensitive way showing compassion and understanding, dealing with relatives' questions by helping them express their thoughts and feelings and structuring the process in such a way that all happens in a well timed way. Breaking bad news and requesting donation should always be made in planned interviews by a team of a doctor and a nurse to ensure optimal support and continuity in the care. ${ }^{18}$ It is important that doctors and nurses support each other during communication with the relative, when breaking bad news or making a request for donation. Both professions should be competent in communicating while recognizing that they may undertake complementary roles at different times. This usually means quieter and supportive role for the nurses while the doctor takes a more 'active' role. ${ }^{60}$

\section{Research question}

The central research question in this article is to what extent subjects' scores on a written communication skills test, focusing on the use of specific skills concerning breaking bad news and requesting donation, have predictive value for their score on a performance test concerning the same domain. In the paper-and-pencil test, using a format that elicits understanding of as well as proficiency in communication skills, two kinds of cognitive skills about communication were assessed: 1) diagnostic accuracy, i.e. interpretation of the (emotional) state of the relatives depicted in short written vignettes and 2) proficiency in the written use of the specific communication skills that are identified as key skills in the donation process: providing information, dealing with emotions, eliciting information and structuring. This is more authentic than the traditional paper-and-pencil test. In this format subjects were confronted with realistic situations, in which they had the opportunity to actively demonstrate their understanding of the functional use of communication skills and their written proficiency of these skills. It was expected that this test format would elicit 
cognitive performances or behaviours that are valid indications of potential performance in real life.

It was hypothesised that the paper-and-pencil test would correlate significantly at moderate to high levels with the overall mean scores on the performance test (hypothesis 1).

In both tests the use of specific key communication skills was required (providing information, dealing with emotions, eliciting information and structuring); in the paper-and-pencil test the written use and in the performance test the actual use of these skills. It was expected that the correlations between the scores on these specific skills in both tests would be higher than the correlations between the written use of these skills and overall mean scores of the performance test (hypothesis 2).

As an additional check on the construct validity of the performance test, simulated relatives rated the performance of the doctors and nurses in the performance test. If the paper-and-pencil test has significant predictive value for the performance test, indicating that similar constructs are measured, the ratings of the simulative relatives would also be indicators for the construct validity of the paper-and-pencil test. It was expected that the ratings by the simulative relatives would correlate significantly and highly positive with the scores on the performance test and moderately to highly with the scores on the paper-and-pencil test (hypothesis 3).

It was expected that the correlations between scores on the specified key communication skills, highly valued by relatives, in the performance test would correlate high with the simulative relatives' ratings on these skills (hypothesis 4).

\section{Method}

\section{Subjects}

Subjects were 14 intensive care doctors and 14 intensive nurses with a mean of 6.7 (sd. 4.7) years of experience of working in intensive care (range 1 - 25 years). The majority of them had ample experience with bereaved relatives. Sixty-eight percent of them had experience with requesting organs; a third of the sample had experience with requesting three to four times a year. Requesting organs was perceived moderately difficult (mean: 4.9 [SD: 1.8] on a 10-point scale ranging from 1:not difficult at all to 10: extremely difficult).

\section{Materials}

Paper-cases test (PCT). For the paper-cases test (PCT) six paper cases were developed, based on typical situations described by intensive care staff experienced in breaking news of death and requesting organ donation. In the cases different emotional reactions by imagined relatives on either the announcement of brainstem death or the donation request for organs was portrayed. The emotion portrayed were: in 
case 1 denial and disbelief about brain stem death; shock in case 2 because of being overwhelmed by the donation request; anger and reproach after diagnosis of drain stem death in case 3; sadness and guilt in case 4; disagreement within the family in case 5; and rational behaviour in case 6 . Five of the cases involved the description of the reaction of one relative; in case 5 the reactions of three family members were described (see Figure 1 for an example). The number of cases was kept to a minimum, since time constraints prohibited more extended measurement. Multiple Station Examination (MSE.) The multiple station examination (MSE) consisted of three stations in which brain death had to be announced and three in which the donation request for organs had to be made. In every set of two stations, in the first station news of brain death had to be conveyed and in the second donation had to be requested. Simulated relatives, all males of about 30 years of age, were trained to react with a different specific emotion and to ask particular questions in each of the two linked consultations. It was assumed that the difficulty subjects had in recognising and responding to emotions was evenly distributed among the subjects. In the first consultation the reaction expressed by the relative showed rational behaviour; sadness and guilt in the second consultation, and anger in the third consultation. The same cases were used in our study into the effects of EDHEP on the performance of communication skills. ${ }^{30}$ The number of stations was kept to a minimum; time constraints prohibited more extended measurement. Simulated patient rating. Doctor and nurse behaviour, the use of communication skills and general conduct in the consultation, was rated by the simulated relatives; the Simulated Relative Rating (SRR). A short questionnaire was developed, adapted from a checklist developed to measure patient satisfaction with physician' communication ${ }^{61}$, in which items had to be rated that reflected the behaviours required in the different phases in the consultation, such as the clarity of information, how emotions and questions were dealt with, space given in expressing thoughts and feelings and how the consultation was structured.

Procedure

Paper-cases test (PCT). The PCT was completed individually. Subjects were given a standardised instruction for completion of all six paper cases. In five of the six scenario's, presented on structured response sheets, the subject was asked to interpret and describe the (emotional) state of the relative(s) portrayed, to be deducted from the description of the verbal as well as the nonverbal behaviour of the relative(s); in case two this description was given. In all six cases the subjects were asked to write down what they would literally say when addressing the relatives portrayed (see figure 1). It was expected that this way of assessing would elicit evidence of diagnostic accuracy concerning the (emotional) state and of written proficiency of four specific communication skills: providing information, dealing with emotions, eliciting information and structuring.

The answers given by the subjects were rated using an answer key, established after consensus of agreement by a panel of experts, for both diagnostic accuracy 
and written proficiency. The answer key, developed for these paper cases, contained the following categories: 'diagnostic accuracy', 'written proficiency', 'coherence' and a 'global judgment'. 'Diagnostic accuracy' refers to diagnostic accuracy concerning the (emotional) state of the relatives. 'Written proficiency' concerns the quality of verbal reaction to the relatives described in the scenarios. As there were a limited number of adequate responses for 'diagnostic accuracy' and 'written proficiency' the answers could be rated 'good' (2), 'doubtful' (1) or 'bad' (0). 'Coherence' refers to the coherence between the diagnostic accuracy and the written proficiency: is the (emotional) state described in the answers on the first question taken into account in the verbal answer to the second question, the ratings were either 'yes' (1) or 'no' (0). Finally a global rating per case was given, using a 5 -point-scale $(1=$ bad, $5=$ very good). The paper cases were rated by three research-assistants, who were trained in the use of the answer key. All paper cases were rated by two raters.

Ms. Winter is a 35 year old woman. She is divorced. Her eight-year-old daughter Susan suffered severe brain damage after a traffic-accident. When Susan was admitted she was already in bad condition. You did everything you could. However, she has just been declared brain dead. You had to tell Ms. Winter that Susan is brain dead.

Ms. Winter has been with her daughter. Susan is on a ventilator.

You are now with Ms. Winter. You have just told her that Susan has died.

Ms. Winter looks at the wall and raises an eyebrow. She has a distant, a bit cynical look in her eyes. She hardly reacts to your message. After some time she says: 'But.....she is sleeping'.

What do you think is Ms. Winter's condition?

You want to clarify Susan's condition to Ms. Winter.

You say to her:"

Figure 1. Example of a paper case.

Multiple-station-examination (MSE). In the MSE the stations were standardised for the actors' portrayal of the relatives, the method of briefing and debriefing of the doctor-nurse pair, and the debriefing of the actor. Doctors and nurses were given instructions to prepare the consultations (the separate stations) and to make a division of tasks. As the MSE was carried out in pairs at least some of the behaviours of doctors and nurses would be complementary. After a short interval after completion of the first station, with a non-specific debrief, the doctor-nurse pair made a request for organ donation. All stations were scheduled to last about ten minutes, and were recorded on videotape. Feedback was given to the pair after the study was completed. The pair received standardised written instructions for the separate stations. They were given time to discuss the general conduct of the interview and arrange a division of tasks. 
Scoring of the performance in each station was done by using the EDHEP Communication Skills Assessment (EDHEP-CSA) that was adapted from the Maastricht History and Advice Checklist.(MAAS-R). ${ }^{62}$ Breaking bad news and the donation request were rated separately for the doctor and nurse, across two defined areas: the structure of the consultation and general communication skills. Rating of phases and general skills took place on scales, covering a number of sub-items, from 0 (absent) to 5 (very good). Phase I focuses on breaking the bad news or requesting donation, Phase II focuses on how the relative's immediate emotional, and other needs, are acknowledged, Phase III focuses on how any discussion of the future is handled. Phase IV focuses on making agreements about further policy. 'General skills' refers to specific verbal and non-verbal behaviours that together

\begin{tabular}{|c|c|c|}
\hline \multicolumn{3}{|l|}{ PHASE II: COPING WITH RELATIVES REACTION } \\
\hline & \multicolumn{2}{|c|}{ Interpretation of scale gradients: } \\
\hline & $0=\mathrm{absent}$ & $1=$ very poor \\
\hline & $2=$ poor & $3=$ not poor $/$ not good \\
\hline & $4=\operatorname{good}$ & $5=$ very good \\
\hline & 012345 & 012345 \\
\hline allows and acknowledges the relative's first reaction & [] & [] \\
\hline reacts directly to relative's information & [] & [] \\
\hline correctly reacts to remarks/questions by relative & [] & [] \\
\hline
\end{tabular}

Phase 2 starts with the response of the doctor/nurse to the first reaction of the relative after the bad news ...

The first sub-item specifically refers to doctor/nurse behaviour that allows and acknowledges the relative's individual reactions... The doctor/nurse should show respect and kindness, and should explore the relative's reaction in an open-ended way...

The focus in this Phase is on the acknowledgement of the relatives' reactions.

(C) Blok G, van Dalen J, Morton M, Morley M J (1996) EDHEP Communication Skills Assessment Checklist: Rating Manual. University Maastricht

Figure 2. Extract from the manual for the rating criteria for Phase II (first sub-item) of Breaking Bad News taken from the EDHEP Communication Skills Assessment. A complete description of the other two sub-items of Phase II, plus the other variables rated in the two encounters, is contained in the EDHEP Communication Skills Assessment manual. The scoring criteria are the same for all items in the manual, apart from the Global Mark (see text).

facilitate effective communication: providing information, eliciting information, dealing with emotions, summarizing, structuring, empathy, naturalness and collaboration. An example of an item, taken from Phase II of the breaking bad news scale is depicted in Figure 2, with a description of the scoring criteria. The 
items in the checklist are judged to reflect the current consensus representing ideal practice in the areas of communication, bereavement, and the donation request. 19,57,63 'Good practice' advocates a clear separation of breaking news of death and requesting donation, and therefore, the donation request scale includes provision for a separate rating of reiteration of the bad news.

Simulative Relative Rating (SRR). Simulated relatives, who were instructed in the use of the 16-item questionnaire, rated the behaviour of the doctor and the nurse using a 5-point scale from 1 (bad) to 5 (very good) after each station. On all but three items the pair was rated. The three items that were rated separately for the doctor and the nurse were introduction by name and profession, showing understanding and indicating availability after the consultation.

\section{Methods of analysis}

Correlation analysis was used for validity calculations. Both observed and 'true' (or disattenuated) correlations, indicating the theoretical relationship between two variables assuming perfect reliability, were calculated, the latter based on the reliabilities using Cronbach's alpha. Combined overall total mean ratings on the PCT (PCT Total) and on the MSE (MSE Overall) were calculated as well as means for the subscales of the phases (Phases) and general skills (General Skills) in the MSE. Combined overall mean ratings of the SRR as well as SSR-scores for the subscales for the phases and the general skills were calculated. Reliabilities of the MSE and SRR were calculated using the mean scores on the three cases as items of the scale; reliabilities of the PCT were calculated using the mean scores of the six cases as items of the scale.

Two breakdown analyses were carried out. For the first breakdown analysis mean scores on the above variables were calculated for doctors and nurses separately. Student T-tests for independent groups were used to calculate any differences between doctors and nurses. For the second breakdown analysis separate total means were calculated for the specific communication skills in the MSE that were identified as key communication skills. A reduction of the simulative relative rating scale (SRR) was made by selecting those items that were relevant for the key communication skills. Correlation analyses were carried out to establish observed and dissattenuated correlations between the key communication skills measured with the MSE, the variables Diagnostic accuracy and written proficiency in the PCT and the adapted SRR.

One-way analysis of variance (ANOVA) was used to establish any differences between the scores of doctors and nurses on PCT and MSE and between ratings by the simulative relatives (SRR). All calculations were made with SPSS 10.0 for Windows. Effects were considered significant if the p-value was less than 0.05. 


\section{Results}

In Table 1 the observed correlations and the correlations corrected for reliability (dissattenuated correlations) between the three instruments used are presented. Correlations between the MSE and PCT at the level of total scores are very low, correlations corrected for attenuation are also very low.

The correlations between the SRR and MSE are also low, but corrected for attenuation they are more substantial, especially between the SRR and the Phases component of the MSE (0.90). Both the observed and dissattenuated correlations between the PCT and SRR ( 0.27 and 0.54 respectively) are higher than those between the SRR and MSE General Skills (0.16 and 0.32 respectively). The reliabilities of the MSE and PCT are good to excellent; the reliability of the SRR is very low. Note that the mean scores of the subjects on the MSE Phases is below average (a score of 3 is considered average) and on general skills just average. The maximum score for the PCT is 50 , so also on the PCT the performance is about average.

Table 1. Observed (first entry) and disattenuated (second entry) correlations between the scores on the MSE, PCT and SRR.

\begin{tabular}{lcc|cccc}
\hline & Mean (sd) & $\alpha$ & \multicolumn{2}{c}{ Paper-cases test } & \multicolumn{3}{c}{$\begin{array}{c}\text { Simulative Relative } \\
\text { Rating }\end{array}$} \\
\hline Multi-Station-Examination & & & & & & \\
$\quad$ Total & $2.7(0.43)$ & 0.82 & 0.05 & 0.08 & 0.26 & 0.52 \\
$\quad$ Phases & $2.4(0.70)$ & 0.79 & 0.03 & 0.04 & 0.45 & 0.90 \\
$\quad$ General Skills & $2.8(0.36)$ & 0.67 & 0.10 & 0.14 & 0.16 & 0.32 \\
Simulative relative rating & $4.0(0.62)$ & 0.35 & 0.27 & 0.54 & & \\
Paper-cases test & $24.7(2.0)$ & 0.75 & & & & \\
\hline
\end{tabular}

Differences between the samples of doctors and nurses: breakdown analysis 1 .

As the MSE was carried out in pairs some of the behaviours of doctors and nurses were complementary. A high score for the doctor on for example making the donation request, should result in a low score for the nurse: they cannot both make the request on the same occasion. For this reason the correlations concerning the predictive validity of the written test were also made for doctors and nurses separately. In table 2 the results are shown. The observed correlations between the PCT and the MSE are higher for the professions separately then when they are considered as one sample, but still low. This is applicable for the disattenuated correlations as well.

Both the observed and disattenuated correlations between the MSE and the ratings by the simulated relatives (SRR) are good to excellent for the sub sample of doctors only. For the nurses these are near zero or even negative. The observed correlations between the PCT and the SRR is moderate for the doctors (0.41), corrected for attenuation it is considered good (0.82). 
For the nurses correction for attenuation of the correlations between MSE and SRR does not lead to acceptable levels. The reliabilities of the MSE and PCT are good to excellent for both sub samples; the reliabilities of the SRR are very low.

Note that the mean score on the MSE Phases for the doctors is significantly higher than the corresponding score for the nurses. This difference is also reflected in the significant difference on the MSE Overall score. With regard to general skills in the MSE and on the PCT there are no difference between the two professions.

Table 2. Observed (first entry) and disattenuated (second entry) correlations between the scores on the MSE, PCT and SRR for doctors and nurses separately.

\begin{tabular}{|c|c|c|c|c|c|c|}
\hline \multirow[t]{2}{*}{ Doctors } & \multirow[b]{2}{*}{ Mean (sd) } & \multirow[b]{2}{*}{$\alpha$} & \multirow{2}{*}{\multicolumn{2}{|c|}{ Paper-cases test }} & \multirow{2}{*}{\multicolumn{2}{|c|}{$\begin{array}{c}\text { Simulative Relative } \\
\text { Rating }\end{array}$}} \\
\hline & & & & & & \\
\hline Multi Station Examination & & & observed & $\begin{array}{l}\text { disattenuat } \\
\text { ed }\end{array}$ & & \\
\hline Total & $3.0(0.34)^{2}$ & 0.82 & 0.13 & 0.16 & $0.60^{1}$ & 1.0 \\
\hline Phases & $2.8(0.52)^{3}$ & 0.69 & 0.16 & 0.21 & $0.65^{1}$ & 1.0 \\
\hline General Skills & $2.9(0.30)$ & 0.68 & 0.15 & 0.21 & $0.54^{1}$ & 1.0 \\
\hline Simulative relative rating & $4.0(0.29)$ & 0.31 & 0.41 & 0.82 & & \\
\hline Paper-cases test & $24.5(2.46)$ & 0.81 & & & & \\
\hline \multirow[t]{2}{*}{ Nurses } & & & \multirow{2}{*}{\multicolumn{2}{|c|}{ Paper-cases test }} & \multirow{2}{*}{\multicolumn{2}{|c|}{$\begin{array}{c}\text { Simulative Relative } \\
\text { Rating }\end{array}$}} \\
\hline & Mean (sd) & $\alpha$ & & & & \\
\hline \multicolumn{3}{|l|}{ Multi Station Examination } & & & & \\
\hline Total & $2.5(0.40)^{2}$ & 0.77 & 0.12 & 0.17 & -0.05 & -0.13 \\
\hline Phases & $1.8(0.51)^{3}$ & 0.51 & 0.13 & 0.26 & 0.12 & 0.40 \\
\hline General Skills & $2.9(0.30)$ & 0.61 & 0.14 & 0.23 & -0.12 & -0.34 \\
\hline Simulative relative rating & $4.0(0.27)$ & 0.21 & 0.01 & 0.03 & & \\
\hline Paper-cases test & $24.8(1.47)$ & 0.56 & & & & \\
\hline
\end{tabular}

Results of correlations concerning specific communication skills: breakdown analysis 2 .

In table 3 the correlations between the MSE scores on the specific skills, MSE total scores, scores on Phases and General Skills and the scores on the sub-items of the PCT are shown. The observed correlations between the scores on the specific general communication skills in the MSE and scores on 'Diagnostic accuracy' in the PCT are moderate ( 0.37 to 0.51 ), but higher then those between the overall mean scores in the MSE and 'Diagnostic accuracy' in the PCT (0.31 to 0.39), except for doctors' score on 'dealing with emotions' (0.04) and the nurses' score on 'providing information' ( 0.25$)$ in the MSE. After correction for attenuation the only exception is the score of the doctors for 'dealing with emotions' (0.07). None of the above correlations are significant. The observed correlations between all MSE scores and 
the scores on 'Written proficiency' in the PCT for the doctors are near zero; for the specific communication skills except structuring they are negative. Correction for attenuation is not possible as the alpha for 'Written proficiency' is zero. For the nurses all observed correlations are negative but stronger, although still low and not significant, than those of the doctors. Correction for attenuation is not possible as the alpha for 'written proficiency' for the nurses is also zero.

Care has to be taken in interpreting these results as the Cronbachs' alpha of 'Written proficiency' (PCT) is 0 .

The observed correlations between the rating of the simulative relatives (SRR) and the total mean MSE scores (Overall, Phase and General Skills) for the doctors are moderate $(0.64,0.68$ and 0.57$)$, but all significant $(\mathrm{p}<0.05, \mathrm{p}<0.01$ and $\mathrm{p}<0.05$ respectively); dissattenuation for these ratings is an overcorrection as similar content is rated. For the nurses the picture is different, even when corrected for attenuation the correlations are low and some even negative, e.g. for MSE general skills (-0.33).

The observed correlation between the SSR for the doctors and 'Diagnostic accuracy'(PCT) is low (0.28), the 'true' correlation is acceptable (0.82). The observed correlation between the SRR for the doctors and 'written proficiency' (PCT) is significant $(0.57, \mathrm{p}<0.05)$; correction for dissattenuation is not possible as the alpha for 'written proficiency' (PCT) is zero. The correlations between the SSR for the nurses and the variables on the PCT are near zero.

\section{Discussion}

The results of this study show that performance in breaking bad news and requesting organ donation on a multiple-station-examination (MSE) using simulative relatives; and performance on a paper-cases test (PCT) concerning this domain are related, although this relationship is complicated. Non-significant correlations (ranging very low to near zero) are found between the overall mean scores of both tests for the sample as a whole and for the sub samples of doctors and nurses, although the 'true' correlations for the sub samples are slightly higher. The first hypothesis (hypothesis 1) will therefore be rejected.

In the performance test the mean scores of the nurses were significantly lower than the corresponding mean scores for the doctors on a number of variables. In breaking bad news and requesting donation it is good practice to support each other during communication with relatives. The division of tasks made before all consultations in the MSE are reflected in the results. The lower scores for behaviour of nurses during the consultations reflect a quieter and supportive role, while the doctor takes a more 'active' role. The performances of doctors and nurses on the paper-and-pencil test were similar, both professions showed similar skill in diagnostic accuracy concerning the (emotional) state of relatives 


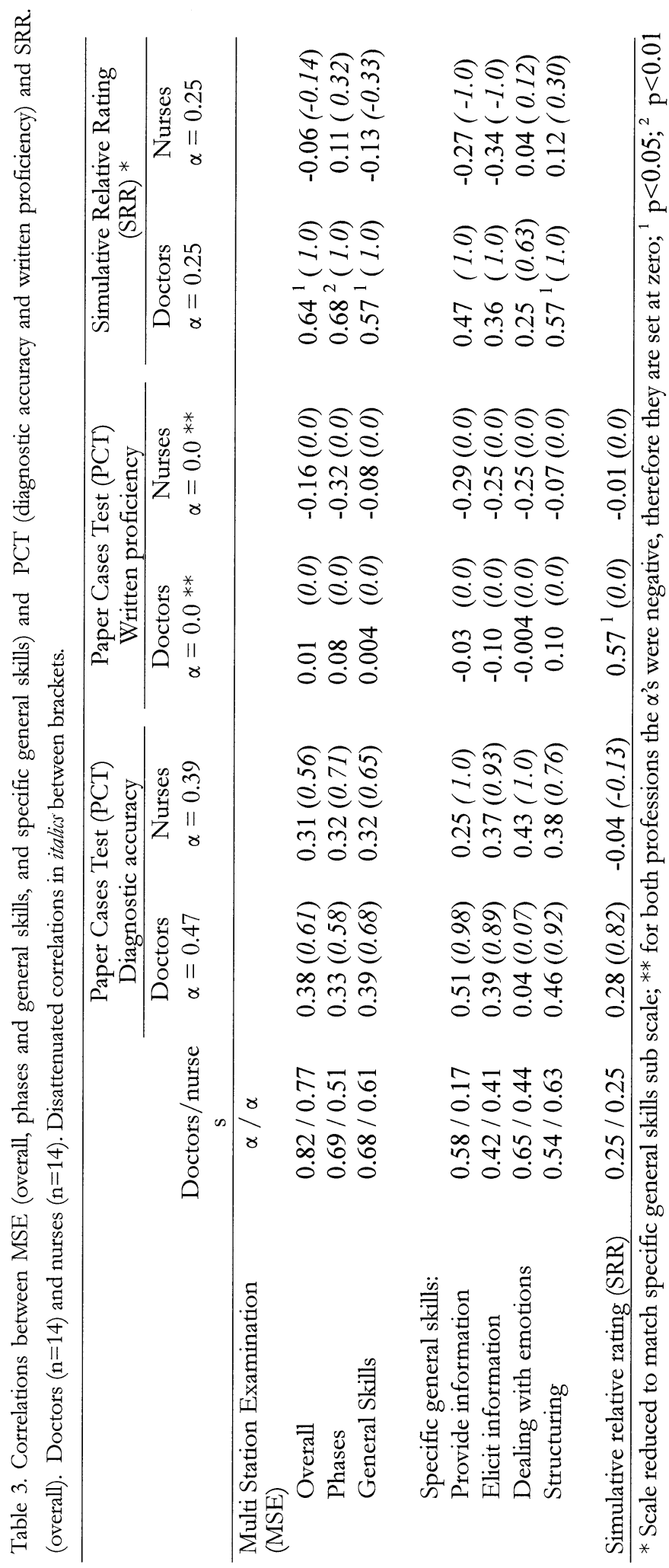


portrayed in written cases. The written proficiency in communication skills was also comparable. Diagnostic accuracy about the state of affairs described in the paper cases was on all but one skill for the doctors, positively related to proficiency in communication skills that are considered as key skills in the communication with relatives. Observed correlations were moderate; 'true' correlations were excellent and higher than both observed and 'true' correlations between diagnostic accuracy and the total mean scores on the performance test. Presumably the diagnostic accuracy in this paper-and-pencil test can predict performance on key communication skills. The second hypothesis (hypothesis 2) is therefore accepted for diagnostic accuracy. The division of tasks is also reflected in these data: the highest correlations for the doctors are with the more active skills 'providing information' and 'structuring' and for the nurses with the more supportive skills 'dealing with emotions' and 'eliciting information'.

The observed correlations between written performance and actual performance on the identified skills were near zero and for three of these negative; for the nurses the correlations were more substantial, and all negative. None of the correlations were significant, this might be due to the limited number of subjects. The pattern is less clear than for diagnostic accuracy. It is hard to draw conclusions as the reliabilities of the written communications skills for both profession were zero. It may also be due to the fact that in the written test the nurses were required to use the same written skills as the doctors, but in the performance test may not have had the opportunity to show these skills. Interpretation has to be made with care, as none of these correlations were significant (the p-values ranged from 0.06 to 0.09 ) and the reliability of the ratings of the reactions in the paper-and-pencil test was zero. Taking these precautions into account, it can be concluded that for doctors written proficiency in specific communication skills is not predictive for the actual performance of these skills. For the nurse the predictive value, if any, of written proficiency in these skills is negative for actual performance. Nurses may perform well on written skills, this is however not reflected in performance, which may be related to the complimentary character of the roles of both professions in the consultation. There was also no systematic pattern of correlations between the written skills and the actual performance of the key communications skills being higher than those with the total mean performance skills, the highest correlation was the negative one between the Phase-score of the nurses and the written proficiency of skills. Based on these mixed results hypothesis two (hypothesis 2) is rejected for the written proficiency in communication skills.

The ratings of the behaviour of the doctors by the simulative relatives correlated significantly with mean total scores of the doctors in the performance test, and strongest with the component dealing with the structure of the consultation (Phases). This was not applicable for the nurses, for the latter there were even negative correlations between these variables. This again may also be due to the division of tasks and hence the complementarity in the consultations. The simulative relatives presumably made their ratings dependent on the active party in 
the consultation. The 'true' correlation of 0.82 between the ratings of the simulative relatives and the paper-and-pencil test scores of the doctors is surprising. If the simulated relatives' ratings are a good indication of the construct validity of the performance test, a positive correlation with the paper-and-pencil test is not expected based on the lack of predictive validity of the written test for the performance test. However, our data indicate that similar skills are measured in the performance test and in the written test as perceived by the simulated relatives; at least for the doctors. The third hypothesis (hypothesis 3 ) is therefore accepted only for the doctors.

At a more detailed level (hypothesis 4) there is a significant and substantial observed correlation between the ratings of the simulated relatives and the written proficiency for the doctors and a low observed, but acceptable 'true' correlation with diagnostic accuracy in the paper-and-pencil test for the doctors. This is probably due to the skill of the doctors in structuring the consultation; as the highest, significant, correlation between the simulative relatives' rating and the performance test is with the mean score of the doctors for the Phases in combination with the significant correlation of the simulative relatives' rating with the specific skill of structuring. This is also in line with the complementarity in the consultations, in which the doctors generally had the lead. Due to the unreliability of the ratings of the written proficiency in the paper-and-pencil test it is difficult to say if this is a justified conclusion. The high 'true' correlation between the paperand-pencil test and the performance test for the doctors (.82) cannot be fully explained. The negative correlations between the ratings of the behaviour of the nurses by the simulative relatives performance test and the key communication skills in the performance test would indicate that not using these skills would lead to higher ratings by the simulative relatives. Again this would indicate that if doctors and nurses show good teamwork, and behave complimentary in the consultations this increases the ratings for both professions. There is no relationship between simulative relatives' ratings of the nurse and the paper-andpencil test. The fourth hypothesis (hypothesis 4) is accepted only for the doctors, taking into account that this conclusion has to be made with care as the reliability of the instruments were low.

Based on the results of this study it may be concluded that diagnostic accuracy concerning written descriptions of authentic situations in intensive care units as measured with the paper-cases test has reasonable predictive value for performance of communication skills in this domain. With respect to the predictive value of written proficiency in key communication skills a less clear conclusion can be drawn and further study is necessary.

\section{Conclusions}

Communication skills in the domain of dealing with death and organ donation can be reliably measured with a multi station examination using three stations. The 
present study showed that diagnostic accuracy in combination with written proficiency of communication skills can be reliably measured with a paper-cases test in which subjects are confronted with real-life situations.

The ratings of the simulative relatives underscored the construct validity of the performance test. The significant relationship between ratings of simulative relatives and the written communication skills of the doctor indicates that the paper-and-pencil test measured at least partly what the performance test measured. The established relationship between some sub-items and variables is intriguing and is different from what is found in other studies. It may well be that the requirement of actually writing down what one should literally say activates other cognitive skills than those required in completing a test with a true-false-?- format. These cognitive skills may, as our results indicate, be closer related to actual behaviour. The contents of the tests may also have been critical. Dealing with death and donation is a very specific domain; it may very well be that if written tests of communication skills using authentic situations are focused on specific domains, the predictive value for performance tests may be better than when communication skills in general are the focus of assessment.

The subjects in the current study had substantial experience in the domain that was assessed; this specific experience may have facilitated diagnostic accuracy. As our results show this kind of knowledge, although a good indicator for actual behaviour, is not sufficient to perform well: all scores were average; on the papercases test as well as on actual performance. The nurses might have shown better performance if they had been able to show actual behaviour. What is striking in our results is that the complementary roles doctors and nurses play in communicating with relatives (an active, leading role of the doctor and a supportive role of the nurses) is validated by the pattern of correlations between the paperand-pencil test, the performance test and the ratings by the simulated relatives.

Further study should be focused at determining what the differences are between the cognitive skills required in different kinds of paper-and pencil tests of communication skills, what the role of specific experience is and to which degree specificity of domain assessed influences the predictive value of paper-and-pencil tests of communication skills. Efforts should be made to increase the reliability of the measurement of written proficiency in communication skills. Our results indicate that providing subjects with a test format, which is more authentic than the traditional paper-and-pencil written test yields different results. When subjects are confronted with realistic situations, in which they have the opportunity to actively demonstrate their understanding of the functional use of communication skills and their written proficiency of these skills, this seems to elicit cognitive performances or behaviours that are a valid indication of potential performance in real life. 


\section{References}

1. Garrison RN, Bentley FR, Raque GH, Polk HC, Jr., Sladek LC, Evanisko MJ, et al. There is an answer to the shortage of organ donors. Surg Gynecol Obstet 1991;173(5):391-6.

2. Pelletier ML. The needs of family members of organ and tissue donors. Heart Lung 1993;22(2):151-7.

3. Blok GA, Kraan GA, van Dalen J, van Gurp ME, van der Vecht E, van Wezel HBM. Ervaringen van nabestaanden van donoren met de donatieprocedure; vergelijking tussen 1995 en 1998. [Experiences of donor relatives with the donation procedure: comparison between 1995 and 1998]. Ned Tijdschr Geneesk 2000;144(14):663-7.

4. Siminoff L, Gordon N, Hewlet J, Arnold R. Factors influencing families' consent for donation of solid organs for transplantation. JAMA 2001;286(1):71-77.

5. Siminoff L, Arnold R, Hewlett J. The process of organ donation and its effect on consent. Clin Transplant 2001;15(1):39-47.

6. Blok G. The impact of changes in practice in organ procurement on the satisfaction of donor relatives. Chapter 8 of this thesis, submitted.

7. Christaki K. A personal reflection on the issues surrounding the use of euphemisms following sudden death. Nurs Crit Care 1998;3(5):249-52.

8. Creagan ET. How to break bad news--and not devastate the patient. Mayo Clin Proc 1994;69(10):1015-7.

9. Franz H, Jong de W, Wolfe M, Nathan HM, Payne D, Reitsma W, et al. Explaining brain death; a critical feature of the donation process. J Transplant Coordination 1997;7:14-21.

10. Marrow J. Telling relatives that a family member has died suddenly. Postgrad Med J 1996;72(849):413-8 .

11. Pearson IY, Zurynski Y. A survey of personal and professional attitudes of intensivists to organ donation and transplantation. Anaesth Intensive Care 1995;23(1):68-74.

12. Rapaport W, Witzke D. Education about death and dying during the clinical years of medical school. Surgery 1993;113:163-5.

13. Smith Brew S, Yanai L. The organ donation process through a review of the literature. Part I. Accid Emerg Nurs 1996;4(1):5-11.

14. Tolle SW, Bascom PB, Hickam DH, Benson JA, Jr. Communication between physicians and surviving spouses following patient deaths. J Gen Intern Med 1986;1(5):309-14.

15. Buckman R. Breaking bad news: why is it still so difficult? $\mathrm{Br}$ Med J Clin Res Ed 1984;288(6430):1597-9.

16. Fallowfield L, Jenkins V, Beveridge $H$. Truth may hurt but deceit hurts more: communication in palliative care. Palliat Med 2002:16(4) 297-303.

17. Espinosa E, Gonzalez-Baron M, Zamora P, Ordonez A, Arranz P. Doctors also suffer when giving bad news to cancer patients. Support Care Cancer 1996;4(1):61-3.

18. Fallowfield L. Giving sad and bad news. Lancet 1993;341(8843):476-8.

19. Maguire P, Faulkner A. Communicate with cancer patients: 1 . Handling bad news and difficult questions. BMJ 1988;297(6653):907-9 . 
20. Ptacek JT, Fries EA, Eberhardt TL, Ptacek JJ. Breaking bad news to patients: physicians' perceptions of the process. Support Care Cancer 1999;7(3):113-20.

21. Siminoff LA, Arnold RM, Caplan AL. Healthcare professional attitudes toward donation: effect on practice and procurement. J Trauma Inj Infec Crit Care 1995;39:553-9.

22. Girgis A, Sanson Fisher RW. Breaking bad news: consensus guidelines for medical practitioners. J Clin Oncol 1995;13(9):2449-56.

23. Randhawa G. Enhancing the health professional's role in requesting transplant organs. British Journal of Nursing 1997;6(8):429-434.

24. Randhawa G. Coping with grieving relatives and making a request for organs: principles for staff training. Med Teach 1998;20(3):247-9.

25. Politoski G, Boller J. Making the critical difference: an innovative approach to educating nurses about organ and tissue donation. Crit Care Nurs Clin North Am 1994;6(3):581-5.

26. Coolican MB, Politoski G. Donor family programmes. Crit Care Nurs Clin North Am 1994;6(3):613-23.

27. Riker RR, White BW. The effect of physician education on the rates of donation request and tissue donation. Transplantation 1995;59(6):880-4.

28. Serwint J, Rutherford L, Hutton N, Rowe P, Barker S, Adamo G. "I learned that no death is routine": Description of a death and bereavement seminar for pediatrics residents. Acad Med 2002;77(4):278-284.

29. Wight C, Cohen R. The European Donor Hospital Education Programme (EDHEP). In: Chapmen JR, Deierhoi M, Wight C (Eds). Organ and Tissue Donation for Transplantation. London: Arnold, 1997:373-381.

30. Morton J, Blok GA, Reid C, van-Dalen J, Morley M. The European Donor Hospital Education Programme (EDHEP): enhancing communication skills with bereaved relatives. Anaesth Intensive Care 2000;8(2):184-90.

31. Blok GA, Morton J, Morley M, Kerckhoffs CMAM, Vleuten van der CPM, Kootstra G. Requesting organ and tissue donation: the case of self-efficacy. Effects of the European Donor Hospital Education Programme (EDHEP). Accepted for publication Adv Health Sci Educ.

32. Blok GA, Vleuten van der CPM, Kootstra G. Effects of the European Donor Hospital Education Programme (EDHEP) on cognitive skills in communication. Chapter 6 of this thesis, submitted.

33. Blok GA, Wezel HBM van, Morley M, Morton M, Mansum van W, Vleuten van der CPM. Effects of an educational programme on teamwork in intensive care. Chapter 7 of this thesis, submitted.

34. Cushing AM, Jones A. Evaluation of a breaking bad news course for medical students. Med Educ 1995;29(6):430-5.

35. Maguire P, Booth K, Elliott C, Jones B. Helping health professionals involved in cancer care acquire key interviewing skills--the impact of workshops. Eur J Cancer 1996;32a(9):1486-9.

36. Sanson-Fisher R, Cockburn J. Effective teaching of communication skills for medical practice: selecting an appropriate clinical context. Med Educ 1997:31(1):52-7. 
37. Eggly S, Afonso N, Rojas G, Baker M, Cardozo L, Robertson RS. An assessment of residents' competence in the delivery of bad news to patients. Acad Med 1997;72(5):397-9.

38. van-Dalen J, Prince CJAH, Scherpbier AJJA, Vleuten van der CPM. Evaluating communication skills. Adv Health Sci Educ 1998;3:187-195.

39. Fallowfield L, Jenkins V. Effective communication skills are the key to good cancer care. Eur J Cancer 1999;35(11):1592-7.

40. Baile WF, Kudelka AP, Beale EA, Glober GA, Myers EG, Greisinger AJ, et al. Communication skills training in oncology. Description and preliminary outcomes of workshops on breaking bad news and managing patient reactions to illness. Cancer 1999;86(5):887-97.

41. Fallowfield L, Jenkins V, Farewell V, Saul J, Duffy A, Eves R. Efficacy of a Cancer Research UK communication skills training model for oncologists: a randomised controlled trial. Lancet 2002;359(February 23):650-6.

42. Kurtz S, Silverman J, Draper J. Teaching and Learning Communication Skills in Medicine. Abington: Radcliffe Medical Press Ltd., 1998.

43. Aspergen K. BEME Guide No. 2: Teaching and learning communication skills in medicine - a review with quality grading of articles. Med Teach 1999;21(6):563-570.

44. Vleuten van der CPM. The Assessment of Professional Competence. Developments, Research and Practical Implications. Adv Health Sci Educ 1996;1:41-67.

45. Willkinson T, Fontaine S. Patients' global ratings of student competence. Unreliable contamination or gold standard? Med Educ 2002;36:1117-21.

46. Heine N, Garman K, Wallace P, Bartos R, Richards A. An analysis of standardized patient checklist errors and their effect on student scores. Med Educ 2003;37:99-104.

47. Macrae H, Vu N, Graham B, Word-Sims M, Colliver J, Robbs R. Comparing checklists and databases with physicians' ratings as measures of students' history and physical examination skills. Med Educ 1995;70:313-7.

48. Vleuten van der CPM, Luyk van SJ, Beckers HJM. A written test as an alternative to performance testing. Med Educ 1989;23:97-107.

49. Jansen JJM, Tan LHC, Vleuten van der C, Luyk van SJ, Rethans JJ, Grol RPTM. Assessment of competence in technical clinical skills of general practitioners. Med Educ 1995;29:247-53.

50. Scherpbier AJJA. Kwaliteit van vaardigheidsonderwijs gemeten (Exploring the quality of skills training) With English summary. [Dissertation]. University Maastricht, 1997.

51. Verhoeven BH, Hamers JGHC, Scherpbier AJJA, Hoogenboom RJI, Vleuten van der CPM. The effect on reliability of adding a separate written assessment component to an objective structured clinical examination. Med Educ 2000;34:525-9.

52. Remmen R, Scherpbier AJJA, Derese A, Denekens J, Hermann I, Hoogenboom RJI, et al. Correlation of a written test of skills and a performance based test: validation study in two traditional medical schools. Med Teach 2001;23:29-32.

53. Kramer AW, Jansen JJ, Zuithoff P, Dusman H, Tan LH, Grol RP, et al. Predictive validity of a written knowledge test of skills for an OSCE in postgraduate training for general practice. Med Educ 2002;36(9):812-9. 
54. Dalen van J, Kerkhofs E, Verwijnen GM, Knippenberg van - Berg van den BW, Hout van den HA, Scherpbier AJ, et al. Predicting communication skills with a paper-and-pencil test. Med Educ 2002;36(2):148-53.

55. Humphris G-M. Communication skills knowledge, understanding and OSCE performance in medical trainees: a multivariate prospective study using structural equation modelling. Med Educ 2002;36(9):842-52.

56. Bögels SM, Vleuten van der C, Blok GA, Kreutzkamp R, Melles R, Schmidt HG. Assessment and validation of diagnostic interviewing skills for the mental health. Journal of Psychopathology and Behavioural Assessment 1995;17:217-230.

57. Ong LML, Haes de CJM, Hoos AM, Lammes FB. Doctor-patient communication: a review of the literature. Soc Sci Med 1995;40:903-8.

58. Pohle von WR. Obtaining organ donation. Who should ask? Heart Lung 1996;25:304-9.

59. Ptacek JT, Eberhardt TL. Breaking bad news. A review of the literature. JAMA 1996;276(6):496-502.

60. Wright B. Sudden death. London: Churchill Livingstone, 1991.

61. Crijnen A, Kraan H. Measuring patient satisfaction with the communication. In: (eds) HKAC, editor. The Maastricht History Taking and Advice Checklist: studies of instrumental utility. Dissertation. Amsterdam: Velden van den Hazelaar, 1987:145-171.

62. van Thiel J, Kraan HF, Van Der Vleuten CP. Reliability and feasibility of measuring medical interviewing skills: the revised Maastricht History-Taking and Advice Checklist. Med Educ 1991;25(3):224-9.

63. Novack DH, Suchman AL, Clark W, Epstein RM, Najberg E, Kaplan C. Calibrating the physician. Personal awareness and effective patient care. Working Group on Promoting Physician Personal Awareness, American Academy on Physician and Patient. JAMA 1997;278(6):502-9. 


\title{
6
}

\section{Effects of the European Donor Hospital Education Programme on cognitive skills in communication ${ }^{1}$}

\begin{abstract}
Communication skills are vital skills for all health professionals. High levels of (expert) knowledge are useless if adequate skills to communicate this knowledge are lacking. This is also applicable in the sensitive area of death and organ donation. Research findings indicate that the communicative behaviour of the professionals involved is of crucial importance for the decision relatives make regarding organ and tissue donation. The European Donor Hospital Education Programme (EDHEP) was developed in order to improve the competence of intensive care staff in breaking news of death and requesting donation, by establishing insight in the grieving process and in relatives' emotional reactions as well as providing insight in the donation procedure. It provides bands-on practice in relevant communication skills needed in sensitively breaking news of death and making a request for organ donation. The aim of the current study was to determine the effects of EDHEP on the cognitive use of communication skills concerning breaking newss of death and requesting donation, measured with a paper-cases test. Participation in EDHEP leads to a transient effect on the cognitive proficiency in communication skills. Moreover EDHEP participants showed they had better insight in the relationship between the diagnosis of a (problematic) situation and the communication skills to use.
\end{abstract}

\footnotetext{
${ }^{1}$ Submitted as: Blok GA, Vleuten van der CPM, and Kootstra G. Effects of the European Donor Hospital Education Programme (EDHEP) on cognitive skills in communication.
} 


\section{Introduction}

Communication skills are vital skills for all health professionals. Expert knowledge is useless if adequate skills to communicate this knowledge are lacking. This is also applicable in the sensitive area of death and organ donation. One of the reasons for the shortage of donor organs is the number of refusals by bereaved relatives. Different studies have shown that relatives who refused to donate had a far less clear understanding of brain death than those who consented; a good understanding of the death of their relation should be established before the issue of organ and tissue donation is raised. ${ }^{1-3}$ Relatives prefer professionals who show compassion, are knowledgeable on the topic and provide adequate support throughout the process. ${ }^{3-5}$ Relatives often have many questions; it is important that medical and nursing staff take time to answer these questions and use understandable language without jargon. ${ }^{3,6}$ These research findings indicate that the communication between relatives and the key staff is very important, and that the behaviour of the professionals involved, is of crucial importance for the decision relatives make regarding organ and tissue donation. However, doctors and nurses find it difficult to deal with death and dying ${ }^{7-11}$ and with requesting (organ) donation. 7,9,10,12 Enhanced awareness of interpersonal variables and training in order to improve competence is necessary for improvement of communication with the bereaved. ${ }^{10,13}$ Communication skills can be improved; there is evidence from general practice and oncology and other areas in medicine, that particular skills can be improved with training based on identified needs ${ }^{14-19}$ (see Kurtz et al. ${ }^{20}$ for an overview).

The European Donor Hospital Education Programme (EDHEP) is an educational programme, that was developed in order to improve the competence of intensive care staff in breaking news of death and requesting donation. ${ }^{21,22}$ It is a one-day interactive workshop with short presentations, exercises, discussion and simulated relative encounters. EDHEP aims specifically at improvement of the communication with the relatives regarding death and donation, by establishing insight in the grieving process and about relatives' emotional reactions as well as providing insight in the donation procedure. It provides hands-on practice in relevant communication skills needed in sensitively breaking news of death and making a request for organ donation. ${ }^{23}$ Breaking news of death, specifically explaining brain stem death and approaching the next of kin for permission to donate organs require appropriate management of emotional reactions of relatives. These are complex tasks for which profound knowledge about these domains and advanced skills to communicate information and understanding are necessary. EDHEP emphasises the necessity for both professions to be competent in communication while recognizing that they may take complementary roles in the encounters with relatives. Competence in communication in this domain involves not only mastery of communication skills but also the ability to adequately interpret the situation at hand and to recognize and use those communication skills that are 
relevant and effective in that situation. From the research described above it follows that the key skills in the communication with relatives are: 1) providing information in a clear and understandable way, 2) dealing with relatives' (emotional) reactions in a sensitive way showing compassion and understanding, 3) dealing with relatives' questions by helping them express their thoughts and feelings and 4) structuring the process in such a way that everything happens in a well timed way. In the EDHEP workshop the participants are made aware of the importance of these skills; the opportunities to practice the skills are limited. ${ }^{23}$

Cognitive skills in communicating

In this article the effectiveness of the EDHEP workshop on cognitions about the communication process and about the effective use of communication skills is described; both are important prerequisites for the adequate performance of communicative behaviour. Patel et al. ${ }^{24}$ indicate that both profound (domain) knowledge and experience in practice (tacit knowledge) lay at the basis of (medical) expertise. The ability to think about issues and solve problems is highly dependent both on the availability of specific knowledge (effective problem solvers rely heavily on domain-specific knowledge), ${ }^{25}$ but also on what Schön ${ }^{26}$ calls the competence to deal with 'indeterminate situations', situations in which there is uncertainty, uniqueness or value conflict. Consider the following situation, when a doctor has to tell a family about the death of their relative. If a deceased patient is a potential donor and in critical medical condition, it is important to act fast to save donor organs for transplants. However, the relatives, of whom he does not know how they will react to the announcement of death, may need time to come to terms with the death before they are able to consider the option of donation. In situations like this a competent practitioner must not only have domain knowledge about organ procurement, grief reactions, communication theory and skills, but he must also decide about the means to use (e.g. which communication skills), and how he will deal with the conflicting appreciations of this situation (mode of approach, timing, teamwork) so as to make it into a solvable problem.

In the EDHEP workshop knowledge about the communication process and the necessary skills about breaking bad news and requesting donation is acquired through presentations, video's and in feedback on role plays. Participants practice communication skills and are stimulated to make explicit how they interpret situations (in responding to video-vignettes as well as in discussing the role plays) and why they used specific communication skills.

In one of our other studies it was found that EDHEP participants increased their self-efficacy beliefs relating to breaking news of death and requesting donation after participation in EDHEP; this was a lasting effect and still demonstrable at sixmonth follow-up. These increased self-efficacy beliefs indicate that they not only 'know' better how to perform required behaviour, but also that they can better 'perform' the required behaviour. ${ }^{27}$ These results are reflected, partially, in the 
results of another of our studies, in which participants' communication skills were measured using authentic performance assessments with simulative relatives. ${ }^{28}$ Consultant intensivists who participated in EDHEP demonstrated a significant improvement in the way they structure an encounter with a relative, and conduct a bad news encounter. At post-test these doctors attended more sensitively to relatives' needs. This was however only a temporary effect. They also showed better skills in explaining the events to come when a relative consents to donation; this effect was still demonstrable at six-month follow-up. There were no changes in the performance of the nurses who participated in EDHEP. Doctors and nurses fulfilled complementary roles in the encounters, where the doctor took the more active and the nurse the more supportive role. ${ }^{28}$

We also wanted to know to what degree cognitions about communication and the effective use of communication skills would be affected through participation in EDHEP. No effect on the performance of the nurses does not necessarily mean that on a cognitive level they did not learn about the communication with relatives. Due to the complementary roles in the encounters they may not have been able to show proficiency in the key communication skills. Therefore, the current study was undertaken to measure the effect of EDHEP on diagnostic accuracy concerning the (emotional) state of relatives depicted in written authentic situations, on the written proficiency of communication skills and on the coherence between these two cognitive aspects of communication, using a paper-and-pencil test concerning the domain of breaking bad news and requesting donation. It was expected that participation in EDHEP would lead to increases on the overall score on the papercases test (hypothesis 1); increases in diagnostic accuracy as this would reflect better insight in authentic situations intensive care staff is confronted with (hypothesis 2); 2 ) increases in the written proficiency in responding to these authentic situations as this would reflect better cognitive use of communication skills (hypothesis 3) and 3) more coherence between the diagnoses of the authentic situations and the mode of responding, as this would reflect insight in 'knowing how to act' (hypothesis 4). A randomised controlled study with three repeated measures was carried out.

\section{Method}

Subjects

Subjects were doctors and nurses working in intensive care. The recruitment of subjects was nationwide; subjects were doctors and nurses from over 40 hospitals, who volunteered for participation in an EDHEP workshop. During the period in which the research took place, the allocation of participants to EDHEP workshops was coordinated nationally. Potential participants were registered centrally and randomly assigned to either an experimental condition (attendance at an EDHEP workshop during the study) or a control condition (attendance at an EDHEPworkshop after the study). During the research period of one and a half year, 7 EDHEP workshops took place. In order to control for effects due to dispersion in 
time, per EDHEP workshop an equal number of future participants were allocated to the control condition.

Table 1. Descriptive statistics of the experimental and control group.

\begin{tabular}{lcc}
\hline & $\begin{array}{c}\text { Experimental group } \\
\mathrm{n}=68\end{array}$ & $\begin{array}{c}\text { Control group } \\
\mathrm{n}=48\end{array}$ \\
\hline $\begin{array}{l}\text { Profession (doctor/nurse/other) } \\
\text { Missing }\end{array}$ & $14.5 \% / 62.3 \% / 11.6 \%$ & $12.5 \% / 85.4 \% / 2.1 \%$ \\
Sex $(\%$ male/female) & $11.6 \%$ & - \\
Age in years (mean, (sd)) & $40.6 \% / 59.4 \%$ & $30.6 \% / 67.3 \%$ \\
Experience in critical care & $33.4(7.0)$ & $32.9(7.3)$ \\
$\quad$ (years: mean, sd) & $6.0(5.0)$ & $6.0(4.6)$ \\
Contact with bereaved families & & \\
$\quad$ Mode) few times/month & $46 \%$ & $58 \%$ \\
Experience with organ donation & & \\
request & $44 \%$ & $48 \%$ \\
None & $45 \%$ & $46 \%$ \\
1-2 times a year & $7 \%$ & $4 \%$ \\
3-4 times a year & $4 \%$ & $2 \%$ \\
$>4$ times a year & & \\
\hline
\end{tabular}

The number of subjects of in the experimental condition was 68 ; in the control condition 48; only those subjects were selected of whom complete datasets of all three measurements were available. Comparison with drop-outs did not reveal any significant differences.

Both conditions were comparable on all descriptive characteristics. The proportion of doctors is rather low compared to the proportion of nurses: $14.5 \%$ in the experimental condition and $12.5 \%$ in the control condition. Nine Transplant Coordinators participated in the study, of which eight in the experimental condition and one in the control condition. The sample had a mean age of about 33 years and a mean experience of six years in their profession (see table 1).

\section{Design}

The experimental design used was an 'untreated control group design with pre-test and post-test' with a follow-up. ${ }^{29}$ There were three measurements: one before attending the EDHEP workshop (pre-test), one after attending the EDHEP workshop (post-test) and one six months after the post-test (follow-up). Measurements in the control condition took place at similar points in time. The tests were sent to the subjects at all three measurements. The subjects in the experimental group handed the completed test-forms to the EDHEP workshop moderators before the start of the workshop. The future EDHEP participants used pre-stamped envelopes for returning the completed test-forms to the 
researchers. At post-test and follow-up this procedure was applied for all subjects. All data were anonimised by allocating a number to each subject.

Instrument

Paper-cases test (PCT). For the paper-cases test (PCT) six paper cases were developed, based on typical situations described by intensive care staff experienced in breaking news of death and requesting organ donation. In the cases different emotional reactions by imagined relatives on either the announcement of brainstem death or the donation request for organs was portrayed. The emotions portrayed were: in case 1 denial and disbelief about brain stem death; shock in case 2 because of being overwhelmed by the donation request; anger and reproach after diagnosis of drain stem death in case 3; sadness and guilt in case 4; disagreement within the family in case 5; and rational behaviour in case 6 . Five of the cases involved the description of the reaction of one relative; in case 5 the reactions of three family members were described (see Figure 1 for an example).

Ms. Winter is a 35 year old woman. She is divorced. Her eight-year-old daughter Susan suffered severe brain damage after a traffic-accident. When Susan was admitted she was already in bad condition. You did everything you could. However, she has just been declared brain dead. You had to tell Ms. Winter that Susan is brain dead.

Ms. Winter has been with her daughter. Susan is on a ventilator.

You are now with Ms. Winter. You have just told her that Susan has died.

Ms. Winter looks at the wall and raises an eyebrow. She has a distant, a bit cynical look in her eyes. She hardly reacts to your message. After some time she says: 'But.....she is sleeping'.

What do you think is Ms. Winter's condition?

You want to clarify Susan's condition to Ms. Winter.

You say to her:"

Figure 1. Example of a paper case.

In a validation study ${ }^{30}$ in which the predictive value of the PCT for a performance was examined a significant relationship between ratings of simulative relatives and the written communication skills of the doctors was found, indicating that the PCT measures cognitive skills that seem to be predictive to actual behaviour to some extent, but that there is a unique component of cognitive skills that is not covered by performance measures. ${ }^{30}$ Diagnostic accuracy concerning the written descriptions of the above authentic situations has reasonable predictive value for performance of communication skills in this domain (observed correlations were found ranging from 0.25 to 0.51 ; disattenuated from 0.56 tot 1.0). With respect to the predictive value of written proficiency in communication skills, a less clear conclusion could be drawn. The correlation pattern between the 
performance test, the PCT and ratings by simulative relatives corresponded with a more active role for the doctor and a more supportive role for the nurse in the encounters.

Procedure. Subjects were given a standardised instruction for completion of all six paper cases. In five of the six scenario's, presented on structured response sheets, the subject was asked to interpret and describe the (emotional) state of the relative(s) portrayed, to be deducted from the description of the verbal as well as the nonverbal behaviour of the relative(s) (diagnostic accuracy). In the second case this description was given, in order to elicit a specific cognitive response (reflection of feeling). In all six cases the subjects were asked to write down what they would literally say when addressing the relatives portrayed (written proficiency) (see Figure 1). The number of cases was kept to a minimum. Time constraints prohibited more extended measurement. All subjects in the study completed the same six cases at all three measurements. Test taking conditions could not be standardized; subjects were free to decide where and when to complete the test.

The answers given by the subjects were rated using an answer key, established after consensus of agreement by a panel of experts, for both interpretation and reaction, developed for these paper cases, that contained the following categories: 'interpretation', 'reaction', 'coherence' and 'global judgment'. 'Interpretation' refers to diagnostic accuracy concerning the (emotional) state of the relatives. 'Reaction' concerns the quality of verbal reaction to the relatives described in the scenarios, the written proficiency. As there were a limited number of adequate responses for 'interpretation' and 'reaction' the answers could be rated 'adequate'(2), 'borderline' (1) or 'inadequate' ( 0$)$. 'Coherence' refers to the coherence between the interpretation and the reaction: is the (emotional) state described in the answers on the first question taken into account in the verbal answer to the second question, the ratings were either 'yes' (1) or 'no' (0) (in 4 of the 6 cases). Global judgment refers to a general evaluation of the approach taken in the case on a 10-point scale $(1=$ very poor, $10=$ outstanding). In order to guarantee for reliable scoring all paper cases were rated by two independent raters, who were trained in the use of the answer key. The raters were unaware of the research condition of the subjects rated.

Methods of analysis

Means, frequencies and percentages were calculated for the background characteristics of the subjects; Chi-square was used to check for any differences between these characteristics. Mean scores for the sub items diagnostic accuracy, written proficiency and global judgment in the paper-cases test (PCT) were calculated. For coherence the sum of the two raters across cases was taken. For the calculation of the overall PCT-score, a composite score, the scores on separate variables were multiplied with different weights in order to generate a 10-point 
scale for all variables: diagnostic accuracy x 5 , written proficiency x 5 , coherence $\mathrm{x}$ 2,5 and global judgment $x 1$. The overall PCT-score is the mean across all separate variables. Analyses of variance (ANOVA's) were carried to calculate any effect within and between groups, with scores on the PCT as the dependent variables and condition and measurement as the independent variables. In order to determine the groups between which an effect was present Tukey's Honestly Significant Difference $(p<0.05)$ was used. All calculations were made with SPSS 10.0 for Windows. Effects were considered significant when the p-value was less then 0.05.

\section{Results}

In Table 2 the results on the PCT are shown. A main effect was found for the PCT overall score in the experimental group $(\mathrm{F}(2)=3.57 ; \mathrm{p}<0.05)$. There was a significant difference in the experimental group on this variable between pre and post-test $(p<0.001)$. No significant changes were found for the control group. At post-test the experimental group's PCT overall score was significantly higher than that of the control group $(\mathrm{p}<0.001)$. This was not maintained at follow-up.

As for written proficiency in the experimental group a main effect was found $(F(2)=3.52 ; \mathrm{p}<0.01)$; there was a significant difference between pre and post-test on this variable $(\mathrm{p}<0.01)$. In this group a main effect was also found for global judgment $(F(2)=4.83 ; p<0.01)$; there was a significant difference between pre- and post-test on this variable $(p<0.01)$. In the control group no effects were found. The experimental group's scores for written profiency and global judgment were superior to those of the control group at post-test (both $\mathrm{p}<0.001$ ).

Participation in EDHEP did not appear to have an effect on diagnostic accuracy EDHEP participants, however, performed better on this variable than the subjects in the control group at the post-test $(\mathrm{p}<0.05)$.

A significant difference between pre and post-test was found on coherence between diagnostic accuracy and written proficiency in the experimental group $(p<0.05)$. EDHEP participants performed better on this variable than control subjects at post-test $(\mathrm{p}<0.05)$.

The effect that was found for global judgment was a lasting effect; part of the increase at post-test $(p<0.01)$ was maintained at follow-up $(p<0.05$ : pre - follow-up difference). EDHEP participants' scores for global judgment were superior to those of the subjects in the control group at follow-up $(\mathrm{p}<0.05)$.

\section{Discussion}

The aim of this study was to determine the effects of a one-day interactive workshop, EDHEP, on cognitive use of communication skills concerning breaking news of death and requesting organ donation as measured with a paper-cases test. The results of the study indicate that participation in the EDHEP workshop indeed leads to a transient improvement in the cognitive use of communication skills. In the control condition nothing changed over measurements. Hypothesis 1 
Table 2. Scores on the Paper-cases test (standard deviation between brackets).

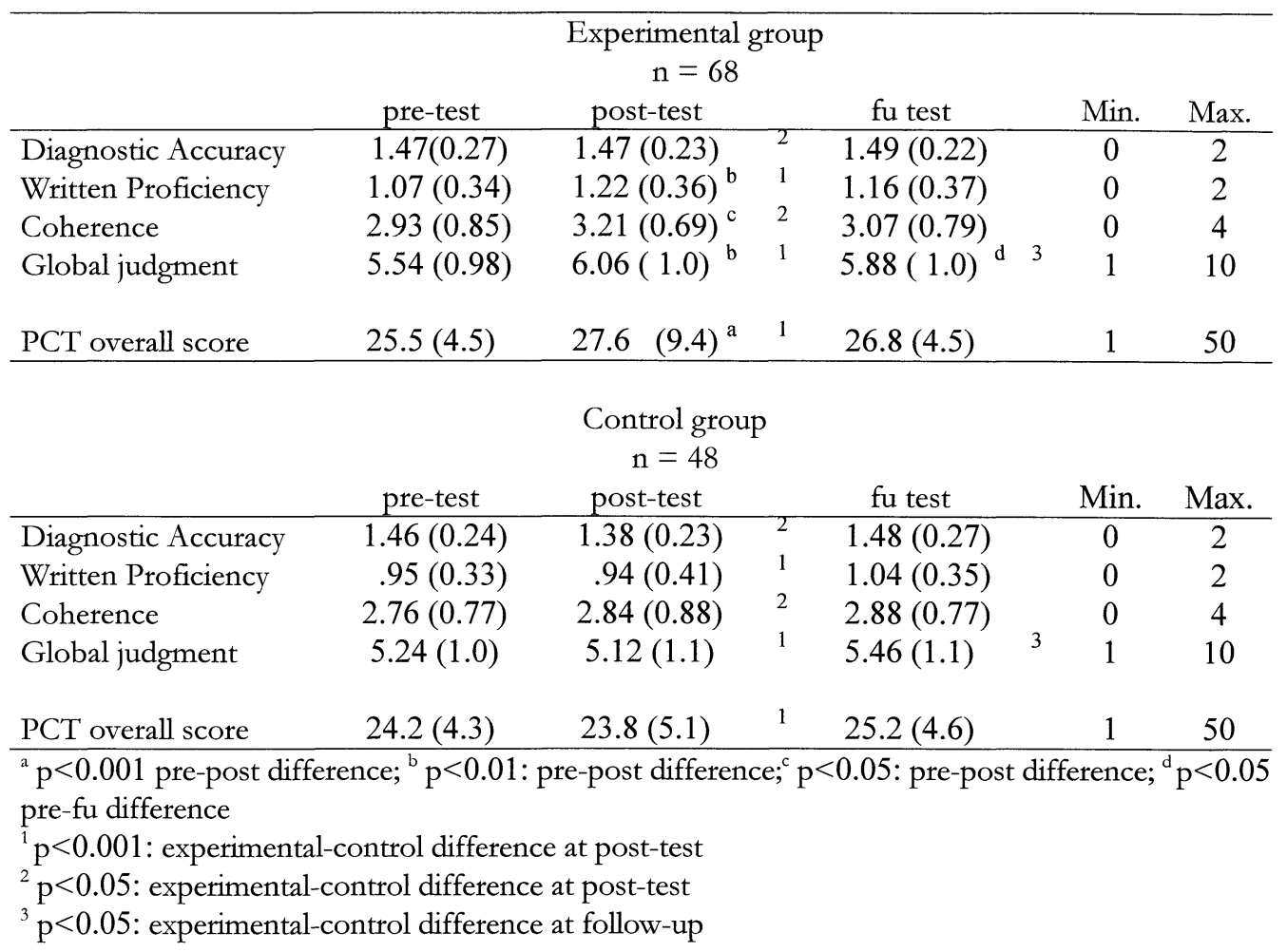

is only partly accepted; as the improvement immediately after the workshop has disappeared at follow-up.

In our second hypothesis we stated that diagnostic accuracy of the situations depicted in written cases would improve after participation in EDHEP. Although EDHEP participants performed better at post-test than the control subjects, no changes over measurements could be established. Diagnostic accuracy of the (emotional) state of relatives depicted in the written cases did not improve after participation. We need to reject hypothesis 2 . However, it is possible that a ceiling effect applies and interpretation of the results must be done with caution; the same cases were used at all three measurements. There was no difference between the pre-test scores of the experimental group and the post-test scores of the control group, apparently there was no learning effect due to exposure of the paper cases in the control group. The written proficiency in communication skills of EDHEP participants improved after attending the workshop; they showed superior cognitive use of communication skills compared to the control subjects. Hypothesis 3 will only partly be accepted as the effect was temporarily and not sustained at followup. 
Increases in the scores on coherence between diagnostic accuracy and the cognitive use of communication skills would be evidence of increased insight in 'knowing how to act'. Attending the EDHEP workshop indeed leads to increases in this area; compared to the control group the EDHEP-participants showed more evidence of linking the interpretation of the (mental) state of relatives depicted in the written cases with the cognitive use of effective communication skills than those who did not participate. Hypothesis 4 is also partly accepted: these effects were only temporarily.

General impressions about the way the written cases were 'solved', were given in a global judgment. A sustained effect of participation in the EDHEP workshop could be established. Only for the global judgment the effect of EDHEP is apparent.

All effects were irrespective of experience in critical care, with bereaved families or in requesting donation; neither had the perceived difficulty of requesting organ donation any influence on the scores in the three measurements. Comparisons between professions were not made as the limited numbers of doctors did not allow further analysis.

The loss of proficiency in actual performance of skills over time is a well recognized problem in communication skills training; regular booster sessions are necessary to remain skilled. In our study into the effects of EDHEP on actual performance in communication skills in this domain similar results were found for the doctors. ${ }^{28}$ The subjects in the current study, of which the majority were nurses, had substantial experience in the domain of breaking news of death and in dealing with bereaved families; this specific experience may have facilitated diagnostic accuracy. The results show that on a cognitive level professionals benefit from EDHEP and that also for cognitive proficiency in communication skills it is necessary to have booster sessions to maintain skilled performance. The opportunities to practice communication skills in the EDHEP workshop were limited; EDHEP is not a training. It is therefore remarkable that improvement on actual cognitive performance was already demonstrable after the workshop.

Further study should be aimed at determining the complex relationship between the cognitive use of communication skills and actual performance and the intermediate role diagnostic accuracy plays. 


\section{References}

1. Garrison RN, Bentley FR, Raque GH, Polk HC, Jr., Sladek LC, Evanisko MJ, et al. There is an answer to the shortage of organ donors. Surg Gynecol Obstet 1991;173(5):391-6.

2. Pelletier M. The organ donor family members' perception of stressful situations during the organ donation experience. J Adv Nurs 1992;17(1):90-7.

3. Siminoff L, Gordon N, Hewlet J, Arnold R. Factors influencing families' consent for donation of solid organs for transplantation. JAMA 2001;286(1):71-7.

4. Blok G, Kraan G, Dalen van J, Gurp M van, Vecht E van de, Wezel HBM van. Ervaringen van nabestaanden van donoren met de donatieprocedure; vergelijking tussen 1995 en 1998. [Experience of donor relatives with the donation procedure: comparison between 1995 and 1998]. Ned Tijdsch Geneesk 2000;144(14):663-7.

5. Siminoff L, Arnold R, Hewlett J. The process of organ donation and its effect on consent. Clin Transplant 2001;15(1):39-47.

6. Blok G. The impact of changes in practice in organ procurement on the satisfaction of donor relatives. Chapter 8 of this thesis, submitted.

7. Siminoff LA, Arnold RM, Caplan AL. Healthcare professional attitudes toward donation: effect on practice and procurement. J Trauma Inj Infec Crit Care 1995;39:553-9.

8. Girgis A, Sanson Fisher RW. Breaking bad news: consensus guidelines for medical practitioners. J Clin Oncol 1995;13(9):2449-56.

9. Randhawa G. Enhancing the health professional's role in requesting transplant organs. British Journal of Nursing 1997;6(8):429-434.

10. Randhawa G. Coping with grieving relatives and making a request for organs: principles for staff training. Med Teach 1998;20(3):247-9.

11. Fallowfield L, Jenkins V, Beveridge H. Truth may hurt but deceit hurts more: communication in palliative care. Palliat Med 2002:16(4) 297-303.

12. Sque M, Payne S, Vlachonikolis I. Cadaveric donortransplantation: nurses' attitudes, knowledge and behaviour. Soc Sci Med 2000;50(4):541-52.

13. Novack DH, Suchman AL, Clark W, Epstein RM, Najberg E, Kaplan C. Calibrating the physician. Personal awareness and effective patient care. Working Group on Promoting Physician Personal Awareness, American Academy on Physician and Patient. JAMA 1997;278(6):502-9.

14. Maguire P, Booth K, Elliott C, Jones B. Helping health professionals involved in cancer care acquire key interviewing skills-the impact of workshops. Eur J Cancer 1996;32a(9):1486-9.

15. Vleuten van der CPM. The Assessment of Professional Competence. Developments, Research and Practical Implications. Adv Health Sci Educ 1996;1:41-67.

16. Sanson-Fisher R, Cockburn J. Effective teaching of communication skills for medical practice: selecting an appropriate clinical context. Med Educ 1997;31(1):52-7.

17. Fallowfield L, Jenkins V. Effective communication skills are the key to good cancer care. Eur J Cancer 1999;35(11):1592-7. 
18. Dalen van J, Bartholomeus P, Lulofs R, van Thiel J, Rethans JJ, Scherpbier AJJA, van der Vleuten CPM. Teaching and assessing communication skills in Maastricht: the first twenty years. Med Teach 2001;23(3):245-251.

19. Fallowfield L, Jenkins V, Farewell V, Saul J, Duffy A, Eves R. Efficacy of a Cancer Research UK communication skills training model for oncologists: a randomised controlled trial. Lancet 2002;359(February 23):650-6.

20. Kurtz S, Silverman J, Draper J. Teaching and Learning Communication Skills in Medicine. Abington: Radcliffe Medical Press Ltd., 1998.

21. Jager K, Ryan M, Dalen van J, Blok GA, Wijnen RMH. European Donor Hospital Education Programme. The grief response and donation request. Moderators manual. Leiden: Eurotransplant International Foundation/Sandoz Pharma Ltd., 1991.

22. Blok GA, Jager K, Dalen van J. European Donor Hospital Education Programme. The grief response and donation request. Participants Manual. Leiden: Eurotransplant International Foundation/Sandoz Pharma Ltd., 1991.

23. Blok G, van Dalen J, Jager K, Ryan M, Wijnen R, Wight C, et al. The European Donor Hospital Education Programme (EDHEP): addressing the training needs of doctors and nurses who break bad news, care for the bereaved, and request donation. Transpl Int 1999;2(3):161-7.

24. Patel V, Arocha J, Kaufman D. Expertise and tacit knowledge in medicine. In: Sternberg R, Horvath J, editors. Tacit Knowledge in Professional Practice: Researcher and Practitioner Perspectives. MahwahNJ: Lawrence Erlbaum, 1999:75-99.

25. Vye N, Delclos V, Burns M, Bransford J. The psychology of human thought. In: Sternberg R, Smith E, editors. Teaching thinking and problem solving: illustrations and issues. Cambridge: Cambridge University Press, 1990:337-362.

26. Schön D. Educating the reflective practitioner. San Francisco: Jossy-Bass Inc. Publishers, 1991.

27. Blok GA, Morton J, Morley M, Kerckhoffs CMAM, Vleuten van der CPM, Kootstra G. Requesting organ and tissue donation: the case of self-efficacy. Effects of the European Donor Hospital Education Programme (EDHEP). Accepted for publication Adv Health Sci Educ.

28. Morton J, Blok GA, Reid C, van-Dalen J, Morley M. The European Donor Hospital Education Programme (EDHEP): enhancing communication skills with bereaved relatives. Anaesth Intensive Care 2000;28(2):184-90.

29. Cook TD, Campbell DT. Quasi-experimentation: Design and analysis issues for field settings. Chicago: Rand-McNally, 1979.

30. Blok G, Ramsay G, van der Vleuten CPM. Two ways of measuring communication skills concerning breaking bad news and requesting donation compared: a validation study. Chapter 5 of this thesis, submitted. 


\section{7}

\section{Effects of an educational programme on teamwork in the intensive care ${ }^{1}$}

Teams in Intensive Care Units (ICU) are confronted daily with the physical and psychological stress of caring for critically ill patients and their families. They are regularly confronted with the death of a patient and on fewer occasions with a potential organ donor. A major reason for the shortage of donor organs is the refusal of relatives. There is evidence that the way the process is timed, the communication skills used and the attitudes of doctors and nurses involved, has a significant effect on the decision relatives make. It is also known that a donation procedure affects all intensive care staff working in the same unit, as continuity of care has to be guaranteed and many additional tasks have to be accomplished. However, teamwork and communication between nurses and doctors is often problematic, due to lack of collaboration or misunderstanding over and disagreement with roles and responsibilities. In this study the effects of The European Donor Hospital Education Programme (EDHEP) are described. The results indicate that, in comparison with units with low EDHEP participation rates, in Intensive Care Units with a high a EDHEP participation rate, subjects were significantly more satisfied about the teamwork relating to death and donation. In these units the subjects were more satisfied about the donation protocol; the donation request was made more often by more than one team member and they were more satisfied about debrief meetings after a request was made. EDHEP has significant effects on teamwork in intensive care, it adds to and it contributes to working in teams and team support.

\footnotetext{
${ }^{1}$ Submitted as: Blok, GA, Wezel, HBM van, Morley M, Morton J , Mansum van W, Vleuten van der CPM. Effects of an educational programme on teamwork in the intensive care.
} 


\section{Introduction}

Teams in Intensive Care Units (ICU's) are confronted daily with the physical and psychological stress of caring for critically ill patients, and their families. Intensive care staff is regularly confronted with the death of a patient and on fewer occasions with a potential organ donor. Worldwide, the gap between demand and supply of donor organs is widening. It is well known, that a major reason for the shortage of donor organs is the refusal of relatives. In the literature several reasons are given for variables that contribute to the relatives' refusal. First, research has shown that doctors and nurses find it difficult to deal with death and dying ${ }^{1-4}$ and that they hesitate in asking for donation. ${ }^{5-7}$ They may have fear of adding to the stress of the relatives or may feel that they are not well trained to make a donation request. ${ }^{8-10}$ Second, there is evidence that the way the process is timed, the communication skills used and the attitudes of doctors and nurses involved, have a significant effect on the decision relatives make. Refusal is positively related to hesitance and insecurity of the person who is making the donation request. ${ }^{11}$ This is not surprising as breaking news of death, specifically explaining brain stem death and approaching relatives for permission to donate are complex tasks. These demanding tasks require not only profound clinical and social knowledge, but also advanced skills to communicate information and understanding. When these tasks have to be performed it is very important that all professions involved work as a team.

Many factors contribute to the quality and effectiveness of and satisfaction out of teamwork in intensive care. ICU-teams face the challenge of having to work efficiently in a highly stressful critical care environment, while also being confronted with the complexities of interprofessional communication and collaboration. ${ }^{12,13}$ Research has shown that collaboration is not only important in improving healthcare outcomes, ${ }^{14}$ but also in improving the team's morale and satisfaction about teamwork by the collaborating professionals. ${ }^{15}$ Patel et al. ${ }^{16}$ indicate that doctors and nurses working in intensive care have different expertise and roles that are clearly and formally defined. Teamwork and communication between nurses and doctors is often problematic, due to lack of collaboration or misunderstanding and disagreement over roles and responsibilities. ${ }^{14,17-19}$ Added to this, Hawryluck et al. ${ }^{12}$ argue that the 'team' in the Intensive Care Unit (ICU) is not a stable entity. The pressures on the core team are considerable, and all members have to be flexible as the core team can vary in size, (in)stability and internal relationships. How individuals and a team as a whole deal with issues such as authority, educational demands, patient needs, knowledge requirements, the use of resources and time constraints is of major influence on the level of cohesion within the team and on the level of collaboration. ${ }^{12}$

A donation procedure is of relevance to all intensive care staff working in the same unit, as continuity of care, both for the (potential) donor as for his or her family, has to be guaranteed. Ineffective communication leads ultimately to a fall in 
the standards of care received by the patient and his/her family. It also prevents unnecessary stress due to lack of information on top of the stress already felt. "Obviously, the quality of care depends greatly on those providing it. The psychological state of the staff will, in part, determine how effective they are. This is particularly true of the intensive care unit .....". ${ }^{20}$ Working in intensive care is experienced as stressful by both nurses and doctors. ${ }^{17,21}$ Adequate levels of social support have shown to have a stress-reducing effect and are negatively associated with burn-out. ${ }^{22}$ According to Edwards et al. ${ }^{22 a}$ doctors have a poor record in giving mutual support and giving and receiving feedback aggravates this. He states: "Working in teams is also associated with being better able to cope with stress, but skills in team working are not universal in the profession"

Attitudes toward stress, hierarchy, teamwork and error in intensive care and aviation were studied by Sexton et al.. ${ }^{18}$ They report that problems in the intensive care included differing perceptions of teamwork among team members, related to status in the team: $77 \%$ of the doctors reported high levels of teamwork with nurses, whereas only $40 \%$ of the nurses reported high levels of teamwork with doctors. In intensive care, training of staff is usually aimed at the separate professions. "In aviation, training is aimed at the entire crew, recognising that safety and good performance is not just a function of the captain, but of the captain using all available resources". Sexton et al. ${ }^{18}$ conclude that many approaches to team training used in aviation are likely to be useful in medicine, but that their design and effect need to be fully validated to avoid haphazard approaches of limited utility. Cannon-Bowers et al. ${ }^{23}$ underscore this warning, pointing at the differences they see between the teams in intensive care and aviation. They state that in teams that are characterized by highly demanding tasks, such as in intensive care, "members must have accurate knowledge about one another (e.g. preferences, task related competence, strengths weaknesses, team-mate characteristics). This knowledge is a basis of expectation regarding what other team members are likely to do in a given situation. In teams with high turnover (e.g., aircrews) but in which members must perform a specific task, it may be more important to possess knowledge regarding the task, problem and an understanding of the task-specific roles".

It can be argued that in intensive care teams, accurate knowledge about the team member with whom one is collaborating in requesting donation is important. Relatives should not be victims of unexpected personal conflict or misunderstanding within the team they are communicating with. On the other hand, it is important for members of this team to have profound knowledge of the domain and an understanding of the task at hand and how best to accomplish it. This enhances teamwork and enables team members to take complementary roles, which is highly valued by relatives. ${ }^{24}$

An effective training programme in the area of donation aims not only at knowledge of transplantation and donation, but also at the difficulties doctors and 
nurses experience in communicating with bereaved and in working as a team. Such a programme is likely to be more effective, when it is designed to match the typical working circumstances of the participants. ${ }^{25}$ Additionally, the results from research in the field of medical expertise are informative for the design of training programmes. In general they indicate that cognitions about the communication process are best learned when training of these cognitions is integrated with training of communications skills in authentic situations. ${ }^{26,27}$

The European Donor Hospital Education Programme (EDHEP) workshop was developed in order to improve the competence of intensive care staff in breaking news of death and requesting donation. It is a one-day interactive inter-professional workshop for intensive care doctors and nurses, designed to meet the training needs of intensive care staff. ${ }^{28} \mathrm{EDHEP}$ is hosted by a transplant coordinator and conducted with small mixed groups, preferably a maximum of eight doctors and eight nurses, working in critical care. The group should consist of doctors and nurses from different hospitals and different units of hospitals in order to neutralise any particular local difficulties, and to encourage exchange of experiences. During the workshop participants have the opportunity to reflect on their knowledge of, and personal and professional attitudes towards loss, bereavement and donation and how to collaborate when approaching relatives. The use of simulated relatives in two role plays enhances the authenticity of the learning situation. Breaking bad news and requesting donation should always be made in planned interviews; ideally by a team of a doctor and a nurse. Therefore, prior to the role plays the doctor-nurse pair is provided with written instructions to prepare the consultation and to make a division of tasks. The participants who do not practice in the role plays are given observation assignments to guide the feedback after the role play, of which one is focused at the collaboration between the doctor and the nurse. The workshop is concluded with an overview of the issues dealt with and guidelines for the collaboration with the transplant coordinator. EDHEP explicitly identified the necessity of doctors and nurses supporting each other when communicating with relatives. Both professions need to be competent in communicating while recognizing that they may undertake complementary roles at different times. Programme evaluations are very positive. Participants recognized the issues addressed and indicated that the barrier for requesting donation had been reduced. ${ }^{29}$ Participation in EDHEP leads to temporary increases in both communication skills ${ }^{30}$ and cognitive skills related to communication as well as to sustained increases in self-efficacy. ${ }^{31}$ These skills and cognitive variables are interrelated parts of professional competence. Improved competence can only be made effective in supportive environments. Although EDHEP is not specifically aimed at improving teamwork in ICU's in general, effects are expected on team skills in dealing with relatives. 


\section{Research questions}

The general aim of the current study was to measure the effect of EDHEP on teamwork in intensive care concerning death and donation. Based on the expected effect of the issues dealt with in EDHEP and results from research described above, seven hypotheses have been formulated:

1. In EDHEP specific attention is paid to the team approach in dealing with relatives concerning organ donation. The approach taken in the programme was positively evaluated by the participants. It was expected that this approach would therefore be implemented in practice and that this in turn would lead to an increase of the overall satisfaction about teamwork concerning organ donation (hypothesis 1).

2. Team preparation of consultations with the relatives about death and organ donation was specifically addressed in EDHEP as this is highly valued by relatives. EDHEP participants positively evaluated this aspect of the workshop. It was expected that the frequency of team meetings to prepare consultations with relatives concerning the death of their family member and the donation request would increase after participation (hypothesis $2 \mathrm{a}$ ). The general approach of the relatives and a clear division of tasks before approaching them was expected to be more explicit, reflected in a higher incidence of topics discussed concerning how to approach the relatives and in a higher incidence of the donation request made by more than one team member (hypothesis $2 b$ ).

3. In the EDHEP workshop participants are stimulated to reflect on their experiences and on their own reactions on relatives' emotions and questions, and to give each other feedback on performances. It was therefore expected that the frequency of debrief team meetings with mutual feedback after consultations with families would increase after participation (hypothesis 3).

4. EDHEP participants valued the feedback sessions after the role plays in the workshop. It was expected that this would result in more satisfaction about debrief meetings after consultations with relatives (hypothesis 4)

5. Although the focus in the EDHEP is not on the collaboration with the transplant coordinator, learning about this collaboration can take place, as transplant coordinators, who introduce themselves and clarify their role and responsibilities, host the workshops. Moreover, they are available for questions throughout the workshop and at the closure of the workshop the characteristics of this collaboration are specifically addressed. It was expected that in the units in which the majority of staff has participated in EDHEP, staff would be more knowledgeable on the donation protocol used, reflected in more satisfaction rates about the donation protocol (hypothesis $5 \mathrm{a}$ ). It was also expected these subjects would be more satisfied about the collaboration with the transplant coordinator, as they would know better what to expect in terms of procedure, tasks and responsibilities (hypothesis $5 \mathrm{~b}$ ). 
6. Adequate levels of social support are important in the prevention of stress. In the EDHEP workshop it is emphasized that supporting each other in demanding situations is needed, to ensure that good quality care is maintained. When team members feel free to express themselves and when mutual support is given, the collaborative efforts of the team may increase. It was not expected that participation in EDHEP would have an effect on the levels of practical support, but it was expected that it would influence levels of emotional support, these being higher after participation (hypothesis 6).

7. EDHEP is primarily aimed at helping participants be more effective in requesting donation, breaking bad news and supporting bereaved families. As the requirement was that participants per workshop should originate from different units or from different hospitals to enhance sharing of experiences, possibilities to have an impact on the ICU teamwork in general would be limited. It was expected that team contribution of EDHEP would be highest with respect to teamwork in breaking bad news, requesting organ donation and supporting bereaved relatives, and limited with respect to teamwork in general and team support in general (hypothesis 7)

A cross-sectional national survey with two contrasting groups was carried out.

\section{Method}

Subjects

The subjects in the study were doctors and nurses from intensive care units of 24 Dutch hospitals, which were taken from a nationwide inventory of ICU's. An inventory was made of the percentages of staff of all Dutch ICU's, which had attended EDHEP workshops. Two contrasting groups were made, group A and B. The twelve units that had EDHEP participation rates of $60 \%$ or higher (including most doctors) made up group A. Group B consisted of twelve units with participation rates of $15 \%$ or lower (with no or few doctors having participated). The units were matched for type of hospital, number of ICU beds and number of staff. The total number of subjects in the study was 408, of which 200 were in group A and 208 in group B. In both groups about three quarters of the total number of subjects were nurses $(75 \%$ in group $A ; 72 \%$ in group B). Just over half of the total number in each group was male (57\% in group A and $54 \%$ in group B). The mean age in group A was 36.4 years (SD6.9) and in group B, 37.8 years (SD: 7.4). The mean number of years they worked in the unit at the time of the measurement was 9.6 years (SD: 6.3) in group A and 10.0 years (SD: 6.4) in group $\mathrm{B}$. The groups can be considered comparable regarding these background variables.

Instrument

In the development of the questionnaire the topics resulting from the studies described above were incorporated. Also, the sequence of events taking place when 
a patient is admitted to ICU and turns out to be a potential donor ${ }^{32}$ is reflected in the questionnaire. Five phases are focused on: (preparation of) announcement of death, debrief of the consultation with the relatives, (preparation of the donation request, debrief of the consultation with the relatives, (preparation of) the donation procedure and (collaboration with the transplant coordinator in) the donation procedure (see Figure 1).

\section{PHASES IN THE DONATION PROCESS}

\section{Patient care}

Team work

1. Patient admitted in ICU

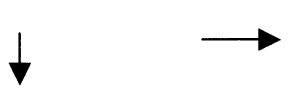

Team meeting:

- medical \& nursing care

- division of tasks

2. Critical medical condition
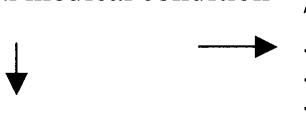

Team meeting:

- discuss procedure

- medical \& nursing care

- division of tasks
Family care

$\longrightarrow \quad$ Meet family

Explain medical condition

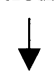

3. Diagnosis of brain stem death (potential donor)

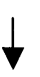

\section{(T)}

Team mee

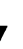

Preparating: I

tion bad news consultation

- formation of doctor-nurse team

- division of tasks

- medical \& nursing care

- notify transplant-coordinator (TC)

4. Body kept on ventilator consultation
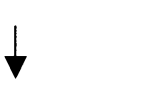

5. Donor maintenance

6. Retrieval operation

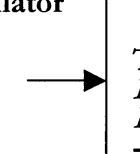

$$
\text { T }
$$

Team meeting: II /III

Debrief of bad news consultation

Preparation of donation request

- formation of doctor-nurse team

- division of tasks

- medical \& nursing care

Team meeting: IV

Debrief of donation request

- further policy

- division of tasks

- call in transplant-coordinator

- medical \& nursing care

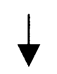

Donation procedure V

Collaboration with TC

\section{$\longrightarrow \quad \begin{aligned} & \text { Keep family } \\ & \text { informed }\end{aligned}$ \\ $\longrightarrow \quad \begin{aligned} & \text { Keep famil } \\ & \text { informed }\end{aligned}$}

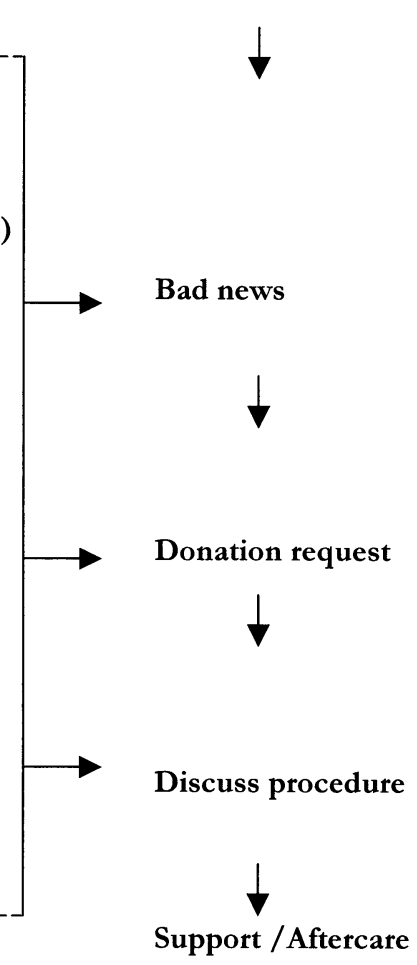

Figure 1: Phases in the process when a patient dies and a donation procedure takes place. The team activities in the box were the focus of the study. Top and bottom lines of the box are permeable as what happens before, affects team efforts within the box and team efforts within the box affect the collaboration with the retrieval team. 
The topics addressed were: a) teamwork relating to the death of a patient and communication with the relatives, b) teamwork relating to requesting donation, $\mathrm{c}$ ) teamwork relating to the donation procedure, e.g. the collaboration with the transplant coordinator, d) practical and emotional support, e) training received. The questionnaire consisted of 40 questions. The first section of the questionnaire consisted of items detailing biographical information, position and experience of the subjects. The remainder of the questionnaire was ordered according to the chronological order of events as depicted in Figure 1.

With respect to teamwork relating the announcement of death and requesting donation, questions were asked about level of teamwork, frequency and contents of, and satisfaction about team meetings (preparatory meetings as well as debriefs). With respect to the donation procedure questions were asked about the donation protocol, impact on the daily workload and the satisfaction about the collaboration with the transplant coordinator. With respect to practical and emotional support subjects were asked to indicate how much of each type of support they received from colleague doctors and nurses and from superiors. In the section about training questions were asked about the type of training (team or individual) and the contents of training programmes attended by the subjects. The last question in this section asked for the contribution of EDHEP to daily practice.

The questions about frequency had five answering alternatives: 'never', 'seldom', 'sometimes', 'often', and 'always'. An example of such a question is: "When a patient is dying, do you and your colleagues talk over how you might care for the family?". Certain questions had the answering alternatives 'yes', 'no' and 'uncertain', e.g. "Are you aware of a written protocol in your unit for dealing with the donation procedure?". In the questions asking for a satisfaction rating, 7-point scales were used $(1=$ very dissatisfied; $7=$ very satisfied $)$, e.g. "How satisfied are you with these discussions?". After each satisfaction-rating an open-ended question asked subjects to indicate the reason(s) for their level of (dis)satisfaction. The questions dealing with the contents of the team meetings were open-ended and asked the subjects to write down the topics discussed, e.g. "What do you typically discuss?" The answering categories for the questions dealing with practical and emotional support were 'never', 'sometimes' and 'often'. The questionnaires were anonymous, in order to minimize socially desirable answers. In the validation process of the questionnaire several versions were constructed and commented upon by a forum of experts, before the final questionnaire was developed.

\section{Procedure}

In each hospital a member of staff was appointed to act as a contact person. This person distributed the questionnaires to the subjects and was responsible for collection of the completed questionnaires. The contact person returned the questionnaires to the researchers. One reminder was sent to all subjects. Of the 625 questionnaires that were distributed, the contact persons returned 408. This is a response rate of $65 \%$. 
Method of analysis

Means, frequencies and percentages were calculated for the background characteristics about experience of the subjects. Chi-Square was calculated to check for any differences between these characteristics.

Frequencies and percentages were calculated for all ordinal data resulting from the questions about frequencies of preparatory and debrief meetings. As the frequencies were more informative for our purposes, for each of these questions Kruskal-Wallis Chi-Square was calculated to establish any differences between these data, taking the condition (group A or B) as the independent variable.

For all separate satisfaction scores means were calculated. A total mean satisfaction score was calculated, reflecting the mean of all separate satisfaction scores. Student T-test for independent samples was carried out to establish any differences between the satisfaction scores, where the condition (group A or B) was the independent variable.

The answers to the open-ended questions concerning issues discussed in team meetings were quantified using an answer key, agreed upon by a panel of experts, which contained rating categories for each question. Two research-assistants rated the answers blindly after having been trained in using the answer key. Per question the percentage of agreement was calculated; these ranged from $70 \%$ to $98 \%$. The categories were mutually exclusive; it was therefore not possible to calculate means. An expert allocated the undecided answers to categories. Frequencies and percentages were calculated for the categories per question. Further analysis was not carried out as the frequency of issues mentioned does not coincide with the number of subjects; some subjects did not answer these questions, others mentioned more than one issue.

All calculations were made with SPSS 10.1 for Windows. Effects were considered significant when the p-value was less then 0.05 .

\section{Results}

In Table 1 the data for the background characteristic concerning experience are presented. The subjects of group A have significantly more experience with families $(p<0.05)$, and more subjects of group $A$ were present when death is announced or when a donation request is made $(\mathrm{p}<0.01$ and $\mathrm{p}<0.05)$ compared with the subjects of group B. Subjects in both groups do not have much experience in either breaking bad news or requesting donation. Satisfaction about the teamwork relating to death and donation (hypothesis 1)

The satisfaction about all team experiences concerning the death of a patient and bad news encounters with families did not differ between conditions, neither for those who actually told the family about the death of their relation nor for those who were present when death was announced. The satisfaction about all team 
Table 1. Experience with bereaved relatives, breaking bad news and requesting donation.

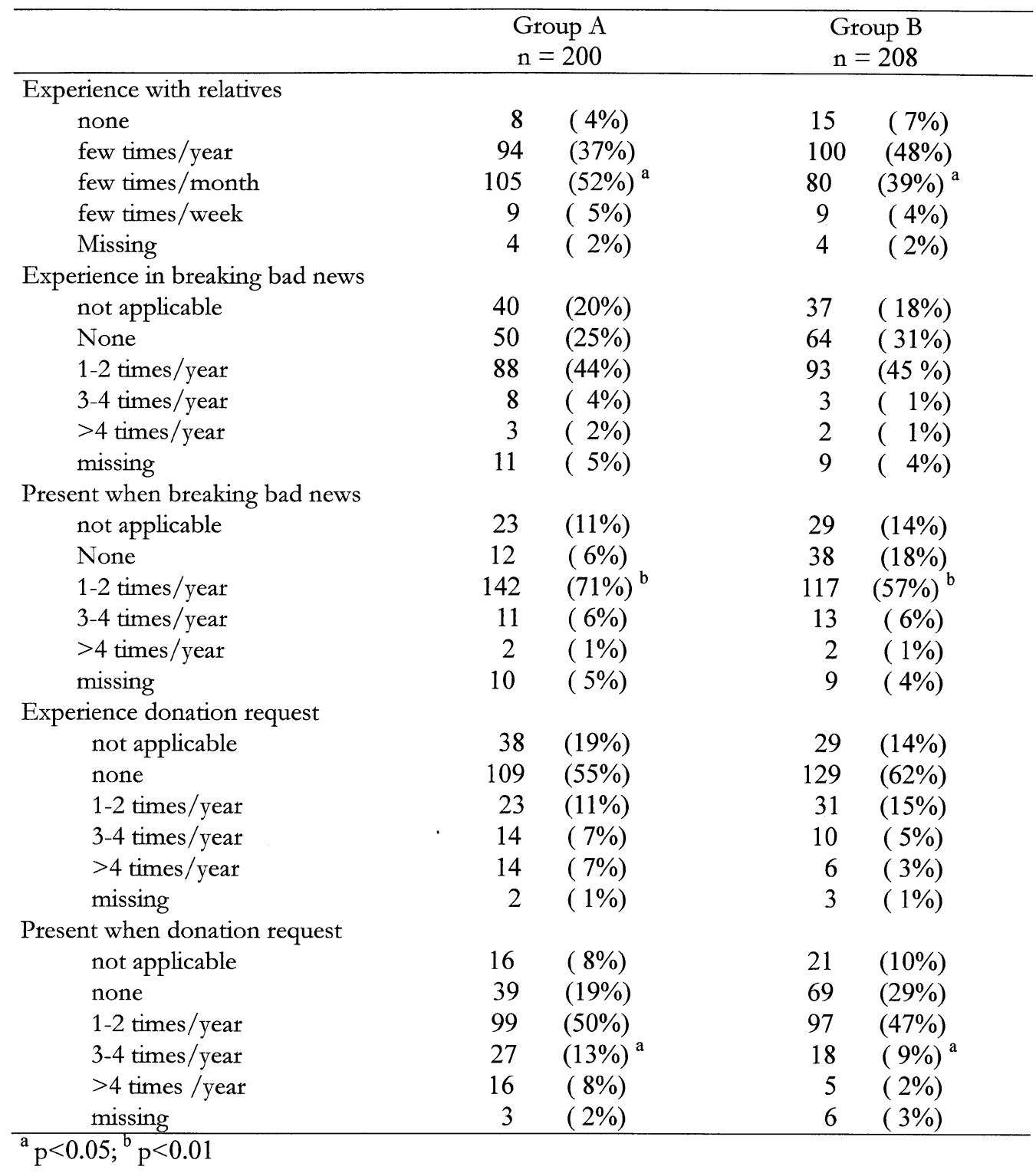

experiences in which organ donation was discussed and families were approached was significantly higher in group A compared with group B, 5.5 (sd: 1.1) and 5.2 (sd: 1.2$)$ respectively $(p<0.05)$. For those who actually made donation requests the satisfaction score was 5.9 (sd: 0.85) in group A and 5.4 (sd: 1.1) in group B; this was also a significant difference $(\mathrm{p}<0.05)$. There were no differences in satisfaction scores between conditions for those who were present at a donation request. 


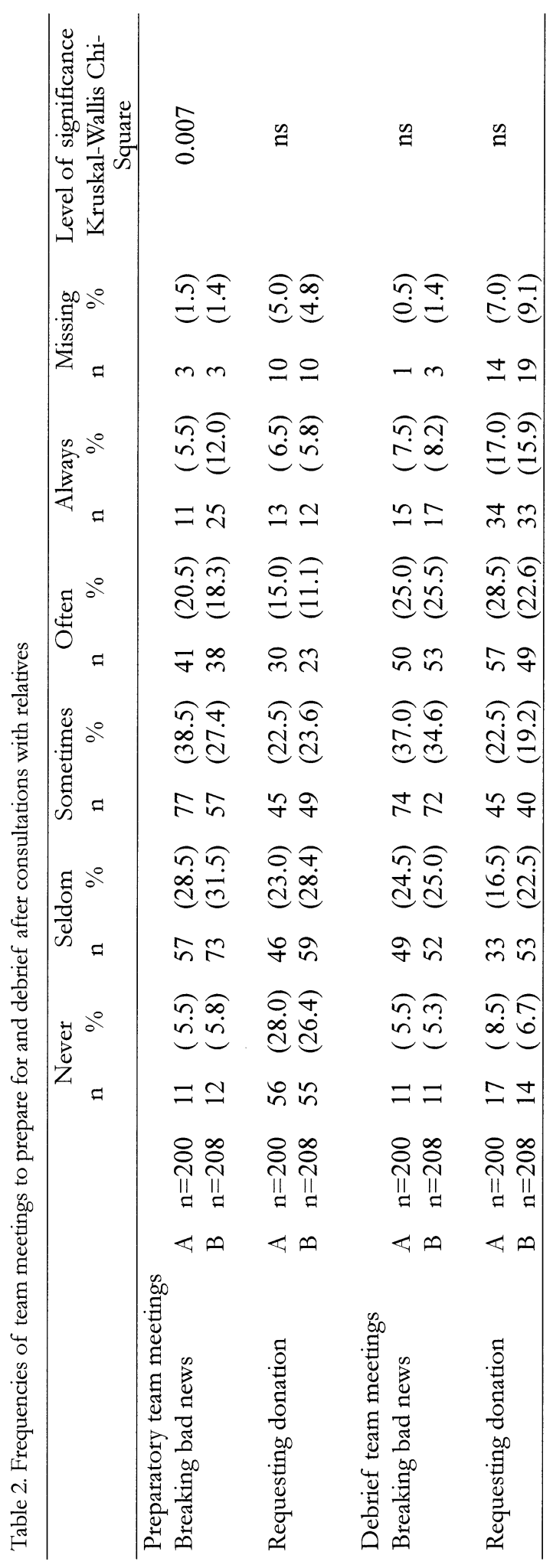


The overall satisfaction score for group A was 5.6 (sd: 0.77) and for group B 5.4 (sd: 0.94). This was a significant difference $(\mathrm{p}<0.05)$.

Frequency of preparatory and debrief team meetings and issues discussed (hypothesis 2a)

The teams of the intensive care units of group A met more often than the teams of group B to discuss how to approach the family when a patient had died (Kruskal-Wallis; $\mathrm{p}<0.01$ ). There was no difference in the frequency of preparatory meetings to discuss how to approach the family about organ donation (see Table 2).

In both conditions the frequency of debrief team meetings after the family was told about the death of a patients is equal. In both conditions about $70 \%$ of the subjects indicate they have these kind of meetings, although this is not common practice, as in more than half of these cases the subjects indicated that they only sometimes meet. Concerning the frequency of debrief team meetings after a donation request is made, in group A $68 \%$ and in group B 59\% of the subjects indicate they have these meetings. This as also not common practice, as in about a third of these cases the subjects indicated they have these kind of meetings sometimes.

Issues discussed in preparatory team meetings (hypotheses $2 \mathrm{~b}$ )

In preparing the bad news consultations the focus was on discussing issues dealing with the patient's family (reaction of family and care of the family); (see table 3).

In preparing the donation request, the exchange of general information about the case (including details about the family) and issues dealing with the strategy to approach the family were equally often discussed (reaction of family and care of the family) in both groups. Subjects in both conditions were equally satisfied with the quality of these preparatory team meetings. In both conditions, of those who indicated they never or seldom had these team meetings; more than half of them indicated they would find it useful to have them.

Breaking news of death and requesting donation as a team (hypothesis $2 \mathrm{~b}$ continued)

News of death is equally often discussed with the family by more than one team member in both groups. When a division of tasks is made, there is no difference between the groups about the degree to which they feel they are being taken seriously by their colleagues. In both groups dividing tasks was felt as useful.

With respect to the donation request, the subjects in group $A$ indicated that organ donation was discussed with the family in $58 \%$ of the cases by more than one team member. In group B this is the case for $34 \%$ of the subjects. This was a significant difference $(\mathrm{p}<0.01)$.

A majority of the subjects in group A $(53 \%)$ indicated that they made a division of tasks before consulting the family about organ donation; in group B this was less than half of the subjects $(45 \%)$. There is no difference between the conditions 
about the degree they feel they are being taken seriously by their colleagues in these preparatory meetings. In both conditions subjects found dividing tasks equally useful.

Issues discussed and satisfaction about debrief team meetings (hypotheses 3 and 4) The issues discussed in the debrief team meetings are presented in table 3 . There are no differences between the two conditions in the kind of issues that are discussed. In both samples the exchange of information in general, and information about the reaction of the families make up the majority of issues discussed.

Table 3. Items discussed in the preparatory and debrief team meetings before and after consulting with the relatives (NB Mentioned by those who indicated they met sometimes, often or always. The figures indicate the frequencies of the issues mentioned ${ }^{1}$ ) and mean satisfaction scores on preparatory and debrief meetings (standard deviation between brackets).

\begin{tabular}{|c|c|c|c|c|c|c|c|c|}
\hline & \multicolumn{4}{|c|}{$\begin{array}{c}\text { Preparation Breaking Bad } \\
\text { News }\end{array}$} & \multicolumn{4}{|c|}{ Preparation Donation Request } \\
\hline & \multicolumn{2}{|c|}{$A(n=127)$} & \multicolumn{2}{|c|}{$\mathrm{B}(\mathrm{n}=119)$} & \multicolumn{2}{|c|}{$A(n=84)$} & \multicolumn{2}{|c|}{$B(n=76)$} \\
\hline & Freq & $\%$ & Freq & $\%$ & Freq & $\%$ & Freq & $\%$ \\
\hline Division of tasks & 46 & $(15.0)$ & 47 & $(16.6)$ & 26 & $(16.5)$ & 33 & $(21.6)$ \\
\hline General information & 75 & $(24.5)$ & 82 & $(29.0)$ & 57 & $(36.1)$ & 38 & $(24.8)$ \\
\hline Reaction of family & 24 & $(7.8)$ & 13 & $(4.6)$ & 10 & $(6.3)$ & 13 & $(8.5)$ \\
\hline Technical (medical \& nursing) & 22 & $(7.2)$ & 23 & $(8.1)$ & 3 & $(1.9)$ & 4 & $(2.6)$ \\
\hline Care of family (medical/nursing) & 132 & $(43.1)$ & 109 & $(38.5)$ & 55 & $(34.8)$ & 58 & (37.9) \\
\hline Team support & 7 & $(2.3)$ & 9 & $(3.2)$ & 1 & $(0.1)$ & 2 & $(1.3)$ \\
\hline Earlier interaction with relatives & & & & & 6 & $(3.8)$ & 5 & $(3.3)$ \\
\hline Satisfaction about the me & 5.8 & sd & 5.7 & sd & 5.4 & sd & 5.2 & sd \\
\hline \multirow[t]{4}{*}{ (7-point scale) } & & 0.85 & & 1.1 & & 1.1 & & 1.2 \\
\hline & \multicolumn{4}{|c|}{$\begin{array}{c}\text { Debrief after Breaking Bad } \\
\text { News }\end{array}$} & \multicolumn{4}{|c|}{$\begin{array}{c}\text { Debrief after Donation } \\
\text { Request }\end{array}$} \\
\hline & \multicolumn{2}{|c|}{$A(n=136)$} & \multicolumn{2}{|c|}{$B(n=136)$} & \multicolumn{2}{|c|}{$A(n=136)$} & \multicolumn{2}{|c|}{$B(n=136)$} \\
\hline & Freq & $\%$ & Freq & $\%$ & Freq & $\%$ & Freq & $\%$ \\
\hline Division of tasks & 3 & $(1.1)$ & 5 & $(1.7)$ & 17 & $(6.3)$ & 1 & $(0.1)$ \\
\hline General information & 87 & $(32.8)$ & 93 & $(31.6)$ & 101 & $(37.5)$ & 82 & $(41.2)$ \\
\hline Reaction of family & 94 & $(35.5)$ & 88 & $(29.9)$ & 79 & $(29.4)$ & 64 & $(32.2)$ \\
\hline Technical (medical \& nursing) & - & & - & & 1 & $(0.1)$ & - & \\
\hline Care of family (medical/nursing) & 14 & $(5.3)$ & 14 & $(4.8)$ & 14 & $(5.2)$ & 8 & $(4.0)$ \\
\hline Team support & 24 & $(9.1)$ & 37 & $(12.6)$ & 12 & $(4.5)$ & 8 & $(4.0)$ \\
\hline Earlier interaction with relatives & 43 & $(16.2)$ & 57 & $(19.4)$ & 45 & $(16.7)$ & 36 & $(18.1)$ \\
\hline $\begin{array}{l}\text { Satisfaction about the meeting } \\
\text { ( } 7 \text {-point scale) }\end{array}$ & 5.5 & $\begin{array}{l}\mathrm{sd} \\
1.0\end{array}$ & 5.7 & $\begin{array}{c}\mathrm{sd} \\
0.86\end{array}$ & $5.6 *$ & $\begin{array}{c}\text { sd } \\
0.96\end{array}$ & $5.3 *$ & $\begin{array}{l}\mathrm{sd} \\
1.2\end{array}$ \\
\hline
\end{tabular}

${ }^{1}$ Not all subjects wrote down issues discussed; some subjects mentioned more than one issue $* \mathrm{p}<0.05$ 
Although the percentages are similar, the actual number of times issues are mentioned in Group A is higher than in group B in the debrief after the donation request. Subjects of group A were significantly more satisfied about the debrief meetings after donation request was made than subjects of group $B(p=0.05)$. The reasons given for being satisfied or dissatisfied with the debriefs are very similar in both samples. Team support and feedback is valued, as well as the effectiveness and quality of the debriefs. Subjects in group A mention the quality and effectiveness more often than subjects in group B. More than $50 \%$ of the subjects in both conditions, who indicated that they not have these meetings or only very seldom, indicated they would find them useful.

The donation protocol (hypothesis 5a)

In both conditions the great majority knew there was a protocol in their unit in which the donation procedure is described (A 95\%; B 87\%). The subjects in group A were significantly more satisfied about the practicality of this protocol and how it was implemented than those in group B, 5.9 (sd: 0.88) and 5.3 (sd: 1.4.) respectively $(\mathrm{p}<0.001)$. In both groups the majority was of the opinion that it was good to have the donation protocol; it clarifies roles and responsibilities. In all units donation procedures were perceived by the majority of subjects as adding considerably to the general workload. In group A the mean was 3.6 (sd: 1.1) and in group B 3.4 (sd: $1.2)$, on a 5 -point scale $(1=$ not at all; $5=$ very much).

The collaboration with the transplant coordinator (hypothesis $5 b$ )

The satisfaction about the collaboration with transplant coordinators was similar in both groups. Satisfaction scores about how transplant coordinators handled the logistics of the procedure was 6.1 (sd: 0.85) in group A and 5.9 (sd: 1.1) in group B; how they collaborated with the ICU-team was 6.0 (sd: 1.1) in group A and 6.0 (sd: 1.2) in group B. Subjects with experience in working with transplant coordinators valued the practical attitude of these professionals and the clarity in division of tasks. There were also subjects who indicated that task-divisions sometimes clashed regarding how to deal with the relatives.

Practical and emotional support (hypothesis 6)

There were no differences between the two conditions regarding practical and emotional support. The general pattern was similar for support surrounding death and donation.

About $20 \%$ of all subjects indicated that they never received practical support from their colleague doctors and 30\% never received this kind of support from their superiors. Only 3\% indicated they never got practical support from colleague nurses. More than two thirds of all subjects indicated they were often given practical support by their colleague nurses.

About $30 \%$ of all subjects indicated that they never received emotional support from their colleague doctors or superiors, only $5 \%$ indicated they never received 
emotional support from colleague nurses. Of all subjects $37-43 \%$ were often given emotional support by their colleague nurses.

These figures are almost similar, when the ratings of doctors and nurses are compared. There are a few exceptions. There are very few doctors $(10 \%)$ who indicated, that they never receive practical support from their colleague doctors; $25 \%$ of the doctors indicated that they never receive emotional support from colleague doctors. Nurses often give each other practical and emotional support. More nurses (67\%) than doctors (37\%) receive emotional support from their superiors.

Contribution of EDHEP to current practice (hypothesis 7)

In table 4 the evaluation of the contribution of EDHEP to current practice by those who actually participated is presented. Subjects indicate that EDHEP contributed most to requesting donation, breaking bad news and caring for bereaved relatives and least, though still to some extent to working as a team and how to support each other.

Table 4. Contribution of EDHEP to current practice rated on a 5-point-scale $(1=$ not at all, $2=$ a little, $3=$ rather, $4=$ much, $5=$ very much)

\begin{tabular}{lcccc}
\hline & \multicolumn{2}{c}{$\mathrm{A}(\mathrm{n}=66)$} & \multicolumn{2}{c}{$\mathrm{B}(\mathrm{n}=16)$} \\
\cline { 2 - 5 } & Mean & sd & Mean & sd \\
\hline Supporting bereaved families & 3.0 & 1.0 & 2.7 & 0.9 \\
Breaking bad news & 3.1 & 1.0 & 3.1 & 1.1 \\
Requesting donation & 3.4 & 1.0 & 3.0 & 1.2 \\
Staff support & 2.4 & 0.9 & 2.3 & 1.0 \\
Working as a team & 2.3 & 1.0 & 2.4 & 0.8 \\
Liasing with the TC & 2.6 & 1.2 & 2.6 & 1.1 \\
\hline
\end{tabular}

\section{Conclusions and discussion}

To a large extent the hypotheses formulated were accepted. The hypotheses will be discussed chronologically, followed by a discussion on the implications of the study.

1.Our first hypothesis, that participation in EDHEP would result in more satisfaction about teamwork relating to organ donation, is accepted. In the units were the majority of staff attended an EDHEP workshop (EDHEP-units) the staff is more satisfied with the collaboration when they take all aspects of donation procedures into account than the units with low participation rates (non-EDHEPunits). The satisfaction about the teamwork in this area contributed strongly to the overall satisfaction, of which the scores of the EDHEP units with a high participation rate were also significantly higher. There were no differences in the appreciation of the quality of the teamwork relating to dealing with dying patients and breaking bad news to their families. 
2a. In the EDHEP-units the frequency of meetings to prepare a bad news encounter was significantly higher than in the non-EDHEP-units, this was not the case for the preparation of consultations in which the donation request would be made. We expected there would be differences, the second hypothesis (2a) will therefore only be accepted for the frequency of preparing for the bad news encounters; it is rejected with respect to preparing the donation request encounter.

$2 \mathrm{~b}$. In the preparatory meetings the strategy to approach the family was most often mentioned in both conditions; in absolute numbers there was a higher incidence of mentioning this topic in the EDHEP-units. News of death is equally often discussed with the family by more than one team member in both types of units. In EDHEP-units, however, more that half of the donation requests was done by more than one team member, whereas in the non-EDHEP-units three quarters of these encounters were done individually. Division of tasks in preparing these meetings was more explicitly done in EDHEP-units; also in the EDHEPunits $58 \%$ of the staff made a division of tasks compared with $45 \%$ in the nonEDHEP units. Hypothesis $2 \mathrm{~b}$ stating that the team approach would be more explicit in EDHEP-units, will therefore be accepted.

3. The frequency of debrief meetings after a bad news encounter or a consultation in which the donation request was made was comparable in both conditions. Only 5 to $8 \%$ of the subjects mentioned that they never held these meetings. It was also not common practice to hold these debrief meetings. In both types of units these meetings were held more frequently after a donation request was made then after a bad news encounter. Team support was not a topic mentioned more often by the subjects in the EDHEP-units. In the debriefs after bad news encounters, team support was more often addressed than after donation request encounters; this was the case in both types of units. Hypothesis 3, stating there would be more frequent debriefs with mutual feedback in EDHEP-units will be rejected.

4. Subjects in the EDHEP-units were more satisfied about the debriefs after a donation request was made. As this was stated in hypothesis 4 , this will therefore be accepted.

5a. In all units the great majority of subjects was aware of the existence of a donation protocol. In the EDHEP-units satisfaction about the practicality and implementation of this protocol was significantly higher than in the non-EDHEPunits. Hypothesis 5a, which said that subjects in EDHEP units would be more satisfied, will thus be accepted.

5b. There were no differences between the two types of units with respect to satisfaction about the collaboration with the transplant coordinator. All subjects expressed that they valued the practical attitude of the transplant coordinator and that it was very helpful to have a clear division of tasks, especially because donation procedures add considerably to the workload in the units. There is presumably some difference of opinion about who should care for the relatives, as this was 
mentioned as a point of conflict. Hypothesis $5 \mathrm{~b}$ will therefore be rejected, subjects in both conditions valued the collaboration with the transplant coordinator equally.

6. The sixth hypothesis, stating that practical support would not differ between the two conditions and that emotional support would be given more often in EDHEP-units, will be rejected: both types of support are given in equal amounts in both types of units. In general nurses gave more support and received more support. Although it is in line with results from other studies, our results have to interpreted with care as the majority of subjects in the study were nurses. About a third of all intensive care staff in this study (122 individuals), especially the doctors, irrespective of condition, never received emotional (or social) support from their superiors.

7. According to those who actually participated in an EDHEP workshop, EDHEP contributed most to teamwork concerning requesting donation, breaking bad news and supporting bereaved relatives. This is what EDHEP is specifically aimed at. EDHEP contributed least, but still to some extent, to working as a team and staff support. This is also in line with the expectations expressed in hypothesis 7; EDHEP is not a team training and the focus is on the interaction with the relatives. Based on these results hypothesis 7 is accepted.

The specific aims of EDHEP concerning teamwork relating to death and donation are indeed reflected in the results. The finding that the frequency of meetings to prepare a bad news encounter was significantly higher than in the nonEDHEP units is an important result, as from research into the satisfaction of bereaved relatives it has become clear that the way the news of death is conveyed is of significant importance for the satisfaction about donation procedures; it is experienced as more significant than how a donation request was made. ${ }^{33}$

EDHEP results in a more explicit team approach when discussing the option of organ donation with relatives. Presumably approaching the relatives with more than one team member have been satisfying experiences. It is possible that this also contributed to the higher satisfaction about the debriefs after a donation request was made. A more structured preparation facilitates efficient debriefing. The implementation of a donation protocol may also have contributed to these experiences, as the different steps in the process are clearly outlined in this protocol. The fact that in EDHEP units more subjects had experience with being present when a request was made may have been a result of this policy. This in turn may have contributed to the greater experience in EDHEP units with bereaved families.

One explicit requirement of the set up of EDHEP was that participants should come from different units and different hospitals in order to prevent the interference with team or unit difficulties, it is not a programme that focused at teams, it is therefore remarkable that subjects indicate that the programme actually has an effect on working as a team and team support in general. It is however worrying that about third of all intensive care staff in this study, especially the 
doctors, indicate they never received emotional (or social) support from their superiors. It is known that this kind of support is very important for team morale and is crucial in creating a safe team environment in which there is no threat to expose one's vulnerabilities. A safe team environment facilitates open mutual feedback. The high percentage of staff reporting lack of emotional support in the sensitive areas of death and donation, and in general, indicate that it might be a good suggestion to train the team as a whole (including the superiors), to learn skills in giving constructive feedback and team support. This kind of training does not necessarily have to be tied to death and donation; it would be beneficial for intensive care work in general as well.

It is reassuring that EDHEP actually has an effect on most aspects of teamwork that are addressed in the workshop. The results indicate that it makes sense to educate intensive care staff on these issues. EDHEP is an awareness raising programme, strictly spoken it is not a training. Using the same ingredients built into a training programme would probably yield even more positive effects on the teamwork in daily practice in intensive care units. It can be expected this will have a positive effect on care delivered to patients and their families. Improved competence in teamwork in the area of death and donation will affect the conditions under which families are asked to consider organ donation. More competent intensive care staff will be more successful in reducing the rate of family refusal.

(C) Questionnaire for teamwork relating to death and donation for staff of Intensive Care Units: G.A. Blok \& J. van Dalen of the University of Maastricht in the Netherlands, and J.M. Morton, University of Liverpool \& J.P. Morley, Manchester Royal Infirmary, United Kingdom. 


\section{References}

1. Christaki K. A personal reflection on the issues surrounding the use of euphemisms following sudden death. Nurs Crit Care 1998:3(5) 249-52.

2. Maguire P. Breaking bad news. Eur J Surg Oncol 1998:24(3) 188-91.

3. Fallowfield L, Jenkins V, Beveridge H. Truth may hurt but deceit hurts more: communication in palliative care. Palliat Med 2002:16(4) 297-303.

4. Ptacek JT, Fries EA, Eberhardt TL, Ptacek JJ. Breaking bad news to patients: physicians' perceptions of the process. Support Care Cancer 1999;(3):113-20.

5. Randhawa G. Coping with grieving relatives and making a request for organs: principles for staff training. Med Teach 1998;20(3):247-9.

6. Franz H, Jong dW, Wolfe M, Nathan HM, Payne D, Reitsma W, et al. Explaining brain death; a critical feature of the donation process. J Transplant Coordination 1997;7:14-21.

7. Siminoff LA, Arnold RM, Caplan AL. Healthcare professional attitudes toward donation: effect on practice and procurement. J Trauma Inj Infec Crit Care 1995;39:553-9.

8. Wakeford RE, Stepney R. Obstacles to organ donation. Br J Surg 1989;76 May:435-9.

9. Stein A, Hope T, Baum JD. Organ transplantation: approaching the donor's family. BMJ 1995;310:1149-50.

10. Pearson IY, Zurynski Y. A survey of personal and professional attitudes of intensivists to organ donation and transplantation. Anaesth Intensive Care 1995;23(1):68-74.

11. Siminoff L, Gordon N, Hewlet J, Arnold R. Factors influencing Families' Consent for Donation of Solid Organs for transplantation. JAMA 2001;286(1):71-7.

12. Hawryluck LA, Espin S, Garwood KC, Evans CA, Lingard LA. Pulling Together and Pushing Apart: Tides of Tension in the ICU Team. Acad Med 2002;77(10):73-6.

13. Salas E, Burke C, Cannon-Bowers J. Teamwork: emerging principles. International Journal of Management Reviews 2000;2(4):339-356.

14. Baggs J, Ryan S, Phelps C, Richeson J, Johnson J. The association between interdisciplinary collaboration and patient outcomes. 1992 1992; Heart Lung(21):18-24.

15. Baggs J, Schmitt M. Nurses and resident physicians' perceptions of the process of collaboration in an MICU. Res Nurs Health 1997;20:71-80.

16. Patel V, Kaufman D, Magder S. The acquisition of medical expertise in complex dynamic environments. In: Ka E, editor. The road to expert performance: Empirical evidence from the arts and sciences, sports and games. Hillsdale NJ: Lawrence Erlbaum Associates, Inc., 1996:127-165.

17. Crickmore R. A review of stress in the intensive care unit. Intensive Care Nurs 1987;3(1):19-27.

18. Sexton JB, Thomas EJ, Helmreich RL. Error, stress, and teamwork in medicine and aviation: cross sectional surveys. BMJ 2000;320(7237):745-9.

19. Melia K-M. Ethical issues and the importance of consensus for the intensive care team. Soc Sci Med 2001;53(6):707-19.

20. Bishop V. Staff stress on intensive care units: this is the age of strain. Nursing Mirror 1981;153(6):18-19. 
21. Cronin Stubbs D, Rooks CA. The stress, social support, and burnout of critical care nurses: the results of research. Heart Lung 1985;14(1):31-9.

22. Kanner A, Kafry D, Pines A. Conspicuous in its absence: the lack of positive conditions as a source of stress. In: McConnell E, editor. Burnout in the nursing profession. St. Louis: CV Mosby Co, 1982:131.

23. Cannon-Bowers J, Tannenbaum S, Salas E, Volpe C. Defining team competencies and establishing team training requirements. In: Guzzo R, Salas E, editors. Team effectiveness and decision making in organisations. San Francisco CA: Jossey-Bass, 1995:333-380.

24. Wright B. Sudden death. London: Churchill Livingstone, 1991.

25. Sanson-Fisher R, Cockburn J. Effective teaching of communication skills for medical practice: selecting an appropriate clinical context. Med Educ 1997;31(1):52-7.

26. Brown J, Collins A, Duguid P. Situated cognition and the culture of learning. Educational Researcher 1989;18:32-42.

27. Regehr G, Norman G. Issues in cogntive Psychology: Implications for Professional Education. Acad Med 1996;71:988-1001.

28. Blok G, Dalen van J, Jager K, Ryan M, Wijnen RMH, Wight C, et al. The European Donor Hospital Education Programme (EDHEP): addressing the training needs of doctors and nurses who break bad news, care for the bereaved, and request donation. Transpl Int 1999;12:161-7.

29. Dalen van J, Blok GA, Morley M, Morton JB, Haase-Kromwijk B, Sells RA, et al. Participants' judgements of the European Donor Hospital Education Programme (EDHEP): an international comparison. Transpl Int 1999;12:182-7.

30. Morton J, Blok GA, Reid C, van-Dalen J, Morley M. The European Donor Hospital Education Programme (EDHEP): enhancing communication skills with bereaved relatives. Anaesth Intensive Care 2000;28(2):184-90.

31. Blok GA, Morton J, Morley M, Kerckhoffs CMAM, Vleuten van der CPM, Kootstra G. Requesting organ and tissue donation: the case of self-efficacy. Effects of the European Donor Hospital Education Programme (EDHEP). Accepted for publication Adv Health Sci Educ.

32. Kwaliteitsinstituut voor de Gezondheidszorg. Modelprotocol postmortale orgaan- en weefseldonatie. [Model protocol for post mortem organ and tissue donation] Utrecht: Kwaliteitsinstituut voor de Gezondheidszorg (CBO), 2001.

33. Blok GA. The impact of changes in practice in organ procurement on the satisfaction of donor relatives. Chapter 8 of this thesis, submitted. 


\section{The impact of changes in practice in organ procurement on the satisfaction of donor relatives ${ }^{1}$}

In the past decade several interventions have been undertaken to close the gap between demand and supply of donor organs. Family refusal is an important factor contributing to the shortage of donor organs. The importance of the quality of communication between staff and relatives has been underestimated. It is in the frontline of practice where decisions are made and behaviour of staff is critical. The current study, undertaken to explore if any changes had occurred in the behaviour of professionals involved in organ donation, took satisfaction ratings of relatives of donors in 1995, 1998 and 2001 as outcome measures. Our results show that relatives in 2001 are significantly more satisfied than those in 1995 and 1998 about staff behaviour. Changes all relate to specific interactions between key professionals and relatives. Results indicate that future interventions may be more effective if macro-oriented and regulatory policies are combined with competence-based educational programmes.

\footnotetext{
${ }^{1}$ Submitted as: Blok GA. The impact of changes in practice in organ procurement on the satisfaction of donor relatives.
} 


\section{Introduction}

The gap between the supply of donor organs and the demand has grown over the last decade. Many interventions were undertaken to increase the organ donor pool. Most interventions were aiming at three areas: 1) Improvement of the organization of organ procurement and donation procedures, more straightforward communication between the stakeholders and through the introduction of standard protocols in hospitals. 2) Interventions were devised to increase awareness among hospital staff and among the general public about the issue of organ and tissue donation through information campaigns. 3) Changes in legislation; either countries changed to an opt-out system (all citizens are donors unless indicated otherwise), e.g. in Spain and Belgium, or national donor registrations were set up within an optin system (citizens or their relatives can make a choice for the option of donation), e.g. in the Netherlands.* All of the above interventions fall into the category of 'regulatory policies'; they have not yielded an increase in the donor pool. The main conclusion of a study in the Netherlands, evaluating the effects of the change in legislation in 1998 and of the accompanying measures taken was that, although procedures in hospitals have improved and professional staff feel more secure with protocols, the number of donations has not increased; indeed Rosendal et al. ${ }^{1}$ point to a further decrease.

The question arises whether different variables should have been targeted as well or different policies should have been chosen. The authors of the evaluation study ${ }^{1}$ conclude that not sufficient attention was paid to the communication between hospital staff and relatives of potential donors, and that training hospital staff in relevant communication skills in this domain is essential and should be an obligatory part of their training.

The present article explores the effects of professionals' behaviour on the satisfaction of donor relatives. The study was carried out to establish if any changes had occurred in the interaction between the doctors, nurses and transplant coordinators and relatives in the past decade. Satisfaction of donor relatives with the treatment by the hospital staff throughout the whole donation process seemed an appropriate outcome measure. The results of three subsequent studies into the satisfaction of relatives with the donation process in 1995, 1998 and 2001, were combined for a cross-sectional longitudinal comparative study.

The main research question was whether satisfaction rates of donor relatives have changed over the years and to explore to which variables these changes can be

* The change in legislation since 1998 implies that all Dutch citizens, when they reach the age of 18 years, are asked to voluntarily register their last will concerning organ and tissue donation in a national Donor Register. Three options are possible: 'yes', 'no' or '(specific) relatives may decide'. It is possible to indicate which organs and/or tissues one wants to donate after death. When the law was implemented, all Dutch adults of 18 years and older were sent a registration form.

In case of a death the treating physician is obliged to consult the Donor Register and to announce a potential donor to the Dutch Transplant Foundation. 
attributed. For example, are there any differences in satisfaction rates about different groups of professionals; to what degree are certain themes related to satisfaction, e.g. the way brain stem death was explained, the timing of the donation request, the way relatives could say goodbye, or how relatives felt about the donation procedure.

\section{Background}

One of the main reasons for the lack of donor organs and tissues is the high refusal rate by relatives. ${ }^{2}$ Different studies have shown that relatives who refused to donate had a far less clear understanding of brain death than those who consented and that a good understanding of the death of their relation should be established before the issue of organ and tissue donation is raised. ${ }^{3-5}$ Relatives prefer professionals who show compassion, are knowledgeable on the topic and provide adequate support throughout the process. ${ }^{5-7}$ Conveying news of death, explaining brain death and discussing organ and tissue donation requires specific knowledge and (communication) skills of the doctors and nurses involved. Siminoff et al. ${ }^{5}$ found that when doctors and nurses were hesitant or showed doubts, relatives were more inclined to refuse. There is a significant relationship between self-confidence and consent for donation. Nurses who felt secure and comfortable got more consents than those who felt insecure and uncomfortable. ${ }^{8}$ The preparedness of doctors and nurses to cooperate with organ and tissue donation is related to a number of factors such as the attitudes towards organ and tissue donation and transplantation; knowledge about brain death, the donation procedure and transplantation medicine; and the self-efficacy relating to requesting. ${ }^{9-13}$ In general relatives are more satisfied about the donation procedure when there was enough opportunity to realize that their family member had died, before the donation request was made. Usually this was the case when the two issues were addressed in two separate consultations. ${ }^{14,15}$ Relatives often have many questions; it is important that medical and nursing staff take time to answer these questions and use understandable language without jargon. ${ }^{5}$ The sight of the dead person facilitates acceptation of the death. ${ }^{16}$ The family should therefore be offered the opportunity to say goodbye after the donor operation; according to Cleiren et al. ${ }^{6}$ this is often not the case instead. This introduction indicates that the interaction between relatives and the key staff is essential, and that the behaviour of doctors, nurses and transplant coordinators involved, is of crucial importance for the decision relatives make regarding organ and tissue donation. 


\section{Method}

\section{Procedure}

In 1991, 1995, 1998 and 2001 the Dutch Transplant Coordinators (part of the Dutch Transplant Foundation) organized one-day meetings for donor relatives. The goal of these meetings was to give information and to offer the possibility to exchange experiences. In all years the relatives were asked to complete a questionnaire concerning the donation process they were involved in.

The results from 1991 indicated that the care for the bereaved needed substantial improvement. ${ }^{14}$ As a result, some interventions were made, e.g. the introduction of a protocol for post mortem organ and tissue donation ${ }^{17}$ and the development of an educational programme for intensive care staff focusing on the communication with relatives, the European Donor Hospital Education Programme (EDHEP). ${ }^{18}$ The studies carried out in 1995, 1998 and 2001 are documented elsewhere. ${ }^{15,19-21} \mathrm{It}$ should be noted that between 1995 and 1998 preparations for the change in legislation were made, i.e. information campaigns for professionals as well as the general public and refinement of the hospital protocols. In 1998 the new law was implemented and a national Donor Register was established.

In this article comparisons of the results of 1995, 1998 and 2001 are made. Comparisons with the data of 1991 were not possible, because a different questionnaire was used.

\section{Subjects}

The subjects in the current study were a selected group: those who attended the one-day meetings. They belonged to samples of all donor relatives who granted permission for organ donation in a given period. In table 1 the background characteristics of the samples of relatives in 1995, 1998 and 2001 are shown. Of the total number of 400 donor families who donated in the period 1991-1995, 79 relatives $(20 \%)$ participated in the study. In 1998 the total number of donor families who donated in the period 1995-1998 was 579; 131 of them (23\%) participated in the study. In 2001 the total number of families who donated in the period 1998-2001 was 404; 184 relatives (46\%) participated in the study.

The cause of death in 1995 and 1998 in nearly half of the cases was a traffic accident and in one third of the cases a cerebral vascular accident (CVA). In 2001 CVA's made up $48 \%$ of the causes of death, whereas $26 \%$ of the deaths were due to traffic accidents. As CVA's usually happen at a later age, the mean age of the donors in 2001 was almost 10 years higher then in the other two groups $(\mathrm{p}<0.05)$. 
Table 1. Descriptives of the subjects that attended the meeting days for relatives of donors in 1995 and 1998.

\begin{tabular}{|c|c|c|c|c|c|c|}
\hline \multirow{3}{*}{$\begin{array}{l}\text { Men /women (\%) } \\
\text { Mean age in years (sd): }\end{array}$} & \multicolumn{2}{|c|}{$\begin{array}{c}1995 \\
\mathrm{n}=79\end{array}$} & \multicolumn{2}{|c|}{$\begin{array}{c}1998 \\
\mathrm{n}=131\end{array}$} & \multicolumn{2}{|c|}{$\begin{array}{c}2001 \\
\mathrm{n}=184\end{array}$} \\
\hline & \multicolumn{2}{|c|}{$20(25) / 59(75)$} & \multicolumn{2}{|c|}{$55(42) / 76(58)^{1}$} & \multicolumn{2}{|c|}{$83(45) / 101(55)$} \\
\hline & & & & & & \\
\hline Relatives & 45 & (12.4) & 46 & (11.4) & 51 & $(11.8)$ \\
\hline Deceased & 29 & $(15.6)$ & 31 & $(17.5)$ & 40 & $(17.5)^{2}$ \\
\hline \multicolumn{7}{|l|}{ Relation to deceased (\%) } \\
\hline Parent & 44 & (56) & 65 & $(50)$ & 72 & (36) \\
\hline Child & 8 & (10) & 9 & (7) & 12 & (6) \\
\hline Spouse & 15 & (19) & 33 & (25) & 82 & (45) \\
\hline Sibling & 11 & (14) & 17 & (13) & 15 & (8) \\
\hline Other & 1 & (1) & 7 & (5) & 8 & (4) \\
\hline \multicolumn{7}{|l|}{ Kind of donation (\%) } \\
\hline Organ donation & - & - & 79 & $(60)$ & 129 & (70) \\
\hline Organ and tissue donation & - & - & 48 & (37) & 55 & (30) \\
\hline Missing & - & - & 4 & (3) & - & - \\
\hline
\end{tabular}

There were significantly more women at the meeting day in $1995(\mathrm{p}<0.01)$. In 1995 and 1998 the majority of subjects were parents; in 2001 the majority of subjects were spouses. The samples in the studies carried out in 1995, 1998 and 2001 consisted of different participants; longitudinal within-group comparisons are therefore not possible.

\section{Instrument}

In the development of the questionnaire the results from the studies described above were critical. The topics addressed were: a) information and support of professionals throughout the process, b) clear explanation of brain stem death, c) donation request in a separate consultation, d) access to their relation, e) acceptable goodbyes, and specifically about $\mathrm{f}$ ) how they were treated by the separate medical and nursing staff and the transplant coordinator. The questionnaire consisted of 75 questions, the majority of which asked for the degree of satisfaction about the items stated in the questions. It started with a number of questions about demographic characteristics and a number of questions dealing with grief reactions and mood. The majority of questions concerned the interaction with professionals. The questions were ordered according to the chronological order of events in the hospital; the phases defined were: arrival in hospital, waiting time while the relative is under treatment in the intensive care unit (ICU), announcement of death, donation request (including the phase of deciding) and aftercare (see table 2). In every phase a number of specific questions relating to the phase were asked and two general questions concerning information and support by the staff. In all 
phases one or more questions were asked about the satisfaction. An example of a question is: "How satisfied are you about the way you were treated upon arrival in the hospital?" Each satisfaction judgment could be given on a 7-point scale $(1=$ very dissatisfied; $7=$ very satisfied). The last two questions of every section were open-ended, in the first question relatives could give additional information; the second asked them for suggestions for improvement of care. A separate section of the questionnaire dealt with feelings the relatives have with regard to the donation procedure.

In the validation process of the questionnaire several versions were constructed and commented upon by a forum of experts, before the final questionnaire was developed. In 1998, questions were added to the questionnaire about two new developments: organ donation after cardiac arrest (non-heart-beating donors) and contact with recipients of organs and tissues. In 2001 some of the questions, which were felt as too demanding for the relatives, were deleted. A question about the national donor register was added.

Method of analysis

Means, frequencies and percentages were calculated for all descriptive data, the data referring to aspects influencing the decision to consent and data about feelings related to the donation procedure. Non-parametric Chi-square was used to check for any differences in these data. For all satisfaction scores means were calculated. A total mean satisfaction score was calculated, reflecting the mean of all separate satisfaction scores. Any differences between groups were calculated using Student T-test for independent samples were carried out, where the year of attendance of the meeting was used as the independent variable and satisfaction ratings as the dependent variables. For the analyses of differences within groups (e.g. timing of goodbyes), analyses of variance (ANOVA's) were carried out. Tukey's Honest Significant Difference was calculated to establish any post-hoc differences within groups. In the latter analyses the answer categories (ordinal data) were used as the independent variables and the satisfaction ratings as the dependent variables. Regression analyses were applied to establish the amounts of explained variance of the total satisfaction. Correlation analysis was applied to establish the relationship between satisfaction ratings and feelings about the donation procedure.

\section{Results}

Overall satisfaction of the relatives

The overall satisfaction of the relatives was defined as the mean of all satisfaction ratings about the treatment by doctors, nurses, transplant-coordinators, morgue staff and the general practitioner during their stay in the hospital and afterwards (table 2). The overall satisfaction, measured on a 7-points scale was 5.3 (sd: 1.1) in 1995, 5.5 (sd: 1.1) in 1998 and 5.8 (sd: 1.0) in 2001. There was no difference in the overall satisfaction between 1998 and 1995. In 2001 relatives were 
significantly more satisfied than in $1998(\mathrm{p}<.05)$ and $1995(\mathrm{p}<.01)$. Although all separate ratings show a slight increase in 1998, the only significant difference with 1995 was found in the satisfaction ratings about the transplant coordinator in the hospital (1998: 5.7 (sd: 2.0); 19955.0 (sd: 1.5); p<0.05). Closer analysis of the data revealed that the more positive judgment in 1998 could be explained by better access and availability of the transplant coordinator. The two variables that showed the greatest increase compared with 1998 were the screening (when the patient was still being treated, before death occurred) and the announcement of death (both $\mathrm{p}<0.01)$. The satisfaction about the information given also increased significantly $(p<0.01)$. In 2001 the satisfaction ratings for the nurses and for the way the donation request was made were significantly higher compared with $1998(\mathrm{p}<0.05)$. On almost all variables there were significantly higher ratings in 2001 compared with 1995, except for arrival in hospital, the general practitioner and general support received

Table 2. Comparison of mean satisfaction rates in 1995, 1998 and 2001 (7-points scale ranging from 1= very dissatisfied to $7=$ very satisfied). Standard deviation between brackets.

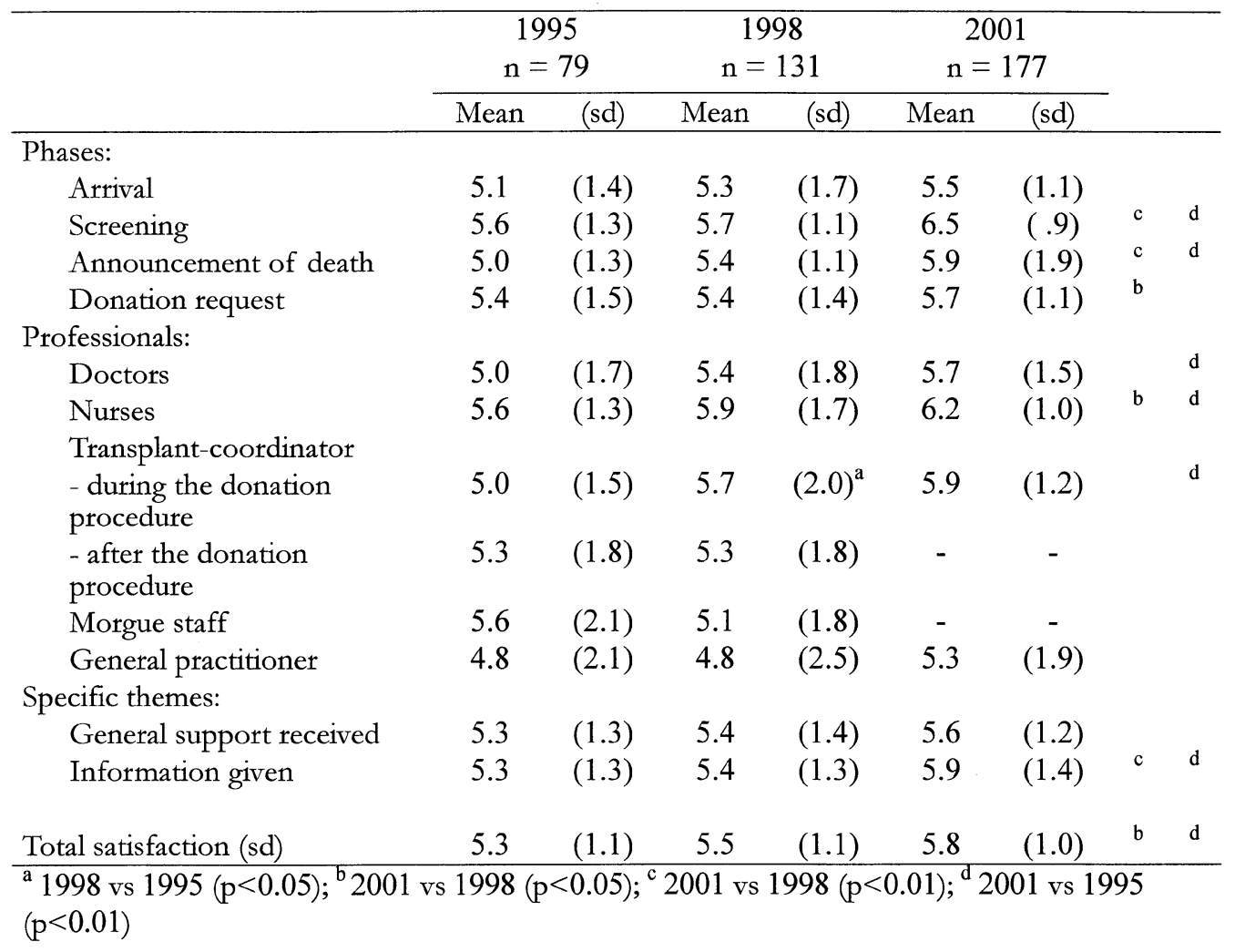

Regression analyses showed that the satisfaction about the consultation in which the death was announced explained $62 \%$ of the variance of the total satisfaction in 
1995, 69\% in 1998 and 55\% in 2001. In 1995 and 1998 the second important variable was the satisfaction about the treatment by the transplant coordinator after the donation procedure (23\% and 15\% added variance, respectively). In 1995 and 1998 the way the satisfaction about how the donation request was made had no substantial influence; in 2001 this was the second important variable, which explained an additional substantial percentage of the variance $(30 \%$ added variance).

The consultation in which (brain) death was announced

The treatment in the consultation in which the death was announced had a major influence on the total satisfaction of the relatives in all years. This was mainly due to the way in which the concept of brain death was explained. The relatives were significantly more satisfied about this in 2001(5.7; sd: 1.5) compared to 1998 (5.1; sd: 1.7) $(\mathrm{p}<0.05)$ and 1995 (4.6; sd: 2.0) $(\mathrm{p}<0.001)$. Clear and understandable language was greatly appreciated as well as compassion shown by the doctor and nurse.

The donation request

In 1995 in the majority of cases the request for donation was made at the same time as or within 15 minutes after the announcement of death (64\%) (see table 3)

Table 3. Timing of the donation request in percentages of the samples; mean satisfaction ratings about the timing of the donation request (standard deviations between brackets).

\begin{tabular}{lrccccc}
\hline & \multicolumn{2}{c}{1995} & 1998 & & \multicolumn{1}{l}{2001} \\
& $\%$ & Mean (sd: $)$ & $\%$ & Mean (sd) & $\%$ & Mean (sd) \\
\hline 1. Before announcement of death & - & & 15 & $5.2(1.5)^{*}$ & 47 & $5.0(2.0)$ \\
2. Same time as announcement of death & 35 & $5.1(2.0)$ & 32 & $4.3(1.9)^{*}$ & 21 & $5.3(1.5)$ \\
3. $<15$ min. after announcement of death & 29 & $4.3(1.7)$ & 15 & $5.3(1.3)^{*}$ & 17 & $5.6(1.2)$ \\
4. > 15 min. after announcement of death & 3 & $4.0(-)$ & 8 & $5.8(1.4)^{*}$ & 4 & $6.3(.5)$ \\
5. Don't remember & 6 & $2.0(-)$ & 10 & $4.8(2.0)$ & 6 & $5.1(1.1)$ \\
Missing & 35 & & 17 & & 5 & \\
\hline
\end{tabular}

* In 1998 significant differences of 2 with 1,3 and 4 , all $\mathrm{p}<0.05$

There was great variety in the judgments of the relatives about the timing of consultation in which the donation request was made. About one fifth of all samples felt overwhelmed by the request, either because there had been no official announcement of death or because the donation request came to early. In 1995 nearly half of the group were dissatisfied about the timing of the donation request $(42 \%)$. The general comment was that the request was made too early. Dissatisfaction increased when relatives had the impression that 'only the organs were important'. In 1998 the satisfaction of those by whom the request for donation was made simultaneously with the announcement of death were significantly less satisfied (4.3; sd: 1.9) then those who were given at least a fifteen- 
minute break between the two consultations (5.8; sd: 1.4) $(\mathrm{p}<0.05)$. In 2001 in almost half of the cases $(47 \%)$ the option of donation was introduced by the relatives themselves, before death was officially announced. Those who had at least a fifteen-minute break, only a small number of relatives, were most satisfied, although there were no significant differences with the other options. In $200165 \%$ of the relatives were satisfied about the timing of the request.

Satisfaction with the donation request after brain death versus after cardiac arrest In 1998, 20 of the 131 relatives were involved in a donation procedure where kidneys were donated after cardiac arrest; the other 111 relatives donated after brain death. In table 4 the satisfaction ratings of both groups are given. Those who were involved in a donation procedure after cardiac arrest were more satisfied both about how the death was announced as well as how the donation request was made $(\mathrm{p}<0.05)$. There are no data for 1995 and 2001 to make this comparison.

Table 4. Comparison of satisfaction ratings in 1998 after being given the diagnose of brain death and after being given the diagnose of cardiac arrest.

\begin{tabular}{|c|c|c|c|c|c|c|}
\hline \multirow[t]{2}{*}{ Satisfaction about: } & \multicolumn{3}{|c|}{$\begin{array}{l}\text { Relatives of } \\
\text { brain death donors }\end{array}$} & \multicolumn{3}{|c|}{$\begin{array}{c}\text { Relatives of } \\
\text { non-heart beating donors }\end{array}$} \\
\hline & Mean & (sd) & $\mathrm{N}$ & Mean & (sd) & $\mathrm{N}$ \\
\hline How death was announced & 5.2 & (1.6) & 102 & 6.1 & $(0.7)^{*}$ & 20 \\
\hline $\begin{array}{l}\text { How the donation request was } \\
\text { made }\end{array}$ & 5.2 & $(1.5)$ & 104 & 6.1 & $(0.6)^{*}$ & 18 \\
\hline
\end{tabular}

The satisfaction about the decision

In 1995, 1998 and 2001 the majority of relatives were satisfied about the freedom they felt to make their own decision about organ donation $(74 \%, 71 \%$ and $80 \%$ respectively). In 1995 and 1998 one third of the relatives knew the wish of the deceased; others indicated that they decided in the spirit of the deceased (in 1998 this was $53 \%$ and in 1995 this was 52\%). In $200180 \%$ of the relatives knew the wish of the deceased, either because they knew their relation was registered in the donor register or because they knew their relation wanted to be a donor. The wishes of the relatives themselves and those of other family members made the decision easier to make. However, there were also factors that complicated the decision-making-process: in $199843 \%$ of the relatives indicated that the information given by the doctor' made the decision more difficult, for 35\% this was 'the attitude of and information given by the transplant coordinator'. In 1995 there were no factors that contributed significantly. In 2001 this question was not asked, therefore this information is not available. 
Of the group of relatives in $199582 \%$ had a positive attitude towards donation, in 1998 this had decreased to $68 \%$; in 2001 this had increased again to $80 \%$. In 1995 and 1998 three quarters of the samples (75\%) indicated that they would make the same decision again, in $200191 \%$ would do so.

The satisfaction about the timing of saying goodbye to the deceased.

In table 5 the satisfaction ratings about the moments in which relatives could say goodbye to their family member are given. In 1995 and 1998 those who had said goodbye after the donor operation in the Intensive Care Unit were most satisfied. In 1998 the difference in satisfaction of these relatives, compared to those who had to say goodbye immediately after consent for donation this was significant $(\mathrm{p}<0.01)$. In 2001 there were no significant differences in satisfaction ratings about the different options. The highest ratings were given for goodbyes after the announcement of death and after the donor operation in the Intensive Care Unit.

Table 5. Relationship between the satisfaction about saying goodbye and the timing of saying goodbye

\begin{tabular}{|c|c|c|c|c|c|c|}
\hline & 1995 & & 1998 & & 2001 & \\
\hline & Mean & (sd) & Mean & $(\mathrm{sd})$ & Mean & $(\mathrm{sd})$ \\
\hline 1. Just after the announcement of death & - & & 5.6 & $(1.6)$ & 5.8 & $(1.5)$ \\
\hline 2. After consent for donation & 4.6 & $(2.1)$ & 4.6 & $(2.1)^{*}$ & 5.3 & $(1.5)$ \\
\hline 3. Right before the donor operation & 4.6 & $(2.3)$ & 5.5 & $(1.8)$ & 5.2 & $(1.9)$ \\
\hline $\begin{array}{l}\text { 4. After the donor operation, in the } \\
\text { Intensive Care Unit }\end{array}$ & 5.4 & $(2.3)$ & 6.1 & $(1.4)^{*}$ & 5.7 & $(1.6)$ \\
\hline 5. In the mortuary & 4.6 & $(2.3)$ & 5.8 & $(1.8)$ & 5.4 & $(1.9)$ \\
\hline 6. Home/funeral parlour & 5.6 & $(2.2)$ & 5.6 & $(1.7)$ & & \\
\hline
\end{tabular}

* Significant difference between saying goodbye after consent for donation and after the donor operation in the ICU in $1998(\mathrm{p}<0.01)$.

The relationship between the donation process and the feelings of the relatives about the donation procedure.

In table 6 the correlations are given for the relationships between the overall satisfaction, the satisfaction about the way death was announced, how the donations request was made and about the staff on the one hand and feelings experience by the relatives on the other hand. In 1998 and 2001 the relationship between relatives' feelings about the donation procedure and the other variables was more differentiated than in 1995.

The data show that in 1995 relationships between feelings and satisfaction ratings were moderate, except for the one between the feeling of being neglected and the overall rating for the treatment by the staff. The strongest relationships are the ones between the overall satisfaction and feelings of anger and being neglected. Anger had very strong relationships with the way the request for donation was made and how death was announced. Relatives were more dissatisfied when they were being neglected and not taken seriously by the staff in general and specifically 
in how death was announced in 1998 and in how the donation request was made in 2001. Feelings of anger and feelings of being neglected were stronger related to dissatisfaction in 1998 and 2001 than in 1995.

Table 6: Significant correlations between the satisfaction about the different phases and feelings about the donation procedure in 1995, 1998 and 2001.

\begin{tabular}{|c|c|c|c|c|c|c|}
\hline & & Anger & Comforted & Neglected & Satisfied & Guilty \\
\hline \multirow[t]{3}{*}{ Arrival } & 1995 & $-.40 * *$ & - & - & - & - \\
\hline & 1998 & $-.60 * *$ & - & $-.56 * *$ & $.41 * *$ & $-.30 * *$ \\
\hline & 2001 & - & - & - & - & - \\
\hline \multirow[t]{3}{*}{ Waiting period } & 1995 & $-.30 *$ & - & - & - & - \\
\hline & 1998 & $-.54 * *$ & - & $-.61 * *$ & $.46^{* *}$ & - \\
\hline & 2001 & - & - & - & - & - \\
\hline \multirow[t]{3}{*}{ Announcement of death } & 1995 & $-.47 * *$ & - & - & - & - \\
\hline & 1998 & $-.56 * *$ & - & $-.57 * *$ & $.36 * *$ & $-.29 *$ \\
\hline & 2001 & - & $.23 * *$ & $-.39 * *$ & $.23 * *$ & - \\
\hline \multirow[t]{3}{*}{ Donation request } & 1995 & $-.36^{*}$ & - & - & - & - \\
\hline & 1998 & $-.63 * *$ & $.28 *$ & $-.53 * *$ & $.43 * *$ & - \\
\hline & 2001 & $-.61 * *$ & $.39 * *$ & $-.57 * *$ & $.41^{* *}$ & $-.27 * *$ \\
\hline \multirow[t]{3}{*}{ Treatment by staff } & 1995 & $-.48 * *$ & - & $-.62 * *$ & $.46^{* *}$ & - \\
\hline & 1998 & $-.41 * *$ & - & $-.42 * *$ & $.31 * *$ & - \\
\hline & 2001 & $-.40 * *$ & $-.29 * *$ & $-.33 * *$ & $.23 * *$ & \\
\hline \multirow[t]{3}{*}{ Support received } & 1995 & - & - & - & - & - \\
\hline & 1998 & & & & & \\
\hline & 2001 & $-.51 * *$ & $.24 * *$ & $-.37 * *$ & $.30 * *$ & - \\
\hline \multirow[t]{3}{*}{ Information dealt with } & 1995 & & & & & \\
\hline & 1998 & & & & & \\
\hline & 2001 & $-.26 * *$ & $.33^{* *}$ & $-.52^{* *}$ & $.34 * *$ & $-.22 * *$ \\
\hline \multirow[t]{3}{*}{ Overall } & 1995 & $-.45 * *$ & - & $-.54 * *$ & $.41 * *$ & - \\
\hline & 1998 & $-.68 * *$ & - & $-.66^{* *}$ & $.56 * *$ & - \\
\hline & 2001 & $-.45 * *$ & $.43 * *$ & $-.55^{* *}$ & $.41 * *$ & -.29 \\
\hline
\end{tabular}

${ }^{*} \mathrm{p}<0.05 ;{ }^{* *} \mathrm{p}<0.01$

A closer look at the satisfaction ratings about the professional staff and the feelings of the relatives about the donation process (table 7) revealed that the strongest feelings were felt towards the transplant coordinators, this is true for both positive and negative feelings. The satisfaction ratings about the treatment by the doctors were moderately correlated with anger and the feeling of being neglected. 
The only meaningful correlation between the satisfaction about the treatment by the nurses was the one with the feeling of being ignored in 1995. There is great variation in the feelings relatives had about the treatment by the different professionals, whereby transplant coordinators evoked the strongest feelings.

Table 7: Significant correlations between the satisfaction about the professional staff and feelings about the donation procedure in 1995, 1998 and 2001

\begin{tabular}{lcccccc}
\hline Profession: & & Anger & Comforted & Ignored & Satisfied & Guilty \\
\hline Doctors & 1995 & -.29 & .01 & $-.36^{*}$ & .25 & -.13 \\
& 1998 & $-.35^{* *}$ & .0 & $-.33^{* *}$ & .19 & -.02 \\
& 2001 & $-.22^{*}$ & .21 & $-.21^{*}$ & .12 & -.06 \\
Nurses & & & & & & \\
& 1995 & -.06 & .02 & $-.45^{*}$ & .16 & .02 \\
& 1998 & .06 & -.11 & -.07 & .11 & -.05 \\
& 2001 & $-.20^{*}$ & .07 & -.06 & .04 & -.06 \\
Transplant coordinators & 1995 & $-.58^{* *}$ & $.51^{* *}$ & $-.61^{* *}$ & $.63^{* *}$ & $-.60^{* *}$ \\
& 1998 & $-.49^{* *}$ & .18 & $-.43^{* *}$ & $.32^{* *}$ & -.09 \\
& 2001 & $-.52^{* *}$ & $.32^{* *}$ & $-.47^{* *}$ & $.42^{* *}$ & -.21 \\
\hline$* \mathrm{p}<0.05 ; * * \mathrm{p}<0.01$ & & & & & &
\end{tabular}

\section{Discussion}

Many interventions were undertaken to bridge the gap between the demand and supply of donor organs and tissues. The main goal of all of these interventions was to increase the number of donor organs and tissues. The majority of these interventions were regulatory-based, aiming at improvement of organization and procedures and increasing knowledge. The organization in hospitals has improved and professional staff feels more secure with standard procedures. There was, however, a further decline of donor numbers. This implies the question whether the variables targeted were critical.

It is widely known that one of the main reasons for the lack of donor organs and tissues is the high refusal rate by relatives. The quality of the interaction and specific (communication) behaviours of key professionals have a significant effect on the decision relatives make. It would appear that the implemented policies did not pay enough attention to the behaviour of the key staff involved.

In the current study the satisfaction of donor relatives with the treatment by the hospital staff throughout the whole donation process in 1995, 1998 and 2001 was compared. In 2001 relatives were more satisfied than those in 1998 on some variables and compared with 1995 on most variables under study. On the basis of these results our first research question can be answered affirmative; satisfaction ratings have indeed changed, there was an increase over the last seven years. In all three years of study, satisfaction about the whole process was most strongly related to how death was announced. In 1995 and 1998 the after care by the transplant 
coordinator, information about what happened with the transplants and sharing experiences, was the second important variable. The variance in the rating about transplant coordinators was rather high in both years; this probably refers to different ways of working by different transplant-coordinators. It is also reflected in the variance in the ratings about the behaviour of transplant coordinators during the procedure in 1995 and 1998. In 2001 the rating was higher and there was less variance than in the earlier years; this may indicate that transplant coordinators have adopted more similar ways of working.

In 2001 the way the donation request was made was the second important variable. It is possible that this is related to the fact that in 2001 almost half the relatives introduced the topic of donation themselves. In 2001 most relatives knew the last will of the deceased; this may be an effect of being better informed and the introduction of the national donor register. The age of the deceased and the fact that in 2001 the majority of relatives were spouses may have may have affected this result. In 2001 more relatives than in earlier years were satisfied about the timing of the request. In 1995 and 1998 the request often came too early; this was not the case in 2001, almost half of the relatives in this year introduced the option themselves. Being kept well informed from the moment of arrival in hospital until the official announcement of death may have created the right circumstances for relatives to initiate the discussion about organ donation. Differences between the processes of a brain death following severe trauma or following CVA may also have added to the effects.

In 2001 relatives were specifically more satisfied than in earlier years about: a) how they were treated during the time before the death was announced, b) how they were told about (brain) death and c) how they were informed throughout the process. It is interesting that these are issues, which are not specifically addressed in the regulatory policies; they are explicitly dealt with in the EDHEP workshops. Information about the diagnosis of brain death and about the donation procedure is found in the 'Model protocol for Post mortal Organ and Tissue Donation'. Doctors and nurses have indicated in one of our studies about teamwork in the intensive care, that they find the protocol very helpful, because all tasks and responsibilities are clearly described. ${ }^{22}$ It may be well that the presence of these protocols helps them to prioritize and to spend more time with the relatives. However, adequate communication skills are needed to communicate all information in a clear and sensitive way. Paying sensitive attention to relatives, offering them the opportunity to be at the bedside in the intensive care unit is not part of the protocol.

In all years the way the news of death was broken contributed for the major part of the variance in the overall satisfaction. This result underlines the importance of this variable. It relates specifically to clarity and sensitivity with which relatives are told about the death of their relation and about the clarity of the explanation about brain death. It may also relate to more information, honesty and clarity in the 
period before the death took place. Keeping relatives well informed prepares them for the worst. In 1995 the relatives were not very satisfied about the explanation of brain death; there was an significant increase in satisfaction in 1998 and a further significant increase in 2001. In 1995 and especially in 1998 a substantial number of relatives (respectively $20 \%$ and $50 \%$ ) were negatively affected by the request; often because they had not yet understood that their family member had died. In 2001 $47 \%$ of the relatives introduced the topic of donation themselves; they will have done this after realizing and accepting that their relation was going to die and might be a donor. Information campaigns, the existence of the national donor register and the quality of the interaction with the key staff before the announcement of death will have contributed to this. In $199582 \%$ of the relatives wanted to be a donor themselves, in 1998 this percentage had fallen back to $68 \%$. The option of donation was relatively new for the sample under study in 1995 and the public in general was positive towards donation. The decrease in 1998 may be related to the negative press in 1997 and 1998, just before the new law was implemented. It may also have been influenced by their experiences in hospital, since half of this sample did not understand their family member had died before the donation request was made. In 2001 the level of 1995 was regained; the relatives in this sample were significantly more satisfied about the treatment in hospital than in earlier years.

Although the majority of relatives in all years felt free to decide about donation, there was still $20 \%$ - 30\% that did not feel free to decide; this might have been the result of pressure within the family or from the hospital staff. In 1998 some relatives indicated that the decision was made more difficult because of the information given by the doctor or the attitude and behaviour of the transplant coordinator. In 1995 and $199825 \%$ of the relatives would not make the same decision again after their experience with this donation procedure; in 2001 this was reduced to $9 \%$. It is arguable to attribute this decrease to more positive experiences during the donation process they were involved in compared with the earlier years.

It is striking that those who were involved in non-heart-beating donation procedures in 1998 were more satisfied about how death was announced than those who were told their relation was brain dead and also about how the donation request was made. It is unfortunate that no data of 1995 and 2001 were available to enable comparisons. It is possible that the staff involved took extra care, as these procedures were relatively new at the time. It is also possible that the fact that the deceased actually looks dead after cardiac arrest plays a role in this. The sight of the dead person facilitates acceptance of this death. Those who were offered to say goodbye after the donor operation in the intensive care unit were most satisfied.

The data show that in 1995 the correlations between feelings and satisfaction ratings were moderate, except for overall rating for the treatment by the staff. In 1998 and 2001 dissatisfaction was strongest related to anger and being neglected. Anger is a natural grief reaction, and may be stronger in case of being confronted with sudden death. In 1998 the feelings of anger were specifically related to the way donation was requested, how relatives were treated upon arrival and to the way 
death was announced; it was also in this year that half of the sample was dissatisfied with the timing of the request. Staff may have felt pressed or may have been too eager to address donation in order to get more donors because of the introduction of the law, without being well prepared to do so. In their focus on donation and the wish to increase the donor rate, they may have forgotten that the pace and understanding of the situation by the relatives was different than their own. Feeling angry about their family members' death may have made the relatives more sensitive. There is however also a strong relationship between feelings of being ignored and how death and donation were addressed and with how the relatives rated the treatment by the professionals. Feeling neglected is a feeling related to interaction, or lack of interaction. The relatives who felt neglected and who still consented in donation must have been very motivated to do so. The significant relationships between the different phases in the donation process and relatives' feelings of satisfaction are in line with findings that relatives find comfort in donating organs.

Our results about the relationship between the feelings of the relatives and the treatment by the different professionals are very revealing. The only feelings of relatives that correlated significantly with the treatment by the doctors were feelings of anger and being neglected, especially in 1998; in 2001 these correlations were much weaker. It is interesting that feelings about the procedure are hardly related to the satisfaction about the treatment by the nurses. Feelings are most pronounced about the treatment by the transplant coordinator. The fact that the correlations between all feelings and the evaluation of the treatment by these professionals are all high and significant probably refers to different ways of working by different transplant coordinators. The satisfaction about the behaviour of all professionals has increased in 2001 compared to 1995 . The relatives are most positive about the behaviour of the nurses; here the greatest increase in satisfaction is observed.

There are several limitations to the study. The samples were small, especially those of 1995 and 1998, and may not be representative for the group as a whole. It is possible that those who had strong feelings about the donation procedure were more inclined to attend the one-day meetings and to complete the questionnaire. Besides this, no data are available from relatives who refused donation. We do therefore not know whether these latter relatives would show a similar response pattern as those who participated in the study. These limitations may reduce the generalizability of the results.

Taking the limitations into account the results show that, according to the relatives in our samples, changes in the practice of organ donation have occurred. Unfortunately no causal inferences between interventions and specific improvements in practice can be made. It is possible, however, to discuss some trends which seem to emerge.

The introduction of the law seems to have had a positive effect on the knowledge of the professionals; relatives are specifically more positive about the 
clarity of the explanation of brain death. Relatives seem to be better informed or more aware of the option of donation, given the fact that in 2001 more than three quarters of the relatives knew their family member's wish, half of the deceased in this sample had registered in the national donor register, and that almost half of the sample introduced the option themselves. As indicated this may also have been related to the kind of relationship the relatives had with the deceased.

On all behavioural variables improvements have been made, because relatives grew more satisfied about these behaviours over the years. They were kept better informed while their relation was still in intensive care. This probably had a positive effect on later stages as they also found that death was better announced and that the option of donation was better discussed. All behavioural variables that were measured in this study are the explicit focus of the European Donor Hospital Education Programme (EDHEP), which in the Netherlands was adapted after the change in legislation and is now called Communication Skills Training. Its main goal is to increase the competence of the key professionals in communicating with relatives. To date a large numbers of staff (doctor, nurses and transplant coordinators) participated in EDHEP workshops, which they valued for the relevance for their practice. ${ }^{23}$ Research has indicated that EDHEP leads to transient improvement of skill in breaking bad news, ${ }^{24}$ to sustained increases of the self-efficacy of the participants in the key tasks in the donation process ${ }^{25}$ and to improved teamwork in intensive care units. ${ }^{22}$ One important conclusion from a study that evaluated the effects of the change in legislation in the Netherlands was that education and training in communicating with bereaved relatives was found to be too noncommittal; the authors suggest that this should be an obligatory part of the training of intensive care staff. ${ }^{1}$ In a study about the relation between patient satisfaction and nurse burnout the authors conclude that “.....organizational profitability rather than staff nurturance often becomes the priority in practice. Neglecting staff well being in the short tem may result in patient dissatisfaction and decrease in service utilization in the long-term". ${ }^{26}$ In business training employees in how to perceive and assess their own performance, is seen as very important and beneficial both for the customer and the employee. ${ }^{27}$ This is also applicable for heath care.

Future research should be aimed at studying the direct relationships between the effects of professional development programmes and relatives' satisfaction. The results from the current study seem to indicate that a well-balanced combination of macro-oriented and regulatory policies with competence-based educational programmes, may be more effective in increasing the donor pool than the policies chosen so far. Well-informed staff, possessing the necessary skills for effective communication with bereaved relatives will feel better prepared for the difficult tasks of breaking news of death and requesting donation. 


\section{References}

1. Rosendal H, Beekum vWT, Legemaate J, Buisen MJAM, Hulst EH, Berg vd, M., et al. Evaluatie. Wet op de orgaandonatie. [Evaluation of the Law on organ donation]. Den Haag: ZonMw, 2001.

2. Schutt GR. 25 years of organ donation: European initiatives to increase organ donation. Transpl Proc 2002;34(6):2005-2006.

3. Garrison RN, Bentley FR, Raque GH, Polk HC, Jr., Sladek LC, Evanisko MJ, et al. There is an answer to the shortage of organ donors. Surg Gynecol Obstet 1991;173(5):391-6.

4. Pelletier M. The organ donor family members' perception of stressful situations during the organ donation experience. J Adv Nurs 1992;17(1):90-7.

5. Siminoff L, Gordon N, Hewlet J, Arnold R. Factors influencing families' consent for donation of solid organs for transplantation. JAMA 2001;286(1):71-7.

6. Cleiren MPHD, Gurp van MEG, Zoelen van AAJ. Zorg en nazorg voor nabestaanden van donoren. [Care and aftercare of donor relatives] Ned Tijdschr Geneeskd 1998;13:34-6.

7. Siminoff L, Arnold R, Hewlett J. The process of organ donation and its effect on consent. Clin Transplant 2001;15(1):39-47.

8. Malecki MS, Hoffman MC. Getting to yes: how nurses' attitudes affect their succes in obtaining consent for organ and tissue donations. Dialysis and Transplantation 1987:276-8.

9. Prottas J, Batten HL. Health professionals and hospital administrators in organ procurement: attitudes, reservations, and their resolutions. Am J Public Health 1988;78(6):642-5.

10. Wakeford RE, Stepney R. Obstacles to organ donation. Br J Surg 1989;76 May:435-9.

11. Gaber AO, Hall G, Phillips DC, Tolley EA, Britt LG. Survey of attitudes of healthcare professionals toward organ donation. Transpl Proc 1990;22(2):313-5.

12. Sque M. Researching the bereaved: an investigator's experience. Nurs Ethics 2000;7(1):23-34.

13. Erdogan O, Yucetin L, Tuncer M, Kececioglu N, Gurkan A, Akaydin M, et al. Attitudes and knowledge of Turkish physicians about organ donation and transplantation. Transpl Proc 2002;34(6):2007-8.

14. Cleiren MHPD. Leven na Geven. Een onderzoek naar ervaringen van nabestaanden van orgaan- en/of weefseldonoren. [Living after Giving: Experiences of donor relatives]. Leiden: DSWO Press Rijksuniversiteit Leiden, 1992.

15. Blok G, Dalen Jv, Gurp Mv, Vecht Evd. Leven na Geven 2. Ervaringen van nabestaanden van orgaan- en/of weefseldonoren. [Living after Giving 2: Experiences of donor relatives]. Leiden: Bureau Transplantatiecoordinatoren, 1996.

16. Littlewood J. Aspects of grief. London: Routledge, 1992.

17. Kwaliteitsinstituur voor de Gezondheidszorg. Modelprotocol Postmortale Orgaan- en Weefseldonatie. [Model protocol postmortem organ and tissue donation] Utrecht: Kwaliteitsinstituut voor de Gezondheidszorg (CBO), 2001.

18. Blok G, Dalen van J, Jager K, Ryan M, Wijnen RMH, Wight C, et al. The European Donor Hospital Education Programme (EDHEP): addressing the training needs of doctors and nurses who break bad news, care for the bereaved, and request donation. Transpl Int 1999;12:161-7. 
19. Blok G, Gurp van M, Kraan G, Vecht van de E, Wezel van HBM. Leven na Geven 3. Verslag van de derde landelijke contactdag voor nabestaanden van orgaan- en weefseldonoren. [Living after Giving 3: Experiences of donor relatives]. Leiden: Sectie Transplantatie Coordinatoren van de Nederlandse Transplantatie Stichting, 1998.

20. Blok G, Kraan G, Dalen van J, Gurp Mv, Vecht Evd, Wezel Hv. Ervaringen van nabestaanden van donoren met de donatieprocedure; vergelijking tussen 1995 en 1998. [Experiences of donor relatitves with the donation procedure; comparison between 995 and 1998] Ned Tijdsch Geneesk 2000;144(14):663-7.

21. Erdman RAM, Ravensbergen J. Leven na Geven 4. Verslag van de vierde landelijke contactdag voor nabestaanden van orgaan- en weefseldonoren. [Living after Giving 4: Experiences of donor relatives]. Leiden: Sectie Transplantatie Coordinatoren van de Nederlandse Transplantatie Stichting, 2001.

22. Blok GA, Wezel van HBM, Morley M, Morton M, Mansum van W, Vleuten van der CPM. Effects of an educational programme on teamwork in the intensive care. Chapter 7 of this thesis, submitted.

23. Dalen van J, Blok GA, Morley M, Morton JB, Haase-Kromwijk B, Sells RA, et al. Participants' judgements of the European Donor Hospital Education Programme (EDHEP): an international comparison. Transpl Int 1999;12:182-7.

24. Morton J, Blok GA, Reid C, van-Dalen J, Morley M. The European Donor Hospital Education Programme (EDHEP): enhancing communication skills with bereaved relatives. Anaesth Intensive Care 2000;8(2):184-90.

25. Blok GA, Morton J, Morley M, Kerckhoffs CMAM, Vleuten van der CPM, Kootstra G. Requesting organ and tissue donation: the case of self-efficacy. Effects of the European Donor Hospital Education Programme (EDHEP). Accepted for publication Adv Health Sci Educ.

26. Leiter MP, Harvie P, Frizzell C. The correspondence of patient satisfaction and nurse burnout. Soc Sci Med 1998;47(10):1611-7.

27. Dolen van W, Lemmink J, Mattsson J, Rhoen I. Affective consumer responses in service encounters: The emotional content in narratives of critical incidents. Journal of Economic Psychology 2001;22(3):359-76. 


\section{Continuing professional development regarding dealing with grief and requesting donation. Worldwide evaluations of Train-the-Trainer courses ${ }^{1}$}

All over the world doctors and nurses need comparable competences, because the problems they encounter in day-to-day practice are also similar. The goal of continuing professional development is to improve professional competence. Continuing professional development covers any activity undertaken to improve professional behaviour, communication skills and knowledge. For an educational programme to be effective its content and format must be tailored to the needs and interests of the target group. Professional learning benefits most from programmes set within the context of professional practice, providing adequate clinical content and integrating knowledge and skills to facilitate retention and transfer to actual practice. Domain specific educational programmes aimed at resolving deficiencies identified in day-to-day practice appear to be most effective. The European Donor Hospital Education Programme (EDHEP) is based on these principles and aims to improve of bealth care professionals' competence in dealing with relatives' grief and requesting organ donation. This paper presents programme evaluations and learning effects of EDHEP workshops and Train-the-Trainers Courses held all over the world. The international interest together with the invariably favourable evaluations of both contents and format suggests that EDHEP makes a valuable contribution to national or local continuing professional development programmes. There is a worldwide understanding that advanced communication skills are critical in this sensitive area of medicine and nursing.

1 Submitted as: Blok GA, Wight C, Cohen B, Kootstra G. Continuing professional development in dealing with grief and requesting donation. Worldwide evaluations of Train-theTrainer Courses. 


\section{Introduction}

The development of transplant programmes throughout the world is hampered by a chronic shortage of donor organs. The number of patients on waiting lists for transplantation has grown dramatically, while the number of donor organs has lagged behind. ${ }^{1,2}$ A major reason for the shortage of donor organs and tissues is relatives' refusal to give consent. ${ }^{1}$ Recovery of donor organs and tissues from patients who are brain dead (heart-beating donors) and from patients with cardiac arrest (non-heart-beating donors) requires prior discussion of the option of donation with relatives. In some countries as many as 70 per cent of relatives refuse consent for post-mortem donation and a significant minority of relatives of potential donors may not be asked at all. ${ }^{3}$

Health care professionals everywhere perceive making a request for organ donation as a difficult and complex task requiring profound knowledge and advanced (communication) skills. Awareness of personal and professional values, attitudes, behaviour and ethics plays an important role in this domain. Professionals' own feelings towards death and their attitudes towards organ donation may cause reluctance to approach relatives with a request for organ donation. Concern about about intruding on a family's grief and insufficient training in relevant knowledge and skills may intensify professionals' lack of confidence in this respect.

In an attempt to tackle the problem of organ shortage, The Eurotransplant Foundation* intiated the development of an educational programme to promote health care professionals' competence in dealing with grief and requesting organ donation. This programme is called the European Donor Hospital Education Programme (EDHEP) ${ }^{4}$ and it was officially implemented in the Netherlands in 1992. The aims of EDHEP are to: 1) raise awareness of the donor shortage and offer potential solutions; 2) develop professionals' awareness of the needs of the bereaved and of the professionals' needs in dealing with the bereaved; 3) provide 'hands-on' communication skills training to enhance competence in dealing with grief reactions and requesting organ donation (using simulated relatives), and 4) provide guidance in developing hospital protocols for dealing with bereaved relatives. The workshop is intended for medical and nursing staff whose work involves contacts with bereaved relatives. ${ }^{5}$

EDHEP was produced in two parts: EDHEP Part 1, 'Meeting the donor shortage', is a one-hour slide presentation about the history and state of the art of organ and tissue transplantation intended for hospital staff, and EDHEP Part 2, 'The grief response and donation request', is a highly interactive, one-day skills awareness workshop. Wight and Cohen ${ }^{5}$ described EDHEP as part of a multifaceted process aimed at closing the gap between demand and supply of

\footnotetext{
* The Eurotransplant Foundation is an organ exchange organization based in Leiden, The Netherlands. It provides a service for The Netherlands, Germany, Austria, Belgium, Luxemburg and Slovenia.
} 
donor organs and tissues. The prototype of the programme was designed for easy adaptability to national circumstances and cultures and as a complement to existing educational programmes. An international EDHEP coordinator was appointed by the International Eurotransplant Foundation to provide advice and assistance in 1) setting up national working groups, 2) recruiting moderators and simulated relatives for the workshop, 3) organizing Train-The-Trainers (TT'T) courses, 4) adaptation of EDHEP to national contexts, and 5) programme quality assurance ${ }^{5}$. To date EDHEP has been translated into 17 languages and is has been incorporated in continuing professional development in 33 countries in Western Europe, the Middle East, the Far East and Central and South America.

What gave EDHEP its worldwide appeal?

From its very introduction EDHEP has attracted global interest. The experiences of participants in the TTT-courses and experiences with implementation of the programme in countries all over the world may confirm or disconfirm the assumption the programme is applicable and relevant for a global audience of medical and nursing professionals. An evaluation study was therefore carried out, of which the principal questions were:

- How are the EDHEP TTT-courses perceived by participants from different countries and do countries differ in participants's satisfaction with and perceived relevance of the EDHEP programme? What is the learning effect of the TTTcourse both for working group members and future moderators? How well are the aims and spirit of EDHEP and its' teaching aids understood and what are the views of working group members and future moderators about national implementation?

- How is the EDHEP workshop perceived by participants from different countries and do countries differ in participants' satisfaction precieved relevance of the issues addressed in EDHEP? Is there a difference between countries in reported learning effect?

- How is the implementation of EDHEP evaluated some years after national implementation?

- Were the TT'T-courses sufficiently instructive to ensure adequate national implementation in different countries?

Before describing the method and results of the evaluation study, we describe the contents and format of the TTT-courses and the EDHEP-workshop as part of these training courses. Finally, an outline is given of the educational principles underpinning the T'T T-courses. 
EDHEP Train-the-Trainers Courses

Standardized 2.5-day EDHEP TTT-courses have accompanied the implementation of EDHEP in different countries. The TTT-courses were conducted by the programme's authors and principal trainers to guarantee acceptable uniformity and quality control. The general structure of the TT'T-courses is depicted in Figure 1. All participants, potential working group members and future EDHEP moderators, attended the preparatory session in which the EDHEP objectives were clarified and the objectives of the TTT-course discussed. All participants attended the entire EDHEP workshop, which was run on day 1 (with the exception of the first TTTcourse). On day 2 future moderators could perform the exercises of the EDHEP workshop. Part of the afternoon session was available for working group members to discuss national adaptations and implementation. The role play sessions, the evaluation and round-up of the TTT-course were attended by all participants.

The design of the TTT-courses included many ingredients considered to be of importance in continuing professional development were incorporated. As indicated in Figure 1, the TTT-courses consisted of three parts: a preparatory session to discuss information on the objectives of the TT'T-course and details of the aims and spirit of EDHEP, the EDHEP workshop, and training of working group members and future moderators.

The EDHEP workshop

The authors of the TT-course thought it was of vital importance that all those responsible for the implementation of EDHEP in their own country should experience the EDHEP workshop before discussing which steps were necessary for successful implementation. This experience would give all participants a thorough understanding of the workshop's contents and format. Figure 1 shows the plkace of the workshop in the course programme. Methods form experiential and adult learning which have been proven to be effective ${ }^{6,7}$ are at the heart of the EDHEP workshop: participants are encouraged to identify their own learning needs; training and facilitation methods are tailored to patiricipants' needs; constructive feedback is an integrated part of all exercises, participants can practice in authentic consultations with simulated relatives; and group feedback and sharing of experiences among colleagues are encouraged. All examples and cases used in the workshop are based on actual situations taken from the participants' working environment. ${ }^{4,8}$ Efforts are made to create a supportive climate where it is safe for patricipants to take risks in interpersonal communication in order to learn from their experiences and from feedback by colleagues. ${ }^{9}$ The trainers model the skills to be learned, how to behave towards relatives and colleagues, and when necessary, elaborate on attitudes that are considered appropriate. Much of this learning of the latter is tacit rather than explicit. In the workshop participants are encouraged to: 1) examine their own feelings aroused by loss and separation; 2) display an appropriate professional response in reaction to different expressions of grief; 3) listen to bereaved relatives describe their feelings of loss and attitude towards 
EDHEP TRAIN-THE-TRAINER COURSE

\section{Preparatory session}

Welcome dinner/lunch (optional)

EDHEP objectives

Role of EDHEP National Working Group

EDHEP Part One 'A Background Briefing'

Objectives of the Train-The-Trainer Course

Introduction to EDHEP Part Two: 'The grief response and the donation request'

Day one

\section{Part one}

EDHEP Part Two: 'The grief response and the donation request': Workshop

\section{Part two}

Evaluation of the workshop and formulation of personal learning goals

Description of and discussion on the role of simulated relatives

Group dinner

\section{Day two}

\section{Morning session:}

Two future moderators practice 'Loss and separation' exercise - Group feedback and feedback from trainers

Three future moderators practice 'Video Vignettes' exercise - Group feedback and feedback from trainers

One future moderator practices 'Talking about loss', exercise - Group feedback and feedback from trainers

Afternoon session 1 (parallel session with Afternoon session 2)

One future moderator practices 'Sudden death'

- Group feedback and feedback from trainers

Two future moderators practice role play 'Breaking bad news'

- Group feedback and feedback from trainers

Two future moderators practice role play 'Requesting organ donation'

- Group feedback and feedback from trainers

Afternoon session 2 (parallel session with Afternoon session 1)

Working group members have opportunity to discuss national adaptation and implementation of EDHEP with one of the trainers

\section{Plenary session}

Presentation of programme-evaluations of the EDHEP workshop Evaluation of the Train-the-Trainer Course

Figure 1. Overview of the programme 
donation; 4) analyse problems of miscommunication; 5) participate in exercises with simulated relatives; and 6) discuss ways of establishing hospital protocols for dealing with the bereaved.

All theory dealt with in the workshop is contained in a 'Participants' Manual' that is handed out at the closure of the workshop. ${ }^{10}$

Training working group members and future EDHEP moderators

The key features of continuing professional development incorporated in the design of the EDHEP workshop, were also fundamental to the format of the TTT-course. As indicated earlier, the authors considered it a paramount need that all participants should experience the EDHEP workshop to gain a thorough understanding of its aims and spirit. As most of the working group members were practising professionals the workshop served the combined goals of improving participants' competence as doctors, nurses and transplant coordinators and encouraging them to act as opinion leaders in their respective professional communities in their home country.

For successful implementation of EDHEP in different countries, it was crucial that it should be run in a professional way. Working group members were therefore supplied with a list of criteria to be used in recruiting future moderators prior to TTT-courses. Appropriate implementation of the EDHEP required that moderators should be experienced in communication skills training and familiar with the psychological aspects of grief, donation procedures and the working environment of the medical and nursing professionals.

Participation in the EDHEP workshop afforded the potential moderators a model of how to run the workshop. After experiencing the workshop future moderators were encouraged to identify their own learning needs: the choice of exercises for the following day was left to the future moderators so that they could choose exercises that would allow them to work on their personal learning goals. Feedback focused on the future moderator's personal learning goals was provided by the group and the TTT-trainers after each exercise. As adults have a need to be self-directed ${ }^{11}$, future moderators were given the opportunity to make a personal interpretation of the exercises. Research on faculty development has shown that it is essential for teachers to no learn how to change and learn didactical techniques and skills, but also to be encouraged to challenge underlying assumptions about teaching and learning. The reason for this is that teachers' behaviour is mostly influenced by their beliefs about teaching and learning. ${ }^{12}$ Therefore, in the group feedback sessions after each exercise performed by a future moderator, both teaching behaviour as well as the pro's and con's of different interpretations of the exercises and assumptions about their effectiveness were discussed.

Working group members spent part of the afternoon session discussing national implementation and adaptation with the international EDHEP-coordinator. This session was devoted to the steps on the path to national implementation, the composition of national EDHEP working groups and the prerequisites of and the 
logistics involved in running EDHEP workshops. Also the adaptation of the material to suit local needs regarding legislative, cultural and religious aspects was discussed, based on the recommendation that for training to be effective it should be placed within a context that participants find familiar and are likely to encounter in their own clinical practice. ${ }^{6,13}$

By way of preparation for the TTT-courses, interested parties were sent an EDHEP Organizer's Manual ${ }^{14}$ with guidelines for the adaptation of the programme to national needs and for the nationwide implementation of the programme. In most of the TTT-courses the majority of working group members and future moderators were able to see the EDHEP material before attending the course. If this was not possible, the material was handed out early in the course.

\section{Method}

Subjects

The subjects in this study were participants in sixteen EDHEP TTT-courses. The participants came from all over the world an comprised experienced doctors and nurses (mostly both in professional and managerial functions), transplantcoordinators, psychiatrists and psychologists, and representatives of Novartis ${ }^{*}$. Six courses were held in the Netherlands and the remaining ten in different countries all over the world.

In October 1995 an official follow-up meeting was organized for representatives of countries, who had participated in TTT Courses and were responsible for implementation of EDHEP in their home country. Forty representatives from different countries attended this meeting.

\section{Materials}

Train-The-Trainer course. A questionnaire was developed by the authors and trainers of the TTT-course $* *$ to evaluate the programme. The first section of the questionnaire consisted of items about biographical information, function in the TTT-course and experience of the participant. The second section of the questionnaire consisted of statements about the organization, structure, working atmosphere and relevance of issues dealt with in the course. The third section of the questionnaire was for working group members only and consisted of statements about teaching aids, adaptation and national implementation of EDHEP. The fourth section of the questionnaire was for moderators only and consisted of statements about the teaching aids and learning effect of the course. All statements in section two, three and four had to be answered on a 5-point scale

* Novartis (formerly Sandoz Basel has funded most of the international deployment of EDHEP

** Celia Wight (Eurotransplant Foundation), International EDHEP-coordinator and Geke Blok \& Jan van Dalen (University of Maastricht), international EDHEP workshop \& TTT course moderators 
ranging from 'fully disagree' to 'fully agree'. The standard programme evaluation questionnaire of the EDHEP workshop was administered as part of the evaluation of the TTT Course. ${ }^{15}$

Follow-up meeting. A questionnaire was developed consisting of open-ended and divided into the following sections: EDHEP programme evaluation, adaptations of the original format, need for further training, issues discussed in National Working Groups and effectiveness of the TTT-course. The follow-up meeting was minuted.

\section{Procedure}

The questionnaires about EDHEP were distributed, completed and subsequently collected at the end of the workshop on the first day. The questionnaire about the TT'T-course were distributed, completed and subsequently collected at the end of the course to guarantee the highest possible response rate. Both questionnaires were anonymous to reduce likelihood of socially desirable responses. The discussions in the follow-up meeting minutes were minuted. The questionnaires about the experiences with the national implementation of EDHEP were sent out and processed prior to the follow-up meeting.

Methods of analysis

Means, frequencies and percentages were calculated for the background characteristics of the participants, Chi-square was used to check for any differences in the descriptive data between different regions. Differences in satisfaction ratings, reported learning effect and evaluation of teaching aids were estimated through analyses of variance (ANOVA's) with region of the world as independent variable. Tukey's Honest Significant Difference was calculated to establish any differences between regions. Student T-tests for independent samples were performed to establish differences in perceived difficulties relating to requesting organs or tissues, and in learning effects between those who did and those who did not participate in role-play sessions. Correlation analysis was used to establish the relationship between reported learning effect and the perceived difficulty of requesting organ donation. All calculations were performed with SPSS 10.1 for Windows. Effects were considered significant when the p-value was less than 0.05 .

A qualitative analysis was made of the answers on the questionnaire sent out before the follow-up meeting.

\section{Results}

Results of the evaluations of the EDHEP workshops are presented first, as these afford better insight in the programme evaluations of the TTT-course as a whole.

The background characteristics of all participants in EDHEP workshops* are presented in Table 1 . The group has had ample experience with bereaved relatives

* $\quad$ Full TTT courses were held in Leiden, Hong Kong, Sao Paulo, Mexico City, Manchester, Bern and Paris; representatives of all other countries attended TTT courses in Leiden. In Ryiadh, Kuwait City and 
and with requesting organ donation. More than half of the group members had not had any experience with requesting tissue donation. The request for organ donation (mean 5.68, SD: 2.59) was perceived as more difficult than the request for tissues (mean 5.01, SD: 2.52) $(\mathrm{p}<0.001)$. There was considerable variance within the group with respect to the two variables.

Table 1. Descriptive statistics of respondents in the international Train-the-Trainers Courses* $(n=234)$

\begin{tabular}{|c|c|c|c|}
\hline \multicolumn{2}{|l|}{ Profession } & \multicolumn{2}{|l|}{ Region } \\
\hline Doctors & $37 \%$ & Europe & $55 \%$ \\
\hline nurses & $11 \%$ & Central and South America & $4 \%$ \\
\hline transplant coordinators & $27 \%$ & Far East & $12 \%$ \\
\hline Psychiatrists & $12 \%$ & Middle East & $22 \%$ \\
\hline Psychologists & $12 \%$ & South-Africa & $7 \%$ \\
\hline Other & $2 \%$ & Australia & $1 \%$ \\
\hline \multicolumn{4}{|l|}{ Sex } \\
\hline men/women & $51 \% / 48 \%$ & & \\
\hline Missing & $1 \%$ & & \\
\hline \multicolumn{4}{|l|}{ Experience: } \\
\hline \multicolumn{2}{|c|}{ Previous contacts with bereaved relatives: } & \multicolumn{2}{|l|}{ General experience with donation } \\
\hline Never & $12 \%$ & Mean years (sd) & $5.18(5.45)$ \\
\hline several times/year & $39 \%$ & & \\
\hline several times/month & $29 \%$ & & \\
\hline several times/week & $14 \%$ & & \\
\hline Missing & $6 \%$ & & \\
\hline Requests for organ donation: & & Requests for tissue donation: & \\
\hline never & $39 \%$ & never & $56 \%$ \\
\hline 1-2 per year & $15 \%$ & $1-2$ per year & $13 \%$ \\
\hline 3-4 per year & $8 \%$ & $3-10$ per year & $9 \%$ \\
\hline$>4$ per year & $36 \%$ & $>10$ per year & $20 \%$ \\
\hline Missing & $2 \%$ & Missing & $2 \%$ \\
\hline \multicolumn{4}{|c|}{ Difficulty of donation requests (10-point scale): } \\
\hline Organ donation (Mean, (sd)) & $5.68(2.59)$ & Tissue donation (Mean, (sd)) & $5.01(2.52)$ \\
\hline
\end{tabular}

* The table does not include data from participants of the first TTT Course held in Leiden

Programme evaluation and learning effects of the EDHEP workshop

Data about the satisfaction with contents and format of the EDHEP workshop and the learning effects are presented in table 2. All aspects of the workshop were rated highly. Further analysis showed no relationship between learning effect and prior general experience or experience with requests for organ donation. There was a low, but significant, inverse correlation between the perceived difficulty of requesting organ donation and the learning effect (Pearson r: -.18, $\mathrm{p}<0.01$ ).

Capetown EDHEP workshops were run to familiarise and interest other local professionals with the programme; for these groups only EDHEP programme evaluations were available. 
Table 2. Satisfaction with the EDHEP workshop and learning effect (5-point scale) ( $n=234)$

\begin{tabular}{lcc}
\hline & Mean & Sd \\
\hline Organization & 4.3 & 0.81 \\
Issues recognizable & 4.4 & 0.60 \\
Teaching aids & 4.3 & 0.51 \\
Simulated relatives & 4.4 & 0.73 \\
Learning effect & 4.1 & 0.58 \\
Barrier to donation request reduced & 3.9 & 0.93 \\
\hline
\end{tabular}

There were significant $(\mathrm{p}<0.05)$ differences between the ratings of the learning effect in South-Africa (mean: 4.5; sd: 0.51), Europe (mean: 4.1; sd: 0.59) and the Far East (mean 4.0;sd 0.45), respectively. The greatest reduction of the barrier to requesting donation was found in Central and South America (mean: 4.6; sd: 0.52) and the difference with the other regions were significant except for South Africa $($ all $\mathrm{p}<0.05)$. The lowest rating were from the Middle East (mean: 3.8; sd: 1.10). The evaluation forms contained comments on specific exercises. The exercise in which personal feelings towards death were elicited was experienced as very powerful. A participant indicated "that did it". The interactive exercises, especially the role-play sessions with simulated relatives. were perceived as very instructive.

Participating in role-plays had a significant impact on the learning effect, with participants reporting a mean learning effect of 4.3 (sd: 0.52 ) compared with a mean learning effect of 4.0 (sd: 0.58$)$ reported by observers $(\mathrm{p}<0.05)$.

Programme evaluation and learning effects of the TTT-courses

Of the participants who completed the TTT-course evaluation forms, $68 \%$ were working group members, $31 \%$ were future moderators and $1 \%$ were others, e.g. representatives of funding organizations.

Satisfaction with the course programme is presented in Table 3 . The participants valued all aspects of the course highly. They had experienced a pleasant working atmosphere in a training session in which relevant information was presented. The participants thought the programme was well structured and well conducted by the trainers, whose feedback facilitated the learning process. All participants were of the opinion that experiencing the EDHEP workshop on day 1 was necessary for a good understanding of how to implement EDHEP locally. They also agreed about the benefits of working in mixed groups. Although all participants rated the structure of the programme highly, there were differences of opinion in this respect between participants from the Far East (mean 4.23; sd: 0.57), Europe (mean 4.63; sd: 0.60) and Central and South America (mean 4.67; sd: 0.68). The differences were significant $(\mathrm{p}<0.01)$. All participants gave high ratings for the pleasant working atmosphere with a significant difference between the ratings by participants from the Far East (mean: 4.43, sd: 0.62) and those from Europe (mean: 4.76; sd: 0.47) $(\mathrm{p}<.05)$. 
Table 3. Satisfaction with EDHEP TTT-course on a 5-point scale ( $\mathrm{n}=203)$.

\begin{tabular}{lcc}
\hline & Mean & sd \\
\hline Information relevant & 4.45 & 0.61 \\
Structure of the TTT- training & 4.58 & 0.62 \\
Mixed groups (working group members and moderators) & 4.37 & 0.86 \\
Pleasant working atmosphere & 4.66 & 0.62 \\
Experience EDHEP workshop necessary & 4.24 & 0.86 \\
Helpful for adaptation \& implementation & 4.16 & 0.80 \\
English language handicap & 2.87 & 1.37 \\
Trainers facilitated the learning process (e.g feedback) & 4.62 & 0.54 \\
\hline
\end{tabular}

The working group members reported a substantial learning effect (table 4). All participants indicated that they had achieved their personal learning goals, and had obtained a good understanding of the aims and spirits of EDHEP and the teaching aids used. There were some differences with respect to local implementation of EDHEP. Although all participants rated their insight into support building relatively highly, the participants from the Far East (mean 3.80; sd: 0.82 ) were least sure about this compared to the participants from Europe (mean 4.02; sd: 0.78), Central and South America (mean 4.40; sd: 0.62) and the Middle East (5.0; sd: 0$)(\mathrm{p}<0.01, \mathrm{p}<0.01$ and $\mathrm{p}<0.05$ respectively). All participants were of the opinion that an EDHEP Newsletter would be a valuable vehicle for sharing experiences.

Table 4. Learning effects of EDHEP TTT-course by Working Group Members on a 5-point scale ( $\mathrm{n}=135)$

\begin{tabular}{lcc}
\hline & Mean & sd \\
\hline Reached personal goals & 4.09 & 0.80 \\
Insight in structure and goals of EDHEP & 4.41 & 0.64 \\
Understand the purpose of the teaching aids in EDHEP & 4.50 & 0.52 \\
Understand the role of a National EDHEP Working group & 4.40 & 0.72 \\
Understand how to build support for EDHEP & 4.10 & 0.80 \\
Understand the qualities of moderators & 4.38 & 0.58 \\
Insight in how to adapt written material & 4.08 & 0.77 \\
Insight in how to adapt video-material & 4.00 & 0.87 \\
EDHEP Newsletter useful & 4.39 & 0.77 \\
\hline
\end{tabular}

The learning effects of the future moderators are presented in table 5. All evaluations are very favourable. The future moderators indicated having achieved their personal goals, having obtained good insight into the structure and goals of EDHEP and that the trainers had facilitated their learning process. As for the didactic methods (teachings aids) used future moderators generally felt quite confident that they would be able to conduct the different exercises. Their confidence was lowest with regard to the acquisition and training of simulated relatives. The lower evaluation of how to conduct the discussion about the video- 
programme 'Talking about Loss' was associated with to ambivalent feelings about the contents. Future moderators thought it would be better to have local relatives talking about their experiences. Further analyses were not conducted as $85 \%$ of the moderators came from Europe, so that meaningful comparisons could not be made.

Table 5. Learning effects of EDHEP TT'T Course by future moderators on a 5-point scale $(n=63)$.

\begin{tabular}{lcc}
\hline & Mean & sd \\
\hline Reached personal goals & 4.36 & 0.68 \\
Insight in structure and goals of EDHEP & 4.56 & 0.56 \\
& & \\
I can give the presentations & 4.00 & 0.71 \\
I can lead the exercise 'Loss \& separation' & 4.26 & 0.71 \\
I can lead the exercise 'Video-vignettes' & 4.25 & 0.83 \\
I can lead the discussion about the video programme 'Talking about & 3.98 & 0.97 \\
Loss' & & \\
I can lead the discussion about the video film 'Sudden Death' & 4.06 & 0.85 \\
I can lead the role play sessions & 4.00 & 0.94 \\
& & \\
I know how to acquire simulated relatives & 3.47 & 1.17 \\
I know how to train simulated relatives & 3.21 & 1.27 \\
& & \\
Mean learning effect & 4.35 & 0.43 \\
The trainers facilitated my learning process & 4.69 & 0.50 \\
Understand the qualities of moderators & 4.49 & 0.61 \\
\hline
\end{tabular}

In the oral evaluations at the end of the TTT Courses participants indicated that it would be necessary to translate all the material in their own language. In addition, that the written material and the videotapes would have to be adapted to local needs concerning legal, cultural and religious issues.

Evaluation of international implementation and results of follow-up meeting. Most countries had kept the original format of the EDHEP workshop, with adjustments in the exercises to suit local legal, cultural and religious requirements. Written material was adapted to this end; the video-programme 'Talking about Loss' which showes relatives' experiences was replaced by local video-programmes. In some countries video-programmes elaborating on brain death and on legal issues were added. In some countries the workshop was extended over two days toi allow more time for the discussion of legal, cultural and religious issues and more role-play sessions. In other countries the workshop was preceded by seminars about brain death, grief and mourning and religious and legal issues.

Generally representatives of the different countries indicated that the programme evaluations in their country were favourable, irrespective of whether the one-day format was kept or extended to two days. Participants in the local 
EDHEP workshops reported improved recognition of grief reactions, improved understanding of the communication process and the relevant communication skills. Generally, a more favourable attitude towards donation was reported as well as increases in self-confidence concerning requesting donation. In Israel and Japan, where extra attention was paid to brain death criteria; increased knowledge of this subject was reported after participation (results presented in Wight and Cohen ${ }^{5}$ ). These countries also reported that participants felt more confident about communicating with bereaved relatives and how to approach them with a request for organ donation, especially those who had never made such a request. ${ }^{5}$

Appreciation was particularly high for the role-play sessions, sharing of experiences and the exercises aimed at eliciting personal feelings about death and donation in the workshop.

Some representatives expressed concern about the self-efficacy concerning requests for donation among those who did not participate in the role-play sessions. Doubts were also expressed as to the level of insight into relevant issues and proficiency in relevant skills which can be reached in a one-day format. In some countries this led to the extension of the workshop by one day.

The importance of a well-functioning organ procurement system was highlighted by the conclusion expressed by one country: it is not enough to change professionals' skills, but the system should also be altered to support individual professionals' efforts.

All countries were enthusiastic about the programme and were seeking ways to safeguard continuation of this of continuing professional development course.

The discussion in the follow-up meeting focused on recruitment of participants and future funding of EDHEP workshops. The recruitment of participants, mainly doctors, was problematic in some countries. Different solutions were discussed: inviting senior staff first, who can then interest others; official accreditation; presenting the workshop as a scarce commodity (the workshop is free, but places are precious), and information brochures.

Funding, especially in the future, was a serious concern for most countries. Potential sources of funding as well as ways of cutting costs were discussed. Funding could be sought from the European Union, Departments of Health, national Kidney and Heart Foundations, individual hospitals and pharmaceutical companies. Different possibilities for reducing workshop costs were also discussed. Everybody agreed that the workshop venue should be in the hospital; different options for outside locations should be studied. Another option was not to record the role-play sessions to save the costs of audiovisual equipment.

The instructiveness of the TTT-courses was evaluated. In the questionnaire and in the follow-up meeting participants described the courses as a very enjoyable experience. They considered it very instructive to have experienced the EDHEP workshop before considering its implementation. The possibility for sharing experiences and the role-play sessions were regarded as very valuable. The 
opportunity for moderators to perform the exercises was greatly appreciated. However, the moderators did indicate, that the TTT-course was not sufficient to achieve a thorough understanding of and ability to run the workshop. They felt they needed more practice.

Some participants indicated that EDHEP had made a profound impression on them, reflected in the statement of a transplant coordinator: "EDHEP has changed my professional life".

\section{Discussion}

Since 1992 hundreds of participants from all over the world have attended international EDHEP TTT-courses, held either in Leiden in the Netherlands, or in another host country. 'The results from the current study indicate that the EDHEP workshop is viewed as a valuable tool in addressing professionals' needs in dealing with grief reactions and requesting donation. Without exception participants appreciate the issues addressed in the EDHEP workshop, confirming that the workshop does indeed address the needs of the professional staff who are confronted with bereaved relatives and the possibility of organ donation. They report strong satisfaction with the programme, irrespective of their country of origin. These results are similar to those of programme evaluations of EDHEP workshops held in the Netherlands ${ }^{16}$, the United Kingdom ${ }^{15}$ and Germany ${ }^{17}$. Presumably the workshop addresses global needs and the format and issues appeal to a global audience. All participants rated the learning effects high, reflecting improved understanding of the processes and skills involved in communicating with bereaved relatives and requesting donation, and more confidence in approaching relatives about donation. South-African participants rated the learning effects highest; it was the first time ever they were taught about these issues. Participants from Arab countries rated the learning effects highly, but indicated that more attention for the complicated relationship between the concept of brain death and Islamic religious assumptions would enhance its' learning effect.

Active participating in role-play sessions with simulated relatives increased the learning effect, underscoring the importance of actual practice in authentic learning situations. The exercise which elicited personal feelings and attitudes toward death and donation was experienced as very powerful; especially the exercise on 'loss and separation' was felt to be very realistic. In many training courses participants telephoned their families to check that they were alright. Some participants felt that performing the exercise was like tempting fate; on the other hand a participant said about this exercise: "that did it".

Participants in the TTT-courses were convinced EDHEP would be a valuable tool to add to continuing professional development programmes in their own country. The learning effect reported by the working group members was very substantial, reflecting a good understanding of the aims, structure and goals of EDHEP and how to proceed in implementing the programme in their home country. Participants from the Far East felt least confident in this respect. They 
were uncertain how to build support for EDHEP. This may have been related to differences in legislation and cultural beliefs. Japan very successfully adapted the programme to local needs by adding information and discussions about brain death.

Future moderators all indicated that they understood the purpose of the didactic methods in the EDHEP workshop and felt able to implement them. There was ambivalence about the video-programme in which relatives talk about their experiences with the donation procedure. It was felt that this programme should, at least partly, be replaced by video-programmes reflecting the local situation. Future moderators were least sure about how to acquire and train simulated relatives, whose contribution to the role-plays they highly valued. This aspect of EDHEP was discussed only in the TTT-course and the moderators did not have the opportunity to practise training a simulated relative. It is therefore not surprising that they should feel unable to do so.

The follow-up evaluation highlighted the global applicability of the workshop. All over the world the workshop was implemented, albeit occasionally in an altered format to adjust to local circumstances and provide EDHEP participants with more opportunities to practice communication skills in role-plays with simulated relatives.

In Denmark increased donor rates were reported after implementation of a follow-up workshop. ${ }^{18}$ Other countries reported increases in donation rates after running EDHEP workshops as well, but these figures were not published officially.

The international interest in EDHEP in combination with the high evaluations of its' contents and format of EDHEP demonstrate that it is accepted as a valuable addition to national or local continuing professional development programmes. There is a worldwide understanding that advanced communication skills are crucial in this sensitive area of medicine and nursing. The rapid developments in transplantation medicine and organ procurement coupled with the shortfall in donation rates call for professional answers.

The results of this study indicate that EDHEP may contribute to resolving the problems. The national adaptations to the programme show that additions and alterations to suit local needs can improve its effectiveness. Its' limitations are also underlined by these evaluations. A number of countries desired more opportunities to practise skills to enhance the impact on practice. Isolated improvement of knowledge and skills by individual professionals is another issue that is important. A supportive climate within intensive care units and between different hospitals on a (inter)national level, is essential to foster individual improvements. 


\section{References}

1. Miranda B, Fernandez LM, Matesanz R. The potential organ donor pool: international figures. Transpl Proc 1997;29:1604-6.

2. Kootstra G, Kievit J, Nederstigt A. Organ Donors: Heartbeating and Non-heartbeating. World J Surg 2002;26(2):181-4.

3. Martinez J, Lopez J, Martin A, Martin M, Scandroglio B, Martin J. Organ donation and family decision-making within the Spanish donation system. Soc Sci Med 2001;53:405-21.

4. Blok G, van Dalen J, Jager K, Ryan M, Wijnen R, Wight C, et al. The European Donor Hospital Education Programme (EDHEP): addressing the training needs of doctors and nurses who break bad news, care for the bereaved, and request donation. Transpl Int 1999;12(3):161-7.

5. Wight C, Cohen R. The European Donor Hospital Education Programme (EDHEP). In: Chapmen JR, Deierhoi M, Wight C, editors. Organ and Tissue Donation for Transplantation. London: Arnold, 1997:373-81.

6. Davis D, Thomson M, Oxman A, Haynes R. Evidence for the Effectiveness of CME. JAMA 1992;268(9):1111-7.

7. Mann KV. Educating medical students: lessons from research in continuing education. Acad Med 1994;69(1):41-7.

8. Jager K, Ryan M, Dalen van J, Blok GA, Wijnen RMH. European Donor Hospital Education Programme. The grief response and donation request. Moderators manual. Leiden: Eurotransplant International Foundation/Sandoz Pharma Ltd., 1991.

9. Edmondson A. Managing the risk of learning: psychological safety in work teams. In: West M, editor. International Handbook of Organizational Teamwork. London: Blackwell, 2002.

10. Blok GA, Jager K, Dalen van J. European Donor Hospital Education Programme. The grief response and donation request. Participants Manual. Leiden: Eurotransplant International Foundation/Sandoz Pharma Ltd., 1991.

11. Norman GR. The adult learner: A mythical species. Acad Med 1999;74(8):886-9.

12. Haney J, Lumpe T, Czernick C, Egan V. From beliefs to actions: the beliefs and actions of teachers implementing change. Journal of Science Teacher Education 2002;13(3):171-87.

13. Sanson-Fisher R, Cockburn J. Effective teaching of communication skills for medical practice: selecting an appropriate clinical context. Med Educ 1997;31(1):52-7.

14. Wight C. EDHEP Organisors' Manual. Leiden: Eurotransplant Foundation, 1992.

15. Dalen van J, Blok GA, Morley M, Morton JB, Haase-Kromwijk B, Sells RA, et al. Participants' judgements of the European Donor Hospital Education Programme (EDHEP): an international comparison. Transpl Int 1999;12:182-7.

16. Dalen van J, Blok GA, Kranenburg J, Haase B. European Donor Hospital Education Programme. Transpl Proc 1996;28(1):398-9.

17. Muthny FA. Fortbildungsprogramm zur Gesprächsführung mit den Angehörigen plötzlich Verstorbener als Beispiel von KommuniKationstraining und affektiv-emotionalen Lernzielen in der Ärztlichen Ausbildung. [Developmental programme for consultations with suddenly bereaved relatives as an example of communication skills training and affective-emotional learning goals in the training of doctors]. Medizinische Ausbildung 1996;13 (1) May:57-64. 
18. Birkeland SA, Christensen AK, Kosteljanetz M, Svarre HM. Rise in organ donations [letter]. Lancet 1997;349(9064):1558. 


\section{0}

\section{Discussion}

In the preceding chapters, studies were reported about perceptions, learning effects, (international) implemtation, effects on competence and teamwork and the relationship with donor relatives' satisfaction of the European Donor Hospital Education Programme (EDHEP).

These studies served several purposes. Firstly, we investigated how EDHEP's format, relevance for practice and learning effects were perceived by the professionals for whom the programme was designed. Secondly, we measured the effects of EDHEP on the competence of health care professionals, both at individual level and at team level. Thirdly, we studied the relationship between issues addressed in EDHEP and donor relatives' satisfaction and finally, we generated some ideas that might enhance continuing professional development.

\section{Perceptions of the European Donor Hospital Education Programme (EDHEP)}

The EDHEP workshop, 'The grief response and donation request' was designed as an awareness raising programme to sensitise doctors and nurses to the issues involved in breaking bad news and asking relatives' consent for donation. The high appreciation of the issues addressed in the programme, described in Chapters 3 and 9, suggest that EDHEP is indeed tailored to the actual needs experienced by intensive care medical and nursing staff all over the world and that it is relevant for practice. This conclusion is underlined by the evaluations of intensive care staff in the study that examined the impact of EDHEP on teamwork (Chapter 7). Staff indicated that the workshop made an important contribution to their current practice in breaking news of death, to requesting donation and supporting relatives. Participants were highly appreciative of the interactive character of the programme, irrespective of background, prior professional experience or country of origin. An interprofessional educational programme for doctors and nurses was viewed as good practice, since these professionals work together in ICU-teams. The availability of the transplant coordinator and the explanations about the donation 
procedure in the EDHEP workshops were highly valued. Participants were able to familiarize themselves with the donation procedure and the tasks, roles and responsibilities of all the professionals involved in the process. Increased knowledge about the donation procedure as a result of participation in EDHEP is likely to have contributed to participants' increased satisfaction with the practicalities and implementation of the donation protocol in EDHEP-units as described in Chapter 7.

Participants around the world rated the learning effects of EDHEP highly (Chapter 3 and 9), reporting a better understanding of the communication process and of relevant communication skills. They indicated feeling more comfortable dealing with bereaved relatives and expected to be more confident in their communication with relatives, the more so since participating in the programme lowered the barrier to requesting donation.

Participants, who actively participated in the role play sessions in the workshops reported a stronger learning effect than those who only observed the role play. This is in line with results from other training programmes for professionals. ${ }^{1}$ An unexpected finding in Chapter 3 was that this could not be confirmed for the Dutch participants, which may be attributable to the Dutch participants' prior experience with this teaching format. Observation of the role play sessions was enhanced by structured observation assignments. This may have contributed to participants' perceived improved ability to comment on communication skills. The fact that the participants were better able to distinguish different communication skills may have contributed to the quality of team work and the division of tasks in the team before approaching relatives about organ donation (Chapter 7).

The international evaluations of the programme indicate that the identified needs are global needs and that the issues addressed are relevant for intensive care professionals all over the world. Our studies, described in Chapter 3 and 9, and the experiences of colleagues abroad, indicate that the programme can be adapted to a country's cultural, legal and religious conditions, which adds to the programme's relevance for local practice.

The EDHEP Train-the-Trainer courses have contributed to the international implementation of EDHEP. Participants appreciated the format and content of the training courses, the positive educational climate, the interactive character of the programme and the feedback from the trainers, which facilitated their learning. This confirms that interactive programmes are the most effective format for professional development. ${ }^{23}$

The programme is internationally regarded as a valuable tool to add to local continuing professional development programmes. Participation in the Train-theTrainer courses gave participants, i.e. working group members and future moderators, an opportunity to familiarize themselves with EDHEP, to gain insight into its aims and spirit and to develop strategies for national implementation. One of the messages of the Train-the-Trainer courses is that, for educational programmes for professionals to be effective, content and format should be closely 
linked to participants' working environment. This requires not only translation into the national language, but also adaptation of cases, role play scenario's and videoprogrammes to local needs and customs. The results of the follow-up meeting with representatives of countries that had adopted EDHEP showed that most countries had indeed adapted the programme to increase relevance and impact of the workshop. There are anecdotic reports that do support the success of this approach. ${ }^{45}$

\section{The impact of EDHEP on the competence of the professional staff}

In developing instruments to measure the effects of EDHEP, we took care to design tasks that approached the reality of professional practice as closely as possible. Some compromises had to be made between measurement rigour and feasability. In the general introduction (Chapter 1), we identified the following key constituents of professional competence in the domain we studied: knowledge, communication and teamwork skills, attitudes towards (organ) donation and communication with relatives, and self-efficacy. The main issues addressed in this thesis are communication and teamwork skills and self-efficacy.

Effects of EDHEP on self-efficacy and communication skills

Internationally, participants report sizable learning effects indicating increased confidence in communicating with relatives about grief and organ donation. The effects of EDHEP on self-efficacy, described in Chapter 4, underscore these evaluations. All subjects reported improved knowledge of how to break news of death, to request donation, to explain the donation procedure and to deal with relatives' grief. They also reported increased appraisal of their performance on these tasks and less difficulty approaching relatives with a request for donation. There were no differences between professions or between men and women in this respect. Experience was found to be associated with an increase in self-efficacy beliefs and a decrease in the perceived difficulty of requests for donation. The relationship between self-efficacy and experience was found to be rather complicated. Experience in the domain, i.e. general experience in ICU and in requests for organ donation, played a specific role. Subjects with little experience in these areas demonstrated greater increases in self-efficacy scores after participation in EDHEP compared with more experienced subjects. Moreover, self-efficacy scores showed larger increases in subjects with little general experience than in subjects with low baseline levels of self-efficacy. This suggests that lack of experience plays a greater role than lack of confidence in one's abilities. On the other hand, self-efficacy was found to continue to increase even above a rather high level of experience (more than ten years). The British subjects had more previous experience and higher self-efficacy scores that the Dutch subjects. On the basis of self-efficacy theory one might argue that participants' positive experiences heightened their self-efficacy beliefs, which were strengthened by the workshop. 
Presumably, the workshop contains the right ingredients for a positive influence on self-efficacy beliefs: personal experience, vicarious learning, constructive feedback and constructive use of physiological arousal.

Self-efficacy theory postulates that increased self-efficacy is associated with improved performance. This was not entirely borne out by the results of the studies into the effects of EDHEP on cognitive skills in communication (Chapter 6) and on communication skills ${ }^{6}$ (not included in this thesis).

All professionals showed a transient improvement in the cognitive use (written proficiency) of communication skills (Chapter 6). The ability to adequately interpret authentic situations presented in written cases (diagnostic accuracy) was not affected by participation in EDHEP. However, EDHEP participants did show a transient superiority compared to control subjects, in the cognitive use of communication skills and also in the ability to link the interpretation of the (emotional) state of relatives presented in the written cases with the recognition of the communication skills that are needed (coherence between diagnostic accuracy and written proficiency). The general approach to 'solving' problems in the authentic situations depicted in written cases showed a lasting change in EDHEP participants. Experience in critical care with bereaved families and requests for donation or the perceived difficulty of making such requests did not add to the above mentioned changes.

Although nurses may perform well on the cognitive use of communication skills, this was not reflected in performance. Only doctors demonstrated a significant, albeit transient, improvement in how they conduct a bad news encounter following attendance of the EDHEP workshop ${ }^{6}$. These doctors attended more sensitively to relatives' needs and showed improved skills in explaining the events to come if relatives would consent to donation. The latter effect was still demonstrable six months later. Mere participation in the measurements was also found to result in the improvement of some skills; doctors in the control group showed a temporary improvement of some of these skills. The behaviour test we used did not detect changes in nurses' communication skills. However, the absence of a demonstrable effect on nurses' performance does not necessarily imply that learning about communication with bereaved relatives did not take place on a cognitive level. Nurses' role in encounters with relatives may not offer them the opportunity to display their mastery of key communication skills.

The results reported in Chapter 5 indicate, that (simulated) relatives' satisfaction with how they were treated by doctors and nurses increased when the professionals showed good teamwork and complementary behaviour.

More confidence than competence in communication skills

The relationship that emerged between the cognitive use of communication skills (Chapter 6), the actual behaviour ${ }^{6}$ and self-efficacy (Chapter 4) is intriguing. Participation in EDHEP yielded sustained effects on self-efficacy both regarding the knowledge compentent and the performance behavioural component, but the 
effects of EDHEP on the behaviours in relation to which self-efficacy were only transient. In terms of Miller's pyramid of professional learning ${ }^{7}$, it means that the participants 'knew' what it was about (cognitions about the communication process; diagnostic accuracy), they indicated that they 'knew how' to do it (coherence between diagnosis and written proficiency, and self-efficacy) and in the measurements immediately after the workshop they showed they were able to perform the required behaviour ('show how)'. However, at follow-up they reported similar self-efficacy beliefs, but failed to perform accordingly.

\section{Effects of EDHEP on teamwork in intensive care}

The results of the study reported in Chapter 7 show that EDHEP had a significant positive effect on teamwork in intensive care units relating to death and donation. Intensive care staff in EDHEP-units were more satisfied with collaboration in the team regarding donation procedures than staff in non-EDHEP units. In EDHEPunits, bad news encounters were more often formally prepared and the donation request was more often made by a team. In EDHEP-units compared with nonEDHEP-units, tasks were more often divided before a donation request was made. In all units staff were well aware of the existence of a donation protocol, but staff in EDHEP-units were more satisfied with its feasibility and implementation. The aims of EDHEP regarding teamwork were largely achieved. The absence of an effect on emotional (social) support is plausible, because EDHEP does not target the intensive care team as a whole and no specific attention is paid to characteristics and quality of the relationship between team members and superiors.

The results of the study described in Chapter 5 indicate that (simulated) relatives were more satisfied with how they were treated by doctors and nurses when the two professionals displayed good teamwork and complementary behaviour. Adequate teamwork skills in communicating with relatives is part of the competence in the domain death and organ donation. The conclusions that could be drawn from the results of the studies described in Chapter 4 and 6 concern individual competence: the relationship between self-efficacy and communication skills. For the study described in Chapter 7 no such direct relationships could be established between individual competence and the effects of EDHEP on teamwork. Both nurses and doctors must be competent in communicating and in recognizing which communication skills are needed, while accepting that they may undertake complementary roles at different times.

The results of the studies described in Chapters 4 and 6 suggest that participation of the majority of staff of an intensive care unit in EDHEP workshops would result in improved competence of those team members on certain aspects: self-efficacy (relating to knowledge and performance), perceived difficulty of the donation request, cognitive skills in recognizing relatives' complex (emotional) situation ('indeterminate situations'), and doctors' skills in structuring bad news consultations and explanation of the donation procedure. The study 
measuring the effect of EDHEP on teamwork addressed the effects on team behaviour rather than on individuals. Improved competence can only be made effective in supportive environments. In EDHEP-units staff showed greater satisfaction with collaboration in general and collaboration relating to death and donation in particular. In EDHEP-units families were mostly approached by more than one team member and team members were more satisfied about the debriefings after the donation request was made. It is arguable that improved individual performances concerning communication with relatives, adequate assessment of the complexity of the situation, and improved collaboration in contacts with relatives (complementary behaviours) contributes to increased satisfaction of both the team members and relatives.

\section{Donor relatives and staff's competence}

The gradual increase in donor relatives' satisfaction ratings regarding treatment by hospital staff, described in Chapter 8, suggests a gradual improvement in organ donation procedures in the Netherlands over the past decade. Unfortunately no causal inferences can be made regarding interventions and specific improvements in practice. The introduction of donation protocols in hospitals and information campaigns accompanying the introduction of new legislation appear to have had a positive effect on professionals' knowledge of the donation procedure, specifically about the concept of brain death. Information campaigns and the implementation of a national donor register appear to have resulted in greater awareness among relatives of the option of donation. This is supported by the fact that in 2001 more than three-quarters of relatives were aware of the deceased's wishes, half the deceased persons in this sample had registered in the national donor register, and almost half of the relatives in this sample brought up the option of organ donation themselves.

Improvements were demonstrated for all behavioural variables, especially the treatment of relatives before the announcement of the death was made, the way relatives were told about (brain) death and the way they were kept informed throughout the process. This will probably have had a positive effect on later phases in the donation process. Over the years relatives have shown increasing satisfaction with the way the death was announced and the timing and the quality of the consultation about the option of donation. The effects may have been affected by the fact that the majority of relatives in the 2001 were spouses, who may have been more knowledgeable about the wishes of the deceased. In 2001 hospital staff have become more attentive to relatives' needs, anger and feelings of neglect have become less common and relatives were more satisfied with the behaviour of all professionals compared to 1995. The largest improvement in relatives' satisfaction was related to nurses' behaviour. There were mixed feelings about the treatment by transplants coordinators.

To date hundreds of Dutch staff, i.e. doctor, nurses and transplant coordinators, have participated in EDHEP workshops. The majority of the participants were 
nurses. It is arguable that relatives' increasing satisfaction with professionals' behaviour over the past decade is associated with an improvement in that behaviour as more and more staff have participated in EDHEP workshops over the years. The following aspects of professionals' behaviour have improved: efficacy beliefs (regarding to knowledge and performance) (Chapter 4), perceived difficulty of the donation request (Chapter 4), cognitive skills in recognizing the complex (emotional) situation of relatives ('indeterminate situations') (Chapter 6), and doctors' skills in structuring consultations and explaining the donation procedure.

The results of the study described in Chapter 5 indicate that good teamwork and complementary behaviour by doctors and nurses increased simulated relatives' satisfaction with both professions. It is possible that a similar relationship would be found in real practice.

The way the death was announced explained more than $50 \%$ of the variance in relatives' satisfaction of the relatives in all the years. The outcomes of the study into the effect of EDHEP on teamwork skills (Chapter 7) indicates that in EDHEP-units the consultation with the family in which death is announced is prepared more frequently in a separate team meeting compared to non-EDHEPunits. Presumably staf in EDHEP-units are more aware of the importance of this consultation. Also in EDHEP-units families are more often approached by well prepared pairs of team members. Not only does this support the team members, it also guarantees more continuity in the care of relatives.

\section{Critical reflection on the main findings}

In summary, the EDHEP workshop receives positive evaluations and is perceived as relevant for practice all over the world. The TTT-courses are highly valued by those who participated and have been successful in helping professionals from different countries to implement EDHEP in a format that was adapted to their local situation.

As for individual competence, participation in EDHEP leads to sustained improvements in the following areas: self-efficacy beliefs, perceived difficulty of making a donation request, doctors' skills in structuring a consultation and explaining the donation procedure and the general cognitive skill of 'solving' emotionally complex situations. Participation in EDHEP has also resulted in transient improvements of doctors' communication skills in breaking bad news, doctors' and nurses' cognitive use of key communication skills and doctors' and nurses' ability to link the interpretation of emotionally complex situations with the recognition of communication skills needed in these situations.

As for team work, EDHEP appears to have a lasting effect on ICU team competence with respect to preparation for bad news encounters, systematic team approach in requesting donation, more satisfactory teamwork, especially regarding donation, and use and implementation of the donation protocol. 
EDHEP addresses those behavioural variables that are experienced as essential by donor relatives. Over the last decade relatives have shown increasing satisfaction with staff performance regarding those variables.

The evaluations of EDHEP indicate that the programme meets the 'true needs' of the participants. It promotes professionals' awareness of deficiencies in professional competence and it is perceived as highly relevant for practice. In addition, the programme is firmly rooted in the context of clinical practice and it uses clinically relevant material. Knowledge and skills are learned in an integrated way. EDHEP is domain specific and contextualized. It uses experienced trainers, case discussions, explicit instructions, role plays with simulated relatives, videotapes and learning goal guided feedback. It addresses the interaction between cultural and individual values, norms, expectations and attitudes. It encourages participants to reflect upon personal and professional attitudes and experiences. It has all the elements that influence self-efficacy beliefs: personal experience, vicarious learning, constructive feedback and constructive use of physiological arousal. It elicits profound personal feelings and experiences relating to death.

There is increasing evidence that the techniques and methodologies used in EDHEP are effective in improving professional competence. ${ }^{2,3,8-20}$

Although most effects of EDHEP on the individual competence are transient, there has been a sustained effect on self-efficacy beliefs and some attitudes. Preliminary results about the effects of EDHEP on individual attitudes to organ and tissue donation indicate a sustained change in a positive direction. The effects on attitudes relating to teamwork show a sustained change towards a preference for approaching donor relatives with more that one team member.

It is important to remember that EDHEP is not a skills training course, but an awareness raising workshop and that not all participants are able to practice what they have learned in simulated relative encounters. Moreover, the workshop offers no opportunity for participants to use the feedback they receive in the workshop. Enhancement of some but not all aspects of communication following a brief training and decay of particular skills at follow-up has been noted before. ${ }^{21}$ This is an indication that increased awareness of the complexity and dynamics of communication with bereaved relatives may not suffice to achieve a permanent modification of professionals' behaviour. ${ }^{22}$ A lasting change calls for repeated practice. When the opportunities for using communication skills in encounters with bereaved relatives are limited, those skills are likely to fade. When we look at sustained effects of EDHEP in this light, it is remarkable that some of the improvements are still demonstrable after six months.

Diminished skills at follow-up may be due to a lack of opportunities to perform the skills, since donation procedures are not daily events. Patel et al. ${ }^{23}$ indicated that profound (domain specific) knowledge and practical experience (tacit knowledge) from the basis of (medical) expertise. The ability to think about issues and solve problems is highly dependent on the availability of specific knowledge (effective problem solvers rely heavily on domain-specific knowledge), ${ }^{24}$ but also on what 
Schön ${ }^{11}$ calls the competence to deal with 'indeterminate situations', i.e. situations in which there is uncertainty, uniqueness or a value conflict. Insufficient exposure to such these situations may contribute to a loss of skill.

The assessment instruments may not have adequately covered the proficienc in (the cognitive use of communication skills. It is known from research in assessment of clinical competence that performance varies across cases. This is generally referred to as the 'case-specificity of performance'. Professionals' knowledge and skills were found to be content or case related, even more so with growing experience. ${ }^{25}$ Performance on one case may therefore be a poor predictor of performance on other cases. A method to establish the sources of error in our performance assessments is generalizability analysis. ${ }^{26}$

The measurement of competence in communication skills may not have covered all variables that are relevant in practice. In Miller's pyramid ${ }^{7}$ ('knows', 'knows how', 'shows how' and 'does' ) a distinction is made between the domains of cognition ('knows' and 'knows how') and behaviour ('shows how' and 'does'). Competence ('shows how') is different from performance ('does'), i.e. performance does not always confirm the results on competence assessment. This is underlined by a study by Rethans et al. ${ }^{27}$ who found assessment of competence under examination circumstances only to have predictive value for performance in real practice when e.g. efficiency and consultation time were taken into account. The authors concluded that substandard performance of doctors physicians did not necessarily reflect a lack of competence and that performance and competence should be seen as two distinct constructs. ${ }^{27}$ The reverse may also be true, given that test conditions are artificial and we usually do not know what actually happens in practice when professionals meet relatives. The question is whether poor performance of communication skills as identified by our competence measures automatically implies poor performance in real practice. We were unable to establish effects on nurses' behaviour and one of the conclusions was that this was due to complementarity in the encounters. Simulated relatives were found to rate the behaviour of both doctors and nurses more highly when these professionals operated as a good team. It should therefore be studied, whether professionals in a team compensate for one anothers' lack of skills. Some evidence of this was found in the results of the validation study where doctors took a more active role and nurses a more supportive one.

The reported sustained effects on self-efficacy should be interpreted with caution. The results of our studies appear to challenge the assumption that selfefficacy beliefs are good predictors of the real performance of the key tasks in our domain: i.e. breaking news of death, requesting donation, explaining the donation procedure and dealing with relatives' reactions. EDHEP has a strong impact on participants' beliefs about their capacities, but improved self-efficacy was not always substantiated by assessment outcomes. This phenomenon has also been reported in other studies and may be related to the unreliability of self-assessment. The 
conclusion drawn in Chapter 4 should to be taken very seriously. Self-assessment of professional behaviour may be suspect and both overestimation and underestimation are found. ${ }^{28,29}$ According to Gordon ${ }^{28,29}$ self-assessments by adult learners are intimately tied to stable self-concepts or to global attributions of ability and therefore less vulnerable to influences from external sources. It is therefore interesting that the experienced professionals in the British sample who had already high self-efficacy scores at baseline, increased their scores after participation, which proved to be unfounded as their performance was below average. ${ }^{6}$ Obviously, they overestimated their abilities. Likewise, the relatively inexperienced intensive care staff in the Netherlands may have underestimated their abilities on the pre-test. Ward et al. ${ }^{30}$ examined the methodological issues in the measurements involved in self-assessment. They state that individuals are able to distinguish between good and poor performance, but are unable or unwilling to apply the same standards to their own performance. They also indicated that self-assessment criteria and external criteria may not be interpreted in the same way and that the conclusion is not justified that the subjects under study had poor self-assessment skills. As indicated in Chapter 4, it is not clear whether the subjects in our samples had adequate skills to assess their own knowledge and behaviour, whether they used the scales and questions consistently and whether their criteria were similar to ours. Gordon ${ }^{28,31}$ suggested that self-assessment can only improve if it is conceived as a skill requiring clear goals and explicit training with feedback.

The results indicate that with respect to mutual emotional support the suggestion by Sexton et al. ${ }^{32}$ to use principles of training in aviation may be useful for training in feedback skills and team support. Those principles state that training should be aimed at the entire crew in recognition of the notion that safety and good performance are a function of the 'captain' using all available resources. This can create the safe team environment referred to by Edmondson, ${ }^{33}$ where team members can safely talk about their vulnerabilities and learn from feedback from their colleagues. This is especially important in the sensitive area of death and donation. It is important to have accurate knowledge about the other team members, i.e. relatives should not be confronted with unexpected personal conflict or misunderstanding in the ICU team. ${ }^{34}$ A positive team environment enhances team work and enables team members to take complementary roles, which is highly valued by relatives.

The potential donor pool and rate of donation are influenced by many organisational and professional factors. Adequate and sensitive communication with bereaved families is not automatically followed by relatives consenting for donation, as relatives tend to respect the wishes of the deceased. Any effect of EDHEP on donor rates can only be indirect and was beyond the scope of this thesis. There are anecdotical reports, however, of implementation of EDHEP having resulted in increases in donor rates. ${ }^{4} \mathrm{~A}$ well-balanced combination of macro-oriented and regulatory policies with competence-based educational programmes, may be more effective in increasing the donor pool than the policies 
chosen so far. Well-informed staff, possessing the necessary skills for effective communication with bereaved relatives will feel better prepared for the difficult tasks of breaking news of death and requesting donation.

The only systematic evaluation was carried out was in Denmark, where increases in donor rates were found only after a follow-up training session of EDHEP. ${ }^{5}$ Carefully designed experiments should be able to relate specific staff behaviour with decisions made by relatives concerning organ donation.

\section{Continuing professional development}

According to Crossley et al. ${ }^{35}$ good assessment depends on systematic definition of the key elements in the practice of health professionals and reliable assessment requires the use of multiple assessment methods. The past years several reviews of educational programmes to improve professional competence and of the ways to assess their impact have been published. ${ }^{2,3,14}$ The provided by $\mathrm{Grol}^{3}$ serves our purposes best, because he suggests that bridges have to be built between different approaches to quality improvement. He refers to the need for integrated methods and comprehensive programmes that '...combine, for instance, evidence based guidelines, indicators for continuous assessments, and quality improvement projects embedded within an wider quality system of a hospital or practice'. He also states that 'there is wide consensus on the need for regular assessment and monitoring of clinical performance for both professional development and quality improvement, and a widespread agreement on the need for public accountability'. Concrete suggestions, however, are not given. ${ }^{3}$

In Figure $1 \mathrm{a}$ tentative model is presented which incorporates the aspects that have been shown to be important in continuing professional development programmes. The model is an attempt to build the bridges mentioned earlier. The chapters of this thesis are shown at the most relevant position in the model.

There are three widely accepted frameworks to evaluate educational programmes. How these frameworks fit into the model is described below.

The model uses a circular approach. Donabedian's distinction between structure or input, process and outcome is helpful for the overall interpretation of the model. ${ }^{36}$ Continuing professional development programmes and assessment of competence constitute the 'input' or 'structure'; performance in practice the 'process' and measures such as relatives' satisfaction, quality of teamwork and efficiency outcomes constitute the 'outcome'. Ideally, the outcome measures should in turn be the input for modifications of professional development programmes or the development of new programmes or approaches. A similar circular process can be used on a smaller scale, with the professional development programme as the 'input' or 'structure'; participation in the programme as the 'process' and programme evaluation as the 'outcome'. The outcomes in terms of format and methodologies should in turn be used as input for modifications of professional development programmes or the development of new programmes or approaches. 

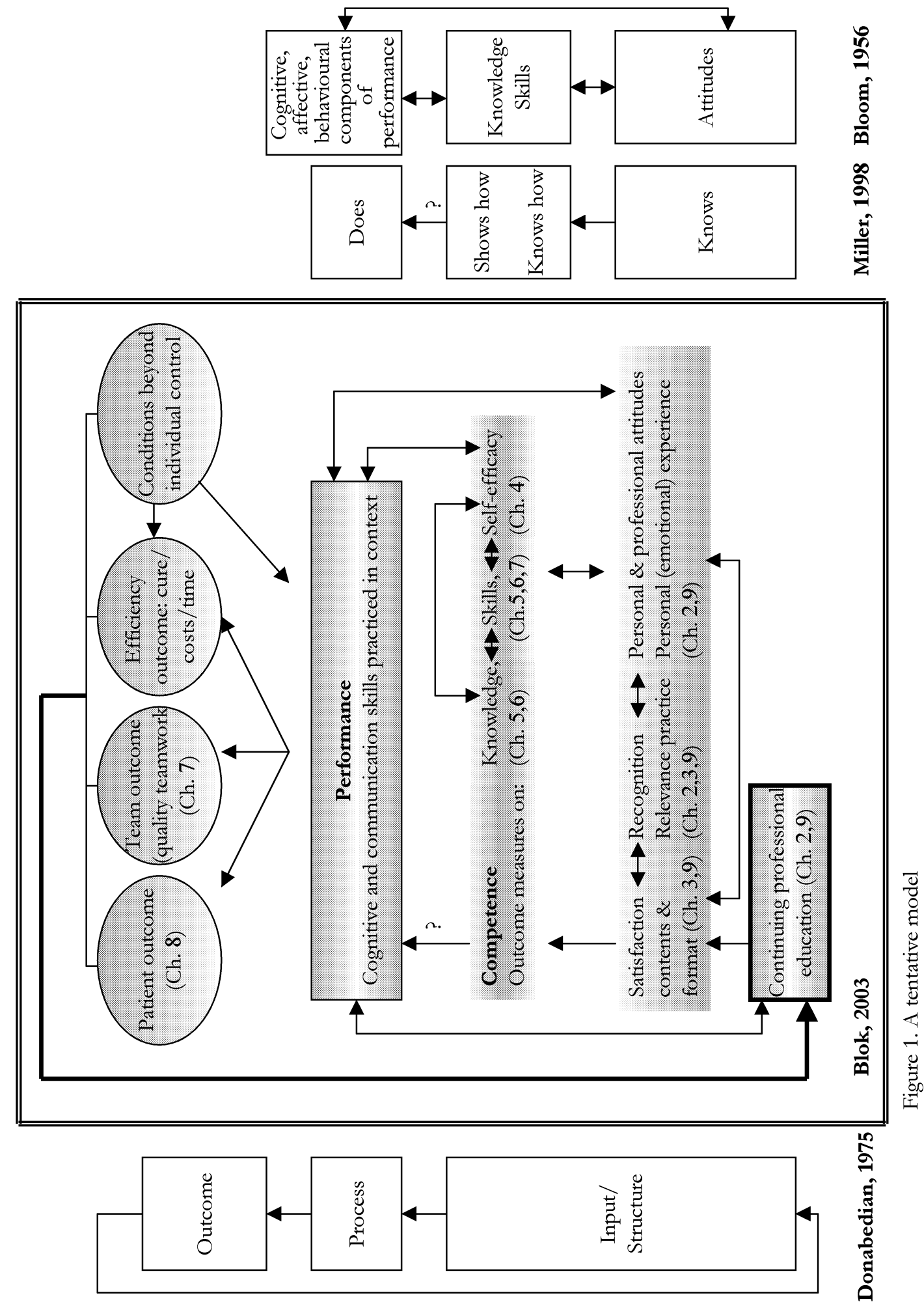
It is not difficult to see where the components of Miller's pyramid ${ }^{7}$ fit into the picture. The cognitive components ('knows' and 'knows how') are placed at the bottom of the model and at the level of competence assessment (knowledge, cognitive components of communication skills and self-efficacy); the behavioural component 'shows how' is also placed at the level of competence assessment (knowledge and skills tests). The behavioural component 'does' is placed at the level of authentic performance in practice.

Competence tests can be used te assess knowledge and skills. Whether subjects' performance in real practice actually measures up to what they showed in competence assessment must be inferred from the outcome measures.

Bloom's original taxonomy of educational objectives is more difficult to fit into the model, as it is very detailed. ${ }^{37,38}$ For our purposes we use a simpler and widely accepted framework derived from his theory, consisting of cognitive (intellectual), affective (emotional and attitudinal) and psychomotor (physical skills) domains: knowledge, attitudes and skills. ${ }^{38}$ All three components come into the model at different levels. Attitudes are placed at the basis. They can be measured as part of competence assessment, but they may also make a direct contribution to performance in practice. Knowledge and skills can be placed at the level of competence. They are influenced by experience. Behaviour in practice has cognitive, behavioural and affective components which are influenced by competence levels, personal experiences and attitudes, and self-efficacy. Individuals bring knowledge, attitudes and skills to professional development programmes, which ideally contribute to further knowledge, improved skills and altered attitudes. Experiences from professional development programmes can also have a direct influence on performance in practice, where knowledge and skills are displayed and the attitudes may be inferred from the behaviour shown.

\section{Directions for further research}

From the model presented in Figure 1 recommendations for future research can be derived. As $\mathrm{Grol}^{3}$ indicated it would be beneficial to build bridges between different approaches to quality management. Ideally in the development of continuing professional development programmes for specific domains all variables in the model should be taken into account. In the remainder of this chapter we will focus on the variables that may be addressed in studies focusing on research questions derived from the results of this thesis.

\section{Outcome research}

Hard data on treatment outcomes related to numbers of patients cured, medical consumption, donor rates, cost-effectiveness and efficient use of time and resources provide important information. Health care is very expensive and cost effectiveness should be the concern of all those involved. Figures about costs, time and resources used and patient outcomes should ideally be included in professional 
development programmes. The majority of staff in our teamwork study indicated that donation procedures added considerably to their workload. Donation procedures often take place outside office hours, which means additional costs in terms of staff salaries and the use of operating theatres. EDHEP participants are told that the costs of one year on heamodialysis equals the costs of a kidney transplantation; patients may have to be on haemodialysis for many years. Health care staff has a responsability for all patients. The welfare and health of patients on waiting lists for donor organs should also be a concern for these professionals. Conditions beyond individual control should always be kept in mind, as they may contaminate outcome results. Hospital regulations that enhance organ procurement may have a positive impact on donor rates, whereas lack of specialized staff and operating theatres may have the opposite effect. Information from the media may affect health consumers' behaviour. This implies that professional development programmes should also pay attention to these issues.

As explained earlier adequate and sensitive communication with bereaved families does not automatically lead to consent for donation, because relatives tend to respect the wishes of the deceased. However, investments in programmes like EDHEP may be expected to have a positive impact on donor rates as effects of staff behaviour of relatives' decisions has been established. Our studies have demonstrated mostly transient effects of EDHEP on individual competence. EDHEP is a skills awareness programme and the fact that lasting effects were found was remarkable. The results points to a need for strategies to maintain skills levels. One such strategy might be extension of the programme or follow-up workshops, which have proven to be effective. ${ }^{5}$ A well-balanced combination of macro-oriented and regulatory policies with competence-based educational programmes, may be more effective in breaking bad news sensitively and in increasing the donor pool than the policies chosen so far.

High quality care and positive outcome is enhanced by good teamwork. Consumers of health care value continuity of care and professionals who have clear roles, tasks and responsibilities and interact with each other in a professional way. The donation procedure puts considerable pressure on the team, as it is an emotionally challenging event and adds to the workload. Our study indicates that EDHEP contributes to better teamwork regarding the donation procedure. However, the response in the study was $65 \%$ and it is unknown whether respondents' views regarding issues addressed were different to those of the $35 \%$ of non-responders. Future studies into the effects of staff development programmes on teamwork, should take into account the opinions of all the team members. It would be interesting to examine the effects of a continuing professional development programme like EDHEP for the ICU team as a whole.

The high percentage of staff reporting lack of emotional support in the sensitive areas of death and donation, and in general, indicate that it might be a good suggestion to also train the team as a whole (including the superiors), to learn skills in giving constructive feedback and team support. Although this kind of 
training does not necessarily have to be tied to death and donation; it would be of interest to study the effects of such an approach on the outcome measures presented in the model: relatives' satisfaction, quality of teamwork, donor rates, cost-effectiveness and efficient use of time and resources.

The results from studies into the satisfaction of relatives or patients and their families provide information that can be used as input for educational programmes. Patients and their families are the customers of the health care system and they as well as health care professionals and the organizations that employ them benefit from the provision of high quality care. Health care can be improved if patients and their families are asked to give their views. Ideally, there should be a direct relationship between professionals' performance and ratings or observations by patients or relatives. Unfortunately, such information was not available in our research in the Netherlands, because EDHEP participants and control group subjects were recruited nationwide. Measuring the satisfaction of relatives who interacted with these professionals would thus have required inclusion of nearly all Dutch hospitals. Obviously, this was not feasable. However, future research might be directed at a limited number of hospitals in which all relatives of potential donors should be asked to participate in the study. This would provide information about the effects of educational programmes like EDHEP on donor rates. It would enable comparisons between evaluations of staff behaviour by relatives who consent to donation and those who refuse to consent. The results of such a study should be used to improve professional development programmes, information campaigns aimed at the public and may also provide valuable input for improvements in hospital procedures.

\section{Competence}

In Chapter 1 it was stated that the definition of professional competence and its assessment are subject to debate. Some considerations must not be neglected when assessment results are used to infer effects on actual practice. Assessment objectives must match the educational objectives. This implies, that assessment tasks should reflect professional reality as closely as possible and that appropriate contexts should be provided in test material to increase the possibility of addressing higher cognitive abilities and to establish differences in professional expertise. ${ }^{39}$

Competence and performance in the domain of communication with bereaved relatives about death and donation involves not only mastery of communication skills but also the ability to adequately interpret the situation at hand and to recognize and use those communication skills that are relevant and effective in that situation and to constructively use personal feelings and attitudes. This means that competence in communicating with relatives thus has a cognitive, a behavioural and an affective component. ${ }^{37}$ As indicated in the discussion on the results of our research, an important topic for further research is the improvement of 
instruments to assess this competence, measurement of cognitions in communication in particular. Generalizability studies will provide us with information about the required number of (paper) cases and raters to be used to solve problems related to unreliability of measurements due to case-specificity. Some of the results we found merit further study, such as a) the relationship between the meta-cognitive skills used in diagnosing complex emotional situations and actual behaviour, and b) the nature of the cognitive strategies used in literally writing down what one would say and the relationship between these strategies and actual behaviour. The results of the generalizability studies will enable us to gain more insight into these matters.

In the model there are bi-directional arrows between all aspects of competence. A study using multi dimensional equation models (LISREL) is currently underway to determine the exact direction of each of the arrows and the interrelationships between knowledge, communication skills, attitudes, self-efficacy and experience. Multidimensional equation models (LISREL) are expected to also provide answers to the questions about the relationship between experience and self-efficacy and the impact each of these variables has on performance. However, additional experiments would be necessary to establish what the basis is for the poor selfefficacy judgments of our subjects. If their ability for self-assessment was indeed limited, training is necessary as poor self-assessment skills may be harmful for patients and their families. Results of studies reviewed by Gordon ${ }^{31}$ suggested that training in self-assessment makes sense, because it promotes more mature, collegial, productive learning environments and requires no special resources. It would thus contribute to improved teamwork as well.

The impact of a team approach on communication efficacy should be a topic of further study. Our studies did not yield adequate answers concerning nurses' proficiency in communication skills; they did, however, learn on a cognitive level. Ideally, an experiment should be carried out in which communication skills of all professionals are rated both separately and in conjunction with a team member, and are related to ratings by (simulated) relatives or patients. Such an experiment would provide an answer to the question if and to what extent team members compensate for one another's lack of skill.

Personal and professional experience and attitudes

In Figure 1 the relationship between satisfaction about the contents and format of an educational programme and the personal and professional attitudes and personal (emotional) experiences is indicated with a double arrow. Personal and professional goals are strong motivators for learning; these goals may have their roots in personal and professional experiences and become more or less explicit in personal and professional attitudes. In EDHEP participants are stimulated to analyse and reflect upon the relationship between these personal feelings and attitudes on the one hand and their professional behaviour on the other hand. As described in Chapter 8 , these exercises are experienced as very powerful, very realistic and very 
instructive. The strong reactions to the exercises highlight the tendency to deny death and the reluctance among intensive care staff to confront their personal feelings and attitudes especially towards death. It is questionable whether denial and hesitance are the appropriate attitudes for professionals who have to help relatives understand and come to terms with the death of a family member. This aspect was not measured in our research, but may have profound influence on performance in practice and in the communication with relatives and colleagues. In the worst scenario, intensive care professional, not aware of their own hesitations, might not approach relatives about organ donation using the argument that it would be too emotionally challenging for the relatives. Future research should establish whether these exercises helped participants to recognize some of their reactions and to become more aware of the relevance for practice continuous reflection on the impact of their own feelings and attitudes may have on the communication with relatives.

'Death is the great pan-cultural and inescapable buman leveller and buman awareness of death is a near life-long awareness. However metaphysically or religiously conceived, however long postponed by medical science, bowever softened by belief of faith, the basic human fact and fear of death cannot be denied. Neither, in opposition, can the basic human craving for more life'

Maxine Sheets-Johnstone Journal of Consciousness Studies 2002;9(2):p.49. 


\section{References}

1. Mazmanian P, Davis D. Continuing medical education and the physician as a learner. JAMA 2002;288(9, September 4).

2. Davis D, Thomson O'Brien M, Freemantle N, Wolf F, Mazmanian P, Taylor-Vaisey A. Impact of formal continuing medical education. JAMA 1999;282:867-74.

3. Grol R. Improving the Quality of Medical Care. JAMA 2001;286:2578-85.

4. Wight C, Jager K, Cohen B, Dalen van J, Blok GA, Wijnen R. The European Donor Hospital Education Programme. In: Englert Y, editor. Organ and tissue transplantation in the European Union. Dordrecht: Martinus Nijhoff, 1995:175-179.

5. Birkeland SA, Christensen AK, Kosteljanetz M, Svarre HM. Rise in organ donations [letter]. Lancet 1997;349(9064):1558.

6. Morton J, Blok GA, Reid C, van-Dalen J, Morley M. The European Donor Hospital Education Programme (EDHEP): enhancing communication skills with bereaved relatives. Anaesth Intensive Care 2000;28(2):184-90.

7. Miller G. The assesment of clinical skills/competence/performance. Acad Med 1990;65(Suppl):S63-S67.

8. Bandura A, Adams NE. Analysis of self-efficacy theory of behavioral change. Cognitive Therapy and Research 1977;1(4):287-318.

9. Nowlen P. A New approach to continuing education for business and the professions. New York: American Council on Education and MacMillan Publishing Company, 1988.

10. Fox R, Mazmanian P, Putnam R. Change and Learning in The Lives of Physicians. New York: Preager, 1989.

11. Schön D. Educating the reflective practitioner. San Francisco: Jossey-Bass Inc. Publishers, 1991.

12. Fox R. New research agenda's for CME: organizing principles for the study of self-directed curricula for change. J. Cont. Educ. Health Prof. 1991;11:155-67.

13. Gask L, Goldberg D, Boardman A. Training general practitioners to teach psychiatric interviewing skills: an evaluation of group training. Med Educ 1991;25:444-51.

14. Davis D, Thomson M, Oxman A, Haynes R. Evidence for the effectiveness of CME. JAMA 1992;268(9):1111-7.

15. Patrick J. Training. Research \& Practice. London: Academic Press, 1992.

16. Curry L, Wergin JF. Educating professionals. Responding to new expectations for competence and accountability. 1993.

17. Mann KV. Educating medical students: lessons from research in continuing education. Acad Med 1994;69(1):41-7.

18. Regehr G, Norman G. Issues in cognitive Psychology: Implications for Professional Education. Acad Med 1996;71:988-1001.

19. Sanson-Fisher R, Cockburn J. Effective teaching of communication skills for medical practice: selecting an appropriate clinical context. Med Educ 1997;31(1):52-7.

20. Perkins JJ, Sanson-Fisher RW, Anseline P, Gillespie WJ, Lowe A. A preliminary exploration of the interactional skills of trainee surgeons. Aust N Z J Surg 1998;68(9):670-4. 
21. Maguire P, Booth K, Elliott C, Jones B. Helping health professionals involved in cancer care acquire key interviewing skills--the impact of workshops. Eur J Cancer 1996;32a(9):1486-9.

22. Novack DH, Suchman AL, Clark W, Epstein RM, Najberg E, Kaplan C. Calibrating the physician. Personal awareness and effective patient care. Working Group on Promoting Physician Personal Awareness, American Academy on Physician and Patient. JAMA 1997;278(6):502-9.

23. Patel V, Kaufman D, Magder S. The acquisition of medical expertise in complex dynamic environments. In: Ericsson KA, (ed). The road to expert performance: Empirical evidence from the arts and sciences, sports and games. Hillsdale NJ: Lawrence Erlbaum Associates, Inc., 1996:127-165.

24. Vye N, Delclos V, Burns M, Bransford J. The psychology of human thought. In: Sternberg R, Smith E, editors. Teaching thinking and problem solving: illustrations and issues. Cambridge: Cambridge University Press, 1990:337-62.

25. Vleuten van der CPM, Swanson DB. Assessment of Clinical Skills With Standardized Patients: State of the Art. Teaching and Learning in Medicine 1990;2 (2):58-76.

26. Shavelson RJ, Baxter GP, Gao X. Sampling variability of performane assessment. Journal of Educational Measurement 1993;30:215-32.

27. Rethans JJ, Sturmans F, Drop R, van der Vleuten C, Hobus P. Does competence of general practitioners predict their performance? Comparison between examination setting and actual practice. BMJ 1991;303(6814):1377-80.

28. Gordon MJ. A Review of the Validity and Accuracy of Self-assessments in Health Professions Training. Acad Med 1991;12:762-769.

29. Arnold L. Assessing professional behavior: yesterday, today, and tomorrow. Acad Med 2002;77(6):502-15.

30. Ward M, Gruppen L, Regehr G. Measuring self-assessment: current state of the art. Adv Health Sci Educ 2002;7(1):63-80.

31. Gordon M-J. Self-Assessment Programmes and Their Implications for Health Professions Training. Acad Med 1992;67(10):672-79.

32. Sexton JB, Thomas EJ, Helmreich RL. Error, stress, and teamwork in medicine and aviation: cross sectional surveys. BMJ 2000;320(7237):745-9.

33. Edmondson A. Manganing the risk of learning: psychological safety in work teams. In: West M, editor. International Handbook of Organizational Teamwork. London: Blackwell, 2002.

34. Cannon-Bowers J, Tannenbaum S, Salas E, Volpe C. Defining team competencies and establishing team training requirements. In: Guzzo R, Salas E, editors. Team effectiveness and decision making in organisations. San Francisco CA: Jossey-Bass, 1995:333-80.

35. Crossley J, Humphris G, Jolly B. Assessing health professionals. Med Educ 2002;36(9):800-4.

36. Donabedian A. The quality of care. How can it be assessed? JAMA 1988;260:1743-8.

37. Bloom B. Taxonomy of educational objectives. New York: David McKay, 1956.

38. Andrich D. A Framework relating to outcome based education and the taxonomy of educational objectives. Studies in Educational Evaluation 2002;28:35-59.

39. Vleuten van der CPM. The Assessment of Professional Competence. Developments, Research and Practical Implications. Adv Health Sci Educ 1996;1:41-67. 


\section{Summary}

This thesis is about educating intensive care doctors and nurses regarding dealing with grief and requesting organ donation. Worldwide there is a widening gap between the demand and supply of donor organs for transplantation. One of the reason for the shortage of donor organs is family refusal. Research has shown that the manner in which donation requests are made and the quality of care by doctors and nurses influences the decision relatives make.

The European Donor Hospital Education Programme (EDHEP) was developed to help these professionals to be more competent in their communication with relatives. This educational programme is the focus of this thesis.

The main question addressed in this thesis is: How is EDHEP perceived nationally and internationally, and what are its effects the competence of professional intensive care staff concerning the breaking of news of death and requesting organ donation? How does this relate to the satisfaction of donor relatives?

The main research question was translated in the following questions:

- What is the effect of EDHEP on intensive care doctors and nurses' self-efficacy regarding breaking bad news and requesting donation?

- What is the effect of EDHEP on (the cognitive use of) communication skills in breaking news of death and requesting donation?

- What is the effect of EDHEP on the collaboration of intensive care teams concerning breaking bad news of death and requesting organ donation?

- How are the issues addressed in EDHEP related to the satisfaction of donor relatives?

International evaluation research was carried out to establish the evaluations of participants about the learning effects and the format of EDHEP about the programme. Randomized controlled research was also carried out to establish the effect of EDHEP on the competence of the participants in dealing with grief and requesting donation. The experiences of relatives of organ and tissue donors with the donation procedure were studied in a longitudinal comparative study. Cross sectional research was carried out to establish the effects of EDHEP on teamwork relating to death and donation in intensive care units.

Finally research was carried out to establish the international value of EDHEP and to evaluate the international implementation

In the general introduction (Chapter 1) the background for the research described in this thesis is described. The chapter provides a review of studies that examined the widening gap between the demand and supply of donor organs for 
transplantation. One of the main reasons for the shortage of donor organs is family refusal. The experiences of donor relatives with the donation procedure and reasons they may have for consenting to or refusing to consent to organ donation as discussed as well as the problems doctors and nurses encounter in the communication with relatives about death and donation. Insufficient training, lack of adequate skills for communicating with relatives and hesitance to approach bereaved relatives about organ donation on the part of intensive care staff are mirrored in the variables that contribute to relatives' dissatisfaction about their treatment by the staff. Explaining brain death, dealing with grief reactions, giving emotional support and sensitively discussing the option of donation with relatives were found to be the key issues. EDHEP was developed to help intensive care professionals to be more competent in their communication with relatives. A short description of the features of EDHEP is given. The issues addressed were considered to cover the broad domain of communication relating to death and were expected to affect the professional behaviour of critical care staff. As EDHEp received international interest from its very development, an international research plan was developed. The chapter is concluded with a description of the requirements for adequate measurement of effects of educational programmes on participants' competence.

In Chapter 2 the background of the development of EDHEP is described as well as the contents and format of the programme. The EDHEP workshop, 'The grief response and donation request' was designed as an awareness raising programme to sensitise doctors and nurses to the issues involved in breaking bad news and asking relatives' consent for donation. The chapter provides a review of studies that were at the basis of the development of EDHEP. A detailed description of the programme, in which these issues are dealt with, is given as well as a description of the educational principles that guided the development of EDHEP. EDHEP was officially introduced in the Netherlands in 1992 and has since received considerable global attention. The international interest has strengthened our belief in the necessity to examine the effects of EDHEP on professional practice.

Chapter 3 presents the results of an evaluation study in which comparisons are made between the Netherlands $(n=1170)$ and the United Kingdom $(n=382)$. In both countries participants' evaluations of the content and format of the programme were very favourable, regardless of experience in intensive care. These evaluations were similar to those from earlier studies in the Netherlands, Germany and Denmark. The interactive character of the programme and the relevance of the issues addressed were highly valued. British participants, who participated in role plays reported higher learning effects than those who did not participate. This effect was not found in the Netherlands, the explanation being that Dutch participants may been more familiar with this training method. Adaptation to meet 
national demands increased satisfaction with the programme. All participants valued the multi-professional approach that is adopted in the programme. The evaluations showed that implementation of EDHEP in other countries is possible and that the programme can be altered to meet national needs.

Chapter 4 focuses on the effect of EDHEP on the self-efficacy of participants in breaking news of death and requesting donation. Randomized controlled trials with a six-month follow-up, were conducted in the Netherlands $(n=132)$ and the United Kingdom ( $\mathrm{n}=66$ ). All subjects reported improved knowledge of how to break news of death, to request donation, to explain the donation procedure and to deal with relatives' grief. They also reported increased appraisal of their performance on these tasks and less difficulty approaching relatives with a request for donation. There were no differences between professions or between men and women in this respect. Experience was found to be associated with an increase in self-efficacy beliefs and a decrease in the perceived difficulty of requests for donation. The relationship between self-efficacy and experience was found to be rather complicated.

Experience in the domain, i.e. general experience in ICU and in requests for organ donation, played a specific role. Subjects with little experience in these areas demonstrated greater increases in self-efficacy scores after participation in EDHEP compared with more experienced subjects. Moreover, self-efficacy scores showed larger increases in subjects with little general experience than in subjects with low baseline levels of self-efficacy. This suggests that lack of experience plays a greater role than lack of confidence in one's abilities. On the other hand, self-efficacy was found to continue to increase even above a rather high level of experience (more than ten years). The British subjects had more previous experience and higher selfefficacy scores that the Dutch subjects. On the basis of self-efficacy theory one might argue that participants' positive experiences heightened their self-efficacy beliefs, which were strengthened by the workshop. Presumably, the workshop contains the right ingredients for a positive influence on self-efficacy beliefs: personal experience, vicarious learning, constructive feedback and constructive use of physiological arousal. The discussion ends with a critical evaluation of the results in the light of the quality of self-assessments and the necessity to relate selfefficacy scores with performance scores..

In Chapter 5 a Dutch validation study $(n=28)$ is described, in which the predictive value of a paper-and-pencil test, feasible to implement on a large scale, for a performance test (described in a separate article) about dealing with grief and requesting donation, was established. The total score on the paper-and-pencil test appeared not to have predictive value for performance, however, specific cognitive skills did predicted specific behaviour. The cognitive skill to diagnose complex situations did predict performance on specific communication skills, such as 
structuring, giving and eliciting information and dealing with emotions. The complementary character of consultations with relatives, when carried out by a pair of a doctor and a nurse was reflected in the results. It is concluded that the paperand-pencil test presumably elicits a unique cognitive skill that is not covered by performance tests. In addition, the specificity of the domain, the authenticity of the cases in the paper-and-pencil test and specific experience of the subjects studied might have contributed to the results. The chapter is concluded with suggestions for further study, such as a) the relationship between the metacognitive skills used in diagnosing complex emotional situations and actual behaviour, and b) the nature of the cognitive strategies used in literally writing down what one would say and the relationship between these strategies and actual behaviour.

Chapter 6 describes the effects of EDHEP on cognitive use of communication skills $(\mathrm{n}=116)$ studied in a randomized controlled trial with a six-month follow-up. All professionals showed a transient improvement in the cognitive use (written proficiency) of communication skills. The ability to adequately interpret authentic situations presented in written cases (diagnostic accuracy) was not affected by participation in EDHEP. However, EDHEP participants did show a transient superiority compared to control subjects, in the cognitive use of communication skills and also in the ability to link the interpretation of the (emotional) state of relatives presented in the written cases with the recognition of the communication skills that are needed (coherence between diagnostic accuracy and written proficiency). The general approach to 'solving' problems in the authentic situations depicted in written cases showed a lasting change in EDHEP participants.

Experience in critical care with bereaved families, requests for donation or the perceived difficulty of making such requests did not add to the above mentioned changes. The discussion focuses on the relationship between cognitive and behavioural changes due to participation in EDHEP. In one of our other studies effects of participation on doctors' behaviour was found. The argument is made that absence of a demonstrable effect on nurses' performance does not necessarily imply that learning about communication with bereaved relatives did not take place on a cognitive level. Nurses' role in encounters with relatives may not offer them the opportunity to display their mastery of key communication skills.

The results show that on a cognitive level professionals benefit from EDHEP and that also for cognitive proficiency in communication skills it is necessary to have booster sessions to maintain skilled performance. The opportunities to practice communication skills in the EDHEP workshop were limited; EDHEP is not a training. It is therefore remarkable that improvement on actual cognitive performance was already demonstrable after the workshop.

Further study should be aimed at determining the complex relationship between the cognitive use of communication skills and actual performance and the intermediate role diagnostic accuracy plays. 
In Chapter 7 the results of a cross-sectional national survey with two contrasting groups EDHEP-units $(n=200)$ and non-EDHEP-unit $(n=208)$ into the effect of EDHEP on teamwork in intensive care units are described. The results of the study show that EDHEP had a significant positive effect on teamwork in intensive care units relating to death and donation. Intensive care staff in EDHEP-units were more satisfied with collaboration in the team regarding donation procedures than staff in non-EDHEP-units. In EDHEP-units, bad news encounters were more often formally prepared and the donation request was more often made by a team. In EDHEP-units compared with non-EDHEP-units, tasks were more often divided before a donation request was made. In all units staff were well aware of the existence of a donation protocol, but staff in EDHEP-units were more satisfied with its feasibility and implementation. There were no differences between practical and emotional support received between the two groups of units, however a substantial number of staff ( $\mathrm{n}=122)$, especially the doctors, indicated they never received emotional support from their superiors relating to the demanding tasks of breaking news of death and requesting donation. The absence of an effect on emotional (social) support is plausible because EDHEP does not target the intensive care team as a whole and no specific attention is paid to characteristics and quality of the relationship between team members and superiors. The aims of EDHEP regarding teamwork were largely achieved.

Chapter 8 describes the results of a cross-sectional longitudinal study into the satisfaction of a selected group of donor relatives with the donation procedure. The subjects were representatives of donor families who attended donor relatives' meeting days in $1995(\mathrm{n}=79), 1998(\mathrm{n}=131)$ and $2001(\mathrm{n}=184),(20 \%, 23 \%$ and $46 \%$ of the total number of donor families approached in those years, respectively). The aim the study was to establish to which factors relatives' satisfaction is related. The gradual increase in donor relatives' satisfaction ratings regarding treatment by hospital staff, suggests a gradual improvement in organ donation procedures in the Netherlands over the past decade. Unfortunately no causal inferences can be made regarding interventions and specific improvements in practice. The introduction of donation protocols in hospitals and information campaigns accompanying the introduction of new legislation appear to have had a positive effect on professionals' knowledge of the donation procedure, specifically about the concept of brain death. Information campaigns and the implementation of a national donor register appear to have resulted in greater awareness among relatives of the option of donation. This is supported by the fact that in 2001 more than three-quarters of relatives were aware of the deceased's wishes, half the deceased persons in this sample had registered in the national donor register, and almost half of the relatives in this sample brought up the option of organ donation without being formally asked. 
Improvements were demonstrated for all behavioural variables, especially the treatment of relatives before the announcement of the death was made, the way relatives were told about (brain) death and the way they were kept informed throughout the process. The announcement of the death explained more that $50 \%$ of the variance in the total satisfaction in all years. This will probably have had a positive effect on later phases in the donation process. Over the years relatives have shown increasing satisfaction with the way the death was announced and the timing and the quality of the consultation about organ donation. In 2001 hospital staff have become more attentive to relatives' needs, anger and feelings neglect have become less common and relatives were more satisfied with the behaviour of all professionals compared to 1995 . The largest improvement in relatives' satisfaction was related to nurses' behaviour. There were mixed feelings about the treatment by transplants coordinators. To date hundreds of Dutch staff, i.e. doctor, nurses and transplant coordinators, have participated in EDHEP workshops. The majority of the participants were nurses. It is arguable that relatives' increasing satisfaction with professionals' behaviour over the past decade is associated with an improvement in that behaviour as more and more staff have participated in EDHEP workshops over the years. The suggestion is made that a well-balanced combination of macrooriented and regulatory policies with competence-based educational programmes, may be more effective in increasing the donor pool than the policies chosen so far. Well-informed staff, possessing the necessary skills for effective communication with bereaved relatives will feel better prepared for the difficult tasks of breaking news of death and requesting donation.

In Chapter 9 the results of a study into global appreciation of EDHEP and the international implementation are presented. The evaluations of sixteen Train-theTrainer courses ('T'T courses) $(n=234)$ and a follow-up meeting $(n=40)$ are described. Full TTT courses were held in Leiden, Hong Kong, Sao Paulo, Mexico City, Tel Aviv, Manchester, Bern, Paris; adapted TTT courses were held in Riyadh, Kuwait City and Cape Town. The EDHEP workshop was part of the TTT course.

Participants around the world rated the learning effects of EDHEP highly, reporting a better understanding of the communication process and of relevant communication skills. They indicated feeling more comfortable dealing with bereaved relatives and expected to be more confident in their communication with relatives, the more so since participating in the programme lowered the barrier to requesting donation. The EDHEP Train-the-Trainer-courses have contributed to the international implementation of EDHEP. Participants appreciated the format and content of the training courses, the positive educational climate, the interactive character of the programme and the feedback from the trainers, which facilitated their learning. This confirms that interactive programmes are the most effective format for professional development.

The programme is internationally regarded as a valuable tool to add to local continuing professional development programmes. Participation in the Train-the- 
Trainer courses gave participants, i.e. working group members and future moderators, an opportunity to familiarize themselves with EDHEP, to gain insight into its aims and spirit and to develop strategies for national implementation. One of the messages of the Train-the-Trainer courses is that, for educational programmes for professionals to be effective, content and format should be closely linked to participants' working environment. This requires not only translation into the national language, but also adaptation of cases, role play scenario's and videoprogrammes to local needs and customs. The results of the follow-up meeting with representatives of countries that had adopted EDHEP showed that the programme can be adapted to a country's cultural, legal and religious conditions, which adds to the programme's relevance for local practice. There are anecdotic reports that to support the success of this approach. The context, however, should also be taken into account, because improved individual professionals' competence can only be made effective in supportive environments. The international evaluations of the programme indicate that the identified needs are global needs and that the issues addressed are relevant for intensive care professionals all over the world.

The various findings and main conclusions are discussed in Chapter 10. EDHEP receives positive evaluations and is perceived as relevant for practice all over the world. The TTT-courses are highly valued by those who participated and have been successful in helping professionals from different countries to implement EDHEP in a format that was adapted to their local situation. As for individual competence, participation in EDHEP leads to sustained improvements in the following areas: self-efficacy beliefs, perceived difficulty of making a donation request, doctors' skills in structuring a consultation and explaining the donation procedure and the general cognitive skill of 'solving' emotionally complex situations. Participation in EDHEP has also resulted in transient improvements of doctors' communication skills in breaking bad news, doctors' and nurses' cognitive use of key communication skills and doctors' and nurses' ability to link the interpretation of emotionally complex situations with the recognition of communication skills needed in these situations. As for team work, EDHEP appears to have a lasting effect on ICU team competence with respect to preparation for bad news encounters, systematic team approach in requesting donation, more satisfactory teamwork, especially regarding donation, and use and implementation of the donation protocol. EDHEP addresses those behavioural variables that are experienced as essential by donor relatives. Over the last decade relatives have shown increasing satisfaction with staff performance regarding those variables. The evaluations of EDHEP indicate that the programme meets the 'true needs' of the participants. The programme is firmly rooted in the context of clinical practice and it uses clinically relevant material. Knowledge and skills are learned in an integrated way. EDHEP is domain specific and contextualized. There is increasing 
evidence that the techniques and methodologies used in EDHEP are effective in improving professional competence.

A tentative model is presented, which incorporates the aspects that have been shown to be important in continuing professional development programmes. The model uses a circular approach. The key point of the model is that ideally for continuing professional development in specific domains all variables in the model should be taken into account. In the measurement of effects of continuing professional development programmes the focus usually is on competence measurements. The argument is made that focusing on effects on competence does not suffice; results from 'outcome'-research should be incorporated in these programmes to a higher degree; health professionals do not only have a responsibility towards their patients and colleagues, but also with regard to using scarce resources efficiently. In addition, more attention should be paid to individual characteristics, such as self-efficacy beliefs and personal experiences and attitudes, as they appear to have a direct impact on performance. Recommendations for future research derived from the model are described. 


\section{Acknowledgements}

Many people have contributed to the work described in this thesis. It is almost inevitable that I shall forget to thank certain persons. Therefore, I want to thank very sincerely, all those who contributed in one way or another. Certain people and institutions I wish to thank specifically.

First of all I wish to express my gratitude to all Dutch and British medical and nursing intensive care staff who participated in the measurements and who offered their precious time to make this research project possible.

I thank my promotores, Cees van der Vleuten and Gauke Kootstra, for letting me explore my own research ideas and for having patience. Time lags between my writing of the different chapters have been considerable. You have always kept faith that I would succeed in finalizing this thesis. For this I am very grateful. Cees, I thank you for your constructive feedback and suggestions and for your help with the analyses of the data. I also thank you for your efforts in providing the conditions to finalize this thesis. Gauke, I thank you for your Northern relativism, at times this gave me just the right push to keep going.

Wim Gijslaers, I owe you a lot. Thank you for providing me with the opportunity to finish the thesis. I appreciate the fact that you gave me an office, equipment and anything else I needed. It has helped finalizing this project tremendously.

The Faculty of Health Sciences is much thanked for giving me time to write.

Jan van Dalen, I appreciate having collaborated with you in the development of the project and the instruments, conducting the majority of the studies and the writing some of the articles. Thank you also for letting me use the article on the comparisons between the Netherlands and the United Kingdom of which you are the first author, as a chapter in this thesis. We were a great team and we have accomplished a lot.

Celia Wight, I admire you for the way you have promoted EDHEP internationally and I thank you for your support, valuable advice and suggestions in all stages of the research project.

I thank you, Celia and Jan, for the excellent teamwork in the Train-the-Trainer courses which we have conducted in some many places. Our enthousiasm will certainly contributed to the international reception of EDHEP. I have very fond memories of the enjoyable times we had when we were travelling or working together. 
Juliet Morton and Mike Morly, thank you for the collaboration on the British part of the project, the translation of the instruments, the development of the teamwork questionnaire, conducting the experiments, the scoring of the videotapes and the writing of some of the articles. Juliet, I appreciate the efforts you made to gain collaboration from the British doctors and nurses, especially concerning the skills assessments. You did a great job. Mike, I appreciate especially all the work you did in making sure that the first results were written down and published. Above all I thank you both for the hospitality with which Jan and I were always received in Liverpool or Manchester and for the many pleasant hours we have spent together in the years we were actively collaborating.

Pina Frazzica, thank you very much for offering me the opportunity to start the writing process in your institute, CEFPAS, in Sicily. I have much appreciated your hospitality. I made a productive start, and I had a very good time.

Petra van der Kooy, Judith Louwers en Wladimir van Mansum, in your role as my student-assistants, thank you for the enjoyable and good collaboration. The tremendous amount of data and people involved have never been a problem to you. You are thanked for entering all the data, (helping with) organizing the Dutch experiments and helping with the statistical analyses. Bob Willems and Glauke Kooimans are thanked for their help with the validation study and Gijs Lummen, Marieke Poelen and Karin van Oijen for with their help with the teamwork study.

Marike Lub, Trudi Kraan, Thera Hoogeveen en Arnold Oostveen, EDHEPtrainers ofthe first hour. I appreciate the enjoyable collaboration we have had and the hospitality with which we were always received in Hoek van Holland, Leiden or Wassenaar to discuss the evaluations of EDHEP workshops. Trudi Kraan, is also thanked for the pleasant collaboration in conducting the second relatives' study and writing of the article about this study.

Marc van Aart, Patricia Batavier, Michel Groot, Marijke van Gurp, Willem Hordijk, Koos Kranenburg, Marian Kruyswijk, Arno Oomen, Jose Popma, Elly van der Vegt, Henriette van Wezel, René Wijnen en Paul van Wijngaarden, transplantatation coordinators in the period in which the research took place, are thanked for their support for the project and for organizing EDHEP workshops. Marlies Broxterman of the Dutch Transplant Society, I thank you for your assistance in the organization of the first Dutch experiment, the teamwork study and the relatives' studies. Patricia Batavier, Marijke van Gurp and Elly van de Vegt, I thank you also for the collaboration in conducting the relatives' studies. Henriette van Wezel, I wish to thank you also for your support in the relatives' studies and for the pleasant collaboration in the teamwork study.

Erica van Ommen and Gèr de Ruiter, you are thanked for the great way in which you performed the roles of simulated relatives. EDHEP participants were always impressed with the realism of your performances. 
Bernard Cohen of the Eurotransplant International Foundation and Bernadette Haase of the Dutch Transplantation Society are thanked for their support for the research project.

Ruud Erdman and Jos Ravensbergen, thank you very much for the data of the relatives' study you performed in 2001.

The directors of the intensive care units, which participated in the validation study are thanked for letting their staff take part. For each individual doctor and nurse this was an investment of at least four hours. I appreciate very much that they were given the this valuable time.

As for the teamwork study I thank all those who acted as contactpersons of the intensive care units involved in the distribution and collection of the questionnaires. Without their help it would have been impossible to have had the respons we have had.

Christian Kerckhoffs, you have helped me a lot with the statistics. I also want to thank Dirk Tempelaar, Arno Muijtjens and Ron Hogenboom.

Mien Segers, I thank you for the constructive feedback on some of the articles in this thesis.

Petry Thiemann, Fien van Deurse $†$, Tonnie de Vries-Spaen and Henny Dankers, I very much appreciate you administrative, organisational and personal support.

Mereke Gorsira, you corrected my English in some of the chapters in this thesis. You did a wonderful job, thank you very much.

Cheryl Reid, Juliet's student-assistant, you are thanked for all the work you did concerning the measurements, and specifically for the skills assessments.

Maureen Wain, thank you for the wonderful job you did in organizing all the EDHEP workshops and the measurements.

Robert Sells, director of the Renal Transplant Unit van het Royal Liverpool University Hospital in Liverpool, you are thanked for acting as the chair of the EDHEP Steering Committee. Without you efforts the British studies would never have been conducted. Robert Johnson, director of the Renal Transplant Unit van het Manchester Royal Infirmary in Manchester, you are thanked for you active support throughout the process.

Ray Sutton, coordinator of the British simulated relatives, and the British actors are thanked for their assitance in the EDHEP workshop and the skills assessments.

John Kincey, Else Guthrie, Sue Kaney, Bill Williams and Hilary Roxborough, EDHEP trainers, thank you for the pleasant collaboration.

Robert Sells, Malcolm Brown, Ali Bacran, Robert Johnson, Neill Parrott, Barry Doran (consultants) en Jim Colbert, Jackie Godfrey, Barry Chapman t, Sue Clarke (transplantation coordinators) formed the EDHEP Steering Committee in the United Kingdom. I am very grateful for their support. 
Finally

Stella Beeldsnijder and Erna Ponds, my paranymphes and dear sparring partners all through the years, thank you for your emotional and practical support and above all for the fun we have; Agnes Scholing, thank you for your support and for doing the lay-out of this thesis, whilst having a busy job yourself; Jan van de Poel, I thank you for your belief in me, your humour, your critical comments and your creative suggestions; Kevin Gibson and Harm Hospers, sparring partners through the years, I thank you for your support and the fun; thank you 'Mah Jong-club', Jacqueline Bomhof, Floor Martens and Erna Ponds, our trekking weekends have been very consoling and gave me a lot of creative ideas; Hannie van Genderen and Leo Scheffer, Paula Deumens, Jacques Mikx I could always join in at your dinner table for a reassuring conversation, whilst enjoying a good meal with a nice glas of wine, thank you for this; Jeannette Hommes, thank you for always being on the right spot at the right time with emotional or practical support; Trudi van Schaik, thank you for teaching me to see the beauty of things, also when they are not exactly as I expected them to be; Peter Knops, thank you for the music, it helped me to see things in a better perspective; and thank you, my family: Ali, Ina and Jan; Folkert and Sven; Rosan, Liset and Stefan, it is reassuring to be with you and to always be aware of your support.

My parents have not been able to share this moment in my career with me. I am sure they would have been proud, likewise I am very proud of them. Their key message was to always keep believing in myself, and trying to find a good balance been achieving an academic career and embracing the other things that make life worth living. 


\section{Samenvatting}

Dit proefschrift gaat over onderwijs aan intensive care artsen en verpleegkundigen met betrekking tot het omgaan met overlijden en vragen om orgaan- en weefseldonatie. Wereldwijd is er een tekort aan organen en weefsels ten behoeve van transplantatie. Een van de redenen voor dit tekort is de weigering van nabestaanden om in te stemmen met een verzoek tot orgaan- en/of weefseldonatie. Onderzoek heeft uitgewezen dat de wijze waarop het donatieverzoek wordt gedaan en de kwaliteit van de zorg door artsen en verpleegkundigen van invloed is op de beslissing die nabestaanden nemen ten aanzien van het donatieverzoek.

Teneinde de professionele hulpverleners, die op afdelingen in het ziekenhuis werken waar zij mogelijk met orgaan- en weefseldonatie te maken kunnen krijgen, handvatten te bieden voor meer competente communicatie met nabestaanden is een onderwijsprogramma ontwikkeld: het European Donor Hospital Education Programme (EDHEP). Dit onderwijsprogramma, waarin de nadruk ligt op orgaandonatie, staat centraal in dit proefschrift.

De centrale onderzoeksvraag die ten grondslag ligt aan dit proefschrift is: Hoe wordt EDHEP nationaal en international gewaardeerd en wat is het effect van deelname aan EDHEP op de competence van professionele intensive care staf met betrekking tot het meedelen van overlijden en het bespreken van orgaandonatie? Hoe zijn bovenstaande resultaten gerelateerd aan de tevredenheid van nabestaanden van donoren?

De centrale onderzoeksvraag is vertaald naar de volgende vragen:

- Wat is de mening van deelnemers over de onderwerpen die in EDHEP aan de orde komen en wat zijn de leereffecten? Komt het programma tegemoet aan de door artsen en verpleegkundigen rapporteerde behoefte aan scholing met betrekking tot het omgaan met rouw en het bespreken van orgaandonatie? Worden de behandelde thema's herkend als relevant voor de praktijk? Hoe wordt EDHEP wereldwijd gewaardeerd als onderdeel van professionele educatie?

- Wat is het effect van EDHEP op de self-efficacy van intensive care artsen en verpleegkundigen met betrekking tot het mededelen van overlijden en het bespreken van orgaandonatie?

- Wat is het effect van EDHEP op het cognitieve gebruik van communicatie vaardigheden bij het mededelen van overlijden en het bespreken van orgaandonatie? 
- Wat is het effect van EDHEP op de samenwerking in intensive care teams met betrekking tot het mededelen van overlijden aan en het bespreken van orgaandonatie met nabestaanden?

- Hoe zijn de thema's die aan de orde komen in EDHEP gerelateerd aan de tevreden van nabestaanden van donoren?

Teneinde de relevantie van EDHEP voor de beroepspraktijk en de leereffecten na te gaan, werd internationaal evaluatie onderzoek gedaan naar de ervaringen van de deelnemers. Hierbij werd niet alleen gekeken naar de inhoud van het programma, maar ook naar de wijze waarop het programma is opgebouwd. Daarnaast werd onderzoek gedaan naar effect van het programma op de competentie van de deelnemers, waarbij het accent zowel op de individuele communicatievaardigheden en self-efficacy opvattingen van deelnemende artsen en verpleegkundigen als op het teamwork in intensive care afdelingen lag. Er werd onderzoek gedaan naar de ervaringen van nabestaanden van donoren met de donatieprocedure en er is gekeken naar de relatie tussen deze ervaringen en de thema's die aan de orde komen in EDHEP. EDHEP werd vanaf het begin zeer positief ontvangen en kon zich in korte tijd in een brede internationale belangstelling verheugen. Er is onderzoek gedaan naar de wijze waarop het programma wereldwijd wordt gewaardeerd en hoe getracht is internationale implementatie te faciliteren

In de introductie (Hoofdstuk 1) worden de achtergronden van en de aanleiding tot het onderzoek beschreven waarvan in dit proefschrift verslag wordt gedaan. Beschreven wordt hoe al in het begin van de negentiger jaren het probleem van het toenemende tekort aan donororganen werd gesignaleerd. Er wordt allereerst ingegaan op onderzoek naar ervaringen van nabestaanden en redenen die zij hebben om al of niet in te stemmen met orgaandonatie. Vervolgens wordt beschreven wat de problemen zijn die artsen en verpleegkundigen ervaren aangaande orgaandonatie en het bespreken van deze optie met nabestaanden. Het wordt duidelijk dat het gebrek aan kennis en vaardigheden voor adequate communicatie met nabestaanden bij de intensive care staf wordt weerspiegeld in de redenen die nabestaanden aangeven voor hun weigering. Uit de beschrijving komt naar voren dat het mededelen van overlijden - vooral een duidelijke uitleg van het begrip hersendood -, het omgaan met rouwreacties, het geven van emotionele steun, het zorgvuldig bespreken van de optie van orgaandonatie en het uitleggen van de donatieprocedure centraal zijn. EDHEP werd ontwikkeld om intensive staf te helpen op een meer competente wijze overlijden mee te delen en orgaandonatie te bespreken. De kenmerken van EDHEP worden kort toegelicht. De thema's die in EHDEP an de orde komen worden verondersteld het brede domein van communicatie met nabestaanden aangaande overlijden en orgaandonatie te bestrijken. De verwachting was dat het effect zou hebben op het professionele gedrag van de intensive care staf. Aangezien er begin vanaf het begin internationale 
interesse voor EDHEP was, is een internationaal onderzoeksplan ontwikkeld. Er wordt een beschrijving gegeven van de eisen, waaraan onderzoek naar het effect van onderwijsprogramma's op de competentie van deelnemers moet voldoen. Het hoofdstuk wordt besloten met een beschrijving van de onderzoeksvragen.

In hoofdstuk 2 worden de achtergronden voor de ontwikkeling van EDHEP en de inhoud en structuur van het programma geschetst. De EDHEP- workshop werd ontwikkeld als een bewustwordingsprogramma voor artsen en verpleegkundigen aangaande thema's die van belang zijn bij het meedelen van overlijden en bespreken van orgaandonatie. Er wordt een overzicht gegeven van het onderzoek dat de basis vormde voor de ontwikkeling van EDHEP. Er wordt ingegaan op onderwijskundige principes die ten grondslag lagen aan het ontwerp van EDHEP.

Het resulterende programma, een interactieve workshop van een dag voor gemengde groepen van artsen en verpleegkundigen die in hun werk met orgaanen/of weefseldonatie te maken kunnen krijgen, wordt vervolgens besproken. De inhoud en de opbouw van programma wordt toegelicht: deelnemers worden allereerst uitgenodigd hun persoonlijke reacties op en attitudes ten aanzien van overlijden en donatie te onderzoeken, om vervolgens na te gaan op welke wijze deze constructief gebruikt kunnen worden in professionele reacties op nabestaanden. Korte presentaties over verlies, rouw en crisisinterventie en discussies naar aanleiding van video-instructiebanden worden afgewisseld met praktische oefeningen, zoals videovignetten en rollenspelen met simulatienabestaanden, waarin de theorie toegepast en besproken kan worden. De gastheer of -vrouw is een transplantatie coördinator, die de gehele dag aanwezig is zonodig uitleg kan geven omtrent de donatieprocedure. De workshop wordt geleid door twee trainers met ervaring op het gebied van training van communicatievaardigheden, bij voorkeur klinisch psychologen met ervaring in het werken met artsen en verpleegkundigen.

EDHEP werd officieel in 1992 in Nederland geïntroduceerd en heeft sindsdien veel belangstelling gekregen uit de gehele wereld. Daarmee werd ook de noodzaak om te onderzoeken of en hoe deelname aan EDHEP zou leiden tot veranderingen in de praktijk.

In Hoofdstuk 3 worden de resultaten beschreven van een evaluatie onderzoek, waarin programma evaluaties van Nederland $(n=1170)$ en Engeland $(n=382)$ zijn vergeleken. De onderzoeksvragen in deze studie waren gericht op de tevredenheid over en herkenning van de thema's die in de EDHEP workshop aan de orde komen, de gerapporteerde leereffecten, interdisciplinaire groepen en de invloed van aan nationale behoeften aangepast cursusmateriaal. Beschreven wordt dat deelnemers uit beide landen, ongeacht hun ervaring, alle aspecten die in de workshop aan de orde komen en het leereffect hoog waarderen en dat deze in overeenstemming zijn met eerdere programma evaluaties uit Nederland, Duitsland en Denemarken. Er wordt geconcludeerd dat het verschil in onderwijscultuur 
tussen Nederland en Engeland weerspiegeld zou kunnen zijn in een hogere tevredenheid met het programma door de Engelse deelnemers, voor wie het interactieve karakter van de workshop relatief nieuw was. Deze conclusie wordt ondersteund door de constatering dat Engelse deelnemers, die participeerden in rollenspellen, wel een hoger leereffect rapporteren dan degenen die niet actief participeerden en dit in Nederland niet het geval was. Er wordt tevens beschreven dat aangepast cursusmateriaal leidt tot hogere tevredenheid, hetgeen aansluit bij het onderwijskundige principe, dat de klinische context van deelnemers zo goed mogelijk weerspiegeld moet zijn in aangeboden cursusmateriaal. In beide landen wordt het principe om de workshop aan te bieden aan gemengde groepen van artsen en verpleegkundigen wordt geapprecieerd. Dit is ook in overeenstemming met het uitgangspunt van EDHEP dat meedelen van overlijden en bespreken van orgaan donatie met de familie een teamaangelegenheid is, waarvoor samenwerking tussen de twee professies nodig is. Het hoofdstuk wordt besloten met de constatering dat het dus goed mogelijk is om EDHEP elders te implementeren, dat het programma op onderdelen aangepast kan worden aan nationale behoeften.

In hoofdstuk 4 worden de effecten van EDHEP op de self-efficacy van intensive care artsen en verpleegkundigen uit Nederland (experimentele groep $n=71$, controle groep $n=61$ ) en uit Engeland (experimentele groep $n=29$, controle groep $n=27$ ) beschreven. Het onderzoek was een gerandomiseerde studie met een voor- en een nameting en een follow-up meting na zes maanden. Uit de resultaten van het onderzoek komt naar voren, dat deelname aan EDHEP leidt een toename in de self-efficacy opvattingen van haar deelnemers in beide landen. Deelnemers geven daarmee aan dat ze meer vertrouwen hebben in hun eigen vaardigheden in het meedelen van overlijden, het aan de orde stellen van orgaandonatie, het uitleggen van de donatieprocedure en het omgaan met de (rouw)reacties van nabestaanden. EDHEP blijkt direct na afloop het meeste effect te sorteren bij deelnemers met lage self-efficacy scores, bij de follow-up meting bleek deze extra toename echter te zijn verdwenen. In de Nederlandse controlegroep trad tevens een effect op, op de follow-up waren de scores op het kennisaspect van selfefficacy hoger dan op de voormeting; dit was niet het geval voor het gedragsaspect.

Het toegenomen vertrouwen wordt weerspiegeld in een afname van de moeilijkheid die deelnemers ervaren bij het stellen van de donatievraag. In Engeland was dit een verschil tussen voormeting en follow-up, in Nederland trad het effect direct na deelname op en bleef daarna op het zelfde niveau.

Ervaring blijkt een belangrijke rol te spelen. In beide landen hebben ervaring in de omgang met nabestaanden en ervaring in het aan de orde stellen van orgaandonatie significante invloed op de toename van de self-efficacy. In Nederland blijken deelnemers met weinig ervaring op deze gebieden het meest van EDHEP te profiteren, voor de Engelse deelnemers kon een dergelijk effect niet worden vastgesteld. De conclusie ten aanzien van de rol van ervaring is, dat boven 
een bepaald niveau van algemene en specifieke praktijkervaring wel effect heeft op de toename van self-efficacy, maar dat dit niet gedifferentieerd is.

In de discussie wordt ingegaan op een bespreking van de kwaliteit en betrouwbaarheid van zelfbeoordelingen, waarvan self-efficacy oordelen een voorbeeld zijn, en het licht waartegen de resultaten uit het onderzoek moeten worden gehouden.

In hoofdstuk 5 wordt verslag gedaan van een onderzoek naar de voorspellende waarde van een schriftelijke toets van cognitieve communicatievaardigheden voor een gedragstoets waarin communicatie vaardigheden worden gemeten. Een schriftelijke toets van cognitieve communicatievaardigheden op basis van zes, op praktijkvoorbeelden gebaseerde, papieren casus en een gedragsmeting van communicatie vaardigheden in een stationstoets met driemaal twee gekoppelde stations (een overlijdensgesprek en een donatiegesprek) met gestandaardiseerde simulatienabestaanden werden afgenomen aan 14 intensive care artsen en 14 intensive care verpleegkundigen. De schriftelijke toets werd individueel afgenomen; de stationstoets in paren van een arts en een verpleegkundige. $\mathrm{Na}$ afloop van elk station in de stationstoets werd het gedrag van de arts en verpleegkundige door de simulatienabestaanden beoordeeld. De totaalscore op de schriftelijk toets hadden geen voorspellende waarde voor de totaalscores op de gedragstoets. Op onderdelen had de schriftelijke toets echter wel voorspellende waarde. Beide toetsen zijn gerelateerd zijn, maar deze relatie is complex. Het juist kunnen inschatten van complexe situaties, diagnostische accuratesse, kan blijkbaar tot op zekere hoogte gedrag voorspellen. De significante relatie tussen de oordelen van de simulatiepatiënten en de cognitieve toepassing van communicatievaardigheden geeft aan dat de schriftelijke toets in ieder geval deels hetzelfde meet als de gedragstoets en deels een uniek aspect meet dat niet door de gedragstoets wordt gemeten. De complementariteit in het gedrag van arts en verpleegkundige in de gesprekken met nabestaanden werd gereflecteerd in het gevonden correlatie patroon tussen beide toetsen. De relatie tussen sub-variabelen in beide toetsen is intrigerend en verschilt van wat in ander onderzoek is gevonden. Het hoofdstuk wordt besloten met enkele mogelijke verklaringen voor de gevonden resultaten. Wellicht activeert de opdracht om letterlijk op te schrijven wat men zou zeggen, andere cognitieve vaardigheden, die dichter bij gedrag liggen, dan de cognitieve vaardigheden die geactiveerd worden bij het bentwoorden van juist-onjuist-?vragen. Mogelijk dragen ook de specificiteit van het domein, de authenticiteit van de geschetste situaties en de specifieke ervaring van de onderzochte professionals bij aan de verklaring van de gevonden resultaten.

In hoofdstuk 6 wordt verslag gedaan van onderzoek naar het effect van EDHEP op het cognitieve gebruik van communicatievaardigheden door intensive artsen en verpleegkundigen (experimentele groep $\mathrm{N}=68$; controle groep $\mathrm{N}=48$ ). Het 
onderzoek was een gerandomiseerde studie met een voor- en nameting en een follow-up na 6 maanden.

Het effect van deelname aan EDHEP werd vastgesteld met de schriftelijke toets die in hoofdstuk 5 wordt beschreven. Het doel van het onderzoek was het vaststellen van het effect van EDHEP op cognities over het communicatieproces en over effectief gebruik van communicatie vaardigheden en de actieve cognitieve toepassing daarvan, deze cognities zijn belangrijke voorwaarden voor adequaat communicatief gedrag. Uit een van onze andere onderzoeken naar het effect van EDHEP is gebleken, dat deelname leidt tot tijdelijke verbetering van een aantal communicatievaardigheden in het slecht nieuws gesprek en tot blijvende verbetering in het toelichten van de gang van zaken bij een donatieprocedure. Deze effecten traden alleen op bij artsen. Echter, het uitblijven van een effect op het gedrag van de verpleegkundigen betekent niet dat zij op een cognitief niveau niet geleerd hebben van deelname. De complementariteit in de gesprekken met nabestaanden gaf hen wellicht niet de mogelijkheid hun vaardigheid in communiceren te tonen.

Uit het onderzoek, dat in hoofdstuk 6 wordt beschreven blijkt, dat alle EDHEP deelnemers, artsen en verpleegkundigen, in tegenstelling tot de professionals in de controle conditie, een tijdelijke verbetering laten zien in het cognitief gebruik van communicatievaardigheden. Deelname aan een EDHEP workshop had geen effect op diagnostische accuratesse, dat wil zeggen op het adequaat inschatten van de in de papieren casus beschreven gemoedstoestand van nabestaanden. De cognitieve toepassing van communicatievaardigheden (het letterlijk noteren van wat men zou zeggen) verbeterde wel significant door deelname aan een EDHEP workshop. Daarnaast werd ook een significante toename aangetoond bij EDHEP deelnemers in de vaardigheid om op grond van de inschatting van de situatie (diagnostische accuratesse) de juiste communicatievaardigheid te kiezen en toe te passen. Beide effecten waren tijdelijk. Voor het 'oplossen' van de papieren casus werd daarnaast nog een globaal oordeel gegeven. Dit globale oordeel was hoger op de nameting voor de EDHEP deelnemers en dit was een blijvende verbetering. De conclusie die aan het eind van het hoofdstuk wordt getrokken is dat de resultaten aantonen dat op een cognitief niveau verpleegkundigen wel degelijk leren van deelname aan EDHEP, zij het tijdelijk.

Het verdwijnen van effecten van trainingen op gedrag na verloop van tijd is een welbekend verschijnsel. De resultaten uit deze studie tonen aan dat dit fenomeen ook van toepassing is op cognitieve communicatievaardigheden. Om vaardig te blijven - ook op cognitief niveau - is het nodig om met een zekere regelmaat opnieuw getraind te worden. De mogelijkheden in de EDHEP workshop om te oefenen met deze cognitieve vaardigheden is beperkt. Daarnaast is de EDHEP workshop geen training, het is daarom opmerkelijk dat er, zij het tijdelijk, een effect op deze cognitieve vaardigheden kon worden aangetoond. Het hoofdstuk wordt afgesloten met de suggestie, dat verder onderzoek gericht zou moeten zijn op nadere vaststelling van de relatie tussen deze cognitieve vaardigheden en gedrag en de intermediaerende rol die diagnostische accuratesse hierin speelt. 
Hoofdstuk 7 is gewijd aan een studie naar het effect van EDHEP op teamwork in intensive care afdelingen. In dit hoofdstuk worden de effecten van EDHEP op het teamwork met betrekking tot overlijden en orgaandonatie besproken. Een voor dit doel ontwikkelde vragenlijst, die de sequentie volgt van de gebeurtenissen, die plaatsvinden als een patiënt overlijdt en een (potentiële) orgaandonor wordt, werd afgenomen aan artsen en verpleegkundigen van 24 verschillende intensive care afdelingen in Nederland. Deze afdelingen werden geselecteerd na een nationale inventarisatie van intensive care afdelingen. Van alle Nederlandse intensive care afdelingen werd vastgesteld welk percentage van de staf had deelgenomen aan een EDHEP workshop. Er werden twee contrasterende groepen samengesteld: groep A en groep B. Groep A bestond uit afdelingen waarvan $65 \%$ of meer, zo mogelijk alle artsen, hadden deelgenomen aan een EDHEP workshop. Groep B bestond uit afdelingen waarvan $15 \%$ of minder, en zo mogelijk geen artsen, hadden deelgenomen aan een EDHEP workshop. De afdelingen werden gematched naar type ziekenhuis, aantal intensive care bedden en aantal stafleden. Het totaal aantal deelnemers aan het onderzoek was 408, waarvan 200 in groep A en 208 in groep B. Er werden 625 vragenlijsten verzonden. De response was derhalve 65\%. In beide groepen was ongeveer driekwart van de respondenten verpleegkundige, met gemiddeld in beide groepen 10 jaar werkervaring in de huidige afdeling. Beide groepen waren goed vergelijkbaar.

Uit de resultaten blijkt dat men in groep A meer tevreden is over de samenwerking met betrekking tot overlijden en orgaandonatie dan in groep B. Dit verschil in tevredenheid wordt vooral bepaald door de tevredenheid over de samenwerking rondom orgaandonatie. Van degenen die de donatievraag zelf stelden waren de professionals in groep A meer tevreden dan die in groep B. Met betrekking tot de tevredenheid over de samenwerking bij overlijden van een patiënt was er geen verschil tussen beide groepen. Besprekingen om het gesprek met de familie over het overlijden voor te bereiden kwamen vaker voor in groep A. In beide groepen werd in het voorbereidende teamoverleg de meeste aandacht besteed aan de manier van benaderen van de familie. De donatievraag werd in groep A vaker door meer dan een teamlid met de familie besproken dan in groep B. In groep A werd vaker een expliciete taakverdeling afgesproken. Uitwisseling van gegevens over de familie en de reactie van de familie in het donatiegesprek was in beide groepen het belangrijkste gespreksthema's van de nabesprekingen. Over deze nabesprekingen was men significant meer tevreden in groep $A$.

De overgrote meerderheid in beide groepen was op de hoogte van de aanwezigheid van een donatieprotocol, in groep A was men echter meer tevreden over het gemak en de implementatie hiervan. Beide groepen waren even tevreden over de samenwerking met de transplantatie coördinator. Er was geen verschil tussen beide groepen wat betreft de ervaren praktische en emotionele steun. Verpleegkundigen gaven en kregen meer van beide soorten steun. Ongeveer een derde van beide groepen in dit onderzoek (122 individuen), met name de artsen, 
gaf aan nooit emotionele (of sociale) steun van hun meerdere te krijgen. EDHEP droeg met name bij aan teamwork met betrekking tot de donatievraag, het overlijdensbericht en steun aan nabestaanden en ook, maar minder, bij aan de samenwerking met de transplantatie coördinator, teamwork in het algemeen en het geven van wederzijdse steun in het team.

Een van de voorwaarden voor de samenstelling van de groepen per EDHEP workshop is altijd geweest, dat de deelnemers van verschillende afdelingen en zo mogelijk uit verschillende ziekenhuizen zouden komen, om te voorkomen dat teamproblemen teveel met de workshopinhoud zou interfereren. Het is dus niet een programma dat in de eerste plaats gericht is op intensive care teams als geheel; het is dan ook opmerkelijk dat een effect op de samenwerking in het team als geheel vastgesteld kon worden. Het gegeven dat er zoveel professionals zijn die geen emotionele steun van hun superieuren krijgen wordt als zorgelijk gezien, aangezien steun van superieuren cruciaal is voor het creëren van een klimaat, waarin mensen hun kwetsbare kanten durven laten zien. Een veilig team klimaat maakt het geven en ontvangen van feedback makkelijker. Teamtraining op dit gebied is dus geen overbodige luxe voor intensive care teams.

In hoofdstuk 8 wordt een onderzoek naar de tevredenheid van nabestaanden van donoren besproken. In het hoofdstuk worden de effecten van het gedrag van professionals tijdens de donatieprocedure op de tevredenheid van nabestaanden beschreven. Het onderzoek werd uitgevoerd om na te gaan of zich in het afgelopen decennium veranderingen hebben voorgedaan in de interactie tussen artsen, verpleegkundigen en transplantatie coördinatoren enerzijds en nabestaanden anderzijds. De resultaten van drie onderzoeken naar de tevredenheid van nabestaanden met de donatieprocedure uitgevoerd in 1995, 1998 en 2001 werden gecombineerd voor een cross-sectioneel longitudinaal vergelijkend onderzoek. De belangrijkste onderzoeksvragen waren of de tevredenheidsoordelen van nabestaanden van donoren veranderd zijn gedurende deze jaren en aan welke variabelen deze veranderingen kunnen worden toegeschreven.

De respondenten waren nabestaanden van orgaan- en weefseldonoren die in 1995, 1998 en 2001 die deelnamen aan een nabestaandendag. Zij vulden een schriftelijke vragenlijst in, aangaande de donatieprocedure waarbij zij betrokken waren geweest. Van het totaal aantal van 400 families die doneerden in de periode 1991 - 1995, participeerden 79 nabestaanden (20\%) in het onderzoek van 1995. In het onderzoek van 1998 waren dit 131 nabestaanden, 23\% van het totale aantal van 579 families die doneerden in de periode 1995-1998. Van het totaal aantal families van 404 families, die doneerden in de periode 1998 -2001 participeerden 184 nabestaanden (46\%) in het onderzoek van 2001. In 1995 en 1998 was een verkeersongeval voor de helft van de donoren de doodsoorzaak, in 2001 was dit in eenderde van de gevallen de doodsoorzaak; hier was 48\% van de doodsoorzaken was een Cerebraal Vasculair Accident (CVA). CVA's komen vaker voor bij oudere personen, het leeftijdsverschil tussen de donoren van 1995 en 1998 vergeleken met 
2001 was 10 jaar. De nabestaanden in 2001 waren dus ook vaker partners, terwijl dat in 1995 en 1998 overwegend ouders van overleden kinderen waren. Aangezien de steekproeven in de studies in de verschillende jaren bestonden uit verschillende mensen, was het niet mogelijk om longitudinale vergelijkingen binnen groepen te doen.

De tevredenheid blijkt over de jaren te zijn toegenomen. Op alledrie onderzoeksmomenten werd de totale tevredenheid vooral bepaald door de wijze waarop het overlijden was meegedeeld. In 1995 en 1998 was de nazorg door de transplantatie coördinator de tweede belangrijke factor; in 2001 was dit de wijze waarop donatie aan de orde was gekomen. Dit laatste hing vooral samen met de kwaliteit van de uitleg van het begrip hersendood. In 2001 gaf bijna de helft van de nabestaanden aan orgaandonatie zelf aan de orde gesteld te hebben. Men was in 2001 beter op de hoogte van de wens van de overledenen. Het is mogelijk dat dit samenhangt met de gemiddeld hogere leeftijd van de overledene of met de relatie van de nabestaanden tot de overledenen (in 2001 bestond bijna de helft van de nabestaanden uit partners). In 2001 was men meer tevreden dan in 1995 en 1998 over de wijze waarop het donatieverzoek werd gedaan. In 1995 en 1998 werden veel nabestaanden overvallen door het verzoek, ze hadden vaak nog niet begrepen dat hun familielid was overleden. Degenen bij wie het donatieverzoek in een apart gesprek aan de orde werd gesteld waren het meest tevreden, dit betrof echter slechts een klein percentage van de nabestaanden. In 2001 werden nabestaanden beter op de hoogte werden gehouden tot aan het moment waarop het overlijden werd meegedeeld dan in 1995 en 1998. Dit zal mogelijk de omstandigheden voor het bespreken van orgaandonatie positief hebben beïnvloed, ook omdat men daardoor eerder het overlijden kon voorzien. Het voorzien van een overlijden wordt wellicht ook beïnloed door de aard van doodsoorzaak, in 2001 was ervaker sprake van een CVA. In 2001 was men significant meer tevreden over de wijze waarop men behandeld was door de verschillende professionals in het ziekenhuis ten opzichte van 1995 en 1998, met name over de verpleegkundigen. In 1998 waren negatieve gevoelens, zoals boosheid en genegeerd worden, het meest uitgesproken en in 2001 het minst.

Geconcludeerd wordt dat nabestaanden meer tevreden zijn over zowel kennis als vaardigheden van de hulpverleners. Er kunnen echter geen causale verbanden worden gelegd. De gekozen strategieën ter verhoging van het aantal donoren (Donatieprotocol, Wet op de Orgaandonatie, Donorregister) waren vooral gericht op kennisoverdracht. Het aanleren van nieuwe vaardigheden komt expliciet aan de orde in de EDHEP workshops. Sinds 1992 hebben honderden intensive care verpleegkundigen en artsen deelgenomen aan de workshops (voor het merendeel verpleegkundigen). Het is aannemelijk de invoering EDHEP heeft bijgedragen aan de verbetering van de vaardigheden van de professionals. Er wordt betoogd dat toekomstige interventies ter verhoging van het donoraanbod effectiever zouden kunnen zijn als macro-georiënteerde en op regulatie gerichte benaderingen worden 
gecombineerd met op verbetering van de competentie gerichte educatieve programma's.

Hoofdstuk 9 is gewijd aan de resultaten van een onderzoek naar wijze waarop EDHEP wereldwijd wordt gewaardeerd en de manier waarop getracht is de implementatie van EDHEP in andere delen van de wereld te faciliteren. Evaluatie gegevens van Train-the-Trainer (T'TT) cursussen $(\mathrm{n}=234)$ worden beschreven, evenals de resultaten van een follow-up $(n=40)$ die plaatsvond een aantal jaren na de eerste van deze cursussen.

Er werden zestien complete TTT cursussen gegeven, waarvan negen in Leiden, en de overige zeven elders (Hong Kong, Sao Paulo, Mexico Stad, Tel Aviv, Manchester, Bern en Parijs). Er werden daarnaast 'aangeklede' EDHEP workshops gegeven in Riyadh, Koeweit Stad en Kaapstad, dat wil zeggen ingebed in een groter geheel. Toekomstige trainers en vertegenwoordigers van een aantal landen die in deze EDHEP workshop vertegenwoordigd waren hadden reeds deelgenomen aan TTT cursussen in Leiden. In totaal waren er 203 TTT $^{\text {TT }}$ deelnemers en 234 EDHEP deelnemers (waaronder de TTT deelnemers) uit meer dan 40 landen. Van de groep van 234 EDHEP deelnemers was $37 \%$ arts, $11 \%$ verpleegkundige, $27 \%$ transplantatie coördinator, $24 \%$ psycholoog of psychiater. De overige $2 \%$ bestond uit vertegenwoordigers van Novartis, die het overgrote deel van de internationale implementatie heeft gefinancierd. Artsen, verpleegkundigen en transplantatie coördinatoren participeerden in de TTT cursussen als EDHEP werkgroepleden $(68 \%)$ psychologen en psychiaters als toekomstige EDHEP trainers $(31 \%)$.

Uit de resultaten van het onderzoek naar de tevredenheid over en het leereffect van de TTT cursussen blijkt dat EDHEP internationaal gezien wordt als een waardevol educatief instrument voor de verder professionalisering van de intensive care staf op het gebied van orgaandonatie. Alle deelnemers rapporteerden zeer tevreden te zijn over zowel de inhoud als de structuur van de TTT cursussen, ongeacht land van origine. Men gaf aan een goed begrip te hebben gekregen van de doelen en structuur van EDHEP en hoe te werk te gaan in het proces van nationale implementatie. Toekomstige trainers gaven aan dat ze een goed inzicht hadden gekregen in het doel van de verschillende in de EDHEP workshop gebruikte onderwijsmethoden en dat ze veel vertrouwen hadden in het uitvoeren van deze methoden.

Zelf deelnemen aan de EDHEP workshop werd als zeer leerzaam ervaren, men gaf aan dat dit zeer instructief was voor een goed begrip van EDHEP en voor het inzicht in de verschillende onderwijsmethoden.

De waardering van de EDHEP workshop, als onderdeel van de TT'T cursus, was zeer positief. De evaluaties waren zelfs hoger dan die in hoofstuk 3 worden beschreven. Deelnemers uit Kaapstad rapporteerden het hoogste leereffect ten opzichte van anderen. Zie gaven aan geen enkele ervaring met onderwijs op dit gebied te hebben gehad. Deelnemers uit het Midden-Oosten rapporteerden de minste reductie in de drempel om de donatievraag te stellen; meer aandacht voor de 
complexe relatie tussen hersendood en Islam zou naar verwachting het effect van EDHEP verhogen. Men waardeerde vooral de interactieve oefeningen, met name de simulatiecontacten. De oefening waarin persoonlijke gevoelens ten aanzien van dood aan de orde komen, werd als erg confronterend, maar zeer leerzaam ervaren.

EDHEP was in het merendeel van de landen die geparticipeerd hadden in T'T'T cursussen ingevoerd als onderdeel van professionaliseringsprogramma's, soms in aangepaste of meer uitgebreide vorm om tegemoet te komen aan locale omstandigheden en om deelnemers meer gelegenheid te geven om te oefenen in simulatiecontacten. In een aantal landen werd vlak na invoering een toename van het aantal donaties vastgesteld, hierover is echter niet gepubliceerd. Men was in het algemeen nog steeds erg enthousiast; er werden wel zorgen uitgesproken over blijvende financiering. Daarnaast werd in een aantal landen, waaronder Nederland, het probleem geconstateerd dat artsen zich minder geroepen voelden om deel te nemen. Terugkijkend op de TTT cursus meldden een aantal trainers, dat een dag training onvoldoende was gebleken om de workshop goed te kunnen geven; men had zelf aanvullende activiteiten ondernomen.

Het hoofdstuk wordt besloten met de constatering dat de veranderingen die aangebracht zijn in andere landen om tegemoet te komen aan locale wensen de effectiviteit kan verhogen. De beperkingen van EDHEP worden daarmee ook onderstreept. Meer mogelijkheden om de vaardigheden te oefenen worden door een aantal landen, inclusief Nederland, als noodzakelijk gezien om een significant effect op de praktijk te hebben. $\mathrm{Na}$ de follow-up training die werd ontwikkeld in Denemarken was er een significante toename van het aantal donaties. Het is daarnaast ook van belang dat gewenste veranderingen in het licht van de context worden bekeken. Meer kennis en vaardigheden van individuele professionele hulpverleners leveren weinig op als een omgeving ontbreekt om deze individuele verbeteringen productief te maken.

De belangrijkste bevindingen en conclusies worden beschreven in hoofdstuk 10 . Geconcludeerd wordt dat EDHEP werelwijd gezien wordt als relevant voor de praktijk. De TTT cursussen hebben bijgedragen aan successvolle implementatie in andere landen, waarbij het programma aangepast werd aan lokale situaties. Met betrekking tot individuele competentie, leidt EDHEP tot blijvende verbeteringen op de volgende gebieden: self-efficacy beliefs, waargenomen moeilijkheid van het vragen om donatie, vaardigheid van artsen in het structureren van een gesprek met nabestaanden en de uitleg van de donatieprocedure, de cognitieve vaardigheid van artsen en verpleegkundigen in het 'oplossen' van emotioneel complexe situaties. Deelname aan EDHEP resulteert daarnaast tijdelijke verbetering in de vaardigheid van artsen om een overlijden mee te delen, cognitieve vaardigheden van artsen en verpleegkundigen in het gebruik van de belangrijkste communicatievaardigheden in dit domein en de vaardigheid van artsen en verpleegkundigen om die communicatievaardigheden te kiezen die het meest adequaat zijn in emotioneel complexe situaties. Met betrekking tot teamwork lijkt EDHEP een blijvend effect 
te hebben op de competentie van intensive care teams ten aanzien van het voorbereiden van slecht-nieuws-gesprekken, een systematische team benadering bij het bespreken van donatie, meer bevredigend teamwork, met name met betrekking tot de donatievraag, en het gebruik en implementatie van het donatieprotocol. In EDHEP komen de gedragingen aan de orde die door nabestaanden van donoren als essentieel wordt gezein. Nabestaanden zijn in de laatste tien jaar geleidelijk meer tevreden geworden over het gedrag van intensive care staf en transplantatie coördinatoren. De evaluaties van EDHEP geven aan dat het programma aansluit op behoeften in de praktijk. Kennis en vaardighden worden geïntergreerd aangeleerd. Er komt steeds meer bewijs, dat de opzet van EDHEP en de gekozen methoden effectief zijn voor het verbeteren van professionele competentie.

Er wordt een tentatief model gepresenteerd, waarin de variabelen die belangrijk zijn gebleken in 'continuing professional development'-programma's zijn opgenomen. De hoofdstukken uit dit proefschift zijn op de meest relevant plek in het model geplaatst. In het model wordt uitgegaan van een circulaire benadering, waarin centraal staat dat bij de ontwikkeling van 'continuing professional development'-programma's in specifieke domeinen alle variabelen in het model betrokken zouden moeten worden. Bij het vaststellen van effecten van onderwijsprogramma's voor professionals is de aandacht in het algemeen vooral gericht op effecten op de competentie van de deelnemers. Er wordt betoogd dat behalve aan het vaststellen van deze effecten, bij de ontwikkeling van dergelijke scholingsprogramma's voor professionals meer aandacht dient te worden besteed aan resultaten uit zogenaamd 'outcome'-onderzoek; professionals, die werkzaam zijn in de gezondheidszorg, dragen niet alleen verantwoordelijkheid voor hun patiënten en teamgenoten, maar ook voor het efficiënt gebruik van schaarse middelen. Daarnaast wordt betoogd dat meer aandacht geschonken moet worden aan individuele kenmerken zoals self-efficacy beliefs en persoonlijke ervaringen en attitudes, aangezien deze een directe invloed lijken te hebben op het handelen in de praktijk. Het hoofdstuk wordt besloten met aanbevelingen voor verder onderzoek. 


\section{Dankwoord}

Aan de totstandkoming van dit proefschrift hebben veel mensen bijgedragen, die ik op deze plaats wil bedanken. Het is bijna onvermijdelijk dat ik personen zal vergeten te noemen. Ik wil dan ook bij deze alle mensen die op een of andere manier hebben bijgedragen aan dit proefschrift bedanken voor hun medewerking. Een aantal personen en instanties wil ik in het bijzonder bedanken.

In de eerste plaats dank ik alle artsen en verpleegkundigen die hun medewerking verleend hebben aan de verschillende onderzoeken. Zonder hun inspanningen en de kostbare tijd die zij hebben gegeven, was het niet mogelijk geweest om dit proefschrift te schrijven.

Mijn promotores, Cees van der Vleuten en Gauke Kootstra, jullie bedank ik voor het feit, dat jullie hebben mij de ruimte gegeven om mijn eigen onderzoeksideeën uit te werken. Ik wil jullie vooral bedanken voor het geduld dat jullie hebben gehad. Tussen het schrijven van de verschillende hoofdstukken heeft soms erg veel tijd gezeten; jullie hebben altijd het vertrouwen gehouden dat het uiteindelijk af zou komen. Er daar ben ik heel blij mee. Cees, ik dank jou ook voor de constructieve opmerkingen en zinvolle suggesties bij elk van de hoofdstukken, en het meedenken over de analyses. Daarnaast bedank ik jou voor jouw inspanningen om mij de gelegenheid te geven om het proefschrift af te maken. Gauke, jou bedank ik ook voor je Groningse nuchterheid, die gaf me soms net het duwtje dat ik nodig had.

Wim Gijselaers, jou ben ik veel dank verschuldigd, omdat je me onderdak hebt verleend tijdens mijn schrijfverlof. Ik waardeer het zeer dat ik een eigen kamer met computer kreeg en daarnaast alles wat ik maar nodig had. Voor de afronding van het proefschrift is deze fase van cruciaal belang geweest.

De Faculteit der Gezondheidswetenschappen bedank ik voor de gelegenheid om het proefschrift af te maken.

Jan van Dalen, ik bedank jou voor de samenwerking bij de ontwikkeling van het onderzoeksproject, de instrumenten en de uitvoering van een groot deel van het project en het schrijven van een aantal van de artikelen. Dank je wel dat ik het artikel over de vergelijking van programma-evaluaties van EDHEP in Nederland en Engeland, waarvan jij de eerste auteur bent, op mocht nemen in het proefschrift. We waren een fantastisch team en we hebben veel werk verzet. 
Celia Wight, jou en Jan, bedank ik voor de geweldige manier, waarop je EDHEP internationaal onder de aandacht hebt gebracht en voor je waardevolle adviezen en suggesties in alle fasen van het internationale onderzoeksproces.

Ik bedank jullie Celia en Jan vooral ook voor het goede teamwork in de Trainthe-Trainer cursussen die we op zoveel verschillende plaatsen in de wereld hebben gegeven. Ons eigen enthousiasme zal zeker hebben bijgedragen aan de goede ontvangst van EDHEP. Bovenal bedank ik jullie voor de gezelligheid als we weer eens op pad waren, ik heb aan alle trips een zeer goede herinnering.

Juliet Morton en Mike Morley, jullie dank ik voor de prettige samenwerking bij het Engelse deel van het onderzoek: de vertaling van de instrumenten, het ontwikkelen van teamwork vragenlijst, de uitvoering van het onderzoek en het schrijven van artikelen. Juliet, ik dank jou voor de geweldige prestatie die je hebt geleverd door de artsen en verpleegkundigen van de deelnemende twintig ziekenhuizen te bewegen om deel te nemen aan de vaardigheidstoetsen, waar zij erg tegenop zagen, en daarnaast om ze alle vragenlijsten in te laten vullen. Mike, jou bedank ik vooral voor het vele werk wat je verricht hebt om de resultaten op papier te krijgen. Ik bedank jullie ook voor de gastvrijheid en de hartelijkheid waarmee wij altijd door jullie zijn ontvangen en de vele gezellige uren die we samen hebben doorgebracht.

Pina Frazzica, jou bedank ik voor de steun die je me hebt gegeven door mij de gelegenheid te geven een maand lang in jouw instituut CEFPAS op Sicilië te kunnen te werken. Ik heb een productieve start gemaakt. Bovenal was het erg gezellig.

Petra van der Kooy, Judith Louwers en Wladimir van Mansum, destijds studentassistenten, jullie bedank ik voor de leuke en goede samenwerking. De grote hoeveelheid gegevens en het grote aantal betrokkenen hebben jullie nooit als probleem gezien. Dank jullie wel voor het invoeren van alle gegevens, het (mede) organiseren van de Nederlandse experimenten en het uitvoeren van statistische analyses. Bob Willems and Glauke Kooimans, jullie bedank ik voor jullie medewerking aan het validatie-onderzoek. Gijs Lummen, Marieke Poelen en Karin van Oijen, jullie bedank ik voor jullie hulp bij de scoring van teamworkvragenlijsten.

Marike Lub, Trudi Kraan, Thera Hoogeveen en Arnold Oostveen, EDHEPtrainers van het eerste uur. Dank jullie wel voor de prettige samenwerking en de gastvrijheid en hartelijkheid waarmee Jan en ik altijd zijn ontvangen als we vanuit het verre Maastricht afreisden naar Hoek van Holland, Leiden of Wassenaar om de EDHEP workshops te evalueren. Trudi Kraan wil ik ook bedanken voor de prettige samenwerking bij het tweede nabestaandenonderzoek en het schrijven van het artikel hierover.

Marc van Aart, Patricia Batavier, Michel Groot, Marijke van Gurp, Willem Hordijk, Koos Kranenburg, Marian Kruyswijk, Arno Oomen, Jose Popma, Elly van der Vegt, Henriette van Wezel, René Wijnen en Paul van Wijngaarden, 
transplantatie coördinatoren in de periode waarin het onderzoek plaatvond, jullie bedank ik voor de steun die jullie aan het onderzoeksproject hebben gegeven en voor het organiseren van EDHEP workshops in jullie regio's. Marlies Broxterman, dank je wel voor je hulp bij het organiseren van het Nederlandse onderzoek, dit geldt vooral voor de randomisatie in het eerste onderzoek, het teamworkonderzoek en het nabestaanden onderzoek. Patricia Batavier, Marijke van Gurp en Elly van de Vegt, jullie bedank ik tevens voor de samenwerking bij het uitvoeren van het nabestaandenonderzoek. Henriette van Wezel, jou wil tevens bedanken voor jouw steun aan het nabestaandenonderzoek, en vooral voor de samenwerking bij het teamworkonderzoek.

Erica van Ommen en Gèr de Ruiter, jullie bedank ik voor de geweldige manier waarop jullie als simulatienabestaanden elke keer weer de deelnemers aan de EDHEP workshops versteld deden staan van de echtheid, waarmee jullie de rollen speelden.

Bernard Cohen, namens de Stichting Eurotransplant International en Bernadette Haase namens de Nederlandse Transplantatiestichting, jullie bedank ik voor de steun aan het onderzoeksproject.

Ruud Erdman en Jos Ravensbergen, dank je wel voor het belangeloos verstrekken van de gegevens van het nabestaandenonderzoek dat julllie in 2001 gedaan hebben.

De hoofden van de intensive care afdelingen die participeerden in het validatieonderzoek bedank ik voor het feit, dat zij hun artsen en verpleegkundigen de gelegenheid hebben gegeven om deel te nemen aan het onderzoek. Per persoon nam dit ongeveer vier uur in beslag. Ik waardeer het zeer dat deze tijd kon worden vrijgemaakt.

Voor het teamwork onderzoek bedank ik de contactpersonen van alle betrokken intensive care afdelingen voor het verkrijgen van medewerking voor het onderzoek, en het verspreiden en weer innemen van alle vragenlijsten. Zonder jullie inspanningen hadden we niet de respons gekregen die we hadden.

Mien Segers dank ik voor het constructieve commentaar op enkele van de artikelen in dit proefschrift.

Christian Kerckhoffs, dank je wel voor je hulp bij de statitistiche analyses. Ik bedank hier ook Dirk Tempelaar, Arno Muijtjens en Ron Hogenboom.

Petry Thiemann, Fien van Deurse t, Tonnie de Vries-Spaen en Henny Dankers, jullie bedank ik voor alle administratieve, organisatorische en persoonlijke ondersteuning bij de uitvoering van het onderzoek en het voltooien van dit proefschrift.

Mereke Gorsira, je hebt een groot deel van het proefschrift gecorrigeerd op het Engels. Je hebt dat fantastisch gedaan, dank je wel.

Cheryl Reid, destijds student-assistent van Juliet, bedankt voor alle werk dat je hebt verricht ten behoeve van de metingen, en met name de vaardigheidstoetsen. Maureen Wain, bedankt voor het organiseren van de workshops en de metingen. 
Robert Sells, directeur van de Renal Transplant Unit van het Royal Liverpool University Hospital in Liverpool, jou bedank ik dat je als kartrekker voor het EDHEP (onderzoeks-)project hebt opgetreden. Zonder jouw inspanningen was het Engelse deel van het project niet van de grond gekomen. Robert Johnson, directeur van de Renal Transplant Unit van het Manchester Royal Infirmary in Manchester, jou bedank voor je onverminderde steun en je inspanningen om het project te laten slagen.

Ray Sutton, coordinator van de simulatienabestaanden, en de Engelse acteurs, bedank ik voor hun inzet bij vaardigheidstoetsen.

John Kincey, Else Guthrie, Sue Kaney, Bill Williams en Hilary Roxborough, de EDHEP trainers van het eerste uur in Engeland, dank ik voor de prettige samenwerking.

Robert Sells, Malcolm Brown, Ali Bacran, Robert Johnson, Neill Parrott, Barry Doran (medisch (transplantatie) specialisten) en Jim Colbert, Jackie Godfrey, Barry Chapman $t$, Sue Clarke (transplantatie coordinatoren) vormden de EDHEP stuurgroep in Engeland, die ik hartelijk bedank voor de actieve ondersteuning van het onderzoeksproject.

\section{Tenslotte}

Stella Beeldsnijder en Erna Ponds, mijn paranimfen en lieve sparring partners door de jaren heen, dank je wel voor alle emotionele en praktische steun en bovenal voor het plezier dat we hebben; Agnes Scholing, jou bedank het feit, dat je ondanks je eigen drukke baan tijd hebt gemaakt voor de mooie lay-out van dit proefschrift; Jan van de Poel, het was niet altijd makkelijk. Ik dank jou voor je geloof in mij, je humor, je kritische commentaar en je creatieve suggesties; Kevin Gibson en Harm Hospers, maatjes door de jaren heen, ik dank jullie voor jullie onvoorwaardelijke steun en de pret die we altijd hebben; Mah Jong-clubje, Jacqueline Bomhof, Floor Martens en Erna Ponds, onze wandeltochten hebben me altijd erg goed gedaan en me veel creatieve ideëen gegeven; Hannie van Genderen en Leo Scheffer, Paula Deumens, Jacques Mikx bij jullie kon ik altijd aanschuiven voor gezelligheid en weer zo'n heerlijke maaltijd met een lekker glas wijn; Jeannette Hommes, dank je wel dat je er altijd op bent op het juiste moment; Trudi van Schaik, jou bedank ik dat je me hebt leren kijken, zelfs een sieraad kun je nooit helemaal van te voren bedenken; Peter Knops, dank je wel voor de muziek, die me heeft me geholpen alles weer een beetje in perspectief te zien; Ali, Ina en Jan; Folkert en Sven; Rosan, Liset en Stefan, het is fijn om bij jullie te zijn en altijd verzekerd te zijn van jullie steun.

Het is een groot gemis dat mijn ouders dit moment in mijn carrière niet meer mee hebben kunnen maken. Ik weet zeker dat ze erg trots zouden zijn geweest, zoals ik dat ook op hen ben. De belangrijkste boodschap die ze meegegeven hebben is altijd in mezelf te blijven geloven en een goede balans te vinden tussen een academische loopbaan en het genieten van de andere dingen die belangrijk zijn in het leven. 


\section{Curriculum Vitae}

Geke Blok was born on the 12th of October 1958 in Wapserveen in the Netherlands. After attending Atheneum A in Steenwijk, she studied Clinical Psychology and Andragology at the University of Groningen, for both of which she graduated in 1988. During her studies she worked many years as a studentassistant for different (training) courses in the psychology curriculum, which is when she started to be interested in education and skills training. In March 1988 she joined the Faculty of Health Sciences at the University of Maastricht, initially at the Skillslab, and since 1989 at the Department of Educational Development and Research. Her main tasks were to help develop the communication skills training curriculum for students in Mental Health Sciences, of which she was the coordinator from 1992 to 1998. Since 1992 she is assistant professor with a research interest in effects of skills training programmes on the competence of students and professionals. In Januari 2000 she was part-time appointed as assistant professor at the Faculty of Economics and Business Administration at the University of Maastricht, where her main task is faculty development. Since March 2002 she is responsible for the evaluation of the use of the Electronic Learning Environment of the University Maastricht (ELEUM) in this faculty and for faculty development aimed at the use of this electronic learning environment.

She is an international consultant for the development and conduct and implementation of educational programmes. In the Netherlands and abroad, she has trained many professionals ranging from specialist medical doctors and nurses, psychiatric nurses, general practitioners, midwives, detectives and police chiefs and managers to faculty of educational institutes in professional job-related skills.

In 2000 she graduated as a consultant psychotherapist, and has since worked on a small scale as a practising consultant. 